UNIVERSIDAD POLITÉCNICA DE MADRID

ESCUELA TÉCNICA SUPERIOR DE ARQUITECTURA

\title{
LA MEMORIA EN EL PROCESO CREATIVO DE JUAN MUÑOZ [MEMORY IN THE CREATIVE PROCESS OF JUAN MUÑOZ]
}

TESIS DOCTORAL

\author{
MARTA GONZÁLEZ RUIZ
}

ARQUITECTA POR LA ESCUELA TÉCNICA SUPERIOR DE ARQUIECTURA DE MADRID UNIVERSIDAD POLITÉCNICA DE MADRID 

DEPARTAMENTO DE IDEACIÓN GRÁFICA ARQUITECTÓNICA ESCUELA TÉCNICA SUPERIOR DE ARQUITECTURA

\title{
LA MEMORIA EN EL PROCESO CREATIVO DE JUAN MUÑOZ [MEMORY IN THE CREATIVE PROCESS OF JUAN MUÑOZ]
} TESIS DOCTORAL

\author{
AUTOR \\ MARTA GONZÁLEZ RUIZ \\ ARQUITECTA LA ESCUELA TÉCNICA SUPERIOR DE ARQUIECTURA DE MADRID \\ UNIVERSIDAD POLITÉCNICA DE MADRID
}

DIRECTOR:

JAVIER SEGUÍ DE LA RIVA

DOCTOR ARQUITECTO Y CATEDRÁTICO EMÉRITO DE LA ESCUELA TÉCNICA SUPERIOR DE ARQUIECTURA DE MADRID

UNIVERSIDAD POLITÉCNICA 

Tribunal nombrado por el Magfco. Y Excmo. Sr. Rector de la Universidad Politécnica de Madrid el día de de 20

Presidente:

Vocal:

Vocal:

Vocal:

Secretario:

Suplente:

Suplente:

Realizado el acto de defensa y lectura de la Tesis el día de de 20 ,

En la Escuela Técnica Superior de Arquitectura de Madrid.

Calificación:

EL PRESIDENTE

LOS VOCALES

EL SECRETARIO 

Ma Teresa y Jorge, mis padres

Mํㅡㄹ Teresa, mi hermana Luis 



\section{AGRADECIMIENTOS}

Desde siempre he escuchado a mis padres decir ante mis olvidos de aquello en lo que han puesto tanto ánimo en enseñarme, que todo deja poso. Su curiosidad es el asiento de la mía. Con su constante apoyo, cariño y esfuerzo, llego a esta tesis donde evidenciar la relevancia de lo que da forma al camino.

Gracias a mi Director de tesis, Javier Seguí de la Riva, por compartir conmigo su sabiduría, por su dedicación y respaldo. Y por enseñarme que proyectar es contar historias. También a Atxu Amann por su entusiasmo y el valioso tiempo que dedica a sus alumnos.

Gracias al Estate de Juan Muñoz, a Cristina Iglesias, James Lingwood, Vicente Todolí y Sandra Feio que generosamente me han ayudado a conocer mejor a Juan Muñoz.

A Eloisa Grano de Oro, Maite García Sanchís y Berta Risueño Muzás por contribuir a que esta tesis sea presentada.

Estoy muy agradecida a mis amigos por el respaldo que siempre recibo de ellos y por su inestimable ayuda sin importar la distancia.

Gracias a Nueva York, donde tanto disfruté aquellos años, a la Universidad de Columbia y a los que allí conocí.

Gracias a mi familia y a Luis, porque donde están ellos está mi casa. 

1.1. Presentación, motivación y objeto de la investigación 3

1.2. Objetivos del trabajo de investigación $\quad 6$

1.3. Interés del objeto de estudio y estado de la cuestión 9

1.4. Metodología 13

$\begin{array}{ll}\text { 1.5. Estructura } & 17\end{array}$

2. EL LUGAR DE LA MEMORIA

2.1. La memoria. $\quad 37$

2.1.1. La memoria y lo pasado $\quad 37$

2.1.2. La memoria y lo futuro 48

2.1.3. La memoria y Juan Muñoz 56

2.2. $1953-2001 \quad 68$

2.3. Double Bind 74

$\begin{array}{ll}\text { 3. EL CIELO } & 101\end{array}$

$\begin{array}{ll}3.1 \text { En una plaza } & 105\end{array}$

3.2 De la precisión en las distancias $\quad 125$

3.3 Tres imágenes o cuatro 131

4. EL INFIERNO

$\begin{array}{ll}4.1 \text { La imagen prohibida } & 147\end{array}$

4.2. De la luminosa opacidad de los signos $\quad 162$

$\begin{array}{ll}\text { 4.3. Construyendo imágenes } & 170\end{array}$

$\begin{array}{lr}\text { 5. EL PURGATORIO } & 179\end{array}$

5.1. La mejor escultura es un caballo de Troya 182

5.2. Una correspondencia sobre el espacio 188

5.3. El ventrilocuismo es una forma de polifonía 205

6. CONCLUSIÓN/ CONCLUSION

BIBLIOGRAFÍA

$\begin{array}{ll}\text { ANEXOS } & 243\end{array}$

ANEXO 1. Conversación con James Lingwood 245

ANEXO 2. Conversación con Vicente Todolí 249

ANEXO 3. Juan Muñoz: cronología 253 



\section{RESUMEN}

Esta tesis integra un estudio reflexivo sobre la relación de dependencia entre la creación y la memoria a través del análisis de la última obra del escultor Juan Muñoz: Double Bind (Tate Modern, Londres, 2001). Desde esta posición es obligado replantear el análisis de la obra, lo que hace necesario su estudio cubriendo el mayor espectro posible de información accesible más allá de la obra en sí, para aproximarse a la convergencia entre memoria y creación. La perspectiva de análisis propuesta abre camino a nuevas consideraciones sobre la relevancia del conocimiento en el desarrollo del proceso creativo. Este análisis no debe tan sólo suponer una aportación al conocimiento del trabajo de Juan Muñoz. Debe también desprenderse de él la innegable participación y necesaria lectura del pasado en el presente. La amnesia de los tiempos pasados impide completar el atlas de imágenes en las que se apoya la creación impidiendo el conocimiento del origen de las fuentes de inspiración y las bases de la creación de una determinada obra. Este hecho limita y distorsiona sus posibles interpretaciones.

Pretendo un acercamiento al entendimiento de la forma de mirar y de crear a través del tiempo que es memoria. La memoria tiene un cometido de crucial importancia para la actividad mental y juega un papel fundamental en la conducta y en la creación. La obra es el resultado de la búsqueda de una idea que exprese algo que el creador no puede expresar de otra manera. Es la necesidad de expresar las ideas mediante un lenguaje que se desarrolla en el tiempo y en el espacio, reflejo del ser que responde al pensamiento. Es una forma de experiencia donde subyacen las sendas del pasado y donde se plantea el futuro.

Sólo el creador accede a la obra desde dentro, el observador llega a ella desde el exterior y mediante su propia subjetividad. Las obras son formas de experiencia de sus autores, comunicar el mensaje de dicha experiencia supone por tanto interpretar. Persiguiendo la necesidad de saber y entender, pretender explicar el sentido de una cosa implica una apreciación intencionada asociada al entendimiento del intérprete. Las obras son productos que portan un mensaje y que contienen en su estructura las trazas del tiempo vivido por su creador. Si se quiere adquirir un acercamiento que represente la posición de un autor, será necesario no solo mirar a través de ella, si no introducirse en el contexto de su historia. Mirar hacia atrás, hacia la profundidad del presente para tener conciencia del pensamiento presente y futuro. Recorrer de este modo la instalación Double Bind de Juan Muñoz proporciona una síntesis de sus preocupaciones e intereses a la vez que aporta un conocimiento no necesariamente inmediato, pero relevante y trascendente de la obra, su creador y la historia. 



\section{ABSTRACT}

This thesis comprises a reflective study of the dependence relationship between creation and memory through the analysis of the latest work by the sculptor Juan Muñoz: Double Bind (Tate Modern, London, 2001). From this position, it is mandatory to rethink the analysis of the work, making it necessary to cover the widest possible range of information available beyond the work itself, in order to obtain a closer view of the convergence between memory and creation. The proposed analytical approach opens up new considerations on the relevance of knowledge during the development of the creative process. This analysis should not only make a contribution to the knowledge of the work of Juan Muñoz. It should also infer the undeniable involvement and the necessary reading of the past in the present. Amnesia regarding past makes it impossible to complete the atlas of images on which the creation is based, blocking knowledge of the origin of the sources of inspiration and the basis for the creation of a specific work. This fact limits and distorts its possible interpretations.

My intention is an approach to how to understand memory as the way of looking and creating over time. Memory has a crucial role to mental activity and plays a key role in behaviour and creation. The work is the result of finding an idea that expresses something that the creator can not express otherwise. It is the need to express ideas by means of a language that develops throughout time and space, a reflection of the being that responds to the thought. It is a way of experience underlying the paths of the past and where the future is set out.

Only the creator can access the work from the inside. The observer sees it from the outside and in accordance with his/her own subjectivity. The works form a part of the experience of their authors, thus implying the interpretation of the message of their experience being passed on. The pursuit of knowledge and understanding, and trying to explain the meaning of something implies a deliberate appreciation associated with the understanding of the interpreter. The works are products bearing a message and containing in their structure traces of the time lived by their creator. If one wants to come close to what the author's posture represents, it will not only be necessary to penetrate it, but also to introduce oneself into the context of its history. Take a look back, towards the depth of the present in order to become aware of present and future thinking. To go across the installation of Double Bind by Juan Muñoz in this way offers a synthesis of his concerns and interests while also providing a not necessarily immediate knowledge, but one which is relevant and important to the work, its creator and history. 

1 INTRODUCCIÓN 



\subsection{Presentación}

El pasado da significado al presente. A través del pasado se crean las historias del presente. Permitir que se desvanezcan sin dejar huella supone no sólo borrar la memoria, si no reducir las posibilidades del futuro, incapaz de inventarse sin referentes pasados. Este trabajo hace un estudio reflexivo de la relación de dependencia entre la creación y lo sustraído del pasado. No se puede comprender la creación artística sin dar la importancia que merecen a la memoria y la experiencia del creador. Para evidenciar dicha relación se recurre a una obra plástica que permita ser reconstruida en el tiempo y a través de la cual se puedan demostrar las relaciones entre la obra y la dinámica de los procesos que dan lugar a la misma. 
Mediante el acercamiento al proceso creativo del artista español Juan Muñoz (19532001) accedemos no solo al conocimiento de su obra material presentada, sino también al entendimiento de los caminos explorados para llegar a ella. Observamos a través del estudio del proceso, sus constantes, la evolución de las mismas y descubrimos los gérmenes de nuevas direcciones de investigación. Este estudio nos ofrece también una visión de futuros alternativos, tanteos que por diversas razones no formaron parte de la historia final y que, de haber sido desarrollados, seguramente resultarían en un presente distinto. Juan Muñoz exploraba la evolución de determinadas ideas dirigido por su intuición; combinaba la evolución de sus constantes temas de estudio con aquello que le inspiraba del mundo que le rodeaba, veía lo que estaba buscando en aquello en lo que se detenía a observar o simplemente, encontraba en lo que miraba una fuente de inspiración. En una calle, un cuadro, una iglesia o en un poema, se encontraba con su mundo. Veía en ellos sugerencias plásticas o narrativas en las que apoyarse para desarrollar sus creaciones. El objetivo de este estudio es comprender el proceso creativo de Juan Muñoz, su origen y evolución, y descubrir las relaciones entre sus ideas y sus referentes, entendiendo primero el funcionamiento de la memoria humana.

Heidegger plantea la necesidad de comprender, porque existir es entender, así mismo, Emilio Lledó sostiene que "ser es, esencialmente, ser memoria". Partiendo de la hipótesis de esta necesidad de comprender y entender y del importante papel de la memoria en el proceso creativo, esta tesis busca reconstruir los lugares de la memoria a partir del análisis interpretativo de la obra de un creador. Esta lectura plantea una comprensión más amplia de la generación de una obra desde el análisis del funcionamiento de la memoria humana. También abre nuevas perspectivas de interpretación al adentrarse en el proceso creativo y no solo centrándose únicamente en el análisis del objeto producido. Es sabido que el creador, bien de manera intuitiva, bien de manera deliberada utiliza los referentes que acumula en su memoria para producir nuevos proyectos. Llegar a descifrarlos y conocerlos aportará una visión capaz de mostrar las capas de realidad de la obra. Esta tesis parte de la premisa de que la obra se sitúa en el contexto de su propia memoria, siendo la creación de un sujeto que acumula historia. Es por ello fundamental recorrer los pasos del creador en busca de ese ensamblaje de ideas visibles o invisibles que dan lugar a una obra y que validen la hipótesis aquí presentada. 
Mediante la percepción el sujeto se sitúa en la realidad, que no es otra que su realidad personal. Se trata pues de una compleja relación entre el medio, las cosas y el sujeto físico y psíquico. Se puede considerar que las reacciones que produce un estímulo no se corresponden con un sólo momento presente sino que deben considerarse como un reflejo consciente unido a otro inconsciente que va ligado al tiempo y al aprendizaje en el pasado. Por otro lado, el acto de recordar lleva asociado el olvido, produciendo un involuntario desencuentro entre lo percibido y lo propuesto. Las relaciones entre el cuerpo de ideas del artista y lo experimentado en el pasado pueden ser neutralizadas por la mente que entiende dicho cuerpo de ideas como propio y ajeno a las influencias. Este legítimo posicionamiento de aislar de referentes aquello que se considera propio se origina sin embargo a partir de una memoria selectiva cultivada en el pasado. 


\subsection{Objetivos del trabajo de investigación}

Durante los últimos años mi atención se ha centrado en el tema de la percepción y en el estudio del "pasado presente". El pasado perdura en el presente y el futuro tiene sus raíces en un pasado visible o invisible. Investigando los distintos palimpsestos ${ }^{1}$, primero en la arquitectura ${ }^{2}$ y ahora en la obra del escultor español Juan Muñoz, estos estudios persiguen recorrer la secuencia de acontecimientos a lo largo de un proceso evolutivo buscando las huellas del pasado y que multiplican el entendimiento de las cosas.

Durante los trabajos tutelados realicé un trabajo de investigación titulado Días del futuro pasado, que supuso un primer acercamiento a la memoria y a la percepción espacial desde el punto de vista sensorial. En un inicio, perseguía establecer un mapa que determinara la naturaleza de las relaciones entre arquitectura y memoria. Partiendo del estudio de la influencia del pasado en el presente a través de la historia de determinadas arquitecturas, surgió la necesidad de ilustrar las relaciones de la sociedad con las mismas, no con el fin de perseguir su conservación histórica, sino entendiéndolas como pilares que condicionan y sustentan la evolución del pensamiento presente y futuro. A través de estos primeros estudios, concluí que todo proceso creativo está ligado a la búsqueda de inspiración dentro de un imaginario de referencias colectivas y personales, temas centrales de esta investigación.

Las instalaciones temporales en la Tate Modern de Londres son un medio de transformación temporal de un espacio permanente que queda transfigurado transitoriamente por su contenido. La intervención temporal no deja rastro en el espacio una vez desmontada, pero sí cambia las capacidades y la percepción del lugar tras poner en tensión las posibilidades espaciales; a su vez, dicha intervención, marca el imaginario colectivo pasando a formar parte de la memoria cultural. Tomando este posicionamiento como metáfora de las influencias provenientes de la experiencia en el proceso creativo, encontré

1 Manuscrito antiguo que conserva huellas de una escritura anterior que fue borrada artificialmente. En este caso no se trata de dos posibles escrituras distintas una sobre otra, si no de las capas de conocimiento superpuestas, la memoria de lo que allí había, las trazas del pasado.

2 Estudiando la evolución sociocultural del barrio del Soho (Nueva York) y las transformaciones visibles e invisibles que esta supone en la arquitectura y el urbanismo de la ciudad. Estudiar la temporalidad en aquello que se muestra como inmutable en el tiempo. 
que la instalación Double Bind de Juan Muñoz expuesta en el año 2001 en la Tate Modern abarca y contiene un amplio conjunto de intereses capaz de ilustrar el objetivo de esta investigación de manera completa. A través de Double Bind podía establecer un marco para investigar el proceso creativo de su autor y establecer una relación entre la creación artística, la arquitectónica y la memoria.

La creación de Muñoz se centra en un principio en la producción de objetos y figuras que presenta de manera aislada al comienzo de su carrera y más adelante formando parte de un conjunto. Tras años de explorar la localización de sus figuras en el espacio, Muñoz se encuentra con la necesidad de generar un contexto para los grupos de figuras dotándolas de un ámbito que las envuelva. Busca crear una narrativa a partir de una estructura arquitectónica donde el contexto que proporciona a las figuras forma parte imprescindible de la historia. Este ejercicio tiene un papel muy importante en su obra $A$ Place Called Abroad, y culmina como estrategia en Double Bind.

Reflexionar sobre el papel de la memoria a través de una obra de arte plástica en una escuela de arquitectura se fundamenta en la aceptación de que en la escultura contemporánea el espacio es un componente esencial de la obra. En el caso concreto de la obra de Muñoz, las relaciones espaciales que se dan entre la disposición física de las figuras en un espacio existente o incluso las formas que configuran un espacio, orientan el interés hacia el campo de la arquitectura. El espacio se considera un elemento activo ofreciendo una experiencia vivencial y sensorial al espectador. En Double Bind el espacio que acoge la obra pasa a formar parte de la misma. La propia obra modifica la galería creando un dialogo entre lo existente y la instalación que no permite identificar la obra como objeto impidiendo diferenciar los límites escultóricos y los arquitectónicos.

En esta investigación, la memoria, que es la facultad humana que nos permite retener el pasado, se estudia como ese lugar íntimo y personal al que se propone acceder mediante el análisis y la interpretación de la vida y obra del escultor. Las obras del escultor son la parte visible de su trabajo, pero lo visible tiene raíces bajo la tierra que se pueden conocer y estudiar. Descubrir aquí los dos tercios del iceberg que Hemingway proponía ocultar con la intención de dar mayor dramatismo a sus obras, para mostrar así la historia entera, la realidad subyacente, las partes no dichas que constituyen la creación, lo sobreentendido, lo que no está contado y que desdobla el conocimiento y acceder a la obra de Juan Muñoz tal 
como él mismo la describe, como las correspondencias entre su presente y su pasado: "Mi obra trata de la historia, de la toma de conciencia de mi condición actual y los fragmentos de mi memoria."3

Dentro del marco conceptual de la memoria humana, esta tesis pretende sintetizar el proceso de creación del artista, intentando poner en orden el cuerpo de ideas que sustenta sus obras, basado en una revisión y pulido constante de un conjunto de preocupaciones que nacen de su interior y que viajan y crecen con él desde su juventud a través de un recorrido no lineal, y de la constante exploración de ciertos temas que cautivaron su interés, que se encuentran en su yo más profundo y que completa con conocimientos que incorpora en el transcurso de su carrera. Al igual que Giacometti, Juan Muñoz trabaja como una mosca $^{4}$, como un ser que vuelve al mismo sitio una y otra vez, sin saber con claridad a dónde va, obstinado con los mismos temas. El escultor es plenamente consciente de este ejercicio y se plantea cuestiones sobre su validez para hallar las oportunidades perdidas en campos explorados y siempre tratando de impedir que la acción sea contraproducente ${ }^{5}$, buscando, no la corrección de una acción pasada, sino la creación de una nueva obra usando y reutilizando dispositivos y estrategias diferentes con nuevos fines.

3 Muñoz, Juan, Lingwood, James, Blazawick, Iwona y Schlieker, Andrea, Una conversación, Julio 1990 en Juan Muñoz, Monólogs y Diálogos. MNSCARS, Madrid, 1996, p.60.

4 Natsume-Dube, Sachiko. Giacometti y Yanaihara: Trabajo como una mosca, Elba, 2013.

5 Muñoz, Juan, subraya el primer párrafo de la introducción del libro de George Steiner A Reader, donde el experto en crítica comparada hace una reflexión sobre "reescribir, alterar y enmendar" el trabajo de juventud en el periodo de madurez. El historiador y crítico eleva la duda sobre si la revisión del trabajo realmente mejora la obra o si es un ejercicio contraproducente en el que se eliminan los "errores" que son los que definen "lo que uno es" en su tiempo de juventud. "The impulse to rewrite, to alter an amend in the colder light of hindsight and maturity, is all but irresistible. Such up-dating, and 'improvement' would, however, not only be transparently dishonest; it could, I suspect, prove self-defeating"en Una introducción (de George Steiner a George Steiner) en Juan Muñoz: Escritos/Writings, Ediciones de la Central. Barcelona, 2009, p.199. Públicado por primera vez en 1991 Juan Muñoz en su texto establece un dialogo entre dos personajes (A, B) que comentan las observaciones de Steiner discutiendo los pros y contras de reescribir un texto o parte de él. 


\subsection{Interés del objeto de estudio y estado de la cuestión}

La memoria es el instrumento que marca el misterioso ritmo de la creación; una caja de resonancia donde se reciben los conocimientos adquiridos a lo largo de la vida. Las técnicas mnemotécnicas de la época clásica empleaban la arquitectura para establecer y organizar los lugares de la memoria, casas de la sabiduría en las que clasificar meticulosamente el saber según distintos principios y jerarquías. El funcionamiento de la memoria continúa siendo un tema de actualidad y trascendencia dentro de los ámbitos científico y filosófico. La memoria es un sistema complejo que para operar se vale de profundas conexiones cuya interrelación no puede todavía ser clasificado por la ciencia dentro de un organigrama. Los mecanismos de la memoria son objeto de estudio de la neuropsicología. Los escritos de José María Ruiz-Vargas, doctor en Psicología y Catedrático de Psicología de la Memoria en la Universidad Autónoma de Madrid, han sido el punto de partida desde el cual adquirir conocimientos respecto al enfoque cognitivo de la memoria (la ciencia cognitiva surge en la década de los'70). A partir de estos, he recogido las nociones básicas del funcionamiento de la memoria, recurriendo a su vez a textos actuales relacionados. Entre estos, cabe destacar los escritos de Endel Tulving, Profesor de Psicología de la Universidad de Toronto, Daniel Schacter, Profesor de Psicología de la Universidad de Harvard, y Larry Squire, Profesor en la UC de San Diego.

Aunque algunos creadores han pretendido recopilar y mostrar los pasos del proceso creativo, no es fácil comprender enteramente el desarrollo de las ideas, ya que los proyectos se elaboran a través de un proceso que va más allá de recorrer los pasos seguidos en la elaboración de un trabajo desde su comienzo. Los datos que se recopilan a lo largo del proceso influyen de manera significativa en el resultado pero también lo hacen aquellos conocimientos acumulados durante la experiencia previa. El proceso siempre está latente, aunque se hace consciente en un momento determinado, éste nunca se detiene. Los pasos que lo anteceden y que no se registran en el progreso de elaboración son también parte de él. Ninguna decisión es final, todas se ramifican en otras dice Borges en La lotería en Babilonia. Este diagrama arbóreo puede aplicarse metafóricamente también a la memoria, el creador se encuentra siempre con múltiples posibilidades en su recorrido, por lo que está obligado a decidir y a orientar su trabajo en una determinada dirección 
pero las alternativas consideradas y descartadas tiene también valor en la comprensión del desarrollo creativo y son necesarias para la interpretación de la obra. La teoría de la inteligencia creadora (Anagrama, 1993) de José Antonio Marina presenta importantes hipótesis respecto a la organización y funcionamiento de los conocimientos que permiten inventar nuevas posibilidades. La evolución creadora de Henri Bergson (Cactus 2008, escrito en 1907) nos ofrece un cuerpo teórico sobre la inteligencia también muy relevante como referente para este estudio.

Es este un ejercicio de análisis para despertar el sentido oculto o simplemente, para entender lo que se comunica mediante una obra y lo que gravita a su alrededor. La obra es un mensaje que descifra el observador desde la subjetividad y mediante su interpretación le otorga significado. La obra habla desde su materialidad pero no responde. Ante la necesidad de entender, y para establecer el diálogo de la obra con el espectador y con su propia historia, se recurre a un método interpretativo que nos acerque a ella y a su trasfondo: la hermenéutica. Gadamer expone en Verdad y Método II que "la obra de arte es un reto a nuestra comprensión, porque escapa siempre a todas las interpretaciones y pone una resistencia, nunca superable, a ser traducida a la identidad de un concepto". Cada obra es susceptible de múltiples interpretaciones, se pretende ofrecer aquella que aporte más datos sobre las fuentes de inspiración del creador. Cuando se intenta comprender se debe abandonar la propia opinión hasta donde sea posible, intentando concebir en primer lugar la cosa. Luigi Pareyson, precursor de la teoría hermenéutica, señala en La contemplación de la forma que la contemplación no es un estado pasivo sino que es mediante un proceso de interpretación complejo como se descubre la obra. Interpretar es explicar y expresar el sentido de una cosa, situándose en el punto de vista del creador. Una lectura sensitiva y empírica en beneficio del conocimiento. El director de esta tesis, Profesor Javier Seguí de la Riva, me ha proporcionado la bibliografía necesaria para comprender los enfoques hermenéuticos relacionados con la interpretación de la obra de arte. Las teorías de Schleiermacher, Dilthey, Heidegger, Ogden y Richards, Payerson, Durand y Betti.

El modo de entender la proyección del pensamiento en la obra de Muñoz a través de Double Bind y mediante un estudio hermenéutico implica, no mirar su obra sino mirar a través de su obra y hacer explícita la relevancia del trasfondo de las ideas. Se descubren así conexiones entre su obra y sus inquietudes más primigenias, destacando la interacción 
entre la arquitectura, la escultura y el observador, temas que particularmente interesaban al escultor.

En la Introducción a la Crítica de la razón pura, Kant expone que nuestro conocimiento necesita de la experiencia. El proceso creativo es una tela de araña que entrelaza las ocurrencias más antiguas con las actuales. La yuxtaposición espacio temporal de ideas conforma una amalgama de estímulos que se apoyan en la memoria y que dan como resultado proyectos novedosos. "Proyectamos perspectivas con las que recuperar y corregir el pasado." ${ }^{6}$ El estudio de la memoria a través de la figura de Juan Muñoz y específicamente, de su obra Double Bind permite reconstruir el mapa de las referencias, influencias, intereses y relaciones de su obra más madura. Double Bind puede considerarse como la memoria de todas sus obras anteriores.

A mediados de los años '80 Muñoz se consagró como uno de los artistas emergentes más prestigiosos del panorama escultórico internacional. Perteneció a una generación de artistas que recuperó la figuración como tema central pero nunca formó parte de un grupo organizado, desarrollando un lenguaje y unas temáticas propias. Fue premio Nacional de Artes Plásticas en el año 2000 y el segundo invitado a participar en las Unilever Series, instalaciones temporales en la sala de turbinas de la Tate Modern. Su obra, además de abordar las consecuencias situacionales de una escultura figurativa, incluye dibujos, instalaciones conceptuales, obras sonoras o ensayos literarios. No hay que olvidar su trabajo como comisario en diversas exposiciones a principios de su carrera. Su obra ha sido expuesta en numerosas galerías internacionales y ha formado parte de varias retrospectivas en importantes museos de todo el mundo (Hirshhorn Museum de Washington en 2001, MNCARS en 2008 o Bilbao también en 2008). Después de la muerte del escultor en el año 2001, su trabajo no ha cesado de formar parte de exposiciones en grupo o en solitario. Su legado se gestiona a través del Estate de Juan Muñoz y muchas de sus obras forman parte de importantes colecciones públicas y privadas. En Mayo de 2015 se instala de nuevo temporalmente su última obra, Double Bind, formando parte de una exposición llamada Double Bind \& Around en el Hangar Bicocca de Milán. Críticos del mundo del arte contemporáneo escriben sobre sus obras: Neal Baeza, Lynne Cook, James Lingwood, Adrian Searle, Paul Schimmel Vicente Todolí y Sheena Wagstaff entre otros

6 O’Doherty, Brian, Dentro del Cubo Blanco: La ideología del espacio expositivo, CENDEAC, 2000, p. 20. 
muchos. La obra de Muñoz es generalmente interpretada desde el campo de la historia del arte, mientras que en este trabajo se aborda ademas desde una perspectiva arquitectónica.

Este ejercicio incorpora el análisis de las circunstancias que rodean a la instalación y que completan el mensaje, vinculando la obra con los recuerdos y experiencias del pasado de su creador, su anamnesis ${ }^{7}$, y recuperando aquellas imágenes que son importantes, pero que no están presentes en la obra, localizadas en cuadernos de notas, en reflexiones escritas, en crónicas de viajes, en sus lecturas, en el estudio de las vivencias personales, en resumen, en las experiencias vitales del creador.

Las obras de arte tienen su espacio individual al margen de la historia pero no profundizar en el estudio de las particularidades socioculturales del artista genera un distanciamiento entre la obra de arte y la memoria colectiva que limita la capacidad comunicativa de las obras al desligarlas de un contexto global y ofrecer sólo una visión parcial. Del mismo modo es importante entender la relación entre el espectador y la obra de arte en el momento en el que es compartida con el público (y en particular la acogida por la crítica). “Los proyectos no documentados pueden sobrevivir como un rumor y vincularse a la individualidad de quienes lo originaron, los cuales se ven obligados a desarrollar un mito convincente. “8 Las obras de arte se someten a la interpretación de inagotables puntos de vista, diferentes disciplinas y distintas épocas, siendo el modo de mirar la obra lo que sustrae una imagen determinada de un objeto. Las reflexiones sobre las obras se filtran a través de un punto de vista determinado que influencia la evolución de su comprensión a lo largo de la historia, más allá de su materialidad. El objeto plástico puede permanecer a lo largo de la historia, pero distintos posos ideológicos se acumulan sobre lo representado al sustraerse y verbalizar las ideas que laten en el objeto. La imagen aglutina pasado y memoria, pero también continúa evocando nuevas miradas y enfoques, algunas teniendo en cuenta su origen, otras basadas en un momento presente.

7 En medicina se denomina anamnesis al conjunto de los datos clínicos e información relevante del historial de un paciente. El término, de origen griego, significa reminiscencia, definido por la R.A.E. como la representación o traída a la memoria de algo pasado.

8 O’Doherty, Brian, Dentro del Cubo Blanco: La ideología del espacio expositivo, CENDEAC, 2000, p. 66. 


\subsection{Metodología}

Mediante el análisis hermenéutico de la obra, he tratado de asumir el punto de vista del artista y transmitir así el estímulo que la obra ha provocado en mí, apartándome del juicio crítico o de la posesión de la verdad. Este ejercicio propone producir un documento capaz de mostrar el proceso creativo del artista. Reconociendo como dice Emmanuel Lévinas en La Realidad y su Sombra, un libro bien conocido y estudiado por Juan Muñoz ${ }^{9}$, que el arte tiene "un fondo de realidad, inaccesible sin embargo a la inteligencia conceptual". ${ }^{10}$ Todo en la mente está interrelacionado y hay que buscar los elementos que dan forma a la creación, la conjunción de pequeños acontecimientos capaces de causar importantes transformaciones.

El primer acercamiento a la obra se realiza a partir de los sentidos, pero es necesario profundizar en el significado y origen de las ideas del escultor para poder llegar al conocimiento de la elaboración de la obra por lo que debe ampliarse el estudio e incluir material adicional al proporcionado únicamente por la obra. Pareyson describe la obra de arte como forma dinámica, ya que es la "conclusión de un movimiento". La labor reflexiva sobre la obra ha de contemplar la comprensión histórica de la misma y la experiencia del propio creador. El investigador debe aspirar en el transcurso de su estudio a rodearse del sistema que consolida la estructura de la obra. Es necesario establecer las relaciones entre las evidencias de la obra, pero también lo es mirar más allá, o debería decir, mirar más atrás, ahondar en la memoria. Rescatar toda la información que permita descifrar la cadena de pensamientos que dan como resultado una obra, descomponer y componer de nuevo los logos de la memoria.

Se trata pues de procurar un análisis que abra el conocimiento de Double Bind, intentando profundizar en la comprensión del proceso creativo y el marco de entendimiento de las obras de Juan Muñoz porque "Articular históricamente lo pasado no significa conocerlo

9 Searle, Adrian, Introducción en Juan Muñoz Escritos/Writings, Ediciones de la Central. Barcelona, 2009, p.25. "el ejemplar que tenía Muñoz del Reader dedicado al filósofo francés de origen ruso Emmanuel Lévinas, una antología publicada en 1989, se encuentra muy usada, sobre todo el ensayo La realidad y su sombra que se publicó por primera vez en Les Temps Modernes 1948."

10 Lévinas,Emmanuel, La realidad y su sombra, Arte y Crítica, Ed Trotta, Madrid, 2001, p.45. 
"tal como realmente ocurrió"”"11. Se pretende una aproximación al origen, aceptando las limitaciones y la distancia entre la interpretación y lo verdadero, que de algún modo deja de existir desaparecido el artista, que incluso puede someter su propia obra a nuevas interpretaciones modificando su discurso. El arte no siempre impone una historia, queda abierta a las sensaciones del espectador.

Juan Muñoz tiene intenciones claras, pero su capacidad de controlar las emociones y las sensaciones que su arte pueda producir están limitadas, su dominio se restringe al mundo material y su contexto que manipula a su antojo, pero la obra no abarca el terreno del significado y las sensaciones, que pertenecen a cada individuo. El filtro al que se somete la obra de arte al ser analizada e interpretada añade capas de entendimiento que pertenecen al que las describe. Tomando prestadas las palabras de la artista Agnes Martin, las impresiones, no está tan solo en los ojos, están en la mente. ${ }^{12}$

Se ha buscado un procedimiento que dé respuesta a la hipótesis planteada y que se basa en un profundo análisis de la obra en cuestión de la producción y vivencias de artista, así como de escritos y relatos de otros autores que reflejen conocimiento de su creación. Las vivencias del autor y los referentes buscados o hallados conforman su saber y determinan su porvenir. Esos elementos referenciales que se integran en la personalidad del creador, pueden tener una relación directa y obvia o indirecta pero determinante en el proceso creativo. Estas últimas son más difíciles de identificar o interpretar y en muchos casos resultan decisivas. Se revela fundamental la interpretación del trasfondo de la obra más allá de los elementos directos ${ }^{13}$. En el creador existen determinadas inquietudes que se desarrollan desde una edad muy temprana y permanecen constantes durante largos periodos de tiempo. Se vuelve a ellas constantemente, y otros temas experimentados más adelante tienen, en muchos casos, un germen en estas inquietudes originarias. El escultor

11 Benjamin, Walter, Tesis de Filosofía de la Historia.

12 Martin, Agnes, "Beauty is the mystery of life. It is not just in the eye. It is in the mind. It is our positive response to life" (1989). Nota en la exposición retrospectiva en la Tate Modern, Londres, 3 Junio-11 Octubre 2015.

13 Gideon, Sigfried señalaba la necesidad de ampliar los marcos de investigación y no reducirlos únicamente a los métodos directos. "The most direct methods have not always proved the most rewarding. The frame has had to be constantly enlarged" Giedion, Sigfried. Space, Time and Architecture, The Growth of a New Tradition. (Harvard University Press Cambridge, Massachusetts) Prólogo de la decimotercera edición (fourth Edition). 
Juan Muñoz cuenta con un abanico amplio de intereses y un archivo que hace posible la disección de su proceso creativo. Muñoz exploró la herencia de la historia a través de la lectura, los viajes, visitas a museos o charlas con otros artistas. En sus obras resuena el eco de su voz y de su cultura, su mirada, su manera de entender el mundo, sus inquietudes, sus miedos, sus invenciones, en resumen, muchas de las cuestiones que gravitaban en su mente y a las que me aproximo con la intención de apreciar en ellas las posibilidades del pensamiento del artista.

He procurado contrastar con su círculo más cercano las relaciones aquí establecidas que permiten una lectura de las distintas capas de entendimiento de la obra del escultor. He consultado su archivo en Torrelodones (Madrid), el Estate de Juan Muñoz, al que he tenido acceso gracias a la generosidad de Cristina Iglesias y de su equipo, que han facilitado y contribuido al desarrollo de esta investigación. He tenido la oportunidad de conversar en varias ocasiones con el comisario, experto y amigo personal de Juan Muñoz, James Lingwood, sobre la obra del escultor y el contenido de esta investigación. Como he mencionado, existen numerosas publicaciones sobre la obra de Juan Muñoz, y muchas de ellas hacen referencia a los intereses del artista. He consultado estos y otros libros de interés en las bibliotecas Avery Library y Butler Library de la Universidad de Columbia, Nueva York, en la que he realizado mis estudios de postgrado, y en la Nacional Art Library del Victoria and Albert Museum en Londres, ciudad en la que resido actualmente. En esta investigación se pretende un análisis de su obra en el que se establezcan las correspondencias entre sus obras, escritos, intereses y referentes. Un estudio que establezca relaciones entre los distintos periodos del proceso creativo del artista, un atlas donde se evidencien los distintos medios de expresión del escultor y de la cercana relación de estos a nivel conceptual o gráfico. Tomando siempre como punto de partida de estas reflexiones la obra Double Bind, en la que, de manera aparentemente involuntaria, se reúnen directa o indirectamente aquellos aspectos que lo retratan como artista.

Una instalación como Double Bind, una vez desinstalada, solo puede ser revisada mediante documentos gráficos y escritos. "Nos vemos conducidos a un espacio que solo podemos ocupar mediante lo que han contado testigos presenciales, y solo podemos recorrer con la mirada unas fotografías que, más que confirmar la experiencia, nos atormentan por 
la imposibilidad de vivirla"14. Como dije anteriormente, en Mayo de 2015, en el Hangar Bicocca de Milán, se instaló de nuevo la obra, algo que ocurría por primera vez, 14 años más tarde de su primera instalación. Tuve la oportunidad de visitar la exposición Double Bind \& Around comisariada en este caso por Vicente Todolí, con quien me reuní en Milán. Se presentaba una serie de trabajos de Juan Muñoz, siendo Double Bind la pieza central de la exposición. Esta visita fue determinante para contrastar todos los datos que había obtenido hasta el momento, sintiendo gran ilusión por percibir la obra tal y como la había imaginado y validar la interpretación que había hecho de ella hasta el momento. Aproximarse al objeto de estudio de la tesis, es sin duda una oportunidad para vivir la obra y expresar desde la experiencia los posicionamientos que aquí se plantean. Los medios gráficos con los que actualmente se documentan este tipo de instalaciones, son tremendamente válidos y se convierten en imprescindibles para un estudio minucioso y completo.

14 O'Doherty, Brian, Dentro del Cubo Blanco: La ideología del espacio expositivo, CENDEAC, 2000, p. 45. 


\subsection{Estructura}

La memoria juega un papel fundamental a nivel individual y social. Es un hecho tan relevante que lo he considerado como el elemento aglutinador de este trabajo. La tesis está organizada en cuatro capítulos. El primero de ellos aborda un análisis del concepto de la memoria y sus funciones y su importancia en el proceso creativo. Se ofrece una aproximación a las cuestiones centrales referentes al proceso de la memoria desde un enfoque científico y su relevancia en el tiempo pasado, presente y futuro. En este primer capítulo se presenta también una biografía de Juan Muñoz que establece un marco referencial para la producción de su última obra Double Bind, principal caso de estudio de esta investigación. Por último y a modo introductorio, se presenta una memoria descriptiva de la obra.

Los capítulos dos, tres y cuatro comprenden una interpretación de la obra que subdivido en tres espacios conceptuales: cielo, infierno y purgatorio. Esta forma de trabajar surge al establecer una relación entre los tres estratos de la obra y la estructura tradicional teológica de los estados del alma. La parte superior de la obra, corresponde al cielo, un espacio abierto al que espectador se asoma, pero al que no puede acceder. El purgatorio es el estrato intermedio entre cielo e infierno, proporciona suelo al cielo y el techo al infierno y es donde se sitúan las figuras escultóricas de Muñoz. Es visualmente accesible desde el nivel inferior de la obra, el infierno, un espacio oscuro y por el que el espectador deambula sin orientación. La tesis se cierra con una conclusión y apéndices relevantes que complementan la investigación llevada a cabo. 



\section{INTRODUCTION}

\subsection{Presentation}

The past gives meaning to the present. Stories of the present are created through the past. Allowing stories to vanish without trace not only implies eliminating the memory but also reducing future possibilities, unable to come up with any past references. This thesis includes a reflective study of the dependence relationship between creation and memory and what has been extracted from the past. The artistic creation cannot be understood without giving due weight to the memory and experience of the creator. In order to demonstrate this relationship it is necessary to use a work of art, that can be rebuilt over time and be used as a basis through which the relationship between the work and the dynamics of the processes to can be demonstrated. 
By getting closer to the creative process of the Spanish artist Juan Munoz (1953-2001), we not only access the knowledge of his artwork presented but also the understanding of unexplored paths that leads us to it. Through the study of the process, we can observe its constants, their evolution and discover the seeds of new research directions. This study also offers an overview of alternative futures, trials that for various reasons were not part of the final story and that, without being developed, would likely result in a different present. Juan Muñoz, led by his intuition, worked on the evolution of certain ideas. He combined the evolution of his constant themes of study with what inspired him from the world around him. He saw what he was looking for from what he observed, or he simply found a source of inspiration in what he observed. He discovered his world in a street, a picture, a church, or a poem. By looking at them, he found plastic or narrative suggestions that he used as a basis to develop his creations. The aim of this study is to understand the creative process of Juan Muñoz, its origin and evolution, and to discover the relationships between his ideas and references, by first understanding how human memory works.

Heidegger suggests the need to understand, because existing implies understanding, while Emilio Lledó argues that "existence is, essentially, memory". Starting from the hypothesis of this need to understand and comprehend and from the important role of memory in the creative process, this thesis seeks to reconstruct the places of memory from the interpretive analysis of the work of a creator. This approach offers a greater understanding of how a work is generated from an analysis of how human memory works. It also opens up new perspectives of interpretation by becoming involved with the creative process and not just focusing on the analysis of the final object produced. It is known that the creator, either intuitively or deliberately, uses the references that he accumulates in his memory to produce new projects. Deciphering and getting to know them will provide a vision capable of revealing the layers of reality of the work. This thesis starts from the premise that the work is set in the context of his own memory as the creation of an individual who accumulates history. Therefore, it is essential to follow the steps of the creator in order to seek that assembly of visible or invisible ideas that result in a work and validate the hypothesis presented here.

Through perception, the subject is in a reality which is none other than his own. It is, therefore, a complex relationship between the environment, things, and the physical and 
psychic subject. Reactions produced by a stimulus can be considered as not corresponding to a single moment in the present. They must be viewed as a conscious reflection together with an unconscious one, which is linked to time and to past learning. On the other hand, the act of remembering comes with oblivion, which produces an involuntary misunderstanding between what is perceived and proposed. The relationship between the artist's ideas and what has been experienced in the past may be neutralized by the mind, which takes those ideas as given and excluded from influences. This legitimate stance of isolating any references from those he considers to be his own does, however, have its origin in a selective memory from the past. 


\subsection{Aims of the research}

Over the last few years I have focused my attention on the issue of perception and the study of the past present. The past endures in the present and the future is rooted in a visible or invisible past. Looking for different palimpsests ${ }^{1}$ first in architecture $^{2}$ and now in the work of the Spanish sculptor Juan Muñoz. The aim of these studies is to follow the sequence of events along an evolutionary process looking for traces of the past which multiply the understanding of things.

During these supervised works, I wrote a research paper entitled Días del futuro pasado -Days of future past-, which was a first approach to memory and the spatial perception from the sensory standpoint. My initial intention was to establish a map that would determine the nature of the relationship between architecture and memory. Starting from the study of the role of the past in the present, through the history of certain architectures, the need arose to illustrate their relationship with society. The aim was not to reach its historical preservation, but to understand them as pillars that condition and support the evolution of present and future thinking. Through these early studies, I concluded that every creative process is linked to the search for inspiration within an imaginary of collective and personal references, which were the central themes of this research.

The temporary installations at the Tate Modern in London are a means of creating a shortterm transformation of a permanent space that is provisionally transfigured by its content. The temporary intervention leaves no trace in space once dismantled, but it does change the capacities and the perception of the venue after stretching its spatial possibilities. In turn, this intervention marks the collective imaginary and becomes part of cultural memory. Taking this position as a metaphor of the influences coming from experience in the creative process, I found that the installation Double Bind by Juan Muñoz exhibited in 2001 at the Tate Modern encompassed a set of interests able to completely illustrate

1 Old manuscript that retains traces of an earlier text which has been artificially effaced. In this case, it is not about two possible texts different from each other one over the other, but about overlapping layers of knowledge, the memory of what was there, the traces of the past.

2 Studying the socio-cultural evolution of the Soho (New York) and the visible and invisible transformations that it means in architecture and urban planning. To study temporality in what appears as immutable over time. 
the objective of this research. Through Double Bind I could establish a framework to investigate the creative process of the author and to establish a relationship between the artistic creation, the architectural creation and memory.

Initially, the creation of Muñoz focuses on the production of objects and figures that he presents in isolation at the beginning of his career and later as part of a whole. After years of exploring the location of his figures in space, Muñoz feels the need to create a context for the groups of figures, by providing them with an environment that surrounds them. He seeks to create a narrative from an architectural point of view where the context that he provides for his figures forms the essential part of the story. This exercise has a very important role in his work A Place Called Abroad and culminates as a strategy in Double Bind.

Reflection on the role of memory through a work of art in a school of architecture is based on recognising that space is an essential component of the work in contemporary sculpture. In the case of Muñoz, the spatial relationships between the physical layouts of the figures in an existing space, or, even forms that constitute a space, are the reason for his interests in the field of architecture. Space is considered to be an active element, which offers an existential and sensory experience to the viewer. In Double Bind, the space that welcomes the work becomes part of the same. The work modifies the gallery producing a dialogue between the previously existing and the installation which does not make it possible to identify the work as an object. It is difficult to establish a difference between sculptural and architectural limits.

In this research, memory, the human ability which makes it possible to retain the past, is studied as that intimate and personal place to be accessed through the analysis and interpretation of the life and work of the sculptor. The sculptor's pieces are the visible part of his work, but the visible has roots beneath the earth which can be discovered and studied. To discover here the two thirds of the iceberg that Hemingway proposed to hide, with the intention of giving more drama to his works, in order to show the whole story, the underlying reality, the unsaid parts which form the creation, what is perfectly understood, what is not told and which unfolds knowledge. And to access the work of Juan Muñoz as he described it himself, as the connection between his present and his past: "My work 
deals with history, with the awareness of my present condition and the fragments of my memory"3.

Within the conceptual framework of human memory, this thesis aims to synthesise the creative process of the artist, trying to put in order the body of ideas behind his works. It is based on a constant and refined review of a set of concerns that arise from his inner and which travel and grow with him since his youth following a non-linear path. Through the constant exploration of certain issues that captivated his interest and which are in his deepest self that he completes with knowledge that he incorporates during his career. Like Giacometti, Juan Muñoz "works like a fly", like a human being who returns to the same place again and again, not clearly knowing where he is going, and who is obsessed with the same themes. The sculptor is well aware of this exercise and questions the validity of the same. He seeks to find in it the "lost opportunities" in explored fields, always trying to avoid the action as counterproductive ${ }^{5}$, seeking, not the correction of a past action but the creation of a new work using and reusing devices and different strategies for new purposes.

3 Muñoz, Juan, Lingwood, James, Blazawick, Iwona and Schlieker, Andrea. Una conversación. Julio 1990 en Juan Muñoz, Monólogos y Diálogos. MNSCARS, Madrid, 1996, p. 60.

4 Natsume-Dube, Sachiko. Giacometti and Yanaihara: Trabajo como una mosca- I work like a fly-. Elba. 2013

5 Juan Muñoz highlights the first paragraph of the introduction of the book of George Steiner A Reader, where the expert in comparative criticism reflects on the fact of "rewriting, altering and amending" in the period of maturity a work that has been developed in youth. The historian and critic raises the question of whether the review of the work actually improves the work or if it is a counterproductive exercise in which "errors" that define "oneself" in youth are eliminated." The impulse to rewrite, to amend and alter in the colder light of hindsight and maturity, is all but irresistible. Such up-dating, and 'improvement' would, however, not only be transparently dishonest; it could, I suspect, prove self-defeating".

In Muñoz, Juan, Juan Muñoz: Escritos/Writings. Una introducción. (de George Steiner a George Steiner) 1991 Ediciones de la Central. Barcelona, 2009, Pág.199 In his text, Juan Muñoz establishes a dialogue between two characters (A, B) commenting Steiner's remarks discussing the pros and cons of rewriting a text or part of it. 


\subsection{Interest of the subject of study and state of the art}

Memory is the instrument that sets the mysterious rhythm of creation; it is a sounding board which receives the knowledge acquired throughout life. Mnemonic techniques of the classical period used architecture to establish and organise the places of memory, homes of wisdom in which to meticulously classify knowledge according to different principles and hierarchies. The functioning of continuous memory is a topical and important issue within the scientific and philosophical areas. Memory is a complex system that uses deep connections whose interaction cannot yet be classified by science within a flowchart in order to operate. The mechanisms of memory are an object of study in neuropsychology. The writings of José María Ruiz-Vargas, PhD in Psychology and Professor of the Psychology of Memory in the Autonomous University of Madrid, have served as the starting point from which to obtain knowledge about the cognitive approach to memory (cognitive science arises in the '70s). From these texts, I picked up the basics of memory functioning, at the same time as also analysing current texts related to this issue. Among these, it is worth mentioning the writings of Endel Tulving, Professor of Psychology at the University of Toronto, Daniel Schacter, Lecturer of psychology at Harvard University and Larry Squire, Lecturer at UC San Diego.

While some artists have tried to collect and show the steps of the creative process, is not easy to fully understand how ideas are developed, since projects are products that are developed through a process that goes beyond following the steps of the creation of a work from its beginning. The information collected during the process significantly influences the outcome. However, the knowledge accumulated from previous experience is also an important factor. The process is always dynamic. However, it becomes conscious at a determined moment in time. It never ceases, the steps that precede it and are not recorded in the progress of development form also part of it. Borges, in The Lottery in Babylon says that no decision is final, all branch out into others. This tree diagram can also be used metaphorically in relation to memory; the creator always finds multiple possibilities in his path, which force him to decide and direct his actions in a specific direction, the alternatives considered and discarded also have a value as regards understanding the creative development and are necessary for the interpretation of the work. The theory 
of creative intelligence (Anagrama, 1993) by José Antonio Marina presents important hypotheses regarding the organisation and functioning of knowledge that allow the invention of new possibilities. Creative Evolution by Henri Bergson (Cactus 2008, written in 1907) offers a theoretical body about intelligence, which is also very important as a reference for this study.

This is an exercise of analysis to awaken the hidden sense or simply to understand what is communicated through a work and what gravitates around it. The work is a message deciphered by the viewer from subjectivity, and by interpreting it, he/she gives meaning to it. The work speaks from its material being but does not respond. Given the need to understand and to establish a dialogue of the work with the viewer and with his/her own history, we resort to an interpretive method that brings us closer to it and its background: hermeneutics. In Truth and Method II, Gadamer states that "art represents a challenge to our understanding because it escapes all explanation, and offers an ever insurmountable resistance to whoever would translate it into the identity of a concept". Each work is susceptible to multiple interpretations. The aim is to offer that which provides more information about the sources of inspiration of the creator. When trying to understand, one's own opinion should be abandoned as much as possible, and first of all try to conceive the thing. Luigi Pareyson, precursor of hermeneutics, in The contemplation of form, states that contemplation is not a passive state, but that the work is discovered through a complex process of interpretation. To interpret is to explain and express the sense of a thing, from the point of view of the creator. It is a sensitive and empirical interpretation for the benefit of knowledge. The director of this thesis, Professor Javier Segui de la Riva, provided me with the necessary literature to understand the hermeneutical approaches related to the interpretation of the works of art. It includes the theories of Schleiermacher, Dilthey, Heidegger, Ogden and Richards, Payerson, Durand or Betti.

The way of understanding the projection of thoughts in the work of Muñoz through Double Bind and by means of a hermeneutical study implies not looking at his work, but through it and to clarify the relevance of what is behind the ideas. Connections between his work and his most primitive concerns are thus discovered, emphasising the interaction between architecture, sculpture and the viewer, issues that particularly interested the sculptor. 
In the Introduction to the Critique of Pure Reason, Kant argues that our knowledge needs experience. The creative process is a spider web that intertwines the oldest events with current ones. The temporary-space juxtaposition of ideas represents a range of stimuli that rely on memory resulting in new projects. "We project perspectives to make up the past" ${ }^{\prime \prime}$. The study of memory through Juan Muñoz and specifically, through his work Double Bind, makes it possible to reconstruct the map of references, influences, interests and relationships of his most mature work. Double Bind can be considered as the memory of all his previous works.

In the mid-80s Muñoz was established as one of the most prestigious emerging artists in the international sculptural landscape. He belonged to a generation of artists who recovered figuration as a central theme, but he was never part of an organised group. He developed his own language and themes. He received the National Prize for the Fine Arts in 2000, and he was the second person to be invited to participate in the Unilever Series, the temporary installations in the Turbine Hall of the Tate Modern. In addition to address situational consequences of a figurative sculpture, his work includes drawings, conceptual installations, sound works and literary essays. Neither should we forget his role as the commissioner of several exhibitions at the beginning of his career. His work has been exhibited in many international galleries, and has been part of several retrospectives at major museums around the world (the Hirshhorn Museum in Washington in 2001, MNCARS in 2008 or Bilbao also in 2008). After the sculptor's death in 2001, his work has not ceased to form a part of exhibitions, either in group or alone. His legacy is managed by the Estate of Juan Muñoz, and many of his works are part of important public and private collections. In May 2015, his last work, Double Bind, is again temporarily installed, as part of an exhibition called Double Bind \& Around in the HangarBicocca in Milan. Critics of the contemporary art world write about his works: Neal Baeza, Lynne Cook, James Lingwood, Adrian Searle, Paul Schimmel Vicente Todolí or Sheena Wagstaff among others. Muñoz's work is usually interpreted from the field of art history.

This exercise includes the analysis of the circumstances which surround the installation and which complete the message linking the work with the memories and past experiences

6 O'Doherty, Brian, Inside the White Cube: The Ideology of the Gallery Space, CENDEAC, 2000, p.20 
of its creator, thus generating its anamnesis. ${ }^{7}$ It recovers those images which are important but that are not present in the work. These can be found in notebooks, in written reflections, in the follow-up of his trips, in his readings, in the study of personal experiences, in short, in the creator's life experiences.

Artworks have their individual space independent from history. However, the fact of not delving into the study of the social and cultural characteristics of the artist creates a rift between the artwork and the collective memory that limits the ability of the same to communicate, by separating them from a global context and providing only a partial view. It is equally important to understand the relationship between the viewer and the artwork at the moment when it is shared with the public (and especially, how it is received by the critics). "Undocumented projects can survive as a rumour and be linked to the individuality of those who created them, who are forced to develop a compelling myth" Artworks are subject to the interpretation of endless points of view, different disciplines and different times. It is how the work is contemplated that extracts a certain image of an object. Reflections on the works are filtered by a certain point of view that influences the evolution of their understanding throughout history, beyond its materiality. The plastic object can remain throughout history, but different ideological grounds about what it represents are accumulated, when the ideas that flutter from the object are extracted and expressed. Image brings together past and memory, but it also continues to evoke new perspectives and approaches, some considering its origin, others based on a present moment.

7 In medicine, anamnesis is the set of clinical data and relevant information of a patient's medical history. The term, from the Greek, means reminiscence, defined by the Royal Academy of the Spanish language as representing or leading to the memory of something from the past.

8 O'Doherty, Brian, Inside the White Cube: The Ideology of the Gallery Space, CENDEAC, 2000, p. 66. 


\subsection{Methodology}

Through a hermeneutical analysis of the work, I have tried to assume the point of view of the artist and thus to transmit the stimulus that the work has provoked in me, avoiding critical judgment or possession of truth. This exercise aims to produce a document able to describe the artist's creative process. Recognising, as Emmanuel Levinas says in Reality and its Shadow, a well-known book that Juan Muñoz had studied", that art has "a background of reality, however inaccessible it may be to conceptual intelligence"10. Everything in the mind is interrelated. We must find the elements that shape creation, the combination of small events that can cause major changes.

The first approach to the work is carried out based on the senses, but it is necessary to delve into the meaning and origin of the sculptor's ideas to reach the knowledge of the development of the work. Therefore, the study should be expanded to include additional material apart from that provided by the work in itself. Pareyson describes artwork as dynamic, given that it is the "conclusion of a movement". The thoughtful study on the work has to consider its historical understanding and the experience of the creator himself. In the course of his study, the researcher should aim at surrounding himself by the system that consolidates the structure of the work. It is necessary to establish the relationships between the evidence of the work. However, it is also necessary to look beyond, or should I say, to look back, delving into memory. To rescue all the information that makes it possible to decipher the chain of thoughts that result in a work, to split and compose new logos of the memory.

Therefore, the aim is to offer an analysis that opens knowledge of Double Bind, trying to delve into the understanding of the creative process and that of the framework of the works of Juan Muñoz, because "To articulate what is past does not mean to recognise how

9 Searle, Adrian, Introducción -Introduction- Juan Muñoz: Escritos/Writings. Ediciones de la Central. Barcelona, 2009, p. 25. "The copy of the Reader dedicated to the Russian-born French philosopher Emmanuel Levinas that Muñoz had, an anthology published in 1989, is widely used, particularly the essay Reality and its Shadow published for the first time in Les Temps Modernes 1948".

10 Lévinas, Emmanuel - La realidad y su sombra -Reality and its Shadow-, Arte y Crítica, Ed. Trotta, Madrid 2001, p.45. 
it really was"11. An approach to the origin is intended, by accepting the limitations and the distance between the interpretation and the truth that somehow ceases to exist once the artist disappears, who can even submit his own work to new interpretations by modifying his speech. Art does not always impose a story; it is open to the viewer's feelings. Juan Muñoz has clear intentions, but his ability to control emotions and feelings that his art can produce are limited. His domain is restricted to the material world and its context, which he manipulates at his will. However, the work does not cover the field of meaning and sensations which belong to each individual. The filter to which the artwork is subjected when analysed and interpreted adds layers of understanding that belong to the person describing it. Borrowing the words of the artist Agnes Martin, impressions, "are not just in the eyes, they are in the mind"12.

A procedure which gives an answer to the hypothesis proposed has been sought. This hypothesis is based on a thorough analysis of the work at hand and on the production and experiences of the artist as well as on writings and short stories of other authors that reflect knowledge of his creation. The author's experiences and the references sought are part of his knowledge and determine his future. These referential elements which are integrated into the personality of the creator may have a direct and obvious or indirect, but decisive relationship in the creative process. The latter are more difficult to identify and interpret and, in many cases, are critical. The interpretation of the background of the work beyond the direct elements becomes fundamental ${ }^{13}$. The creator has certain concerns that are developed from a very early age and remain constant over long periods of time. He constantly comes back to them, and other issues experienced later on have, in many cases, a root cause in these concerns. The sculptor Juan Muñoz has a wide range of interests and a file that allows the dissection of his creative process. Muñoz explored the legacy of history through reading, trips, museum visits or talks with other artists. The echo of his voice and his culture, his vision, his understanding of the world, his concerns, his fears

11 Benjamin,Walter, Thesis on the Philosophy of Histor.

12 Martin, Agnes. "Beauty is the mystery of life. It is not just in the eye. It is in the mind. It is our positive response to life" (1989) Note in the exhibition retrospective in the Tate Modern, London, 3 June-11 October 2015.

13 Gideon, Sigfried noted the need to widen the research frameworks and not to reduce them to direct methods. "The most direct methods have not always proved the most rewarding. The frame has had to be constantly enlarged" Giedion, Sigfried. Space, Time and Architecture, The Growth of a New Tradition. (Harvard University Press Cambridge, Massachusetts) Preface of the thirteenth edition (fourth Edition). 
and his inventions resounds in his works; In short, many of the issues that gravitated in his mind and which I approach with the intention of using them to appreciate the artist's possibilities of thought.

I have tried to contrast the relationships established here which allow an interpretation of the various layers of understanding of the sculptor's work. I have consulted his archive in Torrelodones (Madrid), the Estate of Juan Muñoz, to which I had access thanks to the generosity of Cristina Iglesias and her team, who have facilitated and contributed to the development of this research. I had the opportunity to talk repeatedly with the commissioner, expert and personal friend of Juan Muñoz, James Lingwood ${ }^{14}$, about the work of the sculptor and the content of this research. As I have mentioned, there are numerous publications on the work of Juan Muñoz, and many of them refer to the artist's interests. I consulted these and other books of interest in the Avery Library and Butler Library of the Columbia University, New York, and in the National Art Library of the Victoria and Albert Museum in London. The aim of this research is an analysis of his work in which the relationship between his works, writings, interests and references are established. It is a study establishing the relationships between the different periods of the artist's creative process, an atlas where different means of expression of the sculptor and of the close relationship between these shown from a conceptual or graphical point of view are evidenced. Always taking the work of Double Bind as the starting point of these reflections, where apparently inadvertently those aspects portraying him as an artist meet directly or indirectly.

An installation such as Double Bind, once uninstalled can only be reviewed through graphic and written documents. "We are led to a space that we can only occupy through what we have been told by eyewitnesses, and that we can only go through by looking at some photographs that, instead of confirming the experience, torments us by the impossibility of experimenting $\mathrm{it}^{\prime 15}$. As I said earlier, in May 2015, the work was again set up at the HangarBicocca in Milan, something that happened for the first time in 14 years after its first installation. Here I had the opportunity to visit the exhibition Double Bind \& Around, commissioned by Vicente Todolí, whom I met in Milan. A series of works by Juan Muñoz

15 O’Doherty, Brian Inside the White Cube: The Ideology of the Gallery Space, CENDEAC, 2000, p. 45. 
were presented, with Double Bind as the centrepiece of the exhibition. This visit helped me to contrast all the information that I had obtained so far, feeling a great enthusiasm to perceive the work as I had imagined it and to validate the interpretation of the installation that I had carried out up to that point. To approach the thesis' object of study is certainly an opportunity to live the work and to express through the experience the positions that are raised here. The printed media, which currently document this type of installations, are extremely valid and become essential for a thorough and complete study. 


\subsection{Structure}

Memory plays a key role on an individual and social level. It is such a significant element that I have considered it to be the unifying element of this work. The thesis is organized into four chapters. The first one is an analysis of the concept of memory and its role and importance in the creative process. It provides an approach to the central themes concerning the process of memory from a scientific point of view and its relevance in the past, present and future time. This first chapter also includes a biography of Juan Muñoz that provides a referential framework for the production of his last work Double Bind, the main case of study in this research. Finally, and as an introduction, there is a descriptive memory of the work.

Chapters two, three and four include an interpretation of the work subdivided into three conceptual spaces: heaven, hell and purgatory. This way of working arises by establishing a relationship between the three layers of the work and the traditional theological structure of the states of the soul. The upper part of the work corresponds to heaven, an open space from which the viewer peer out, but to which he/she has no access. Purgatory is the intermediate layer between heaven and hell. It forms the floor of heaven and the ceiling of hell. This is where Muñoz' sculptural figures are located. It is visually accessible from the lower level of the work, hell, a dark space where the viewer wanders without direction. The thesis ends with a relevant conclusion and appendices to complement the research carried out. 

2 EL LUGAR DE LA MEMORIA 


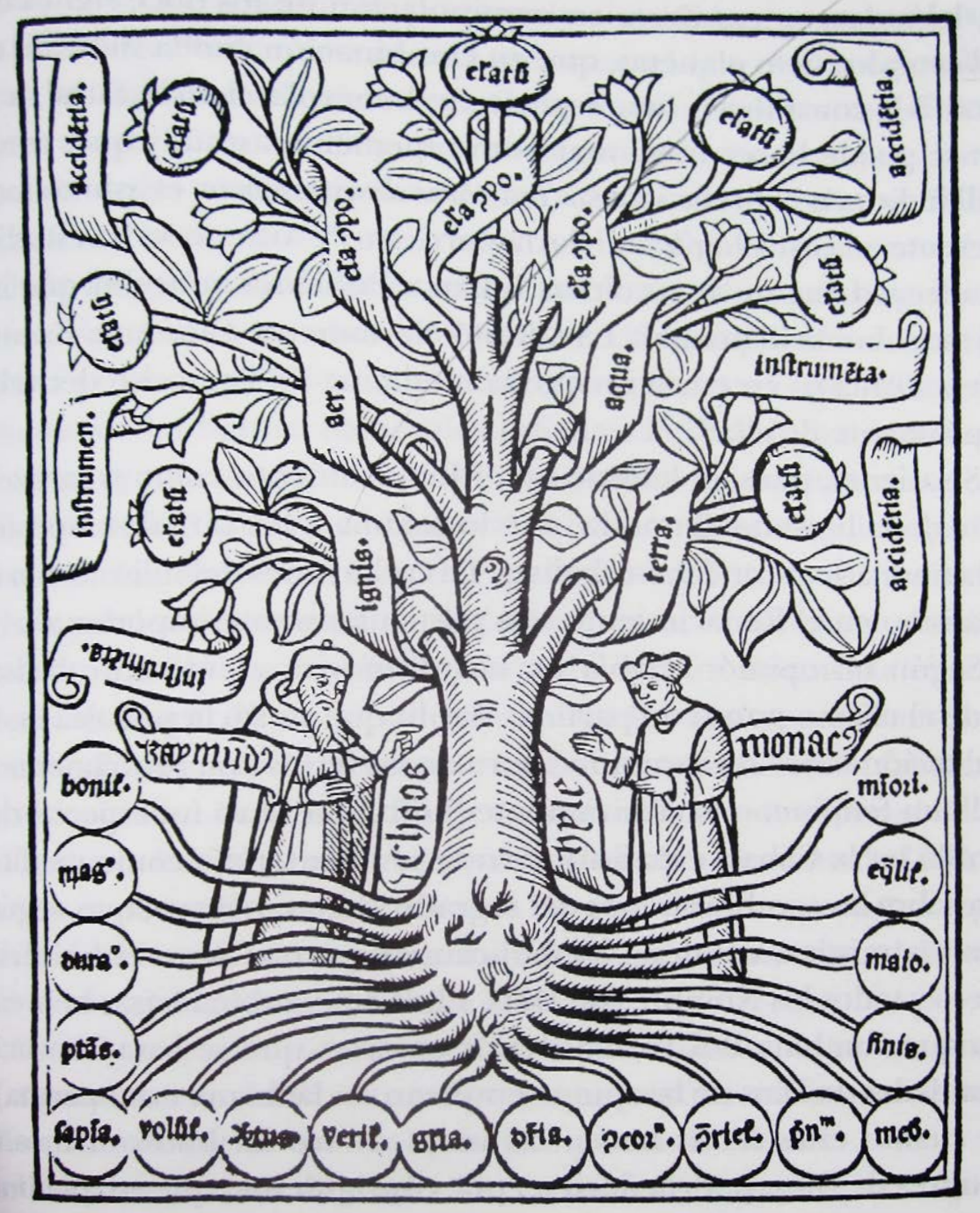




\subsection{La memoria}

\subsubsection{La memoria y lo pasado}

San Agustín, en un pasaje de sus Confesiones, reflexiona sobre el tiempo diciendo "Pero aquellos dos tiempos, pretérito y futuro ¿cómo pueden ser, si el pretérito ya no es y el futuro todavía no es? Y en cuanto al presente, si fuese siempre presente y no pasase a ser pretérito, ya no sería tiempo sino eternidad." Con un pasado que ya no existe y un futuro que aún no existe, San Agustín encuentra tres formas de manifestar el tiempo presente: la memoria ("presente del pasado") la contemplación ("presente del presente") y la esperanza ("presente del futuro").

Relaciona el tiempo con conceptos relativos al ser, que enlazan con el pensamiento de Heidegger y la reciprocidad entre ambos: "Ser y tiempo se determinan recíprocamente, pero de una manera tal que ni aquél -el ser- se deja apelar como algo temporal, ni este -el tiempo- se deja apelar como ente" ${ }^{1}$. La cultura moderna tiende a asumir que el futuro

1 Heidegger, Martin, Tiempo y ser, Editorial Tecnos 2000, Madrid. p.29. 
ha empezado $\mathrm{ya}^{2}$ en el sentido de comprender que el tiempo futuro contiene el tiempo pasado, y que el pasado son los cimientos en los que se asienta el futuro. El concepto del tiempo se asocia con la duración y también con el cambio. Si todo permaneciera inmóvil, las cosas serían eternas e inmutables (intemporales).

Es en este tiempo cambiante donde discurre la vida, en la transición entre pasado, presente y futuro cuando se desarrolla la evolución creadora.

Al avanzar en el camino del tiempo, la memoria (el presente del pasado de San Agustín) arrastra partes del pasado al presente. La correspondencia entre memoria y ser, es, según Lledó, inseparable: "Ser es, esencialmente ser memoria; es encontrar una forma de coherencia, un vínculo entre lo que somos, lo que queríamos ser y lo que hemos sido.”3

La memoria ${ }^{4}$ es capaz de traer al presente el recuerdo, prolongando el pasado en el presente y es indispensable para el desarrollo de la inteligencia. Esta capacidad sirve para recordar y almacenar información, pero es una facultad distinta al entendimiento, que está ligado con la inteligencia.

A través del conocimiento de la realidad se es capaz de inventar nuevas posibilidades y es a partir de la memoria como la inteligencia creadora engendra nuevos proyectos. Por ello, para proyectar, es necesario construir una subjetividad propia que se forma a partir de las experiencias sensoriales que se almacenan en la memoria y las relaciones que se establecen entre los recuerdos. La memoria va engrosando con el paso del tiempo, adquiriendo mayor capacidad y profundidad y por tanto, estando más preparada para asumir una función activa, permitiendo evocar sólo aquello que tenga sentido en la situación presente.

La inteligencia humana tiene la capacidad de imaginar, su característica esencial es "la invención y promulgación de fines"5 y se define la como la "facultad psíquica por medio de

2 Puntualiza Heidegger: “...lo cual no es el caso, porque el futuro nunca jamás comienza, en la medida en que el estar ausente como el estar presente de lo todavía-no-presente nos atañe siempre ya de alguna manera, es decir, está presente tan inmediatamente como el pasado. En el por-venir, en el ad-venir-nos se extiende el estar presente." en Tiempo y ser, Editorial Tecnos 2000, Madrid. p.41.

3 Lledó, Emilio, El silencio de la escritura, Espasa, 2011 p.7

4 Bergson,Henri, “...memory-is just the intersection of mind and matter" en Matter and Memory, MIT Press, 1991 p.13

5 Marina, José Antonio, Teoría de la inteligencia creadora, Anagrama, 1994. p.17. 
la cual se retiene y recuerda el pasado"6. Sabemos que el sujeto actúa desde su memoria es decir, su presente y su futuro están dirigidos por su pasado, siendo a través de la memoria como el sujeto reelabora los recuerdos en el momento en que los recupera. Este vínculo con el pasado ofrece un marco referencial para elaborar futuras respuestas. Continuamente actualizándose y reconstruyéndose formando nuevos conjuntos de estrategias. Los recuerdos se adquieren durante el desarrollo de la vida y aparecen y desaparecen del presente, algunos tal y como fueron concebidos originalmente, otros diluidos y transformados por otros recuerdos y las condiciones del presente en las que son evocados. Somos memoria al mismo tiempo que hacemos memoria.

La memoria está íntimamente ligada a la percepción, que a su vez se define por como "sensación interior que resulta de una impresión material hecha en nuestros sentidos." De la misma manera que no se puede desvincular del aprendizaje, mediante el cual se adquiere el conocimiento. Memoria, percepción y aprendizaje son los procesos cognitivos que procede estudiar para comprender el funcionamiento de la mente humana, la ciencia que se ocupa de su estudio se llama psicología cognitiva. Mediante la memoria elaboramos la historia personal que almacena las experiencias y emociones, por medio de ella se recuperan las imágenes del pasado y gracias a ella se es capaz de expresar las ideas. Sin la memoria todo perdería sentido.

Como dice el psiquiatra Luis Rojas Marcos, "Los recuerdos del pasado tienen un gran peso sobre las decisiones que tomamos y los comportamientos que adoptamos en el presente", lo que significa que las experiencias pasadas son constituyentes de la personalidad. La memoria es un una capacidad mental compleja y fascinante pero debemos tener en cuenta que el estudio de la mente humana está todavía lleno de incógnitas.

Los recuerdos se registran debido a la necesidad de aprender, eso sucede de manera consciente o inconsciente y se forman dentro de lo que conocemos como realidad, que se constituye de pequeños fragmentos en el tiempo y en el espacio que configuran una continuidad.

6 Real Academia Española de la Lengua.

7 Bergson,Henri, Matter and Memory, MIT Press 1991. Según Bergson, la memoria es inseparable de la percepción, y trae el pasado al presente:”... memory, inseparable in practice from perception, imports the past into the present"

8 Real Academia Española de la Lengua. 
Esta acumulación de datos se ve influenciada por nuestra personalidad y capacidad de atención. Aunque en muchos casos se utiliza el sustantivo imagen para hablar del recuerdo, hay que tener en cuenta que los recuerdos retenidos no son perfectas fotografías, en muchos casos están cargados de distorsiones y no son un fiel reflejo de la realidad.

Lo que interesa en este apartado de la tesis es comprender la dinámica de la inteligencia creadora, para lo que es necesario entender el funcionamiento de la memoria, que como vemos, se apoya en un tejido de complejos tiempos y múltiples sistemas basados en el recuerdo que más adelante permiten proponer soluciones innovadoras. Por lo tanto, las personas más inteligentes, y con más capacidad de creación son, según Juan Antonio Marina, las que más datos hayan sido capaces de recoger, los que más y mejor hayan visto, y aquellas que sean capaces de establecer variadas y novedosas relaciones entre todos los conceptos que manejan.

Algunos de los sucesos que dan lugar al desarrollo de una obra son incomprensibles e inexplicables, pero los psicólogos coinciden en que se alimentan de todo cuanto vive en el recuerdo ${ }^{9}$. Paul Klee describía este pasaje refiriéndose a la obra como la génesis diciendo “La obra es, en primer lugar, génesis y su historia puede representarse brevemente como una chispa misteriosamente brotada de no sabemos dónde y que inflama el espíritu, acciona la mano y al trasmitirse como movimiento a lo material, se convierte en obra"10. Se busca recopilar las nociones que nos permitan comprender la necesidad de los referentes que permiten la elaboración de nuevos proyectos para subrayar la importancia y destacar el papel de su función en el proceso creativo. Aristóteles (384 a. C. 322 a. C.) ya vinculaba la memoria al paso del tiempo y a los acontecimientos pasados, señalando que la imaginación y la memoria pertenecen a la misma parte del alma y que la percepción de las cosas no parte del presente sino del pasado, de las imágenes mentales de la memoria. (De memoria et reminiscentia). ${ }^{11}$

9 Bergson, Henri, Matter and Memory, MIT Press, 1991. Los recuerdos se influencian unos a otros, Bergson expone este enfoque refiriéndose a las imágenes: "As a rule, any image influences other images in a manner which is determined, and even calculable, through what are called the laws of nature" p.20.

10 Klee, Paul, Teoría del Arte Moderno, Filosofía de la creación, Argentina, Ediciones Caldén, Colección El hombre y su mundo, 2007, p. 89.

11 Ver Yates, Frances A. El arte de la Memoria, Biblioteca de Ensayo Siruela, 2005, p.52.

"La teoría aristotélica de la memoria y la reminiscencia está basada en la teoría de conocimiento que expone en De anima . Las percepciones que aportan los cinco sentidos son, en primer lugar, tratadas y elaboradas por 
La exploración del arte de la memoria comenzó con los griegos, “(...) en el seno de una sociedad de cultura oral que deifica a la "Memoria", la Mnemosyne del poeta Hesiodo (s VIII-VII a. C.. ${ }^{12}$, madre de las nueve Musas, y en la que existe un magistrado, el llamado "recordador" (mnemon) que es el encargado de recordar de memoria el pasado"13, y desde entonces se han elaborado múltiples teorías y conceptos para explicar los sistemas de la memoria. San Agustín (354-430) relata en sus Confesiones un precioso pasaje sobre la memoria donde resalta la concepción de que las imágenes se perciben mediante los sentidos y se acumulan en una inagotable cámara que es la memoria. Ya por entonces San Agustín sugería una memoria que se va construyendo y actualizando en el tiempo.

"Avanzo hacia los campos y los espaciosos palacios de la memoria donde se encuentran los tesoros de imágenes innumerables, transportadas allá desde las cosas de toda especie que los sentidos perciben. Se almacena allí todo cuanto pensamos ya por ampliación ya por disminución ya por otra clase de variación de las cosas que aporta el sentido; y todo lo que, no habiendo sido aún devorado y enterrado por el olvido, se ha encomendado y atesorado allí. Cuando entro allí, demando al punto lo que quiero que se me aparezca y al punto comparece alguna cosa; otras cosas habrán de ser buscadas por largo tiempo, como si se encontrasen fuera de cierto receptáculo interno; otras salen precipitadamente en tropel y, en la búsqueda y pesquisa de la cosa deseada, comparecen como diciendo: “¿Es esto por ventura?” A éstas las expulso, con la mano de mi corazón, de la faz de mi memoria; hasta que aparezca, sin velos y a la luz, la que yo quiero, saliendo fuera de su lugar secreto. Advienen prestamente otras cosas en orden ininterrumpido, según se las ha convocado; al frente, aquellas que abren paso a las siguientes; y según abren el paso se ocultan de la vista, aprestándose a comparecer a voluntad. Todo esto tiene lugar cuando recito algo de memoria."14

la facultad de la imaginación, y son las imágenes así formadas las que constituyen el material de la facultad intelectual. La imaginación es la intermediaria entre la percepción y el pensamiento. Así en tanto que todo conocimiento deriva de las impresiones sensoriales, el pensamiento actúa sobre ellas, ya cualificadas tras haber sido tratadas y absorbidas por la facultad imaginativa. Es la parte hacedora de las imágenes del alma la que realiza el trabajo de los procesos más elevados del pensamiento. De ahí que "el alma nunca piensa sin un diseño mental".

12 Hesiodo, Teogonía 54 ss., 135, 915 ss.

13 Lopez Eire, Antonio,Velasco López, Maㅡ Henar, La Mitología Griega:lenguaje de dioses y hombres, Arco Libros S.L., 2012, p.26.

14 Citado también en Yates, Frances A. El arte de la Memoria, Biblioteca de Ensayo Siruela, 2005, p. 567. 


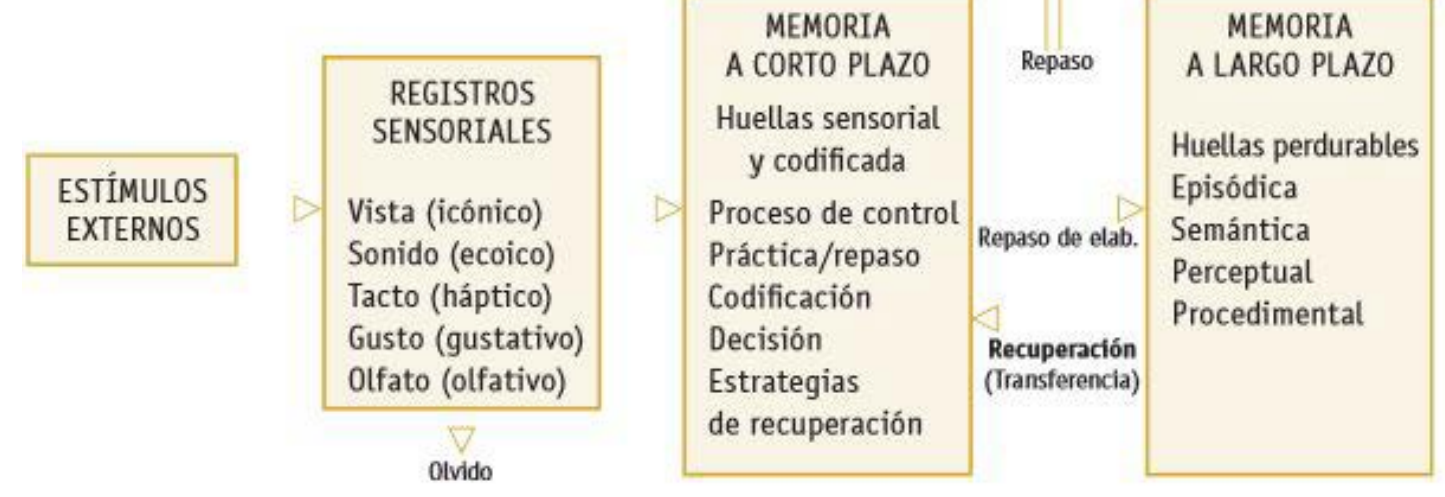

Diagrama de memoria de Richard Atkinson y Richard Shiffrin

Desde el punto de vista neuropsicológico, a lo largo del siglo XX se ha desarrollado el estudio de la memoria como un proceso dependiente de las estructuras del sistema nervioso. A partir de los años 60, la memoria ya no se considera como un sistema unitario ${ }^{15}$. Buscando explicar cómo relacionamos unos recuerdos con otros, y analizando las fases y dinámica de la memoria humana, en 1968 Richard Atkinson y Richard Schiffrin desarrollaron la teoría multialmacén de la memoria, que clasifica tres tipos de memoria, la sensorial, la memoria a corto plazo y la memoria a largo plazo. ${ }^{16}$

La memoria sensorial registra la información y las sensaciones que provienen del ambiente externo (imágenes, sonidos, olores, sabores y el tacto de las cosas). Existe un subsistema

15 Román Lapuente, Francisco, del Pino Sánchez López, María, Rabadán Pardo, María José, Tratado de Neuropsicología Clínica, Universidad de Murcia 2012Memoria y Amnesias, Tema 6, p.1.

16 Baddeley, A. D, Memoria humana: Teoría y práctica, McGraw-Hill Interamericana de España, 1998. Disponible en http://assets.mheducation.es/bcv/guide/capitulo/8448180607.pdf 
para cada sentido. Su información se transmite a la memoria a corto plazo. Esta es la memoria que se activa en primer lugar al situarse frente a una obra.

La memoria a corto plazo tiene como función organizar y analizar la información e interpretar nuestras experiencias en el tiempo presente y ante el futuro. La duración del almacenamiento de la información es temporal y breve. Es una memoria de trabajo de capacidad limitada, que solo si se organiza de forma lógica puede ser recordad durante más tiempo. Con ella retenemos durante un tiempo las impresiones que produce en nosotros la obra que estemos experimentando.

La memoria a largo plazo contiene nuestros conocimientos del mundo físico, así como el lenguaje y los significados de los conceptos. La información está bien organizada, y se utiliza cuando es oportuno. Es una estructura de almacenamiento permanente, salvo cuando surge el olvido como la incapacidad de recuperar cierta información. Mediante el uso de la memoria a largo plazo se establecen relaciones entre los conocimientos almacenados.

Esta estructuración no es fija y existiendo un flujo permanente entre las tres memorias. Existen más teorías sobre la organización de la memoria, pero los principios establecidos por Richard Atkinson y Richard Schiffrin siguen vigentes, aunque están en constante revisión y desarrollo. En 1988 Nelson Cowan propone un modelo que prima el tipo de procesamiento voluntario sobre el temporal y que conserva la estructura del modelo multialmacén de la teoría antes mencionada. Cowan la completa en respuesta a las críticas a dicha teoría, que basa todo su peso en dimensión temporal del procesamiento. El científico destaca el papel del procesamiento controlado, donde la atención toma un papel importante sobre el recuerdo posterior. La calidad de lo recordado depende de la forma en que se procesa, que puede ser superficial, o más profunda, dependiendo del interés.

La memoria a largo plazo es la que persiste a través del tiempo y se consolida mediante el aprendizaje, puede ser generada de manera automática, o de manera consciente. El aprendizaje modifica el comportamiento como resultado de una experiencia (produce cambios en las propiedades reactivas de las neuronas). Según el psicólogo Endel Tulving existen dos tipos de memoria a largo plazo, la episódica, que almacena recuerdos de acontecimientos que han tenido lugar a lo largo de la vida (autobiográficos) y la semántica, 


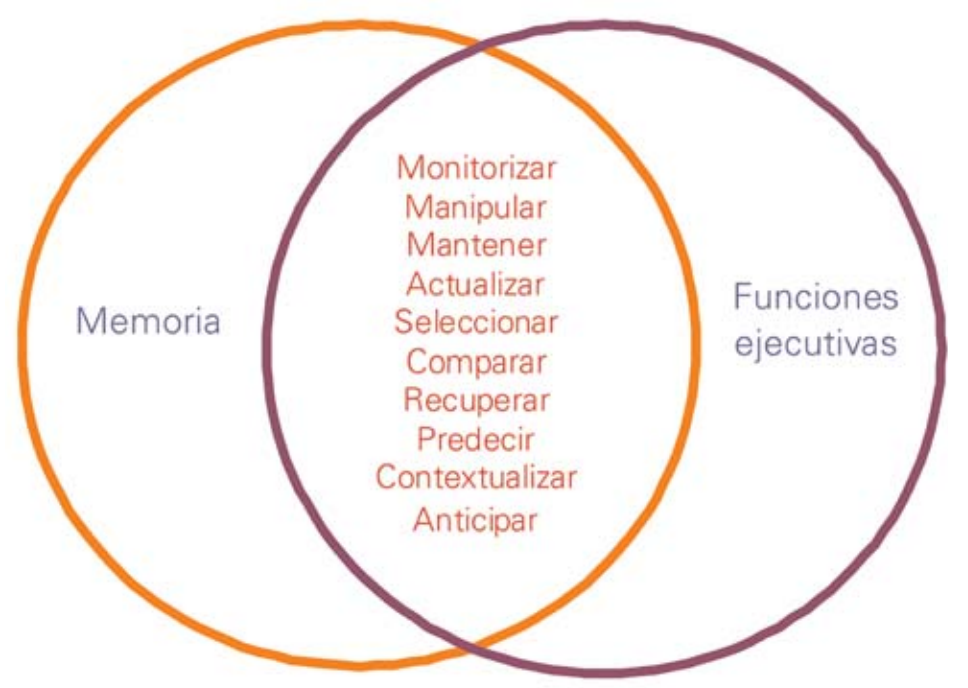

Memora y funciones ejecutivas

que acumula el conocimiento cultural, y que es la más relevante dentro del proceso creativo, ya que es la que está ligada a la inteligencia. Es una memoria explicita e intencional. Las funciones ejecutivas tienen un papel fundamental en los procesos de la memoria, a corto y a largo plazo. A día de hoy, está científicamente demostrado que, dentro de la estructura cerebral, son los lóbulos frontales los que se hallan implicados en la ejecución de operaciones cognitivas específicas: memorización, metacognición aprendizaje y razonamiento. Estas funciones se agrupan en torno a varios factores como las capacidades implicadas en la formulación de metas, la formulación de procesos, las estrategias para lograr los objetivos y las aptitudes para llevar a cabo estas actividades de forma eficaz. Las funciones ejecutivas responden a un sistema supramodal de procesamiento múltiple, existiendo una relación recíproca con otras funciones cerebrales en una doble dirección. Así las funciones ejecutivas (proceso top-down) afectarían a los procesos mnésicos pero también los procesos mnésicos (proceso bottom-up) influyen en un adecuado proceso ejecutivo. 
El córtex prefrontal se relaciona más con el funcionamiento de la memoria que con el contenido de ésta: el cerebro ejecutivo dota de inteligencia y orienta hacia conductas adaptativas a la información contenida en el hipocampo y los lóbulos temporales mediales. La relación entre memoria y funciones ejecutivas es por tanto un sistema de gran complejidad en el que intervienen diferentes aspectos: la memoria del trabajo, la metamemoria, la memoria de la fuente y la memoria prospectiva. Se ha estudiado con técnicas de neuroimagen, la localización de la memoria del trabajo observándose la activación del córtex prefrontal dorsolateral que sería esencial para mantener la unidad en la actividad cognitiva. La metamemoria, se refiere al conocimiento de la propia memoria e implica procesos complejos, como estimar la capacidad del propio aprendizaje, elegir estrategias de memorización, adquirir conciencia de lo que se conoce y lo que no se conoce y presunción sobre la propia memoria. Se localizaría en el sector ventromedial prefontal derecho con múltiples conexiones con la región temporal media. La memoria de la fuente, retiene los contextos en los que se adquirió la información, permite que el conocimiento se convierta en experiencia, se localizaría en la región prefrontal y hace que se recuerde la información además del contexto espacio-temporal en el que se adquirió. La memoria prospectiva, capacidad de proyectarse hacia el futuro, se refiere al recuerdo de la intención de hacer algo en un momento concreto del futuro y a la ejecución de un plan formulado previamente. ${ }^{17}$

Como hemos visto, la primera reacción de la mente al exponerse a una determinada situación, activa la memoria sensorial, que es la que involucra en los sentidos. El papel de los ojos es fundamental a la hora de interpretar los estímulos del arte, el sentido de la vista es el primer receptor. Posteriormente establecemos conciencia de esa imagen, que se inserta dentro de una matriz de recuerdos controlada por el sujeto. Establecemos relaciones de lo visto con lo que vemos, una vez establecida la relación, nos provocan distintas sensaciones según la repercusión del hecho y nuestra sensibilidad. Eulalia Bosch $^{18}$ describe este momento como mágico, un momento "suspendido en el tiempo, que combina instantáneamente la percepción inmediata con lo ya sabido y desemboca en el lenguaje de la sorpresa y la pregunta."

17 Tirapu-Ustárroz, J,Muñoz Céspedes, J.M, Memoria y funciones ejecutivas, Rev Neurol, 2005, 41 (8):475484

18 Bosch, Eulalia, El presente está solo, en Berger, John, Modos de ver, Ed. GG, 2000. p. 7. 
Depende del sujeto que percibe una situación y que retiene una imagen en su memoria, que esta imagen se almacene como una fotografía muerta, o que utilizando su imaginación y su memoria, componga relaciones entre lo que ha visto antes, y lo que percibe en ese preciso instante. José Saramago comienza su novela Ensayo sobre la Ceguera con una cita del Libro de los Consejos: "Si puedes mirar, ve. Si puedes ver, repara". Casi todos los hombres tenemos el sentido de la vista, pero no el sentido de reparar en lo visto.

El pasado es fuente de inspiración constante. Es frecuente encontrar en una obra restos de obras anteriores propias o ajenas. La importancia de comprender este proceso puede sacar a la luz evidencias en el estudio de obras de cualquier campo que abren nuevos caminos de comprensión de las mismas, lo cual, no solo nos permite profundizar en la obra de un solo individuo y en su memoria individual, sino también en los posos que se transmiten a través de la influencia de estas obras que son referentes para otros individuos y que configuran la memoria colectiva.

Las situaciones a la que son expuestos los protagonistas, privados del sentido de la vista, en la novela de Saramago nos hacen reflexionar sobre el uso de esta como sistema perceptivo. El hombre acostumbra a ver, pero no a reparar en lo visto. La falta de este sentido, pone de manifiesto la importancia del sistema perceptivo en la relación del hombre con su entorno. Saramago escribe en el cuerpo de la novela "En realidad, los ojos no son más que unas lentes, como un objetivo, es el cerebro quien realmente ve.(...) algunos de estos ciegos no lo son solo de los ojos, si no también lo son del entendimiento".

De la misma manera que la memoria está al servicio de la inteligencia creadora, el análisis al que se expone la obra al ser percibida está sometido a la inteligencia interpretativa del que la observa, "Lo visible no es más que el conjunto de imágenes que el ojo crea al mirar. La realidad se hace visible al ser percibida. Y una vez atrapada, tal vez no pueda renunciar jamás a esa forma de existencia que adquiere en la conciencia de aquel que ha reparado en ella"19

La investigación de un acción presente o pasada, se realiza desde la perspectiva del sujeto que la percibe, siendo participes de esta interpretación su memoria y su tiempo. Emilio Lledó recoge en El silencio de la escritura el mito de Theuth y Thamus de Platón donde

19 Ibíd. 
Thamus alerta a Theuth sobre los peligros del descubrimiento y uso de las letras; "Porque es olvido lo que producirán en las almas de quienes las aprendan, al descuidar la memoria, ya que, fiándose de lo escrito, llegarán al recuerdo desde fuera, a través de caracteres ajenos a ellas, no desde dentro, desde ellos mismos y por sí mismos"20. He aquí donde surge la necesidad de entender qué es lo que la obra quiere decir, y establecer un diálogo con ella, pretendiendo recibir el mensaje de otros siguiendo métodos hermenéuticos. El análisis de una obra requiere un acercamiento desde fuera hacia dentro.

Sólo el creador accede a ella desde dentro, el observador llega a ella desde el exterior y mediante su propia subjetividad. Las obras son formas de experiencia de sus autores, comunicar el mensaje de dicha experiencia supone por tanto interpretar. Persiguiendo la necesidad de saber y entender, pretender explicar el sentido de una cosa implica una apreciación intencionada asociada al entendimiento del intérprete. Las obras son productos que portan un mensaje y que contienen en su estructura las trazas del tiempo vivido por su creador, si se quiere adquirir un entender que represente la posición de un autor, será necesario no solo mirar a través de ella, si no introducirse en el contexto de su historia.

Para Gadamer (Marburg, Alemania, 1900-2002) una de las reglas de la hermenéutica es que el todo debe entenderse desde lo individual, y lo individual desde el todo. "Como la palabra pertenece al conjunto de la frase, así cada texto al conjunto de la obra de un escritor, y ésta al conjunto del género literario o de la literatura correspondiente."21 Este mismo principio es aplicable en la arquitectura y al arte.

\subsubsection{La memoria y lo futuro}

Decíamos que el tiempo presente y el tiempo pasado están presentes en el futuro. Según Ruskin, el presente pertenece al futuro y al pasado. Esta pertenencia no significa que el futuro sea una simple prolongación del pasado y del presente, ya que el futuro es algo abierto e imprevisible. El pasado y el presente son condicionantes del futuro que se define entre lo planeado, lo imprevisible y lo desconocido. El enfrentamiento a nuevas situaciones activa la necesidad de proponer soluciones. La memoria almacena datos y

20 Lledó, Emilio, El silencio de la escritura, Mito de Theuth y Thamus, Platón, Fedro, 274c-275a Espasa, 2011, p. 28.

21 Gadamer, Hans-Georg, Verdad y Método II, Ediciones Sígueme, Salamanca, 2010, p.63. 
experiencias a lo largo de la vida, cultivando el conocimiento que permitirá la invención de nuevas posibilidades. Estas se forman a través del razonamiento, que evoca los recuerdos y los relaciona, conformando así la novedad y por lo tanto, produciendo el cambio. El acto de relacionar conceptos se define por la lógica del individuo, y la necesidad de activar la memoria inteligente depende de la voluntad del sujeto y de su capacidad para desarrollar proyectos personales. Aquello que deseamos que perdure del pasado lo elegimos en el presente, con los limites de nuestra capacidad de interpretar aquello que sucedió.

"No definamos el presente dado como tal; definámoslo en el pasado y el futuro y precisémoslo en el pasado y en el futuro y precisémoslo con amplitud, dentro de una perspectiva multilateral. Definir el presente de manera aislada es matarlo"22 Así plantea Klee su visión del mundo respecto a lo temporal, y resume las principales etapas del trayecto creador como: "el movimiento previo en nosotros, el movimiento actuante, operante, vuelto hacia la obra y por último el paso a los demás, a los espectadores, del movimiento consignado en la obra; pre-creación, creación y re-creación.”23

La creación se produce cuando la memoria se utiliza de un modo inteligente, en el momento en el que recordar se utiliza para construir. La creatividad se nutre del poso de los recuerdos, está directamente vinculada a las experiencias vitales de cada individuo, y determinada por la atención y conciencia del mismo, teniendo las emociones un papel importante en el proceso de almacenamiento y recuperación de la información en el futuro $^{24}$. Cada ser humano asimila las experiencias de un modo distinto, y las transforma en su interior de manera personal, influyendo determinante en su porvenir. En el relato de Borges Funes el Memorioso (1944), Ireneo tiene la capacidad de que su memoria establezca un elevado número de relaciones a partir de un estímulo, en oposición a una relación más limitada de otros individuos: "Nosotros, de un vistazo, percibimos tres copas en una mesa;

22 Klee, Paul, Teoría del Arte Moderno, Exploración Interna de la Naturaleza, Argentina, Ediciones Caldén, Colección el hombre y su mundo, 2007, p. 83.

23 Ibíd. p. 90.

24 Bergson, Henri, Matter and Memory, MIT Press, 1991. "...there is no perception which is not full of memories. With the immediate and present data of our senses, we mingle a thousand details out of our past experience. In most cases these memories supplant our actual perceptions, of which we then retain Only a few hints, thus using them merely as "signs" that recall to us former images." p.33. 
Funes, todos los vástagos y racimos y frutos que comprende una parra." ${ }^{25}$ Solo vemos lo que somos capaces de ver y de entender, por lo que el recuerdo es la base de la inteligencia creadora, pero no su motor.

La imaginación del creador recibe estímulos sin cesar y estableciendo relaciones con lo ya vivido, "Valiéndose, para expresarse, de las cosas que lo rodean, de las imágenes que pueblan sus sueños y de todo cuanto vive en el recuerdo." ${ }^{26}$ Los recuerdos no son simples, ni nítidos y pueden ser tramposos. Seguir el hilo del entramado de los recuerdos no es siempre sencillo, Borges describía esta cualidad de Ireneo Funes como algo excepcional "Esos recuerdos no eran simples; cada imagen visual estaba ligada a sensaciones musculares, térmicas, etcétera. Podía reconstruir todos los sueños, todos los entre sueños.”

Serán capaces de crear nuevos proyectos aquellos que posean la habilidad de interrelacionar conceptos de manera novedosa. En el cuento de Borges, Funes es capaz de almacenar toda la información que llega a su alcance, sin embargo su cabeza no es capaz de procesarla, y solo la almacena, convirtiéndose en un mero banco de datos. "Sospecho, sin embargo, que no era muy capaz de pensar. Pensar es olvidar diferencias, es generalizar, abstraer. En el abarrotado mundo de Funes no había sino detalles casi inmediatos". La capacidad de recordar es sin duda una virtud, pero virtuoso es aquel que tiene el talento de utilizar los recuerdos que atesora de una manera inteligente. Para poder entender hay que recordar, pero no debe darse mayor importancia a la capacidad de recordar que a la de pensar.

Persiguiendo el objetivo de utilizar e incorporar las ideas identificadas en algo para darles un nuevo sentido, es necesario hacer uso de la imaginación. La imaginación está relacionada con la facultad de formar nuevas ideas, es también la "Facultad del alma que representa las imágenes de las cosas reales o ideales"27. Ni las ideas ni las imágenes se dan solas, la imaginación se sirve de la memoria y los recuerdos. La capacidad y potencia de

25 Borges, Jorge Luis, Funes el Memorioso, 1944, en http://users.clas.ufl.edu/burt/spaceshotsairheads/ borges-funes_el_memorioso.pdf

26 Rilke, Rainer María, Cartas a un Joven Poeta, París, a 17 de febrero de 1903. En http://hum.unne.edu. ar/asuntos/concurso/archivos_pdf/cartas.pdf

27 Real Academia Española de la Lengua. 
la imaginación es tal, que Baudelaire casi lo consideraba un poder; "la imaginación es una facultad cuasi divina"28.

Pero imaginar no se reduce a fantasear, se puede pensar con imágenes, y soñar despierto, pero el poder de la imaginación también persigue objetivos reales. Didi-Huberman resalta ciertas notas sobre la definición de imaginación expuesta por Baudelaire en relación a la obra de Edgar A. Poe: "La imaginación acepta lo múltiple y lo renueva sin cesar a fin de detectar nuevas relaciones "intimas y secretas, nuevas correspondencias y analogías, que serán a su vez inagotables, como inagotable es todo pensamiento de las relaciones que cada montaje inédito será susceptible de manifestar". 29

El proceso creativo no tiene un desarrollo lineal, así como la acumulación de recuerdos no se almacena en un orden determinado, las nuevas ideas progresan siguiendo diferentes cursos, siendo en algunos casos muy inmediatos y en otros un complejo proceso de idas y venidas.

La inteligencia creadora del individuo se nutre de su propia esencia para producir ideas y explorar nuevas direcciones. Dice Klee de aquellos a los que llama artistas, y que, según él, buscan una evolución que "no reproducen lo visible con mayor o menor temperamento, sino que hacen visible una visión secreta” ${ }^{30}$. Para Klee este camino adelante en la búsqueda del descubrimiento solo es posible gracias al impulso de la creación, que busca en el mundo de las ideas nuevos medios de expresión, y añade Klee: “Nuestro latiente corazón nos impulsa más abajo, nos hunde siempre más al fondo original. Pero lo que induce a esa inmersión, -llámeselo como se quiera: sueño, idea, imaginación- no podría llamarse realmente en serio antes de haberse ligado estrechamente a los medios apropiados para convertirse en Obra. Así pues, solamente Curiosidades se convierten en Realidades. Realidades del arte que amplían los límites de la vida tal como ésta se presenta de ordinario"31

28 Baudelaire, Charles, 1857, Notes nouvelles sur Edgar Poe citado en Didi-Huberman, George. I. DISPAR(AT) ES “Leer lo nunca escrito" en Atlas ¿Cómo llevar el mundo a cuestas?, MNCARS, 2011, p.16.

29 Didi-Huberman, George. I. DISPAR(AT)ES “Leer lo nunca escrito" en Atlas ¿Cómo llevar el mundo a cuestas?, MNCARS, 2011, p.16.

30 Klee, Paul. Teoría del Arte Moderno. Acerca del Arte Moderno Argentina, Ediciones Caldén. Colección el hombre y su mundo. 2007, p. 51.

31 Ibíd. 
La obra es el resultado de algo que se va buscando, sin saber con exactitud qué es. Es la necesidad de expresar las ideas mediante un lenguaje que se desarrolla en el tiempo y en el espacio reflejo del ser, y que responde al pensamiento. Es una forma de experiencia donde subyacen las sendas del pasado y donde se plantea el futuro. Para ampliar los límites de la vida, la imaginación creadora del individuo inventa un mundo propio a partir de lo ordinario, pero también se entrelaza con las creaciones de otros, y su conjunto constituye el imaginario colectivo que va dando forma a su propia sociedad y a su historia. La sociedad avanza apoyándose en cimientos que permiten alcanzar la innovación y el progreso. Como decía Luigi Pareyson: "Es en virtud de la innovación que las tradiciones no sólo nacen, si no que se perpetúan. Continuar sin innovar es sólo copiar y repetir, e innovar sin continuar significa a menudo construir sobre arena y fantasear en el vacío. En la más fiel de las imitaciones siempre está presente una exigencia de originalidad y una necesaria referencia al pasado está presente en la más abierta ruptura. Los polos opuestos del puro conformismo o de la mera rebelión no hacen más que confirmar en su estéril unilateralidad la fecunda solidaridad de estos dos polos."32

Por lo tanto, no se trata de copiar sino de innovar. Las referencias son necesarias, porque mediante ellas se establece el recuerdo que es la base para producir nuevas creaciones. Enric Miralles explicó este concepto referido a la arquitectura durante una entrevista: “... La arquitectura que copia no tendrá nunca la fuerza de lo que copió. No se trata de copiar, sino de incorporar, de asimilar. Cuando uno se identifica con algo, ese algo se convierte en una especie de fantasma, y uno se mete en su propio cuerpo. Uno se incorpora repitiendo los gestos de un lugar o una persona"33. Y también según sus palabras "No existe la tabula rasa" y paradójicamente "se avanza por sucesivos comienzos".

Podríamos extender las palabras utilizadas por Emilio Lledó refiriéndose a la escritura a otros campos creativos como la arquitectura y el arte: "Porque el autor, en el curso de la tradición, nos sirve para engarzar, por medio de él, los eslabones de una memoria que,

32 Pareyson, Luigi, Tradición e innovación en Conversaciones de estética, Madrid, Visor, 1987, [1a edición 1966] p. 35

33 Zabalbeascoa, Anatxu, Miralles Tagliabue en Arquitecturas del Tiempo. Editorial Gustavo Gili, Barcelona, 1999, pp. 60-63. 
individual o colectivamente, alimentan la historia, más o menos abstracta, de la que el texto es eco." ${ }^{34}$

“La verdad más grande de la influencia es que es una ansiedad irresistible." Harold Boom (Nueva York 1930), en su obra La Ansiedad de la Influencia ${ }^{35}$, expone que la gran escritura se produce siempre mediante una fuerte (o débil) malinterpretación de la escritura previa. No debe entenderse malinterpretar como interpretar de manera incorrecta, si no como interpretar de manera creativa. "Los muertos podrán regresar o no, pero su voz revive, paradójicamente, nunca por una imitación sino en la malinterpretación agonística que solo los más dotados de sus sucesores llevan a cabo sobre poderosos precursores".

Nada sale de la nada, todo creador está en deuda con lo que le precede, que llega a él por muy distintos medios (la historia, los libros, la pintura, etc.). Añade: "Las profundidades de la influencia poética no se pueden reducir al estudio de las fuentes, ni a la historia de las ideas ni a los patrones de las imágenes" ${ }^{36}$. La influencia, o el equívoco, son necesarios para el creador que, mediante un profundo acto de comprensión, se hace con la idea precursora y, en un acto de malinterpretación, se apropia de la misma. Todo cambia, la mutabilidad es la única constante.

Según Bloom, Nietzschey Freud son “las primeras influencias sobre la teoría de la influencia”, pero ambos, "a pesar de su idealismo moral, idealizaron excesivamente la imaginación. El discípulo de Nietzche, Yeats, y el discípulo de Freud, Otto Ranking, muestran una conciencia mayor de la lucha del artista contra el arte y la relación de esta lucha con la batalla antitética del artista contra la naturaleza, Freud reconocería la sublimación como el logro humano supremo, un reconocimiento que lo vincula a Platón y a las tradiciones morales del judaísmo y el cristianismo. La sublimación freudiana supone el abandono de modos de placer principales por otros más refinados, lo que equivale a destacar la segunda oportunidad por encima de la primera." ${ }^{37}$ El sueño abandonado no es solo una fantasmagoría de la gratificación infinita, sino la mayor de las ilusiones humanas, la visión de la inmortalidad." Bloom continúa: En la Oda Atisbos de inmortalidad en los recuerdos de la primera

34 Lledó, Emilio, El silencio de la escritura, Espasa, 2011, p. 159.

35 Bloom, Harold, La ansiedad de la influencia. Una teoría de la poesía, (1973), Oxford University Press, Inc.:Minima Trotta, 2009

36 Ibíd. p.57

37 Ibíd. pp.58-59. 
infancia de Wordsworth, se "considera la repetición, o segunda oportunidad, esencial para el desarrollo y, su Oda admite que podemos revertir nuestras necesidades mediante la sustitución o la sublimación." ${ }^{38}$ Según Bloom, el crítico wordsworthiano Geoffrey Hartman, 'insiste en distinguir con claridad entre prioridad, como concepto tomado del orden natural y autoridad, tomado del orden espiritual." ${ }^{39}$ Pero en esta oda no se hace esta distinción de forma que " Al tratar de superar la prioridad - dice Hartman - el arte lucha contra la naturaleza en el terreno de la naturaleza y no tiene más remedio que perder. Aún cuando retenga su gran sueño" 40 .

La teoría de la influencia de Bloom, según sus palabras, "trata de ser una meditación unificada sobre la melancolía de la desesperada insistencia del creador en la prioridad" 41. Bloom dice de Giambattista Vico (Nápoles 1668 -1744), notable abogado y filósofo conocido por su concepto de verdad como resultado del hacer (verum ipsum factum), cuya obra más importante es la Scienza nuova, publicada por vez primera en 1725: “..comprendió que la prioridad en el orden natural y la autoridad en el orden espiritual habían sido una y tenían que seguir siéndolo" 42 porque solo este rigor constituía la Sabiduría. "Vico redujo la prioridad natural y la autoridad espiritual a propiedad, una reducción hermética"43 que Bloom llama "ANANKÉ, (el destino, lo ineludible en la mitología griega y la Necessitas en la romana), la temible necesidad que aún rige la imaginación occidental."44 "Tratar de saber dónde estamos es la más sombría de las búsquedas y la más fatídica." "Ninguna búsqueda termina si su contexto es lo Incondicionado, el cosmos"45, más allá del Límite, desde nuestro mundo, donde Valentino, (especulador gnóstico nacido en Alejandría en el siglo II), situó la Pasión u Oscura Intención.

En su libro Bloom utiliza seis pautas revisionarias del escritor frente a la obra y su precursor, que pueden ser aplicables al proceso creativo:

$\begin{array}{ll}38 & \text { Ibíd.p.59. } \\ 39 & \text { Ibíd.p.59. } \\ 40 & \text { Ibíd.p.59 } \\ 41 & \text { Ibíd.p.62. } \\ 42 & \text { Ibíd.p.63 } \\ 43 & \text { Ibíd. p.63 } \\ 44 & \text { Ibíd.p.63 } \\ 45 & \text { Ibíd.p.63 }\end{array}$


La primera, que denomina Clinamen, es propiamente la malinterpretación o equívoco. La palabra está tomada de Lucrecio para quien significa una "desviación de los átomos que hace posible el cambio del universo" (todo es movido por otra cosa, formando parte de una cadena causal finita). Así un creador se desvía de su precursor "para ejecutar un clinamen en relación con él" 46 .

La segunda o "Tessera, que es la complexión y la antítesis". Palabra tomada, "no de la construcción de mosaicos, donde aún se usa, sino de antiguos cultos mistéricos en los que significa prenda de reconocimiento, es la compleción y la antítesis. Un creador antitético completa a su precursor conservando sus términos pero dándoles otro sentido, como si el precursor no hubiera llegado suficientemente lejos" ${ }^{47}$.

En tercer lugar, introduce la Kenosis que es, según Bloom un recurso de ruptura, un movimiento de discontinuidad respecto al precursor. La palabra es de San Pablo, para quién significa el vaciamiento de Jesús por sí mismo cuando acéptala reducción de la condición divina a la humana. El creador se vacía de su divinida imaginativa y parece humillarse.

La Demonización o movimiento hacia una contrasublimación personalizada, es la cuarta fase, Bloom toma el término del "uso general neoplatónico, en el que un ser intermedio, ni divino, ni humano, entra en el adepto para ayudarle"48.

La Askesis o movimiento de autopurgación que procura un estado de soledad es la quinta pauta, El término es tomado "de los chamanes presocráticos como Empédocles"; el creador "entrega parte de su dotación humana e imaginativa, para separarse de los demás, incluyendo al precursor" 49 .

La sexta pauta llamada Apophrades, o retorno de los muertos corresponde a la fase final de "soledad imaginativa" del creador, que "se mantiene ahora expuesto al precursor" y el "extraño efecto es que no parece que el precursor haya creado la obra sino que la impresión es que el creador tardío ha creado la obra característica del precursor"50.

\footnotetext{
46 Ibíd. p.63

47 Ibíd.p.64

48 Ibíd. p.64.

49 Ibíd.pp.64-65.

50 Ibíd. p.65.
} 
Para Bloom, lo que el creador puede experimentar como ansiedad y lo que su obra está obligada a manifestar son consecuencia del equívoco poético antes que su causa.

Según Paul Klee: "El arte no es una ciencia que haga avanzar paso a paso el impersonal esfuerzo de los investigadores. Por el contrario, el arte atañe al mundo de las diferencias: cada personalidad, una vez dueña de sus medios de expresión, tiene voz y voto en este asunto"51. En el contexto del arte moderno, "hasta las repeticiones pueden expresar una nueva especie de originalidad y convertirse en formas inéditas del yo" ${ }^{\prime 2}$. De ello se infiere que la influencia sobre la obra puede surgir también de la obra propia del creador. La revisión de un mismo tema es una constante común, ya sea en busca de un perfeccionamiento, o persiguiendo una obsesión, a veces de manera inconsciente. Buscando una evolución personal.

La memoria, como precursor intelectual, nos hace captar en una intención única, momentos múltiples. Según Bergson ${ }^{53}$, partimos de un estado virtual que conducimos poco a poco a través de planos de conciencia diferentes hasta que se materializan en una percepción actual es decir hasta el extremo que deriva en un estado presente y actuante.

No obstante, la relación entre memoria y creación, aunque evidente en muchos casos, muestra una complejidad ilimitada como ilimitadas son las variables posibles que intervienen en el proceso.

Bergson ${ }^{54}$ lo expresa de la siguiente manera: "El progreso de la materia viviente consiste en una diferenciación de las funciones que conduce primero a la formación, luego a la complicación gradual de un sistema nervioso capaz de canalizar excitaciones y de organizar acciones (...) Una libertad cada vez más grande, dejada al movimiento en el espacio es lo que se ve realmente. Lo que no se ve es la creciente y concomitante tensión de la conciencia en el tiempo. No solamente a través de la memoria de las experiencias ya pasadas, la conciencia retiene cada vez mejor el pasado para componerlo con el presente en una decisión mas rica y mas viva y de una nueva vida más intensa; contrayendo a través

51 Veasé Klee, Paul, Teoría del Arte Moderno en Enfoques del Arte Moderno Argentina, Ediciones Caldén. Colección El hombre y su mundo, 2007, p.31.

52 Ibíd. p.31.

53 Bergson, Henri, Materia y Memoria, Editorial Cactus, 2013, p.246.

54 Ibíd. p. 255. 
de su memoria de la experiencia inmediata, un numero creciente de momentos exteriores en su duración presente, ella deviene más capaz de crear actos cuya indeterminación interna, debiendo repartirse sobre una multiplicidad tan grande como se quiera de los momentos de la materia, pasará en la misma medida más fácilmente a través de las mallas de la necesidad. De este modo, se la considere en el tiempo o en el espacio, la libertad parece siempre echar raíces profundas en la necesidad y componerse íntimamente con ella. El espíritu toma de la materia las percepciones de donde extrae su alimento, y se las devuelve bajo la forma de movimiento en la que ha plasmado su libertad."

Recorreremos entonces, con la obra de Juan Muñoz ,este camino complejo, sin aparente rumbo pero con un fin, que se extiende ante nosotros como una tela de araña tridimensional, senderos que van y vuelven al mismo punto, un laberinto sin principio ni final, con el propósito de avanzar en el camino del conocimiento.

\subsubsection{La memoria y Juan Muñoz}

Permítaseme o Permítaseme una imagen, o permítaseme una y otra vez, repite Muñoz en sus textos y constantemente en su discurso. Cuenta Adrian Searle ${ }^{55}$ que utilizaba la expresión casi como una muletilla. Aparentemente tomó la expresión de un discurso de Paul Klee ${ }^{56}$, pronunciado en Jena en 1924 que dice así: “Permítanme emplear una parábola, la parábola del árbol". En esta parábola, intentando explicar a su audiencia el papel del artista, Klee lo describe como si se tratara de un árbol. El artista es el tronco, con raíces que reciben información "de las profundidades" y la savia que lo mantiene vivo le entra por los ojos, la información que recibe, que se abre como las ramas de un árbol en todas las direcciones mediante aquello que produce, es una representación alegórica del proceso creativo a través del tiempo, desde la memoria hasta la proyección futura.

Las obras de Juan Muñoz recogen la memoria de sus propias obras, su propia memoria, y a su vez contienen la memoria de sus referentes, que permanecen en el recuerdo durante el

55 Adrian, Searle Introducción en Muñoz, Juan, Escritos/Writings, Madrid. Ediciones de La Central. 2009 p. 23.

56 Véase Klee, Paul, Teoría del Arte Moderno. Argentina, Ediciones Caldén. Colección El hombre y su mundo, 2007, p. 35. 
proceso creativo, siguiendo su interés personal. "El significado de la forma aparece como resultado de una labor técnica que conforma lo que es informe" ${ }^{57}$ dice Gadamer.

Juan Muñoz fue inicialmente encasillado dentro de distintos movimientos, pero se desligó de ellos persiguiendo su propio interés en busca de su narrativa escultórica propia. No deja de reconfigurar las imágenes de su mente que ha creado en el pasado y con las que constituye nuevos presentes. Es un proceso en espiral que da lugar a que las esculturas de Muñoz tengan una cierta indiferencia al tiempo. En sus primeras obras, hasta finales de los años ochenta, todavía buscaba un lenguaje propio, más adelante, sus obras no necesariamente presentan una evolución respecto a las anteriores, si no que son simplemente diferentes.

Se dice de Juan Muñoz que no le gustaba especialmente hablar de sus obras y se mantenía al margen de los actos públicos cuanto podía, sin embargo su sed intelectual le llevaba a perseguir el contacto con aquellas personas cuya obra admiraba, como distintos artistas a los que procuró conocer personalmente.

Isaac Asimov, reflexiona sobre la creatividad que es, a su parecer, un acto solitario en el que el aislamiento es necesario. Añade que la presencia de otros puede interferir negativamente en el proceso, ya que puede ser un acto embarazoso, durante el cual se producen pruebas y errores que probablemente no se quieren compartir. ${ }^{58}$ La actividad de Muñoz se era solitaria "Probablemente sea la condición de todo artista; que pasa la mayor parte del tiempo solo en una habitación. Ahí es donde todo sucede, en esas horas en que no pasa nada." ${ }^{59}$ Desde muy temprano, quiso empaparse de las imágenes del mundo,

57 Gadamer, Hans-Georg, Verdad y Método II, Ediciones Sígueme, Salamanca, 2010. p.90.

58 Arthur Obermayer invita a Asimov a colaborar en un proyecto de nuevas armas nucleares y estructuras espaciales relacionado con el MIT, una sociedad que buscaba a intelectuales con capacidad de pensar fuera de lo común con el fin de obtienen nuevas ideas. Asimov escribe unas notas publicada por primera vez en Octubre 2014 con reflexiones acerca de la creatividad. Isaac Asimov Asks, "How Do People Get New Ideas? 1959. "My feeling is that as far as creativity is concerned, isolation is required. The creative person is, in any case, continually working at it. His mind is shuffling his information at all times, even when he is not conscious of it. (The famous example of Kekule working out the structure of benzene in his sleep is wellknown.)" "The presence of others can only inhibit this process, since creation is embarrassing. For every new good idea you have, there are a hundred, ten thousand foolish ones, which you naturally do not care to display."

59 Muñoz, Juan, Lingwood, James. Una conversación, Enero 1995 en Monólogos y diálogos. MNCARS. Madrid 1996 p. 125. 
hacerlas suyas, y trabajar las ideas propias, para las que encontraba referentes en todo lo que le rodeaba. Leyendo subrayando y copiando obras teatrales y literarias, revistas de arte, recortes de periódicos con imágenes que le resultaban evocadoras, visitas a museos, viajes, etc. el escultor fue componiendo todo su imaginario.

La escultura es un lenguaje capaz de establecer un diálogo entre el creador y el observador a través de la obra, que es el medio de comunicación. Juan Muñoz, que admitió ser un contador de historias ("storyteller") y un productor de espacios físicos y psicológicos que pone a prueba la realidad. "Para mí lo que ves no es lo que parece"60. Sus obras están cargadas de memoria que se transmite al espectador que la observa y que entra en este juego de sensaciones y recuerdos.

Cuando Juan Muñoz recibió el encargo para la Tate Modern, recuerda que el primer paso fue salir en busca de imágenes que resonaran en su mente (paseos, libros, incidentes y accidentes del día a día). "I did what I relieve many artist probably do, and walked through endless amounts of books, and through the streets, taking in all of the little incidents and accidents and encounters of everyday life. You hope the images will resonate in your mind and that they will help to lead on, to find some shape and form to begin with" ${ }^{61}$. La inspiración surge de la meditación y la búsqueda de una idea. Juan Muñoz tenía un repertorio propio y se alimentaba del mundo a través de su mirada para ampliarlo y enriquecerlo; "El arte no reproduce lo visible; hace visible." 62 "El arte atraviesa las cosas, va mas allá, tanto de lo real como de lo imaginario". ${ }^{63}$

La voluntad de recordar algo, de estudiar un tema, un concepto, una imagen ${ }^{64}$ queda latente en la obra del escultor, pero también se genera a partir de un proceso de acumulación de información no controlado completamente. El recuerdo tiene la capacidad de surgir de

60 Schimmel, Paul, Muñoz, Juan, An Interview with Juan Muñoz, September 18, 2000 cita "The difference between these artists and myself is illustrated by Frank Stella's famous remark. "For me what you see is what you see". "For me what you see is not what it seems to be"

61 Muñoz, Juan. Juan Muñoz, Double Bind at Tate Modern, 2001, Tate Publishing, p. 67.

62 Klee, Paul, Teoría del Arte Moderno. Credo del Creador. Argentina, Ediciones Caldén, Colección El hombre y su mundo, 2007, p. 55.

63 Ibíd. p.64.

64 Bergson, Henri, Matter and Memory, MIT Press 1991, p. 9. Para Bergson la imagen es aquello que está entre la representación y la cosa: "Matter, in our view, is an agregate of "images". And by "image" we mean a certain existence which is more than that which the idealist calls a representation but less than that which the realist call a thing" 
manera instintiva. No se es consciente de estar haciendo uso de ideas ya exploradas en el pasado, se retoman de manera inconsciente y automática durante el proceso creativo de nuevas concepciones. Muñoz, hablando de Double Bind, cuenta que se sorprendió al darse cuenta de que algunas de las primeras ideas de sus esculturas de balcones que comienzan en los años '80 se ven reflejadas en esta última obra: "I am surprised how some of the very early ideas implied in the balcones seem to have reappeared in this work" 65 De manera inesperada el escultor se hace consciente a posteriori del uso de estrategias experimentadas en el pasado al detenerse a observar su propia obra y recaer en las similitudes con sus obras anteriores. Recurre a una estrategia conocida para resolver o proponer una cuestión diferente y nueva. Casi como los recuerdos evocados mediante el sabor en Proust, Juan Muñoz ve reflejada la imagen de sus primeros balcones al situarse en frente de su nueva obra. "Indudablemente, lo que así palpita dentro de mi ser será la imagen y el recuerdo visual que, enlazado al sabor aquel, intenta seguirlo hasta llegar a mí. Pero lucha muy lejos, y muy confusamente"66

La obra de Muñoz está marcada por ciertas ideas a las que siempre vuelve y que no logra o no quiere abandonar. "Es verdad que mirando atrás a la primera exposición, hay obras que parecen crecer en el tiempo. Las obras más interesantes generan un lenguaje con el que todavía puedo hablar." ${ }^{67}$ A su vez estas ideas que pertenecen al escultor y que arrastra a lo largo de su carrera, tienen referentes en ciertos acontecimientos que se dan durante su vida, encuentros casuales con distintas personas de las que se empapa, las experiencias en el exilio, sus estudios en distintas ciudades del mundo, la búsqueda de información para cumplir con sus proyecto como comisario, o la necesidad de saciar su curiosidad intelectual. Estas ideas primigenias están a su vez influenciadas por nuevas circunstancias y nuevos recuerdos que dan como resultado una visión nueva de las mismas.

Juan Muñoz utilizaba su capacidad de mirar para crear. La necesidad de inventar es propia del ser humano, aquellos que inventan están reinterpretando la realidad que han percibido. La capacidad de imaginar está directamente relacionada con la capacidad de

65 Unilever Series. Double Bind. Tate Modern London, Tate Publishing, 2001 p. 73.

66 Proust, Marcel. En busca del tiempo perdido I. p.39 en http://dspace.utalca.cl:8888/bibliotecas/ librodot/busca_tiempo_perdido_1_camino_swann.pdf

67 Muñoz, Juan, Lingwood, James, A Conversation, Septiembre 1996 en Monólogos y diálogos, MNCARS, 1997, p.35. 
interpretar lo que se percibe. Nunca se mira solo a una cosa, siempre se mira en relación a lo conocido, y depende de nuestra facultad el situar las cosas dentro de otro sistema de relaciones que es capaz de dar como resultado una nueva imagen.

La escultura se percibe en principio a través de los ojos, se recibe la información mediante el sentido de la vista. Muñoz busca transmitir ideas y producir sensaciones no necesariamente expresadas con palabras, aunque si cargadas de narración, una narración visual que se nutre de la composición y el gesto. Como decía Bachelard “Sólo las imágenes pueden volver a poner en movimiento los verbos." ${ }^{68}$

Frente una escultura, en primer lugar se activa la memoria sensorial con la que se reciben los estímulos visuales que provocan sensaciones diversas en la mente. Aunque la imagen llega mediante la vista, rápidamente activan la psique (alma humana, según los griegos, que designaba la fuerza vital de un individuo) del receptor, que responderá de distinta manera según su capacidad para recibir dicho estímulo. Si la provocación le interesa, la memoria a corto plazo se pone en funcionamiento, siendo sensible a la situación de aquello que percibe. La memoria a largo plazo grabará la escena según nuestra voluntad y capacidad para recordarla. El propio Juan Muñoz tenía una actitud frente al órgano de la vista casi místico, comentó: "no hace mucho mi madre me contó que había cedido todo su cuerpo a la ciencia menos los ojos, y de alguna manera lo entiendo, con esa sensación con esa emoción de decir, lo que yo he visto es mío. Creo que en el ojo esta todo, esta desde la belleza al pecado y entre ambas debe estar todo el abanico de emociones"69

Juan Muñoz plasmaba los dictados de su imaginación en dibujos, escritos, planos o esculturas. Conoce las cosas que son, e inventa otras posibilidades sobre la realidad. Buscó y alcanzó su propio lenguaje con la voluntad de no repetir lo que otros habían hecho antes "yo no he querido hacer nunca lo que otros han hecho" ${ }^{70}$.

Algunas de su obras no son más que elementos arquitectónicos abstraídos de su contexto, aquello que las diferencia de otras obras está fuertemente ligado con su capacidad

68 Bachelard, Gaston, La poética del espacio, Fondo de Cultura Económica, Madrid, 2000, p. 108.

69 Arranz, Manel y Solana, Anna. Documental Imprescindibles - Juan Muñoz, poeta del espacio, 2014, Imágenes y declaraciones de Juan Muñoz grabadas en el Centro Gallego de Arte Contemporáneo en Santiago de Compostela en 1996. Comentario del artista.

70 Ibíd. 
narrativa. Por ejemplo, los famosos balcones, una balconada metálica colgada en una pared, sin mayor complejidad que lo descrito donde su simplicidad material contrasta con la carga simbólica de la obra que percibe el observador. La innovación no está en la materia, si no en el concepto, en la narrativa, en la imagen proyectada, en la sensación causada en el sujeto que la percibe, en la magia de la comunicación no verbal y la provocación de los estímulos visuales que llevan al espectador a sentir la ausencia de lo no representado.

Los materiales que utiliza en sus obras están llenos de posibilidades, así mismo los conceptos que maneja. El escultor es capaz de todo ello en una realidad nueva que proviene de sí mismo y de lo aprendido, cuya acción surge de su inteligencia. Cualquiera puede tener acceso a las herramientas que utilizaba el escultor, pero se necesita una mirada inteligente y creadora para proponer algo nuevo que además tenga repercusión en los demás. De la misma manera que para Miguel Ángel un bloque de mármol puede contener un Cristo o una Virgen, y su destino depende de las manos que sujetan el cincel y el martillo; "Se levantó, tomo su martillo más pesado y un cincel, y eliminó la cabeza de Cristo; en su lugar esculpió un nuevo rostro y cabeza con lo que antes había sido el hombro de la Virgen"71 o del mismo modo que Duchamp es capaz de transformar un urinario en una obra de arte (La Fuente, 1917) rompiendo y cambiando los cánones de la escultura de manera radical.

Los tres casos ejemplifican como el futuro que se inventa nunca excluye el presente. Se utiliza la experiencia, para inventar otra cosa, en definitiva, inventar el futuro. Son muestras de una memoria dinámica que aprovecha los conceptos que posee de una manera eficaz. Son exploraciones hábiles de la memoria que logran cambiar la percepción y las realidades conocidas hasta el momento. Pero para que esto suceda la percepción necesita tener ciertos conocimientos. Es necesario que exista una autodeterminación para transformar las ocurrencias en proyectos, y que estos se desarrollen como proyectos artísticos. José Antonio Marina escribe al respecto "Crear es someter las operaciones mentales a un proyecto creador. (...) Nos dice por ejemplo, que el arte no depende de operaciones nuevas, si no de un fin nuevo que guía un uso distinto de las operaciones mentales comunes."

71 Relato sobre Miguel Ángel esculpiendo la Pieta Rondanini en Stone, Irving, La agonía y el Éxtasis, 1961. en http://www.librosmaravillosos.com/laagoniayelextasis/libro11.html 
Así mismo, la libertad del acto creador se realiza mediante la búsqueda interna o externa de referentes “El proyecto, que es una invención del sujeto, está simultáneamente dentro y fuera de él."72

Al tratar del futuro se vuelve a la idea del recuerdo, todo aquello que está dentro del individuo, el poso que han dejado los estímulos recibidos en su memoria, se unen a los nuevos estímulos. El proyecto creador es el resultado de permutar e interrelacionar de manera diferente los conocimientos ya adquiridos. Crear es transformar, y para ello es necesario manejar información. La destreza del creador está condicionada por lo que sabe, y por su capacidad para crear un proyecto y su éxito depende en gran medida de su habilidad para buscar. Uniendo su capacidad para relacionar conceptos, su destreza para saber buscar y obtener la información que necesita, y manejando consciente o inconscientemente estas relaciones, proyecta una idea que "ve" a través de su mente. La colección de referencias de Juan Muñoz proviene de fuentes muy distintas, "tanto su arte como sus escritos le deben mucho a sus lecturas. Su biblioteca era muy extensa y variada, y su curiosidad intelectual se reflejaba en lo que hacía o escribía"73

Juan Muñoz navega entre textos en busca de sus temas de interés. Sonsaca ideas de aquello que lee, y lo lleva a formar parte de sus composiciones. Los escritos del artista se reparten entre publicaciones en diferentes revistas, catálogos de exposiciones, ensayos o piezas radiofónicas. Es fácil hallar interconexiones entre sus escritos y su obra, ésta es otro canal de expresión artística donde toca los mismos intereses.

Los textos se convierten en breves piezas artísticas de narrativa conceptual. Un collage escrito. Son un juego sicológico en el que el contenido mezcla realidad y ficción, originalidad y citas, en algún caso, veladas. No se oculta el uso de referencias o frases tomadas de otros textos, pero tampoco se especifican ni se incluyen notas. Juan Muñoz trata como suyo aquello que ha leído y pasa a formar parte de su ideario. En algunos casos no se adivina la inclusión de frases intercaladas procedentes de otros si no se profundiza en el mundo de referencias del artista. Algunos textos tienen un carácter contemporáneo, otros histórico,.

72 Marina, José Antonio, Teoría de la inteligencia creadora, Ed. Anagrama, Barcelona 1994, pp. 150-151.

73 Searle, Adrian, Introducción en Juan Muñoz en Escritos/Writings, Barcelona, Ediciones de la Central, MNCARS, 2009, p. 27. 
Nunca se puede estar seguro si los relatos de Juan Muñoz hablan sobre hechos reales o de ficción.

Ni si quiera se puede estar seguro de si todo lo escrito es enteramente suyo, o si ha tomado prestados fragmentos de otros escritores para realiza una nueva composición. Para Juan Muñoz no era importante resaltar este aspecto, ya que como en la escultura, él solo buscaba contar historias sin necesidad de explicar su porque. "Al principio me preocupaba más cuando la gente decía que mi obra era como la de un contador de cuentos, que lo mío era más literatura que arte...en el fondo es quizás lo que siempre he querido, contar historias, permítaseme una vez más contar una historia" 74

Lo producido no siempretiene un sentido claroy único, quedando abierto a interpretaciones por parte de el que contempla su obras. La comunicación de ideas a través de una obra no encuentra un lenguaje universal que sea comprendido por todos por igual, esto da lugar a múltiples interpretaciones, y al almacenamiento de los recuerdos con muy distintos matices según el receptor. A menudo el escultor introduce en sus textos la frase "es posible imaginar"75, dando pie a nuevas interpretaciones sobre los temas que trata. Juan Muñoz crea su obra pensando en el espectador, en sus posibles preguntas y reacciones, pero las hace ante todo para si mismo. Pretende que el que las mira, comparta y haga suyas las preguntas que el autor se hace a si mismo. "Construyo estas obras para explicarme cosas que no entendería de otra manera. Yo quisiera que la obra fuera, en parte, incomprensible para mi" ${ }_{76} \mathrm{Su}$ obra es un vano intento de explicar lo que no se entiende y avanzar en ellas supone para el artista continuar expresando sus inquietudes pidiendo ayuda para encontrar respuestas, sabiendo que eso es imposible, ya que la respuesta no existe. De este modo, se comparte la incertidumbre, incluso la incertidumbre de no saber si se comparte.

En el proceso creativo de Muñoz, recuperar sus propias obras, no solo a nivel personal, si no por la necesidad de volver a exponerlas, era también una oportunidad para el cambio

\footnotetext{
74 Arranz, Manel y Solana, Anna. Documental Imprescindibles - Juan Muñoz, poeta del espacio, 2014, Imágenes y declaraciones de Juan Muñoz grabadas en el Centro Gallego de Arte Contemporáneo en Santiago de Compostela en 1996. Comentario del artista.

75 Muñoz, Juan, Notas afines a tres en Correspondencias: 5 arquitectos 5 escultores, Madrid, Ministerio de Obras Públicas y Urbanismo, Dirección General de Arquitectura y Vivienda, 1982, p. 17.

76 Muñoz, Juan. Lingwood, James, Una conversación. Enero 1995, en Monólogos y diálogos, MNCARS, 1997, p. 123.
} 
y la exploración de su lenguaje propio. Es una manera de forzar la revisión de un trabajo. El escultor elaboraba un trabajo meditado, pero dejaba cierto espacio a la improvisación, relacionada generalmente con la disposición de las obras en una sala o el dialogo entre las figuras. Siendo conocedor de la espontaneidad de sus decisiones ante ciertas piezas, accedía a la flexibilidad de reinterpretar sus obras al volver a ser expuestas, lo que abre las posibilidad de crear nuevas situaciones jugando con la disposición de los elementos. "En las decisiones originales hay un elemento de improvisación, y ahora no puedo volver a conectar con las piezas de la misma forma. Es más interesante si una pieza tomada del pasado admite transformaciones, si puede abandonar la caja que la guarda para vivir una nueva vida"77

Era plenamente consciente del peso de la memoria en su obra. En la conversación con James Lingwood (A Conversation, May 2001) publicada en el catálogo de la exposición de la obra que tituló Double Bind, deja claro que en ella se evocan situaciones que forman parte de su repertorio escultórico, "There where images that were already there, already used"78. Juan Muñoz explica que vino a Londres en busca de su hermano, y fue entonces cuando se familiarizó con la teoría del Double Bind (Teoría del Doble Vínculo) de Gregory Bateson $^{79}$. Esta teoría descrita por Gregory Bateson y su equipo en 1972, está relacionada con la enfermedad de la esquizofrenia. La hipótesis principal de la teoría del Double Bind es que al sujeto se le comunican dos mensajes que son incompatibles entre sí, y éste es incapaz de salir de esta situación. ${ }^{80}$

77 Muñoz, Juan, Lingwood, James, A Conversation. Septiembre 1996, en Monólogos y diálogos, MNCARS, 1997, p.35.

78 Muñoz, Juan, Lingwood, James, A Conversation, May 2001, Unilever Series. Double Bind, Tate Modern London, Tate Publishing, 2001, p. 77.

79 Ver A Conversation, May 2001: James Lingwood:"There's a feeling of looking for something?" Juan Muñoz: "I remember we were sitting in your kitchen not too long ago and you asked me why I came to London in the first place, back in the 1970's, and I said I came to London to look for my brother. I did find him, and I did find a small flat to rent, and I did find a job, and I did find a language I could deal with, in orther to buy food and pay the rent; and I did find a culture that allowed me to respect myself as a contemporary European." JL: "Why were you looking for your brother?" Juan Muñoz: “I was looking for my brother who was looking for David Cooper, a famous psychiatrist. Cooper was part of a group of analysts, along with R.D. Laing, who were rethinking parts of George Bateson's theory of the 'Double Bind' as a way of dealing with schizophrenia." JL: "Is the theory of the Double Bind important to this new project?" Juan Muñoz: No, not really. The title of the piece came very late." Ibíd. pp. 75-76.

80 Ver Bateson, G., Jackson, D. D., Haley, J. \& Weakland, J., 1956, Toward a theory of schizophrenia. 
1. Cuaderno de notas $n^{\circ}$ años ' 80

Cuaderno de notas del artista.

Cortesía del Estate de Juan Muñoz

2.Cuaderno de notas del artista $n^{\circ} 18$ 1991

3.Notas en preparación a Double Bind. 2000-2001

Cuaderno de notas del artista.

Cortesía del Estate de Juan Muñoz
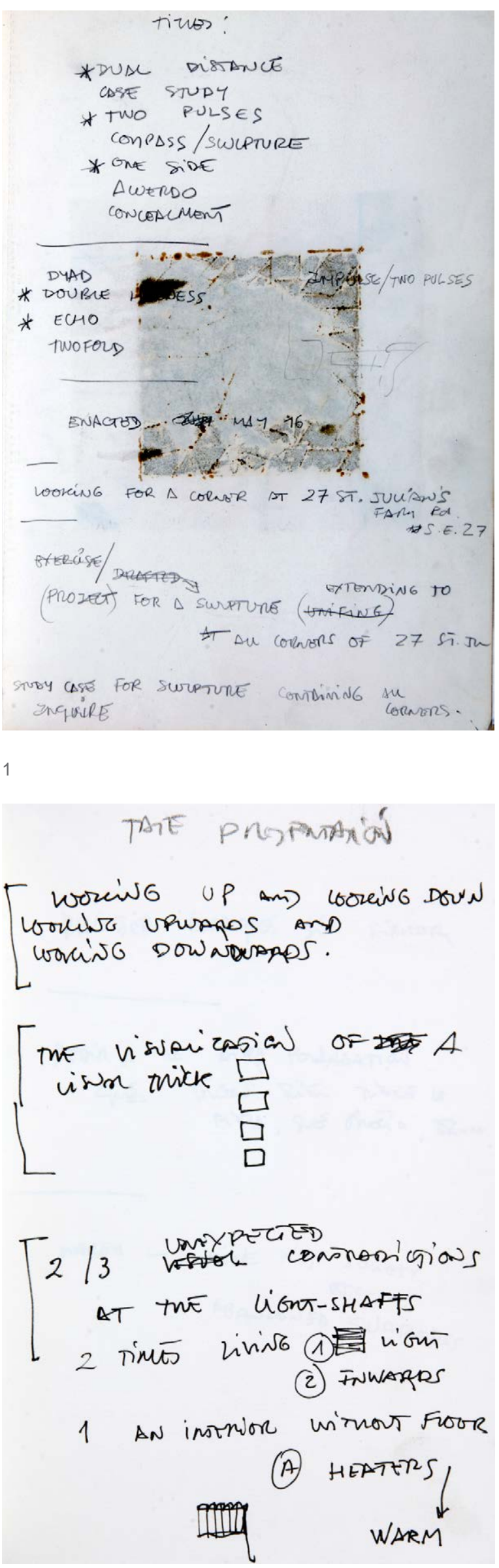
Muñoz aclara que el título de la obra lo decidió tarde dentro del proceso, y que dicha teoría no es necesariamente importante para la obra. Además, descarta afirmar que su obra este vinculado a sus experiencias vividas en Londres treinta años antes. ${ }^{81}$ "It will be a mistake to think about this piece as a reinterpretation of my memory" ${ }^{22}$. Muñoz piensa que hubiera realizado este proyecto igualmente en otras ciudades no asociadas a su experiencia personal. Admite que su memoria, la memoria que ha adquirido a lo largo de su vida esté relacionada con Londres, porque ha recorrido sus calles, se ha fijado en ciertos lugares de la ciudad, en definitiva, crecido en ella; pero añade que haber visitado otras ciudades recientemente, en concreto en Oriente, también le ha influenciado. Muñoz toma conciencia de los referentes que desea utilizar, y aunque apoyado en las experiencias vividas, ambiciona un escenario que se aleja de lo personal, y persigue unas claras intenciones que desea controlar. Ya en sus primeros cuadernos de notas en Londres muestra una fijación por lo dual , lo doble. Al mismo tiempo desarrollaba su otra afición, el ilusionismo y los trucos de magia. Aquí se encuentran lo dual y la paradoja (lo doble y la contradicción entre lo que se ve y lo que se comprende). Estudiando su obra siempre se capta la esencia de una continuidad de propósito.

El origen de las referencias puede ser variado y dispar, mediante la inteligencia se disocian y sustraen las partes que resultan útiles ante la elaboración de nuevos conceptos, sin necesidad de que la relación entre los primeros y los últimos forme parte de la misma familia o realidad.

Escribe Michael Sorkin a propósito de la obra de Emilio Ambasz en un texto incluido el la exposición comisariada por Muñoz Correspondencias: 5 Arquitectos, 5 Escultores: "Cuando se ha buscado una idea que pueda servir de base para un paso adelante en la arquitectura, tradicionalmente los profesionales han recurrido a una de dos estrategias. La primera es el redescubrimiento, un proceso por el cual el arquitecto encuentra enterrado en el cuerpo de la arquitectura del pasado nada menos que sus propias raíces... La búsqueda comienza con el descubrimiento de una forma que estimula el cambio; las ideas vienen después. La segunda estrategia, la reinvención, es notablemente distinta. Este proceso es más elemental; se trata de una búsqueda de secretos más que de fuentes. Si el texto que

81 Ver A Conversation, May 2001: James Lingwood: "Have you been surprised that your experience in London almost thirty years ago has somehow come into the present work?" Ibíd. p. 76.

82 Ibíd. p. 76. 
utiliza el redescubridor es un libro de historia, el del reinventor es una fábula"83. Si tuviera que situar a Muñoz en uno de los dos campos, sería en el del reinventor, un reinventor con cierto rigor, que sí recurre a los libros de historia en busca de secretos, creando él mismo la fábula.

83 Sorkin,Michael. Emilio Ambasz: La casa-berma arcádica en Correspondencias 5 Arquitectos, 5 Escultores, Madrid, Ministerio de Obras Públicas y Urbanismo, Dirección General de Arquitectura y Vivienda, 1982, p. 13. 


\section{2. $1953-2001$}

En Febrero del 2000 el escultor Juan Muñoz (Madrid 1953- Ibiza 2001) recibe una invitación para participar en las llamadas “Unilever Series", uno de los patrocinadores de la Tate Modern londinense. La comisión anual convoca a un artista a realizar una instalación en el museo para el llamado turbine hall, la sala de turbinas, espacio central de la galería, concebido como un lugar público y con capacidad de albergar muy diferentes actividades relacionadas con el arte. Por aquel entonces, Juan Muñoz es ya un aclamado escultor reconocido internacionalmente, recibió el Premio Nacional de Artes Plásticas en este mismo año. Desafortunadamente, poco tiempo después de la inauguración de Double Bind, su llamada "capilla sixtina" ${ }^{84}$ el escultor fallece repentinamente, dejando un legado de intrigantes y sugerentes obras. Deja a su paso un compendio de referencias que han sido parte fundamental durante el proceso creativo a lo largo de su carrera.

Double Bind es la conclusión del relato de Juan Muñoz. De algún modo es el lugar donde quedan recopilados los intereses y campos en los que el autor estaba interesado desde el inicio de su carrera y al mismo tiempo es su pieza más afinada, donde lleva al límite sus narrativas, prescindiendo de lo innecesario.

Para llegar a Double Bind, Juan Muñoz realiza un largo recorrido que comienza en Madrid. Durante sus estudios escolares, tanto Juan Muñoz como su hermano Vicente reciben clases particulares del historiador y crítico Santiago Amón ${ }^{85}$, una figura importante en la

84 Arranz, Manel y Solana, Anna. Documental “Imprescindibles - Juan Muñoz, poeta del espacio" 2014. Imágenes y declaraciones de Juan Muñoz grabadas en el Centro Gallego de Arte Contemporáneo en Santiago de Compostela en 1996. Comentario de la comisaría de arte Carmen Gimenez, con la que Juan Muñoz colaboro en diversas exposiciones y con la que mantenía una relación de amistad.

85 Santiago Amón (Baracaldo, Vizcaya, 1927 - Valdemanco, Madrid 1988). Es relevante incluir una breve biografía del poeta, escritor y crítico, donde se resaltan algunos de los trabajos y áreas de especialización, que puede encontrarse en su página web oficial. Santiago Amón mantuvo un contacto estrecho y constante con Juan Muñoz desde que este era adolescente, le inculcó el interés por el arte, y fue referente para el artista en materia de crítica de arte y arquitectura, llegaron a colaborar en varios proyectos a lo largo de sus carreras. Santiago Amón "Se incorporó a la primera vanguardia poética de la posguerra colaborando en publicaciones ("Decaulion”, “El pájaro de paja”, ...) representativas del "postismo”. Entre sus biografías destaca la dedicada a Giotto, y entre sus monografías, la escritura acerca del arte de Chillida. Ha colaborado en la práctica totalidad de las revistas de arte españolas y en unas cuantas extranjeras ("Aujour d'hui”, "Derriere le miroir", "La architettura" ...), en periódicos como "Corriere della sera", y ha prologado exposiciones en 
sociedad intelectual de este periodo, y fue él quien desató el interés por el arte en Muñoz, que no había estado particularmente interesado en este campo hasta entonces. Amón ofrece a Muñoz un amplio repertorio de lecturas y conocimientos que captan su atención intelectual. En 1970, al finalizar sus estudios, comienza la carrera de arquitectura en la Escuela de Madrid, abandonándola a los pocos meses, sin embargo su interés por ella continuará a lo largo de toda su vida.

Se traslada a Londres en busca de su hermano Vicente, donde trabaja como pintor para poder pagar sus gastos, y viaja ocasionalmente por Europa. A principios de los años '70 reside durante algo más de un año en Estocolmo, y establece contacto con las políticas de izquierda. Pasa algunos periodos en España, durante los cuales ayuda a su padre en su empresa de construcción. Durante estos años en Londres y Europa Muñoz sigue estudiando historia del arte por su cuenta, y animado por su hermano Vicente comienza a pintar y a desarrollar pequeñas esculturas en su tiempo libre. Visita a menudo los principales museos de la capital, en especial la National Gallery. Aún sin una convicción clara de convertirse en artista, baraja la posibilidad de ser director de cine, y graba un corto en $16 \mathrm{~mm}$ donde documenta la escultura pública en Madrid.

Consigue en 1976 una Beca del British Council que le permite asistir a la Central School of Art and Design de Londres, la actual Central Saint Martins-London University of the Arts, donde estudia litografía. Comienza a realizar esculturas vinculadas al arte procesual y conceptual, en las que incorpora grabadoras, sonidos, cables u objetos en equilibrio.

las más importantes galerías (Maeght, Marlborough, Claude Bernard ...).Perteneció al grupo fundador del diario "El País", en cuyas páginas ejerció la crítica de arte durante tres años. Ha colaborado en publicaciones de pensamiento (Revista Occidente), de opinión (Cuadernos para el diálogo), de historia (Historia 16), de información internacional (Correo de la UNESCO) y en periódicos nacionales como "ABC", "La Vanguardia", "Las Provincias", "Diario de Mallorca”, “Diario Montañés”... Escribía una página semanal sobre urbanismo en "Diario 16".Fundador y director de COMUN (Arte, arquitectura, pensamiento y ciudad), dirigió hasta su desaparición la sección de arte de "Nueva Forma". Ha presentado programas de TVE ("Espacio XX", "Otros lugares y otros caminos"...) y estuvo a cargo de la sección de arte, cultura y patrimonio de "Antena 3". Fue vicepresidente de ADELPHA (Asociación de Defensa Ecológica y del Patrimonio Histórico y Artístico) y del Centro de Estudios Ambrosio de Morales. Premio Nacional, en 1976, a la mejor labor de defensa del Patrimonio Histórico - Artístico llevada a cabo en Prensa. Perteneció a la Junta directiva de ICOMOS (Comité Internacional de Monumentos y Sitios), dependiente de la UNESCO. Profesor ponente de la Universidad libre de Berlín. Profesor en cursos sobre Música Barroca y Rococó de El Escorial, miembro de honor del Instituto Francés de Madrid. Especialista en Picasso, siendo suyo el prólogo de "Guernica" de Juan Larrea. Es autor de la bandera y el escudo de la Comunidad de Madrid. Ha recibido a título póstumo, la Medalla de Oro de la Ciudad de Madrid." En http://www.santiagoamon.net/contenido.htm 
Conoce y estudia la obra de Bruce Nauman, entre otros artistas. Juan Muñoz antes de decidir que quería dedicarse profesionalmente a la escultura, mostraba un gran interés por los artistas, e incluso intentaba acercarse y conocer personalmente desde su juventud a algunas de las figuras más importantes en el campo del arte y en particular de la escultura. ${ }^{86}$

En 1978 regresa a Madrid, y un año más tarde recibe otra beca del British Council de nuevo para realizar un curso de litografía en Londres, esta vez en la Croydon School of Art.

Es entonces cuando conoce a la que será su esposa, la escultora donostiarra Cristina Iglesias. Continúa estableciendo contactos con escultores británicos importantes de este periodo, familiarizándose con la corriente del Arte Povera, interesándose particularmente por Mario Merz. En 1980 levanta un minarete de mimbre en la plaza de toros de Málaga, del que toma diversas fotografías, algunas de ellas empujando el minarete hasta tumbarlo. Continuará explorando las posibilidades del minarete en obras posteriores.

Se traslada a Nueva York en 1981, tras recibir una beca Fullbright para realizar estudios de grabado, obtiene a su vez una plaza de artista residente en el P.S.1 Contemporary Art Center de long Island City (New York), donde continúa produciendo obras, experimentando con los objetos o el movimiento. Escribe sus primeros textos sobre arte, conoce las corrientes escultóricas norteamericanas de la época, el minimalismo, el post-minimalismo, y muestra un interés especial por el Land-art y Robert Smithson. Realiza una entrevista a Richard Serra centrada en el arte público.

Vuelve a España en 1982, aún sin estar completamente decidido a ser artista (pero continuando con su labor escultórica y formando parte de algunas exposiciones colectivas en Londres o Berlín), realiza su primer trabajo como comisario y junto a Carmen Giménez organiza la exposición Correspondencias: 5 arquitectos, 5 escultores. Tras esta primera exposición comisaría La imagen del animal: arte prehistórico, arte contemporáneo, donde incluye una obra suya, Portrait (1983). Después de esta exposición, Juan Muñoz decide dedicarse plenamente al arte y realiza sus primeros trabajos en hierro fundido.

86 Arranz, Manel y Solana, Anna. Documental Imprescindibles - Juan Muñoz, poeta del espacio $2014 .$. Comentario de el crítico de arte y amigo personal de Juan Muñoz Adrian Searle. 
Será en 1984 en la Galería Fernando Vijande donde Muñoz muestre su primera exposición individual, en la que exhibe varios dibujos, y un buen número de esculturas. Y a están aquí recogidas algunas de las temáticas que le acompañarán a lo largo de toda su carrera y que incluyen diversas formas arquitectónicas presentadas de manera aislada, como escaleras, balcones o minaretes. En la mayoría de ellas, la figura es la gran ausente.

Durante estos años en España continúa desarrollando su carrera escultórica con numerosas exposiciones en Europa. Participa en la Bienal de Venecia de 1986, donde expone una obra escultórica acompañada de sonido en colaboración con el compositor Alberto Iglesias. En este periodo realiza The Wasteland, obra cuyo título está basado en el poema homónimo de T. S. Elliot, (cuyos textos Muñoz admiraba) donde combina por primera vez un suelo de juegos geométricos con una figura, un muñeco de ventrílocuo realizado en bronce.

Simultáneamente Muñoz continúa trabajando con objetos ordinarios e incorporando carga psicológica a sus obras, un ejemplo son sus barandillas que esconden una navaja en la cara posterior. En estos últimos años de la década de los '80 el escultor incorpora en su repertorio la figura del enano (Dwarf with Three Columns, 1988) y comienza a expandir el uso de las figuras en sus esculturas explorando distintos temas. Produce una serie de esculturas de bailarinas en bronce (que aluden a Edgar Degas) con una base de semiesfera, desafiando la capacidad de movimiento. Tanto el tema del movimiento limitado (figuras sin pies) como el uso de la semiesfera, volverá a utilizarlos como solución para las extremidades inferiores de figuras que realizará en años sucesivos. Al mismo tiempo que trabaja con las figuras, elabora los llamados "dibujos sobre tela de gabardina", telas de gabardina sobre las que pinta en tiza escenas de interiores arquitectónicos domésticos.

A comienzos de la época de los 90, Muñoz coloca en actitud de diálogo varias figuras anónimas que colonizan un cierto espacio, comenzando así con las series "conversation pieces" (varias figuras en conversación), el tamaño de las mismas mantiene una escala menor a la real de un ser humano, algo que mantendrá de ahora en adelante.

Muñoz se traslada a vivir a Roma en el 92, donde profundiza aún más en la historia de la arquitectura barroca, tema de constante interés para el escultor a lo largo de su vida, y fuente de inspiración y referencia para su obra. Hace sus primeras colaboraciones con James Lingwood, quien le encarga varias obras, una de ellas le pone en contacto con el 
compositor musical Gavin Bryars. A partir de esta colaboración Muñoz producirá una serie de obras sonoras, involucrando en algunas de ellas de nuevo a Alberto Iglesias, el crítico de arte John Berger o al crítico Adrian Searle. Este último será quien años después del fallecimiento del escultor recopile los escritos de Muñoz en una publicación ${ }^{87}$. Durante estos años realiza y expone varias Conversation Pieces que proyectan una profunda carga de aislamiento psicológico entre el conjunto de las figuras y el espectador.

Se traslada a Boston, donde trabaja como artista residente en el Isabella Stewart Gardner Museum durante 1995. En 1996 tendrán lugar dos importantes exposiciones monográficas: Juan Muñoz: monólogos y diálogos, organizada por James Kingwood en el Palacio de Velazquez de Madrid, y A Place Called Abroad, en el Dia Center of the Arts de Nueva York, de la que dos años más tarde se presenta una versión llamada Streetwise en Nuevo México (Santa Fe, 1998).

Ambos trabajos muestran una relación entre la figura y la arquitectura, anudando dos intereses fundamentales en la obra del artista. La incorporación de la arquitectura en sus obras extiende las posibilidades de las Conversation Pieces y presenta a su vez una particular visión del mundo, que culmina en su obra Double Bind, en la que comienza a trabajar en el año 2000.

87 Ver Muñoz, Juan, Juan Muñoz: Escritos/Writings. Barcelona. Editado por Adrian Searle. Ediciones de la Central. MNCARS. 2009 


\subsection{Double Bind}

Double Bind es el título de la obra que Muñoz presenta en el año 2001 para la sala de turbinas de la Tate Modern Gallery de Londres como respuesta a la comisión de las llamadas Unilever Series. Como introducción al lugar, y para tener un mejor conocimiento del marco en el que se instala la obra, comienzo con una breve introducción sobre la institución de la Tate y el edificio donde se aloja la Tate Modern Gallery, asi como un breve resumen de la historia de las Unilever Series, que me perite continuar con una descripción introductoria concreta de Double Bind.

La Tate Modern Gallery de Londres se aloja en la antigua Bankside Power Station desde el año 2000, y tanto la institución de la Tate como el edificio Tate Modern, se han convertido en uno de los espacios más exitosos en el campo cultural de las últimas décadas. El edificio industrial fue originalmente diseñado por Giles Gilbert Scott (1880-1960) en 1947 y remodelado por los arquitectos suizos Herzog \& de Meuron que lo adaptaron para albergar el presente museo. Esta situado en la rivera sur del río Támesis en la zona de Southwark en un área muy expuesta desde diferentes puntos de la ciudad. Debido a su céntrico emplazamiento, su arquitectura destaca en el perfil de la ciudad, resaltando por su monumentalidad, pronunciada tanto por su tamaño como por una alta chimenea tan solo pocos metros menor que la cúpula de la Catedral de Saint Paul. La central de energía dejó de funcionar casi en su totalidad en 1981. Desde este mismo momento se plantea como mantener en uso la emblemática estructura, que no volverá a ser utilizada hasta su reconversión en galería de arte. Finalmente, en un esfuerzo de transformación y regeneración de la zona en la que se sitúa, y tras un concurso convocado en 1994, el edificio acogió la colección de arte moderno de la Tate Gallery.

La Tate Gallery fue fundada en 1897 al recibir el estado la donación de la colección de arte de Sir Henry Tate. Por aquel entonces, el estado ya tenia la intención de crear una galería nacional de arte británico, la donación económica y el valor de las obras cedidas por el magnate azucarero son el empujón necesario para abrir la galería. El edificio original se situada en Milbank, Pimlico, y sufre varias ampliaciones durante su historia. Sin embargo, y como sucede con tantas otras instituciones, por problemas de espacio, únicamente 


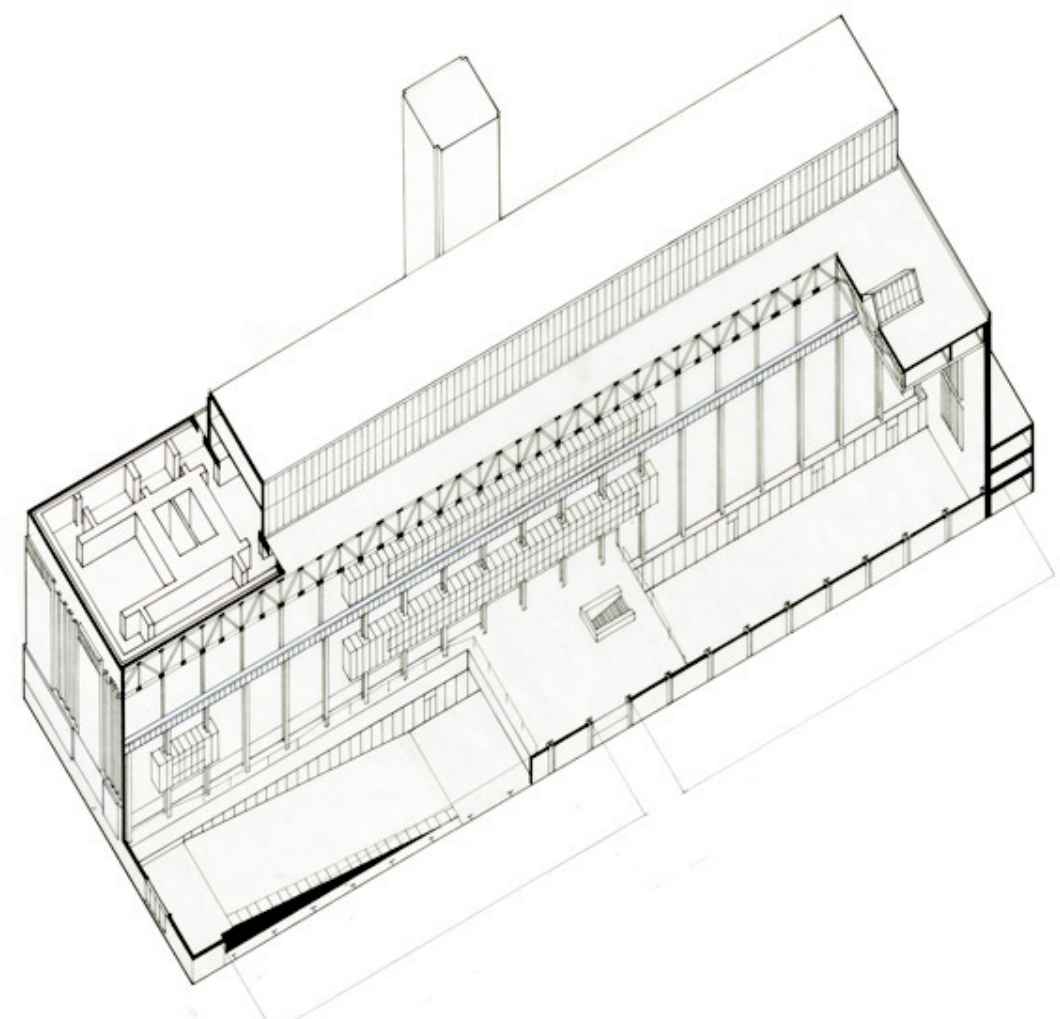

FIGURA 54: Tate Modern Gallery, Londres.

puede exponer alrededor del veinte por ciento de las piezas de la colección, y además existe una cierta incoherencia entre la disposición de las obras. En 1988 se nombra a Nicholas Serota director del centro, potenciando así el arte moderno y contemporáneo. En 1992, con el impulso de Serota se decide dividir la colección y establecer una nueva galería dedicada exclusivamente al arte moderno y contemporáneo. En la búsqueda de un nuevo emplazamiento, se plantea la construcción de un nuevo edificio, sin embargo, y debido a la falta de presupuesto, se considera también la reutilización de un edificio existente. Es en este momento cuando se sopesa la posibilidad de reutilizar la Bankside Power Station. La transformación del edificio de la central eléctrica en galería de arte supone dos grandes beneficios para la institución, por un lado, la disminución del coste de la construcción al tratarse de una readaptación del espacio, y por otro, una ubicación céntrica y estratégica de un espacio de unas dimensiones difíciles de plantear a nivel de presupuesto para un edificio cultural de nueva planta en esta localización. Sin la intención de celebrar el carácter industrial del edificio, se convoca un concurso de arquitectura con 


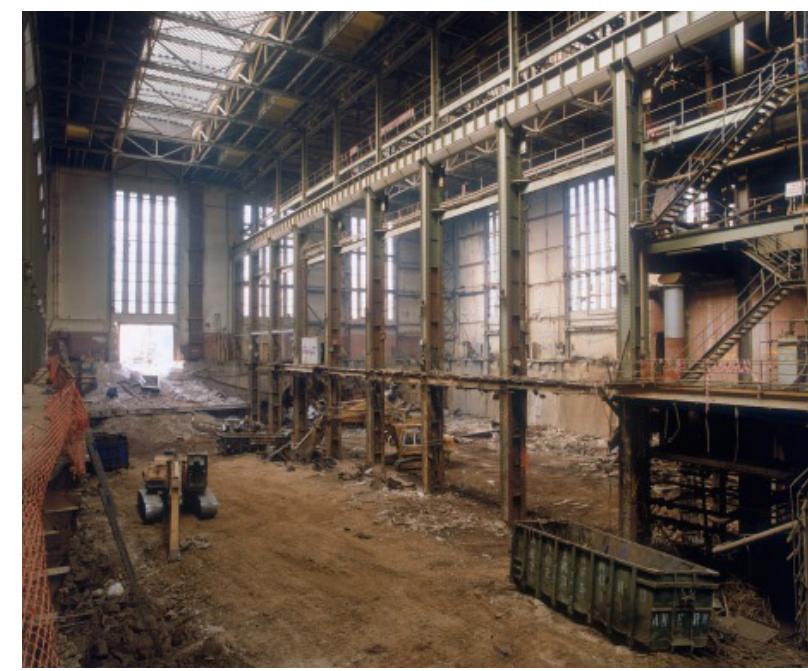

FIGURA 54: Reforma Tate Modern Gallery, Londres.

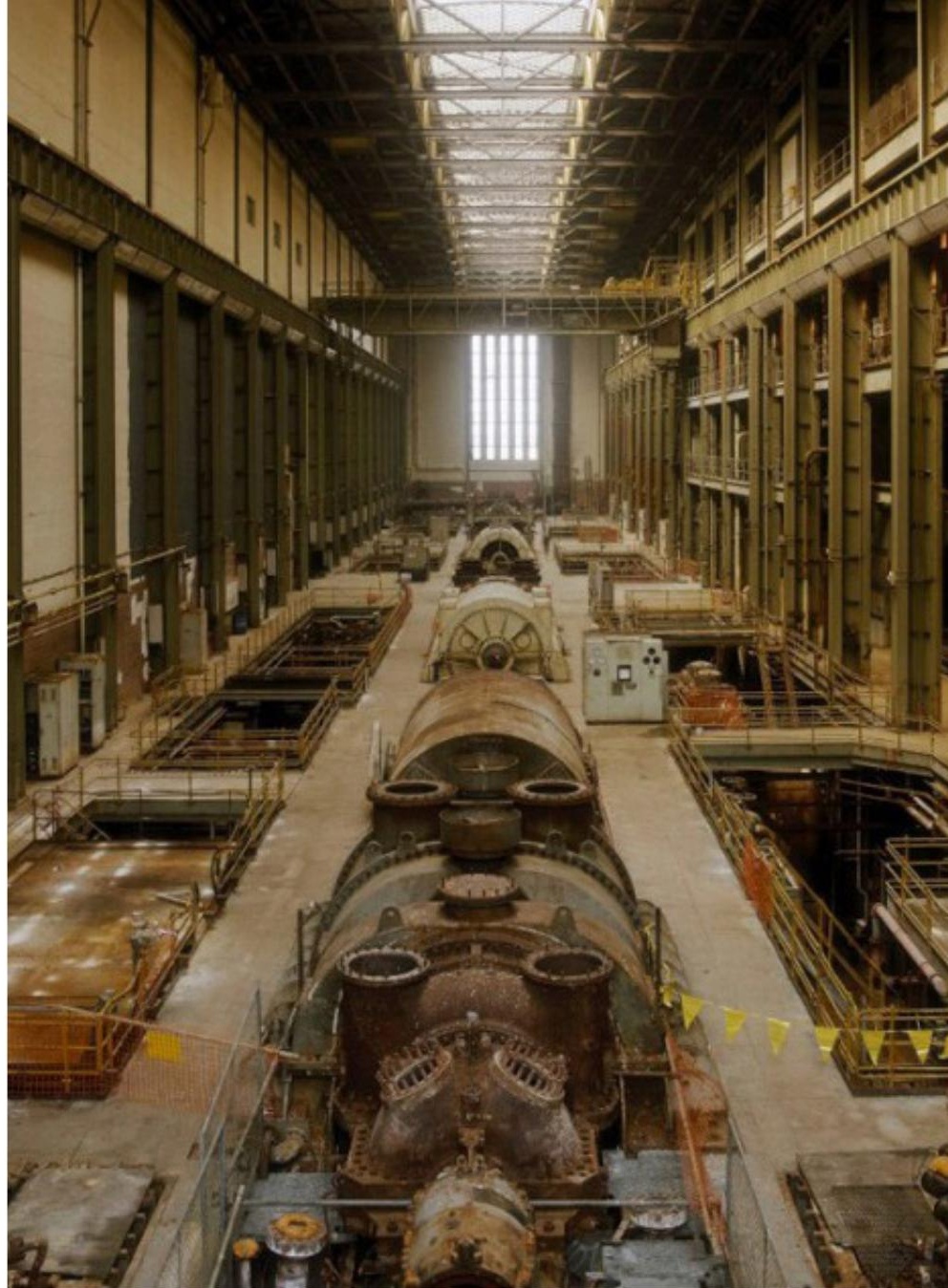

FIGURA 54: Sala de Turbinas, Disposición original.

trece equipos invitados en primera ronda. Los seis equipos que pasan a una segunda fase son: Tadao Ando Architects and Associates, David Chipperfield Architects, Rafael Moneo, Rem Koolhaas/Office of Metropolitan Architecture, Renzo Piano Building Workshop y Herzog \& de Meuron ${ }^{88}$. De todos ellos, los únicos que preservan el espacio de la sala de turbinas de la que hablaré más adelante son Herzog \& de Meuron.

En el diseño original de la central, Gilbert $\operatorname{Scott}^{89}$ plantea un edificio siguiendo pautas similares a las utilizadas en sus obras anteriores, todas ellas de carácter conservador. El

88 Para más información ver Moore, Rowan. Ryan, Raymund. Building Tate Modern: Herzog \& De Meuron transforming Giles Gilbert Scoot. Tate Gallery Publishing. London, 2000 y http://www.tate.org.uk/about/ who-we-are/history-of-tate

89 Giles Gilbert Scott (Londres 1880-1960). Scott era hijo y nieto de los arquitectos que fueron los mayores exponentes del Gótico Victoriano. Con apenas 22 años ganó el concurso para construir la Catedral de Liverpool. Modificó el diseño inicial en gótico tradicional del siglo anterior , simplificando las formas, eliminando una parte importante de la decoración e introduciendo un diseño más simétrico, moderno y monumental , y colocando una impresionante torre central, en lugar de las dos del diseño original , que 


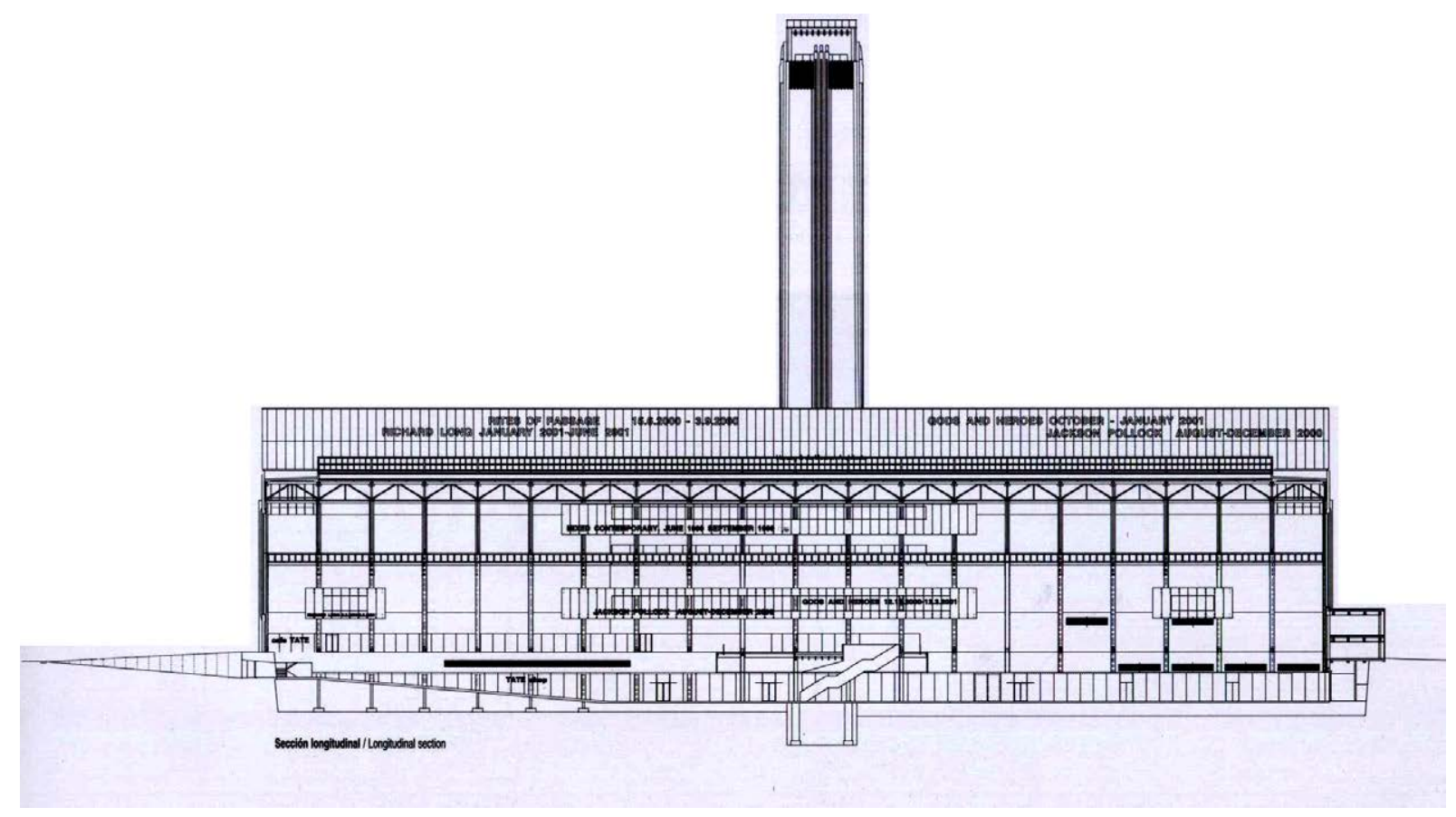

FIGURA 54: Sección longitudnal por sala de turbinas. Tate Modern Gallery, Londres.

arquitecto, que era conocido por su trabajo en distintas iglesias, muchas de ellas de un marcado estilo neogótico aunó en esta obra tradición y modernidad tratando de armonizar las bastas dimensiones que requería un espacio capaz de albergar la maquinaria necesaria en una central eléctrica. Plantea una estructura de acero y una fachada de ladrillo marrón,

aumentaron considerablemente el espacio interior. La catedral se finalizó en 1978, dos décadas después de su muerte. Durante sus primeros años como arquitecto diseñó varias iglesias manteniendo el estilo gótico simplificado que caracterizó su primera etapa. Posteriormente utilizó un estilo neo-Georgiano en el diseño de sus edificios civiles, como el Clarence College de Cambridge, o las casas de Clarendon Place, con las que ganó la medalla anual de arquitectura urbana de Londres en 1928. En 1930 la London Power Company le contrató como consultor para diseñar su nueva estación generadora de electricidad en Battersea. Su cometido era dar un aspecto arquitectónico a una estructura industrial enorme. Scott decidió realizar la estructura exterior en ladrillo y colocar cuatro chimeneas blancas una en cada esquina, rememorando unas columnas clásicas y que contrastaban con el ladrillo rojo. En 1939 Scott fue considerado por la revista The Architect Review como uno de los dos mejores exponentes de la arquitectura moderna inglesa. En el diseño de la biblioteca de la Universidad de Cambridge, un edificio de seis pisos, en la torre central de doce pisos, unió verticalmente las ventanas, en cinco hileras paralelas, como su fueran las ventanas de una catedral gótica. El diseño más conocido de Scott son las típicas cabinas telefónicas rojas. El Kiosk no 2 o K2, como se llamaba el prototipo, está inspirado en el mausoleo de Sir John Soane, a quien Scott tanto admiraba. 


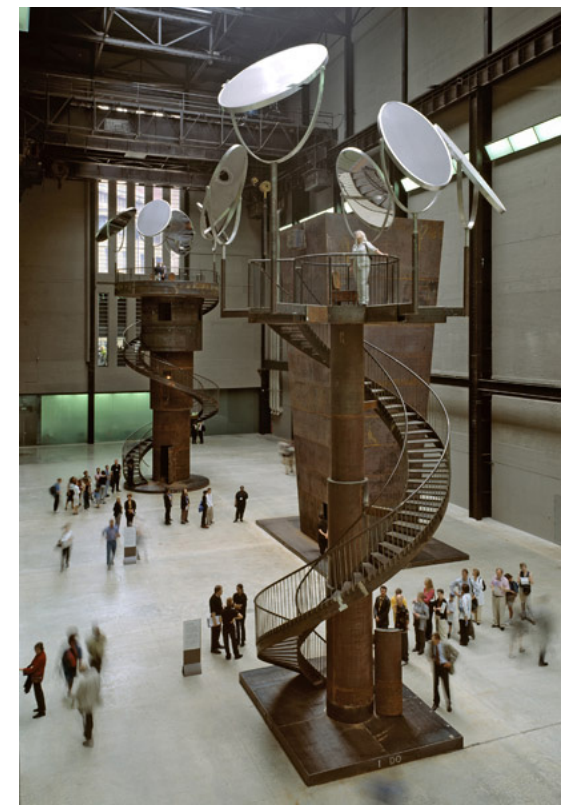

Unilever Series, Tate Modern, Londres. Louise Bourgeois (I Do, I Undo, I Redo, 2000)

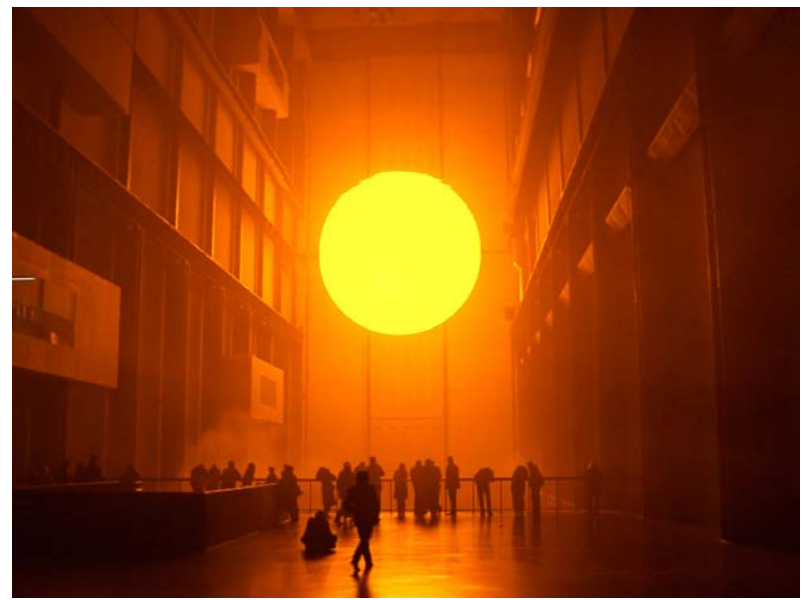

Unilever Series, Tate Modern, Londres. Olafur Eliasson (The Weather Project, 2003)

característica de las construcciones industriales de la época. El edificio iba a localizarse en una posición céntrica y dominante ya que, aunque situada en una zona que en el momento se programaba como puramente industrial, al planificarse junto al río quedaba muy expuesta. Su envergadura tendría un impacto en el perfil urbano, era crucial tener un especial cuidado con la relación de la nueva construcción y la muy visible cúpula de la catedral de St. Paul, cuyas vistas están protegidas y no deben ser obstruidas por las nuevas construcciones.

La intervención de los arquitectos suizos era la propuesta más conservadora del las presentadas en el concurso en cuanto al nivel de intervención en el edificio. No propone grandes cambios en el volumen general, respetando el esquema original de Gilbert Scott. El edificio mantiene su inequívoco carácter industrial y la propuesta interior sigue las mismas pautas que el proyecto original, particularmente en la gran nave este-oeste: la sala de turbinas. Con el proyecto de los suizos se mantenía el carácter icónico del edificio 
industrial poniendo atención en proveer a la institución con un espacio capaz de albergar las mejores instalaciones de arte y no necesariamente una nueva fachada. El éxito de la institución fue tal, que por supuesto la percepción que se tenía de la central eléctrica cambio totalmente, pero fue por lo que el edificio ahora ofrecía, y por el cambio que supuso para la regeneración de la zona, pero no por su nuevo aspecto, que era exteriormente casi el mismo al que llevaba allí una cuarentena de años.

La central se vacía en su totalidad, se retira toda la maquinaría y se proyecta un esquema capaz de albergar instalaciones de arte. El volumen general del edificio queda dividido en dos grandes bloques, aquel ocupado por el cuerpo de galerías de diversos tamaños y funciones, y próximo a la fachada norte, y la sala de turbinas, una gran nave con orientación este-oeste adyacente a la anterior en el lado sur. La relación entre los dos cuerpos se genera a través del muro vertical que las separa. Un muro con aperturas y cajas de luz que entran ligeramente sobre el espacio de la sala de turbinas.

El edificio queda definido por dos ejes principales. En la parte central del edificio se marca el eje norte-sur (acceso natural desde el norte vía puente del Milenio y desde la rivera sur del río) por el que se accede al volumen donde se sitúan las salas de exposición, y que es a su vez acceso directo a la sala de turbinas. Nos encontraremos sobre una gran pasarela, único elemento que cruza transversalmente el vasto volumen de esta sala. El tránsito entre la pasarela y el nivel inferior de la nave de turbinas se resuelve con una escalera ascendente desde el oeste. Esta plataforma es la única pieza que se mantiene al nivel del forjado original, una porción del piso de hormigón con estructura metálica y grandes perforaciones por las que asomaban las maquinas apoyadas en la cota inferior y que cubría entonces toda la nave.

En la parte oeste se encuentra el acceso principal del eje este-oeste. Una gran rampa a nivel de la calle proporciona un acceso directo a la enorme sala de turbinas. La rampa continua en el interior del edificio. Nicholas Serota mantiene una conversación con los arquitectos durante la construcción del edificio y comentan que entienden la sala de turbinas como una calle que se recorre entre dos fachadas, los muros norte y sur de la nave. ${ }^{90}$ Una calle que es el vasto vestíbulo de acceso público que se utiliza a su vez como

90 Moore, Rowan. Ryan, Raymund, Conversation. Jacques Herzog, Nicholas Serota and Rowan Moore. Agosto 1999 en Building Tate Modern: Herzog \& De Meuron transforming Giles Gilbert Scoot, Tate Gallery Publishing. 
sala de exposiciones. Un gran vacío que supone todo un reto para los artistas que han sido invitados a exponer en este espacio, como lo fue para Juan Muñoz en el año 2001.

El actual espacio interior de la sala de turbinas tiene un gran parecido con la nave central de una catedral. La sala de 155 x 23 x 35 queda definida por una serie de columnas perimetrales en los laterales, una cristalera de huecos verticales estrechos y muy alargados que asemejan vidrieras en la fachada este, y un gran lucernario, intervención de Herzog \& de Meuron a lo largo de toda la nave, solo interrumpida por la pasarela del eje norte-sur. La estructura de acero vista, con grandes tornillos, dos enormes grúas en funcionamiento en la parte alta de la nave, que se mueven a lo largo de la misma, rememoran el carácter original del edificio. La sala tiene un predominante color negro, con paredes oscuras, parcialmente iluminada por la luz que entra a través de las cristaleras verticales antes descritas y el lucernario. Las cajas que cuelga hacia este espacio proporcionan luz artificial, al igual que una serie de focos dispuesto a lo largo de la pared opuesta.

La Sala de Turbinas es una continuación de la calle, del espacio exterior. Un lugar público que funciona como plaza y lugar de encuentro.

Las llamadas Unilever Series de la Tate Modern Gallery se pusieron en marcha en el año 2000 al mismo tiempo que se inauguraba la galería. Patrocinadas por la compañía Unilever (una compañía multinacional ligada a la alimentación, la investigación y el desarrollo), invierten entre los años 2000 y 2013 unos 4.5 millones de libras, encargando anualmente a un artista una intervención libre en el espacio de la sala. A partir del año 2015 será la compañía Hyunday la nueva patrocinadora de este vasto espacio, con un volumen de 155 metros de largo, una altura de $35 \mathrm{~m}$, y un ancho de $23 \mathrm{~m}^{91}$. Esta sala se ha convertido en el corazón del museo, un espacio popular de libre acceso, y un lugar donde los artistas tienen una capacidad enorme de movimiento. El primer encargo fue para la artista francesa Louise Bourgeois (I Do, I Undo, I Redo, 2000), seguida de Juan Muñoz (Double Bind, 2001), Anish Kapoor (Marsyas, 2002), Olafur Eliasson (The Weather Project, 2003) Bruce Nauman (Raw Materials, 2004), Rachel Whiteread (EMBANKMENT, 2005), Carsten

London, 2000, p. 38. Ibíd. "Herzog \& de Meuron realised that the turbine hall was essentially a street that ran through the building and that it had both a north facade and a south facade..."

91 Ver http://www.theguardian.com/artanddesign/2014/jan/20/tate-modern-sponsorship-dealhyundai 


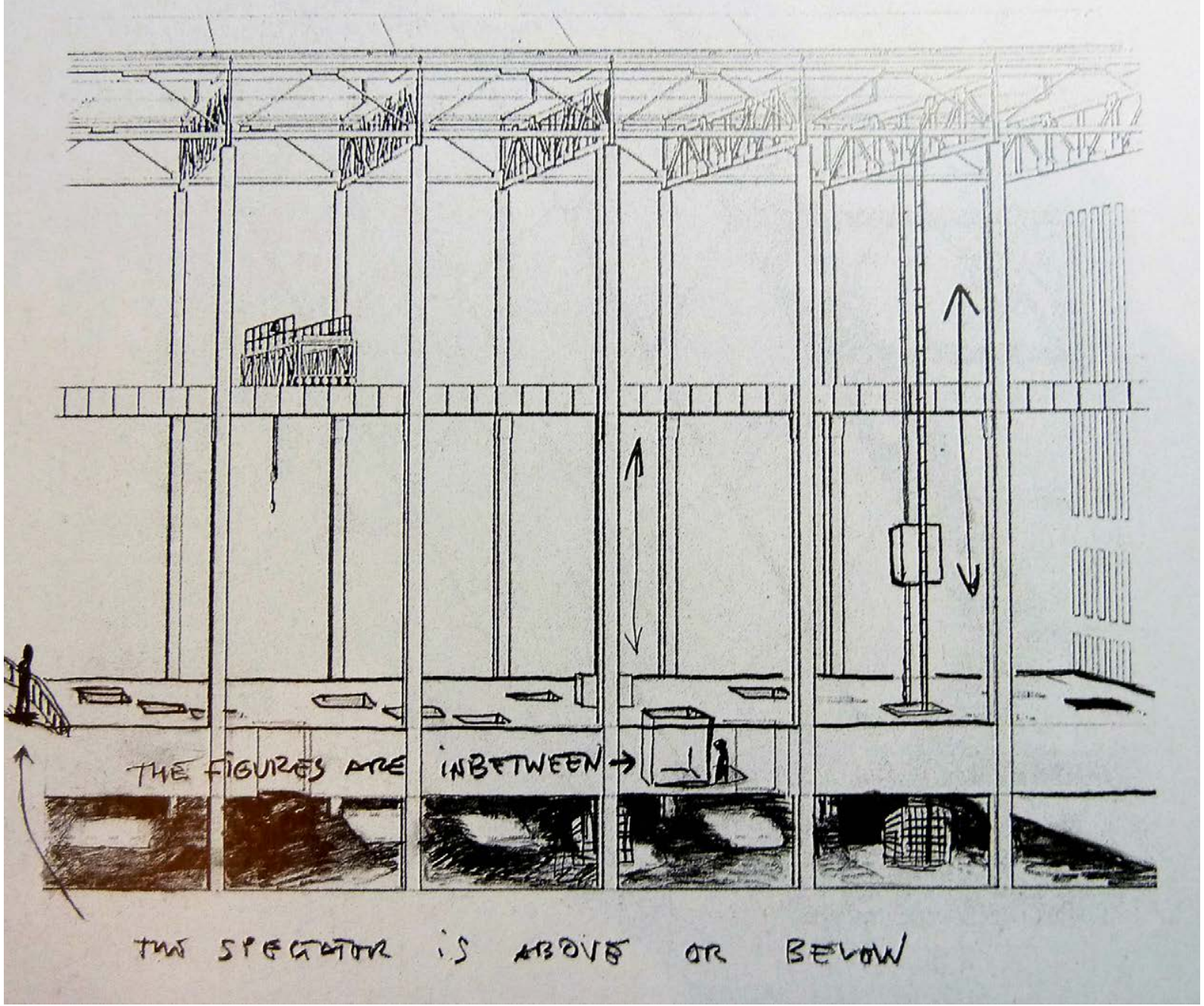

Double Bind. Dibujo de estudio del artista

Höller (Test Side, 2006), Doris Salcedo (Shibboleth, 2007) Dominique Gonzalez-Foerster (TH.2058, 2008) Miroslaw Balka (How It Is, 2009) Ai Weiwei (Sunflower Seeds, 2010), Tacita Dean (FILM, 2013), Tino Sehgal(2012, 2012) ${ }^{92}$

Todas las instalaciones son radicalmente diferentes a nivel formal y conceptual, y todos los artistas declararon que se trataba de un espacio expositivo intimidatorio,fundamentalmente debido a sus dimensiones. Por lo general, las instalaciones que proponen optan por una intervención global en el espacio, ya sea por repetición, percepción, expansión, etc. Bourgeois presenta tres torres de acero con escaleras, plataformas y espejos, e instala una de sus gigantescas arañas en la pasarela central de la sala, entendiéndola como una galería a gran escala. Juan Muñoz será el segundo en activar la sala de turbinas. Cundo Juan Muñoz recibió su encargo, aun no se había instalado la propuesta de Bourgeois, por lo que puede considerarse que no tenía precedentes. Una aproximación diferente a este espacio fue

92 Ver http://www.tate.org.uk/whats-on/tate-modern/exhibitionseries/unilever-series 
...Quizás comprender que cada posibilidad, cada espacio engendra los otros. Que lo que en verdad existe es la multiplicación de los espacios, donde cada uno de ellos contiene implícitamente a todos los demás"

\section{Un objeto metálico (1988), Juan Muñoz ${ }^{95}$}

En la obra que presenta Juan Muñoz para la sala de turbinas, es difícil distinguir entre lo añadido por el artista y lo preexistente, así como es difícil identificar algunas de las intervenciones de los arquitectos Herzog \& de Meuron de aquello que originalmente perteneció a la Bankside Power Station. Juan Muñoz integra su obra en el interior de este espacio, colonizando lo existente, y sumando estructuras que se ensamblan de manera natural entre los escasos elementos de la gran sala, todos ellos con un perfil muy funcional (estructura, entradas de luz, escalera, pasarela). El planteamiento de los arquitectos al diseñar la Tate Modern era el de mantener su estructura original y ordinaria, y el espacio existente tiene tanta potencia que resulta inquietante, produciendo al mismo tiempo una sensación de belleza y extrañeza que no se encuentra en otras salas de exposiciones. Ofrece una sensación contradictoria, donde uno tiende a preguntarse si las cosas son lo que parecen, en un gran espacio de coexistencia de muchas sombras y algo de luz ${ }^{96}$, pero una luz con mucha claridad. Este espacio inquietaba a Juan Muñoz, quien visitó en numerosas ocasiones la sala de turbinas, paseando arriba y abajo, intentando imaginar una pieza escultórica capaz de sorprender en semejante espacio. En su busca de respuestas busca imágenes que resuenen en su cabeza sumergiéndose en libros y paseando por las calles.

Sin el aparente animo de buscar una mímesis con el entorno, la estrategia de colonizar el espacio que plantea Muñoz se acomoda al entorno arquitectónico existente de manera casi natural respondiendo a la geometría a y lenguaje de la sala de turbinas. En una búsqueda de integración de la obra escultórica con el espacio arquitectónico de la sala de turbinas el límite entre los objetos escultóricos y el espacio arquitectónico se pierde hasta hacerse ilegible.

95 Muñoz, Juan, Un objeto metálico en Juan Muñoz: Escritos/Writings. Barcelona. Editado por Adrian Searle, Ediciones de la Central, MNCARS. 2009, p. 77.

96 Moore, Rowan, Ryan, Raymund, Building Tate Modern: Herzog \& De Meuron transforming Giles Gilbert Scoot, Tate Gallery Publishing, London, 2000. p. 10. 


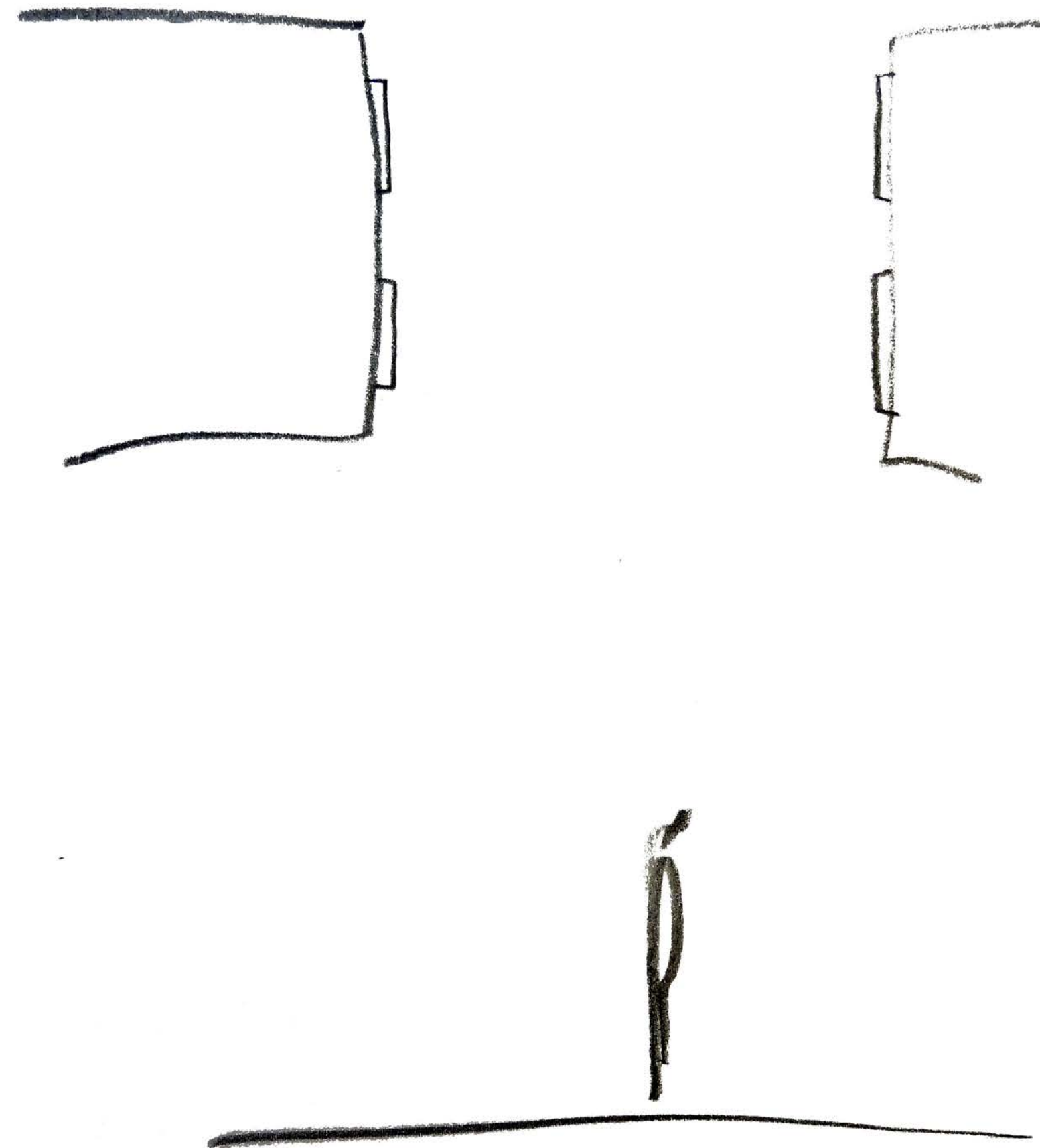


Como se ha descrito en párrafos anteriores, la sala de turbinas es un extenso espacio de 152 metros de largo con una plataforma central que corta la sala transversalmente al nivel de la primera planta, una altura de $30 \mathrm{~m}$, y un ancho de $24 \mathrm{~m}$. Ninguna obra anterior de Muñoz hasta entonces había ocupado un volumen tan extenso de la manera en que lo plantea en este espacio, aunque es reflejo de muchas de las ideas que ha utilizado durante su carrera, donde ya había utilizado la estrategia de extender la narrativa de una misma obra a través de distintas salas colonizando los pasillos de las salas expositivas, plantea una instalación radical y novedosa. Asegura en su conversación de Mayo de 2001 con James Lingwood que no tenía una idea en su imaginación aguardando para un volumen espacial semejante.

El espacio escultórico propuesto Muñoz se genera a través de una construcción que establece tres niveles. Un nivel superior entendido como un plano longitudinal, un forjado habitable donde Muñoz coloca diversas figuras, y que es además atravesado por dos ascensores en movimiento perpetuo y un piso inferior engendrado entre el suelo y la parte inferior del forjado. El gesto propuesto por Muñoz puede simplificarse descriptivamente como una extrusión longitudinal del forjado de la plataforma existente prolongándolo hasta el final de la sala sobre la que se dibuja una retícula con cuadrados, este forjado se apoya en una estructura de pilares metálicos con once huecos que lo perforan.

Entrando a describir la obra en detalle, podemos comenzar situándonos en la plataforma central de la sala de turbinas a la altura del primer nivel, donde, mirando hacia el este, una barandilla separa la plataforma de un plano horizontal que choca con los limites laterales de la galería, donde se dibuja una retícula de cuadrados oblicua respecto a la barandilla. El escultor juega con el arte del trampantojo y la volumetría real de las perforaciones que atraviesan el forjado, intentando engañar al ojo para que crea que todos ellos son perforaciones. Sin embargo, de los 22 huecos, la mitad de los cuadrados de la retícula son un dibujo plano. Cada lado del cuadrado tiene una longitud aproximada de $2.45 \mathrm{~m}$.

Desde este punto se ven dos ascensores que suben y bajan a destiempo traspasando este forjado. La cabina de los ascensores es de una altura aproximada de $2.5 \mathrm{~m}$, y alcanzan los 22.3m de altura medidos desde el piso inferior. 


\section{atelier one}
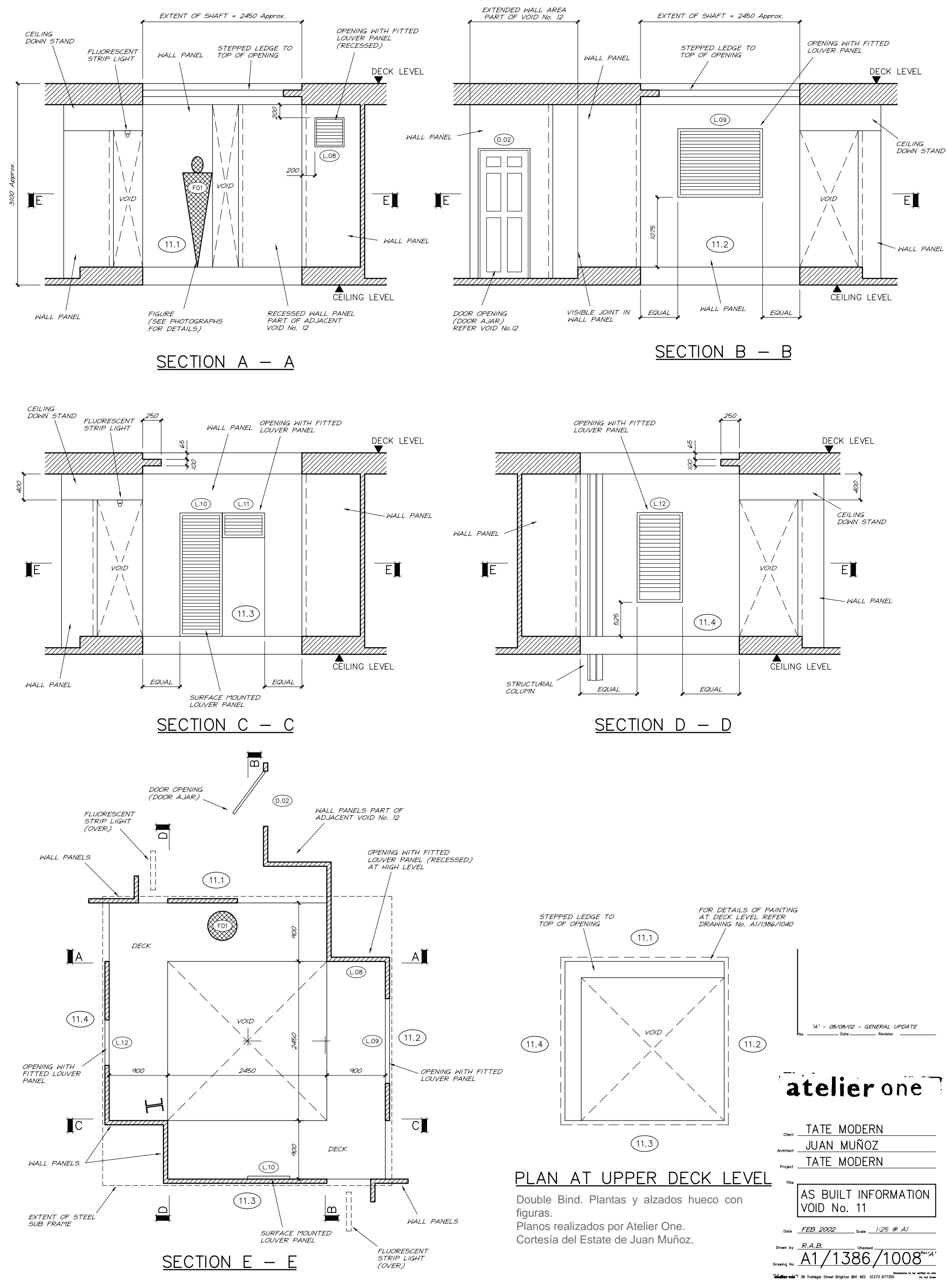


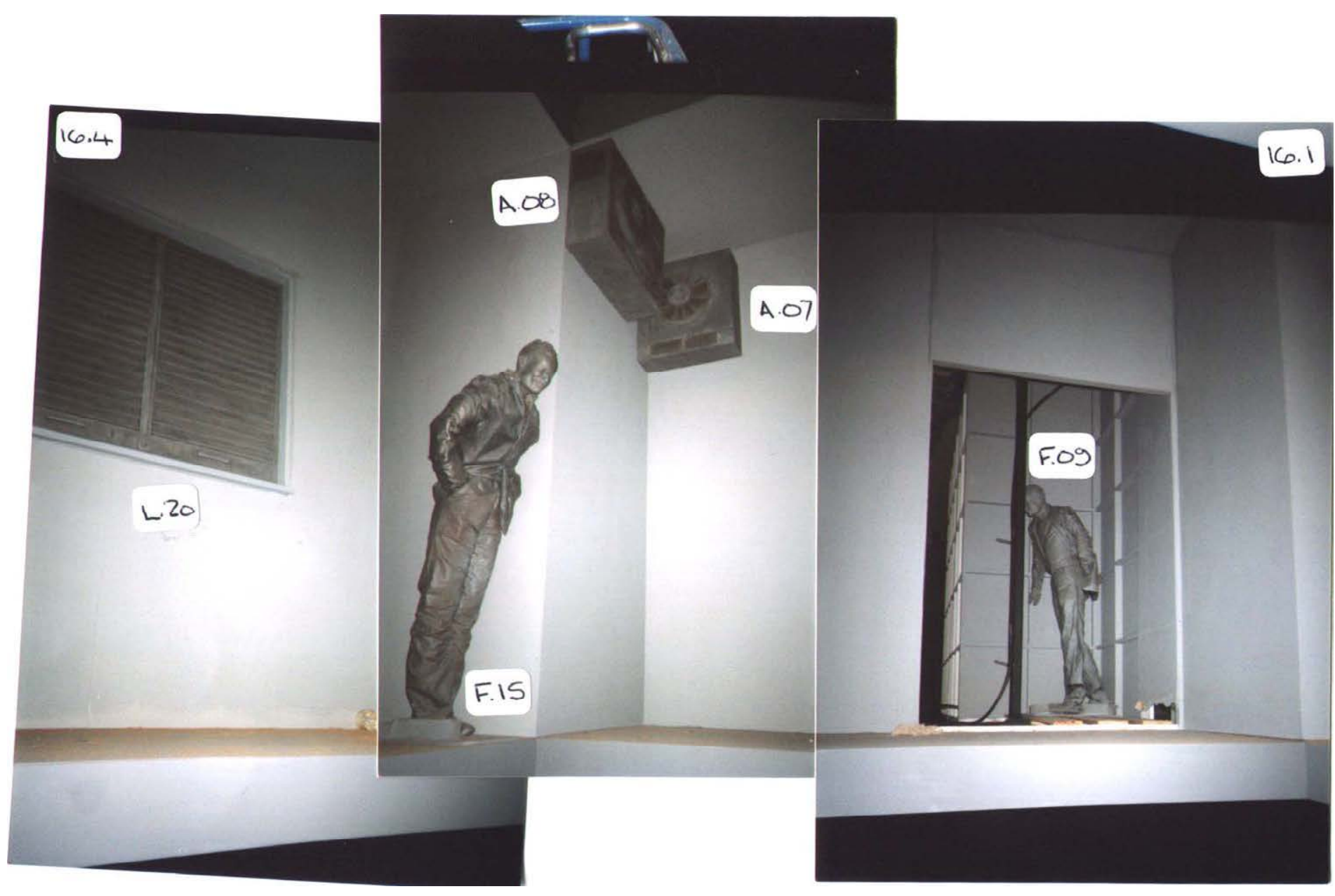

Image Reference : 1015-1.JPG

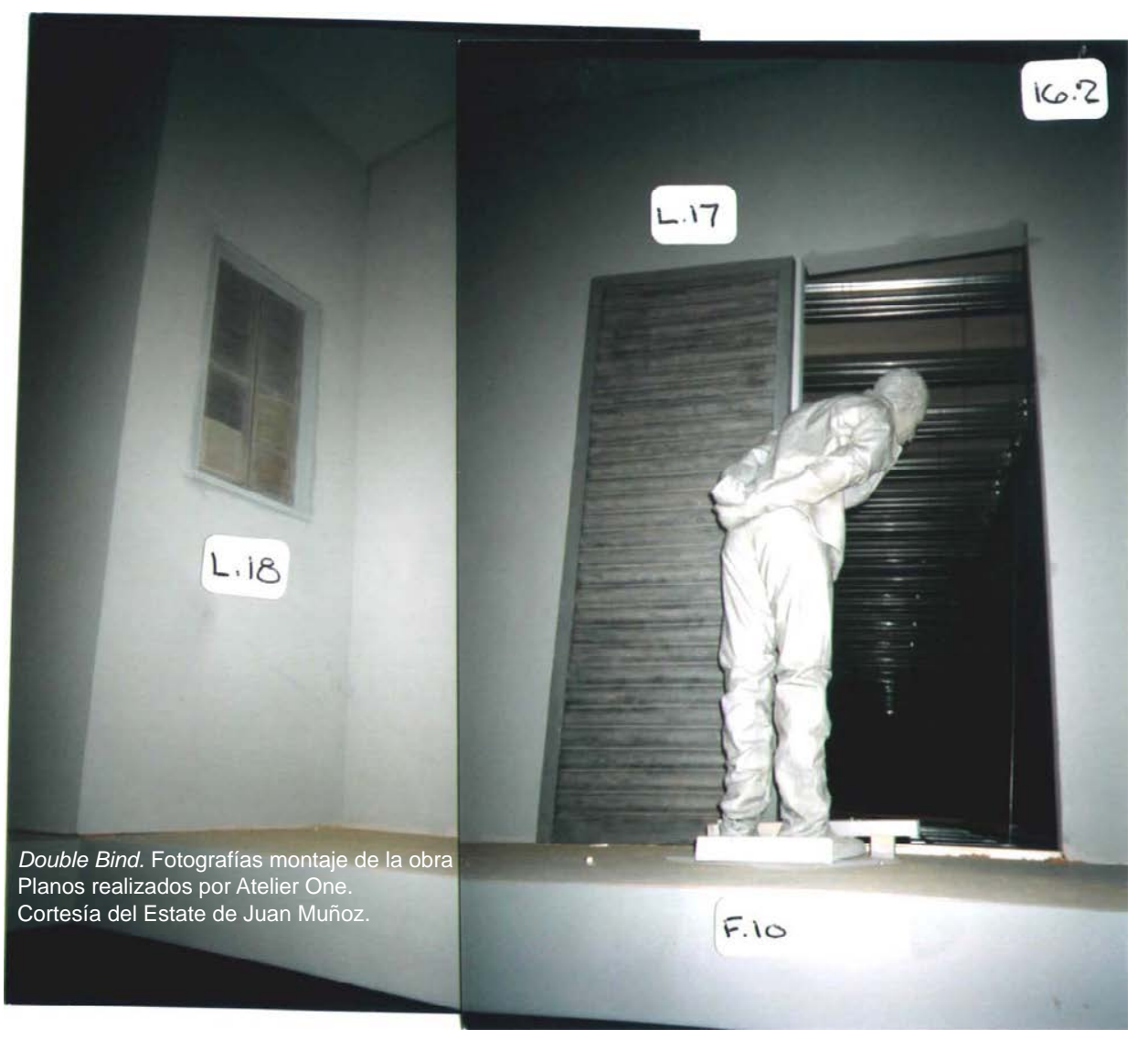

Image Reference : 1015-2.JPG

\section{atelier one}

\begin{tabular}{|c|}
\hline $\begin{array}{l}\text { TATE MODERN } \\
\text { JUAN MUÑOZ } \\
\text { TATE MODERN }\end{array}$ \\
\hline $\begin{array}{l}\text { AS BUILT INFORMATION } \\
\text { VOID No. } 16 \text { Photo's } \\
\end{array}$ \\
\hline 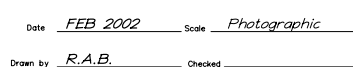 \\
\hline 然 \\
\hline
\end{tabular}




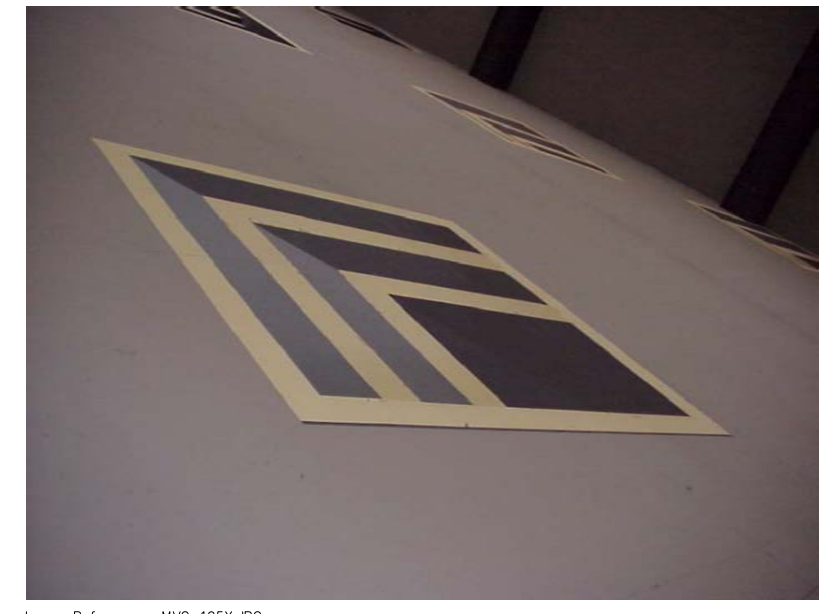

Image Reference : MVC-195X.JPG
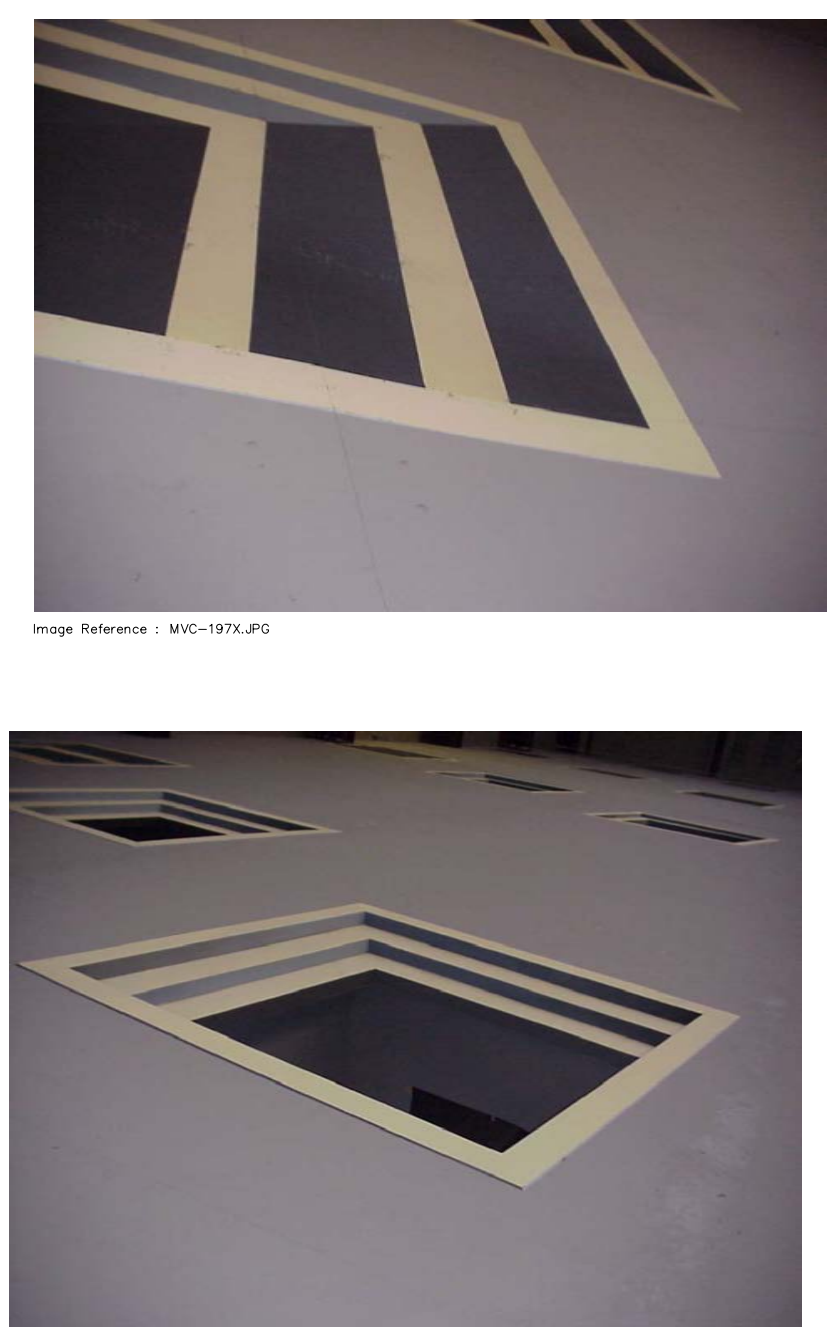

Image Reference : MVC-190X.JPG

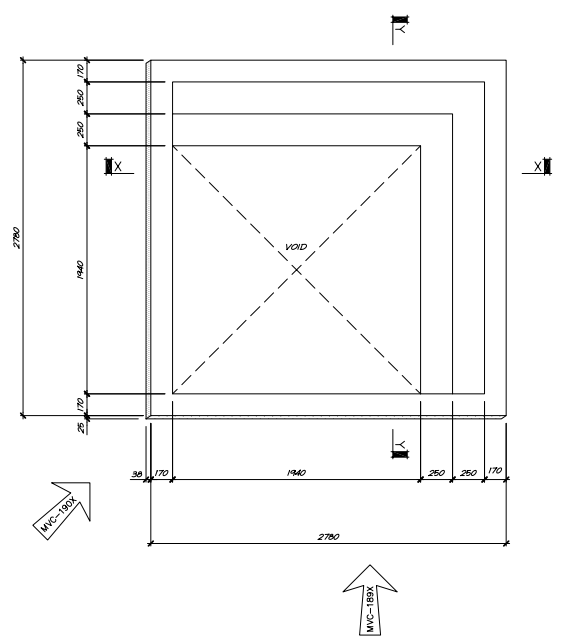

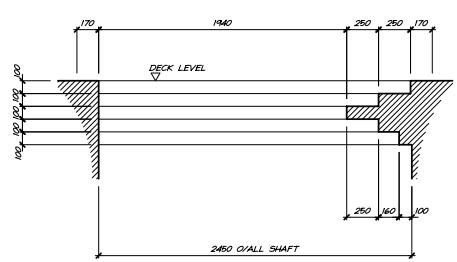

SECTION $x-x$

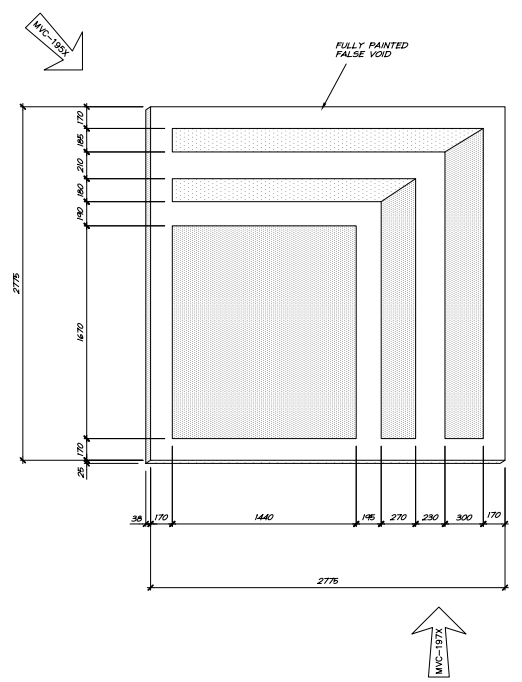

VOID No. 01

DECK LEVEL DETAILS
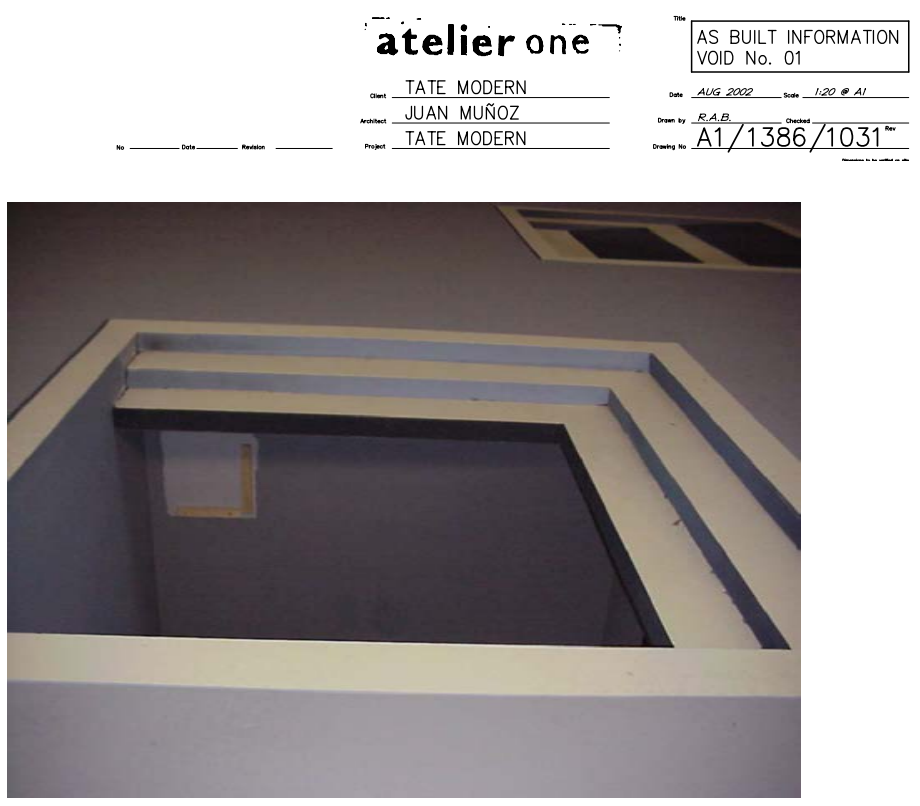

Image Reference : MVC-189X.JPG

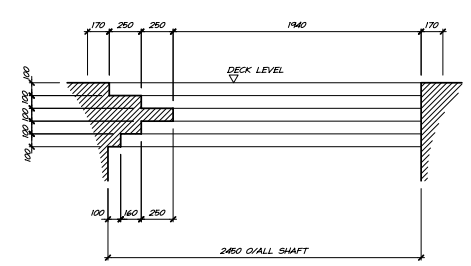

Double Bind. Detalle $\frac{\text { SECTION Y }-\mathrm{Y}}{\text { trampantojo y detalle }}$ wwhueco.

Planos realizados por Atelier One.

Cortesía del Estate de Juan Muñoz.

\section{atelier one \\ VOID No. 06 \\ Nometer JUAN MUNOZ

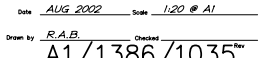


Desde la planta inferior a esta plataforma central de la sala de turbinas, es posible adentrarse en la parte inferior de la obra, aquella que queda entre el forjado y el suelo del nivel inferior de la sala de turbinas. Se camina por un lugar oscuro, entre un mundo de pilares donde se descubre que algunos de los huecos que veíamos desde la parte superior, y que iluminan el espacio dejando pasar la luz están a su vez abiertos hacia el interior del forjado, generando un nivel de actividad donde ciertas figuras, de escala ligeramente menor a la humana, habitan. Este nivel intermedio tiene una altura de unos $3 \mathrm{~m}$, mientras que las figuras rondan todas el $1.45 \mathrm{~m}$ de altura. La altura libre del espacio inferior es aproximadamente de $2.9 \mathrm{~m}$.

La simplicidad espacial de lo que se percibe a primera vista podría llevar al equívoco al que no conoce previamente el espacio de la galería, llegando a dudar de los límites entre el volumen museístico y la pieza escultórica. Hace ya muchas décadas que la escultura ha dejado de ser entendida solo como un objeto que está en el suelo y que el espectador rodea. Se exploran las relaciones entre el espacio, el observador y la pieza, sinergias en las que Juan Muñoz esta especialmente interesado. En Double Bind la obra se recorre, se observa desde arriba, y también es posible introducirse en su parte inferior, desde donde puede contemplar su parte central, que queda inaccesible para el espectador, pero hacia la que si puede mirar.

Es sin duda una escultura con una fuerte vocación arquitectónica. Estamos ante lo que podríamos llamar metaescultura, donde la escultura toma la geometría propia de la arquitectura y se construye con materiales arquitectónicos (vigas y pilares metálicos, escayola, montantes de aluminio...) conteniendo a si mismo otras piezas que se moldean con los medios y materiales propios de una escultura más tradicional (las figuras o las rejas metálicas, que se producen utilizando textiles, maderas, cartón, pintura...). La obra escultórica somete a la arquitectónica y la transforma a través de su gesto. La obra de Muñoz se impone ante el vacío arquitectónico de la sala sin alterar el carácter del espacio que ocupa, pero transformándolo en su totalidad.

Muñoz se plantea cuál es el carácter de los espacios museísticos en su texto Notas afines a tres ${ }^{97}$ de 1982: "todo museo es diseñado para albergar en sus muros pintura y, entre

97 Muñoz, Juan, Notas afines a tres en Juan Muñoz: Escritos/Writings. Barcelona, Editado por Adrian Searle, Ediciones de la Central, MNCARS. 2009 p.43 
muro y muro escultura". Por aquel entonces Muñoz concibe el museo como un espacio que debe quedar en un segundo plano respecto a las piezas que lo colonizan, siendo dos entes autónomos y diferenciables. O’Brian escribe “Hemos llegado a un punto en el que ya no vemos el arte, sino que vemos en primer lugar el continente, de ahí la sorpresa que nos produce una galería cuando entramos en ella"98. Del mismo modo, Juan Muñoz considera que el museo Guggenheim de Nueva York diseñado por Frank Lloyd Wight en 1959 no funciona bien como museo, y lo describe como "una gran escultura" ${ }^{99}$ que rivaliza con aquellas obras que quieren ocuparlo. Pone el ejemplo de las exposiciones retrospectivas de Eduardo Chillida que tuvo lugar en 1980 y de la de Joseph Beuys en 1979. La arquitectura del museo produce presión sobre el arte, en la primera compitiendo con el museo en la coincidencia de formas espirales, y la segunda disputándose el protagonismo de los objetos escultóricos repartidos por el pasillo en espiral con la fuerza del espacio central, llegando incluso a afirmar que Beuys impuso bajar la intensidad de las luces y la temperatura del ambiente $^{100}$. Por lo que podría decirse que según Muñoz la arquitectura del museo debe estar al servicio del arte. Parece entender mejor la posición de Richard Serra que la de los arquitectos del Centro de Arte George Pompidou, Piano y Rogers cuando, según el escultor, los arquitectos se opusieron a la instalación de una obra de Serra que bloqueaba la entrada del metro y este respondió que consideraba que el acceso no quedaba bloqueado, si no que se accedería rodeando su escultura. Refiriéndose de nuevo a una obra de Serra, artista con el que Juan Muñoz colaboro a principios de los años 80 en Nueva York, ahora subraya como el trabajo de Mies van der Rohe en la Nationalgalerie de Berlín de 1968 tampoco funciona para toda forma de arte, ya que no era capaz de soportar el peso de una obra del artista americano, en este caso, Muñoz plantea que Mies, al que considera un fuerte influyente del minimalismo, "siempre favoreció esculturas de referencia antropomórfica o decorativas a lo Henry Moore, para subrayar así la claridad abstracta de sus edificaciones"101. De nuevo, la arquitectura debiera estar al servicio del arte.

Diez años más tarde, en 1992, Juan Muñoz se pregunta mientras analiza el Museo de Mérida de Rafael Moneo “¿qué es un museo? un espacio que da unidad a algunos fragmentos de

98 O’Doherty, Brian, Dentro del Cubo Blanco: La ideología del espacio expositivo, Cendeac 2000.

99 Ibíd. p43

100 Ibíd. p.45

101 Ibíd. p.45 
historia que no guardan relación entre sí, los acerca, y al hacerlo intenta darles sentido, crear una unidad ilusoria"102 Su visión de museo no ha cambiado desde su definición anterior de 1982. Para el catálogo de una exposición en Zurich en 1996 escribe el texto Rein, I am sitting in this train Station. A continuación en un fragmento de este texto, Juan Muñoz escribe sobre la intencionalidad de individuos o colectivos de representar ciertas ideas sobre su presente, y que se muestran en los museos que recopilan fragmentos de momentos que fueron presentes:

"Un museo es como un recipiente, una especie de cápsula del tiempo en movimiento, un lugar donde se depositan momentos actuales $<<$ el ahora es el ahora perfecto>>..." "Estoy contemplando tu tren de pensamiento, mi tren...Percepción...<<el ahora $>>$ en cuanto futuro aplazado indefinidamente. ...Lo único que puedo ver desde la ventana de un museo es la adición de momentos pasados, una perspectiva o un punto de fuga de un pasado común que se ofrece al espectador como presente...Yuxtaposición...como $<<$ el ahora $>>$...<<el ahora $>>$ como condición de la que no se puede escapar, y el museo, ahora, como la creación de una crítica real, objetiva y necesaria del saber visual recibido, así como la voluntad de reordenarlo...De vez en cuando, distintos grupos de personas deciden que quieren repensar los valores que han heredado...Y no quieren hacerlo reproduciendo opiniones ajenas, si no expresando las suyas propias. No es que aspiren únicamente a crear signos diferenciales; lo que sucede es que esas opiniones adecuadas a sus convicciones necesarias para construir una presencia representativa a partir del presente que perciben...<<el ahora perfecto $>>$ Un instante de sentido...como el otro día en el Museo de Israel de Jerusalén." ${ }^{103}$

Con esta actitud frente al espacio museístico, Muñoz busca romper con esta idea e intenta ante todo llamar la atención del espectador para incitarle a que mire. En la conversación del artista con Lingwood en Mayo del 2001, Muñoz expone su preocupación ante la actitud de los visitantes de los museos describiendo la experiencia como si se tratase de un paseo a lo largo de una calle moderna. Le recuerda a la idea de galería comercial de Walter Benjamin ${ }^{104}$, donde la gente pasea delante de objetos de lujo que seguramente no puede

102 Muñoz, Juan, Rein, I am sitting in this train Station, Juan Muñoz: Escritos/Writings. Construyendo imágenes: Juan Muñoz. Barcelona, Editado por Adrian Searle, Ediciones de la Central, MNCARS, 2009, p.155 103 Ibíd. Rein, I am sitting in this train Station p.267

104 Benjamin, Walter, Libro de los Pasajes ,1950. 

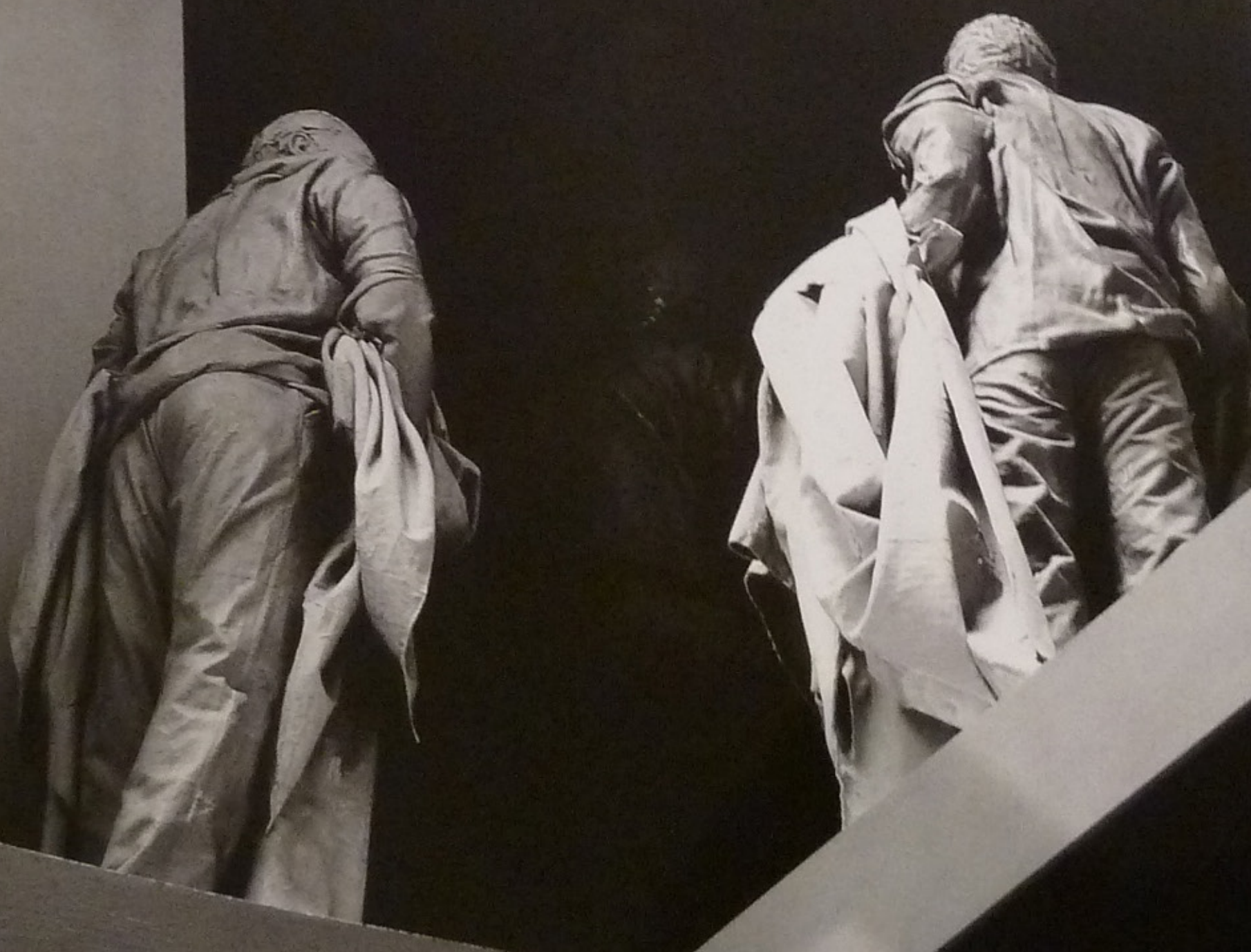


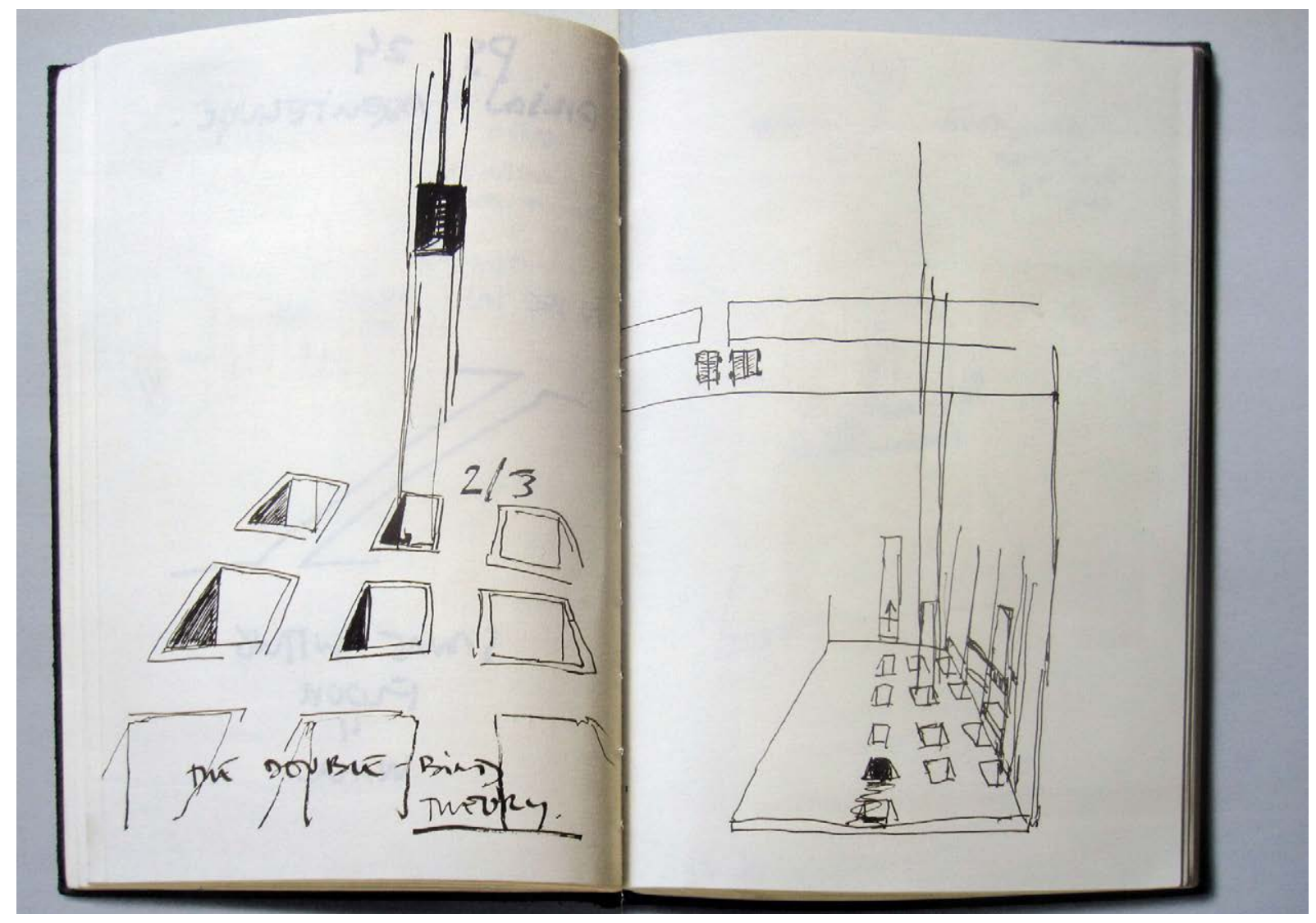

Double Bind. Cuaderno de notas del artista. 2000-2001

comprar. Juan Muñoz se ve como el creador de estos objetos que se exponen en la galería, y ante esta posición lo que busca es crear una experiencia en donde el espectador se sienta como si fuera el único que está en el espacio, individualizando el acto de mirar, impidiendo así sentirse entre una multitud que mira un objeto y estableciendo una relación directa entre la obra y el observador ${ }^{105}$. "La gente camina los museos con una cierta indiferencia a lo que ven, en este caso era frenarles un poquito y hacerles que se detuvieran y que miraran con cuidado"106

A mediados del siglo XX almacenes, lofts y fabricas comienzan a transformarse en espacios expositivos. El minimalismo promovió el auge de nuevos formatos expositivos más allá de

105 Muñoz, Juan, Lingwood, James, A Conversation, May 2001 en Juan Muñoz. Double Bind at Tate Modern, Tate Modern London, Tate Publishing, 2001. pp.72-73

106 Arranz, Manel y Solana, Anna. Documental Imprescindibles - Juan Muñoz, poeta del espacio, 2014, Imágenes y declaraciones de Juan Muñoz grabadas en el Centro Gallego de Arte Contemporáneo en Santiago de Compostela en 1996. Comentario del artista. 
los espacios gubernamentales y las salas de paredes blancas, parecía razonable que si el arte se creaba en nuevos espacios (como fue el caso de los lofts en el SoHo neoyorkinoen los años 60) tuviera cabida un espacio expositivo distinto al tradicional ${ }^{107}$. Al mismo tiempo surge la cuestión de la contextualización y la localización de las obras que en el caso del arte minimalista pasa a formar un papel fundamental en el modo en que se percibe la obra. Como indica Hal Foster, Michael Freid en su ensayo Art and Objecthood (Arte y Objetualidad) la experiencia de "teatralidad" que Freid ve de manera negativa como una aportación del arte minimalista se potencia en este tipo de espacios industriales, donde el arte no crea imagen, sino que propone obras que han de ser experimentadas y donde el espectador tiene un papel fundamental. El entorno, el tiempo y el movimiento del observador pasan a formar parte de la experiencia de la percepción de la obra. Artistas como Richard Serra, Carl Andre, Robert Smithson o Michael Heizer, cuyas obras Muñoz estudiaba, tuvieron un importante papel en las cuestiones de la contextualización de la obra. Juan Muñoz no pierde de vista la importancia del emplazamiento del observador a la hora de contemplar la obra de arte, y le obliga a ubicarse en distintas posiciones, y a contemplar la obra desde determinados puntos de vista, requiriendo una peregrinación del sujeto. La localización del individuo determina la percepción de la obra. Juan Muñoz lleva al limite este concepto, incorporando en engaño mediante juegos de ilusiones ópticas de las que hablaré más adelante.

Double Bind tiene una carga escenográfica, pero diferente a aquella descrita por Freid. Al contrario que en el minimalismo, el espectador en movimiento no es el que activa el espacio. El complejo escultórico genera una dinámica por sí mismo, que incluso contiene movimiento (los dos ascensores que sube y bajan). Invita al espectador a recorrer ese espacio, y a observarlo desde distintos puntos de vista. La participación del espectador no completa la obra, sino que establece relaciones de extrañeza entre la obra y el espectador que invade sus límites al recorrerla. Para entrar en el debate de la cualidad escenografía de Double Bind es necesario definir la relación entre el espacio arquitectónico de la galería y la obra.

107 Foster, Hal, El Complejo Arte-Arquitectura, Turner, 2013, p.143 
El espacio ofrecido a Juan Muñoz para su instalación dista mucho de su concepto de museo como institución gubernamental, ese espacio de "entretenimiento especializado"108 al que se refería Robert Smithson, y que Allan Kaprow definía como "mausoleo". La localización viene dada, el encargo tiene como requisito colocar una instalación en la sala de turbinas. No es la primera vez que expone en entornos fuera de la galería de arte, su obra había sido expuesta tanto en espacios públicos y abiertos como en jardines o naves industriales. En el caso de la Tate Modern, el espacio tiene una escala imponente, no está concebido como una sala de exposiciones tradicional, conserva su volumetría original y presencia industrial. Este espacio en el museo también parece responder a las necesidades del arte contemporáneo de ofrecer espacios de muy amplias dimensiones y gran flexibilidad espacial. Muñoz describe este espacio como exterminador ("killer") y finalmente lograra con su instalación que quede dominado por la escultura que lo ocupa ${ }^{109}$.

En el catalogo de la exposición de 1982 “Correspondencias: 5 Arquitectos, 5 Escultores” de la que Juan Muñoz es comisario junto a Carmen Gimenez, Richard Serra habla de la obra concebida para un sitio concreto, y de la problemática de el lugar no neutral "todo contexto tiene su marco y sus alusiones ideológicas" añade "Uno de los problemas básicos que se plantea en cualquier contexto (el paisaje urbano o arquitectónico) es el problema del contenido. La relación entre el contexto y el contenido es semejante a la paradoja de la gallina y el huevo. Para que sea eficaz, mi obra tiene que liberarse del contenido que ya existe en el lugar elegido"110. Este es el problema al que se enfrenta Juan Muñoz en la Tate Modern, un lugar con un fuerte lenguaje arquitectónico y una volumetría dominante a la que ha de imponer una obra de tal manera que el lugar quede redefinido, asimilando lo existente y proponiendo un cambio radical en la percepción de un espacio existente. A

108 Ver Smithson, Robert and Kaprow, Allan, What Is a Museum? 1967

109 En Junio de 2015 se presenta de nuevo Double Bind por primera vez desde su instalación en 2001. Una exposición llamada "Double Bind \& Around" comisariaza por Vicente Todolí en el Hangar Biccoca de Milán. La instalación se había conservado integra en el Estate de Juan Muñoz. En una de las grandes naves del Hangar se reconstruye mediante una plataforma el forjado o medio nivel que queda suspendido en la estructura existente de la nave. Unas escaleras de andamiaje permiten acceder a la parte superior. Se suprimen las columnas en el piso inferior. Los huecos se distribuyen conforme a la nueva estructura del forjado, y los ascensores se localizan en posiciones similares a la original, siendo su viaje mucho mas corto debido a la altura de este espacio. La fuerza de la instalación continua inquebrantable en este espacio cegado a la luz natural. Se concluye que un espacio industrial es el volumen idóneo para reproducir la obra. 110 Serra, Richard, Richard Serra en Correspondencias:" 5 Arquitectos, 5 Escultores". 1982. p. 88-91 
Juan Muñoz no le interesa que su obra se entienda como un objeto aislado en un espacio, su intención es la de transformar el espacio hasta convertirlo en su totalidad en el mundo que él quiere crear. No busca una integración, ni un dialogo entre dos estructuras, busca apoyarse en el contexto para crear un contenido. Serra defiende la autonomía de la obra respecto a la localización, creando un paradigma entre la independencia de la obra y su vinculación al entorno. Este paradigma se da en Double Bind, donde lo escultórico participa de lo arquitectónico, pero al mismo tiempo no depende de él, sino que lo define recalificándolo. Se crea una estructura escultórica de escala arquitectónica con un fuerte sentido escenográfico.

Como he referido en La memoria y Juan Muñoz, el título de esta obra, Double Bind, es un término con el que Juan Muñoz se familiarizó a raíz de la enfermedad de su hermano, y aunque el escultor explica que no existe vinculación directa entre este hecho y el título de la obra, es interesante explicar el enunciado de la teoría del "doble vinculo o doble lazo" del científico Gregory Bateson ${ }^{111}$ que intenta abordar la problemática de la vinculación madre/hijo que subyace en la esquizofrenia, en correspondencia con las contradicciones informativas que se producen en su comunicación diádica. Bateson y su equipo abordan un nuevo concepto del trastorno mental como trastorno de la comunicación interpersonal. Comenzaron a interesarse por cómo la identidad y la función del sistema de autorregulación de la persona se mantiene a través de mecanismos de información, control y feedback. La hipótesis de double bind y el dilema esquizofrénico se muestran como un continuum de la experiencia de comunicación humana que está envuelta en relaciones intensas y en la necesidad de discriminar entre las órdenes del mensaje. La esencia de su enorme y singular contribución en el campo de la terapéutica se encuentra contenida en "Hacia un Teoría de la Esquizofrenia”. La hipótesis esencial de la teoría del double bind es que la "víctima" se encuentra a sí misma en una matriz comunicacional en la que los mensajes se contradicen entre sí, la contradicción no puede ser comunicada y la persona no es capaz de abandonar este campo de interacción. Los componentes críticos de esta situación son: dos o más personas una de las cuales se designa como "víctima". Repetición de la experiencia.

111 Ver Bateson, G., D. Jackson, J. Haley,and J. Weakland, 'Toward a Theory ofSchizophrenia', Behavioural Science

1 (1956), pp251-254. In Bateson, G.1972. Steps to an Ecology of Mind: a Revolutionary Approach to Man's Understanding of Himself. New York: Ballantine Books. 
Una orden primaria negativa cuyo contexto incluye una amenaza de castigo. Una orden secundaria en conflicto con la primera, más abstracta y que incluye metamensajes. Una tercera orden que prohíbe a la "víctima" escapar de este campo de influencia. Esta situación repetida conduce a la incapacidad del individuo para discriminar de forma lógica cómo debe asumir los mensajes.

Más de cincuenta años después, la hipótesis del doble vínculo de Bateson y su equipo, continúa ofreciendo motivos para profundizar y reflexionar. ${ }^{112}$

112 Ver Gibney, Paul, The Double Bind Theory: Still Crazy-Making After All These Years, Psychotherapy in Australia, Vol. 12, N. 3, May 2006. 


\section{EL CIELO}




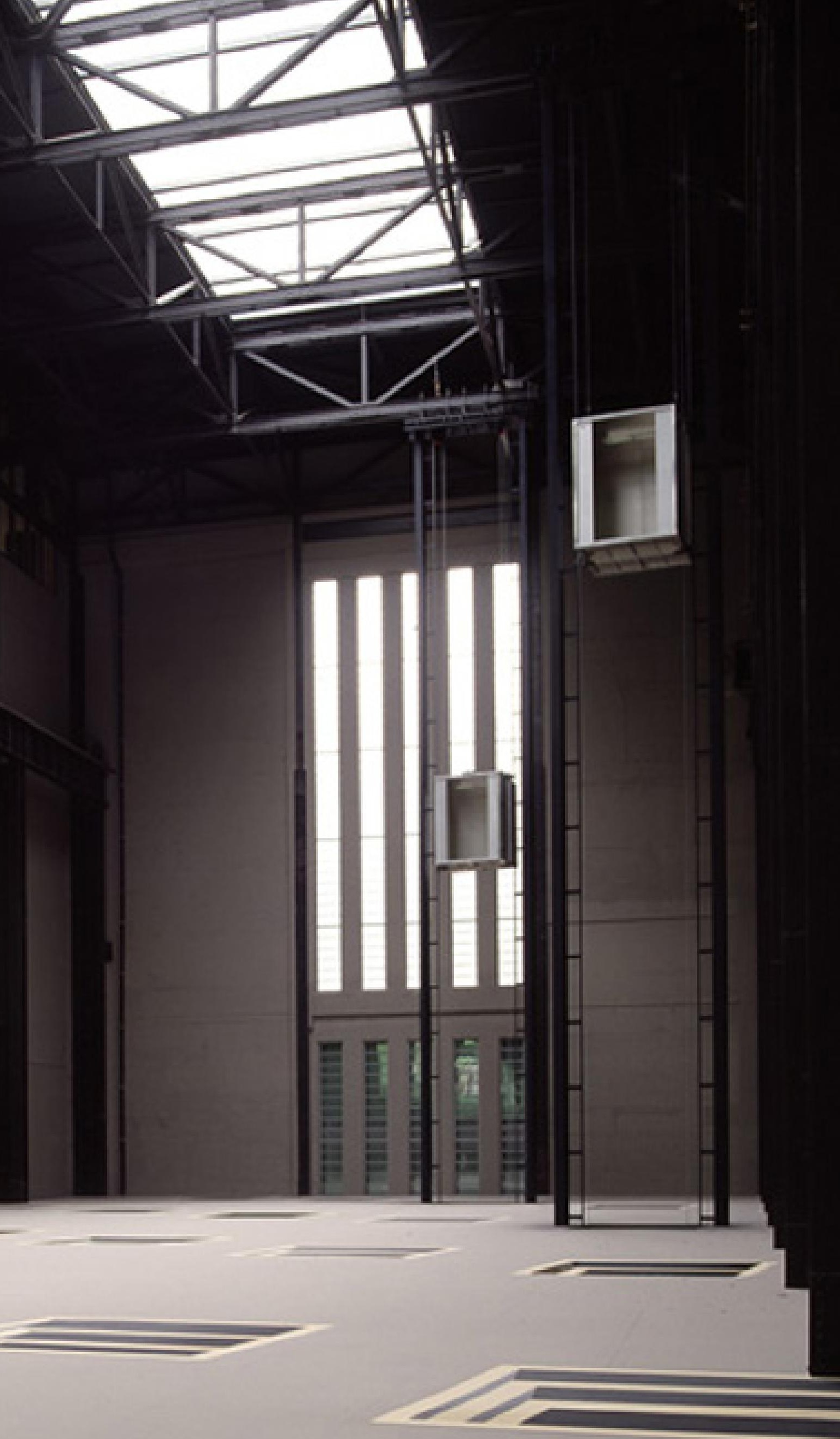


“...siamo usciti fore...al ciel ch'è pura luce...”

Paradiso Canto XXX. Dante Alighieri Divina Comedia.

Las catedrales góticas fueron además de un símbolo del progreso en el medievo, una expresión tangible del pensamiento teológico, que por medio de la técnica, orientó hacia el cielo el espacio interior que contenía. Representaban el cielo. Además de su condición constructiva, contaban también con la simbólica. Si las iglesias románicas con su materialidad están cercanas al Jerusalén Celestial del Apocalipsis como ciudad o fortaleza, las góticas lo hacen como cielo o paraíso. Los autores medievales utilizan términos como lux, claritas o splendor cuando hablan de ellas tanto como conceptos estéticos como teológicos.

Santo Tomás cuenta cómo el paraíso o cielo empíreo es uniforme e inamovible y que allí es donde están los bienaventurados, cuya belleza reside en la luz. La bienaventuranza consiste en ver y contemplar la claridad de la esencia divina, en el espacio encontrado 
en las altas catedral góticas. Los fieles medievales cuando asistían al oficio en la catedral tenían necesidad de ver, de contemplar ${ }^{1}$.

La mitología griega sitúa en los Campos Elíseos a los guerreros más valientes y a los hombres virtuosos que llevan una vida dichosa y feliz. El concepto que aparece en el Antiguo Testamento fue importado por los judíos desde el zoroastrismo. Para los cristianos el cielo es el jardín del Edén donde está Dios y donde reina el gozo, la paz y felicidad infinita. Dante Alighieri en la tercera de las cánticas de La Divina Comedia describe el paraíso como el lugar al que se accede al finalizar el paso por el purgatorio y su estructura se basa en las cuatro virtudes cardinales: prudencia, templaza, justicia y fortaleza y las tres virtudes teologales: fe, esperanza y caridad y se organiza en nueve esferas asociadas a astros donde localiza las virtudes y los pecados del hombre.

Como podemos ver en distintos momentos, el cielo es entendido como un lugar al que el hombre no tiene acceso desde su condición física pero que puede contemplar como destino al que llegar según sus actos. Su verticalidad hace que la mirada se eleve hacia lo alto con la esperanza de encontrar la virtud y en definitiva la presencia de Dios. Se mira hacia el lugar, inaccesible, y se hace desde fuera, desde el exterior.

Cuando se llega a la pasarela central de la sala de turbinas de la Tate Modern, no queda otra opción que pararse a contemplar el espacio vacío que Muñoz muestra ante nosotros, delimitado por un inmenso plano gris y las paredes de la central construida por Scott. La luz entra por los huecos rasgados de los laterales y los lucernarios sobre la cubierta. Las proporciones son tales que no es difícil pensar en las la nave central de una catedral. ¿Acaso no encontramos los elementos que nos llevan a pensar en el cielo de Santo Tomás? Dos ascensores marcan aún más la verticalidad de la sala y el ritmo de un tiempo que parece parado en la contemplación desde el exterior, desde la barandilla, que nos impide penetrar en él. En cierto modo, este es el cielo.

1 Fernández Arenas, A., La imagen espiritual de la catedral gótica, Tierras de León: Revista de la Diputación Provincial, Vol. 4, № 5, 1964, pp. 83-98. 


\subsection{En una plaza ${ }^{2}$}

"Suelo. Lo repito aquí, en este suelo que no ha llovido nunca. Un paisaje lleno de pozos, agujereado, esos diminutos agujeros como piedras colocadas unas sobre otras. Indicaciones para el caminante. También es cierto que nadie se ha caído"

Monólogo del ventrílocuo (1995), Juan Muñoz ${ }^{3}$

Como antes se explicó, un denso plano de color gris cubre el espacio que se extiende entre la pasarela central y el perímetro de la gigantesca sala. El visitante ha entrado en ella a través del hueco horizontal que los arquitectos suizos abrieron en la fachada este y avanza bajando la rampa del mismo modo que lo haríamos orientados en una iglesia. Una vez en el centro la oscuridad hace que subamos por una escalera a la plataforma central desde la que se abre a nuestros ojos la gran plataforma. Como si de un cuadro tumbado en el suelo se tratase, sobre el fondo gris se disponen veintidós formas geométricas que juegan a engañar a quien hasta allí ha llegado. Una barandilla separa la realidad de la ilusión , como si uno se asomase a una extensa llanura desde la que contemplar el cielo.

En el plano no hay figuras o escala. De sendos agujeros emergen dos cajas que se deslizan sobre dos guías verticales y que pretenden alcanzar el techo de la sala. Como las ciudades que fueron abandonadas, parece como si el tiempo se hubiese detenido y sólo estas dos cajas mantuvieran su movimiento ascendente y descendente, arriba y abajo... La emoción que produce la escena vacía establece una relación entre el espacio y el espectador desde la ausencia de elementos ${ }^{4}$.

Como en los cuadros de De Chirico, reduce la presencia a algunos elementos ordinarios que pierden su condición original al ser aislados del medio en el que solemos verlos. Los cuadros del italiano se organizan como escenas urbanas vacías donde elementos como arcos, columnas, templetes o chimeneas recrean un paisaje de una ciudad vacía sin rastro

2 Muñoz, Juan, En una plaza en Juan Muñoz: Escritos/Writings. Ediciones de la central. Barcelona, 2009 p. 145. Publicado por primera vez como Auf einem Platz. Weitersehen (1989-1990), Museen Haus Lange and Haus Esters, Krefeld, 1990 (exh. cat.)

3 Muñoz, Juan. Monólogo del ventrílocuo en Juan Muñoz: Escritos/Writings, Ediciones de la Central. Barcelona, 2009 p. 101.

4 "Si retiras todas las figuras, todas las camas y todo de Delvaux quizás te encontraras con algo" en Muñoz, Juan, Lingwood, James, Una conversación, Enero, 1995 en Monólogos y diálogos, MNCARS, 1997 p. 124. 


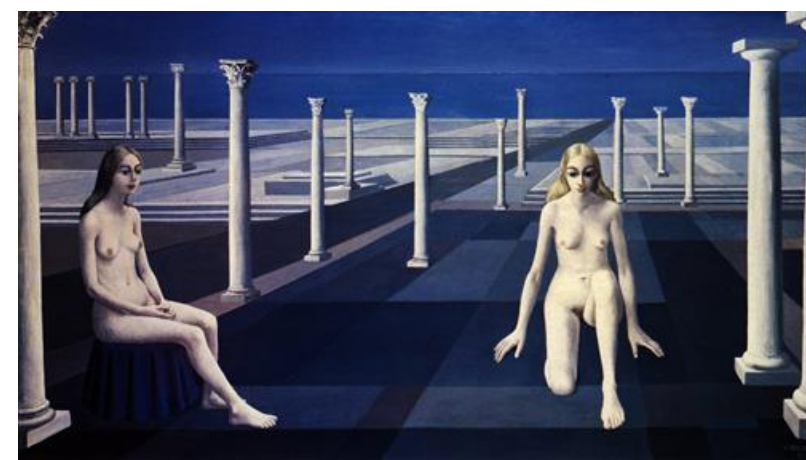

Dialogue, Paul Delvaux, 1974.

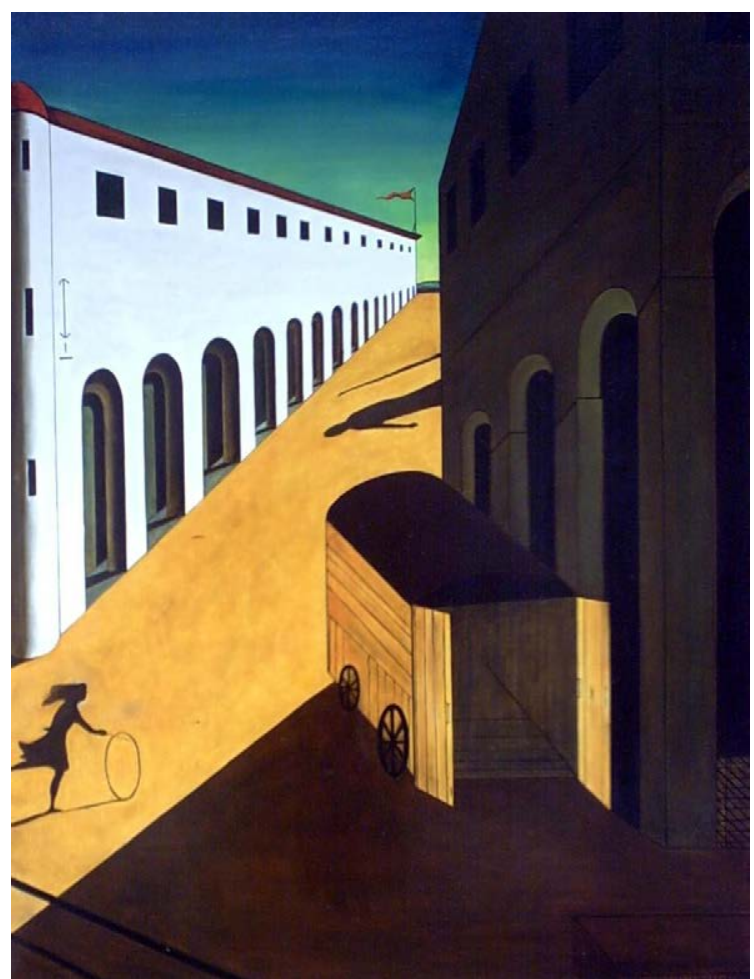

Mystery and Melancholy of a Street by Giorgio de Chirico, 1914

de la presencia del hombre. En ellos y en el espacio sobre la plataforma de Muñoz, parece que surge un sentimiento de nostalgia por el ilusionismo clásico que llega a convertirse en surrealista. Sin caer en el clasicismo del lenguaje con el que trabaja De Chirico, Muñoz trabaja con elementos geométricos. Con ellos genera una atmósfera onírica. El vacío se da en torno a la plataforma donde se dibujan los huecos geométricos, y sobre el espacio vacío de la sala dos únicos elementos verticales dan buena cuenta del espacio al que el espectador no le es permitido acceder.

Una barandilla que corta transversalmente la sala a la altura de la plataforma impide el acceso a ésta. Muñoz se la encuentra ya en la sala, pero con la instalación, su condición cambia del mismo modo que lo hacen otros elementos de la sala como las perforaciones del fondo, las vigas perimetrales o las cerchas. La instalación absorbe el lenguaje y la forma de los elementos que conforman la sala, los hace parte de ella, en el caso de esta barandilla, de una manera muy activa. Casualmente, es muy similar a aquellas Primeras Barandillas (First Banister, 1987) que Muñoz instalaba sobre una pared lisa. Las barandillas, objetos 


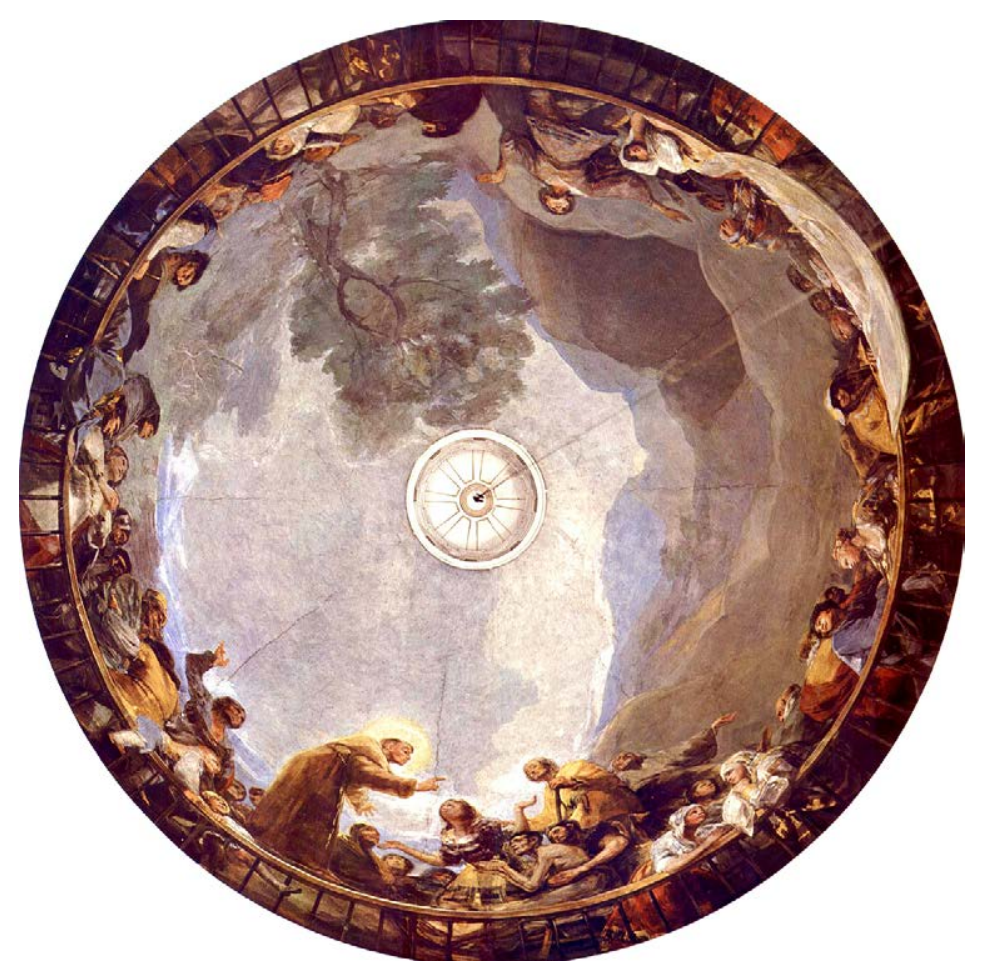

Ermita de San Antonio de la Florida. Francisco de Goya y Lucientes, 1798.

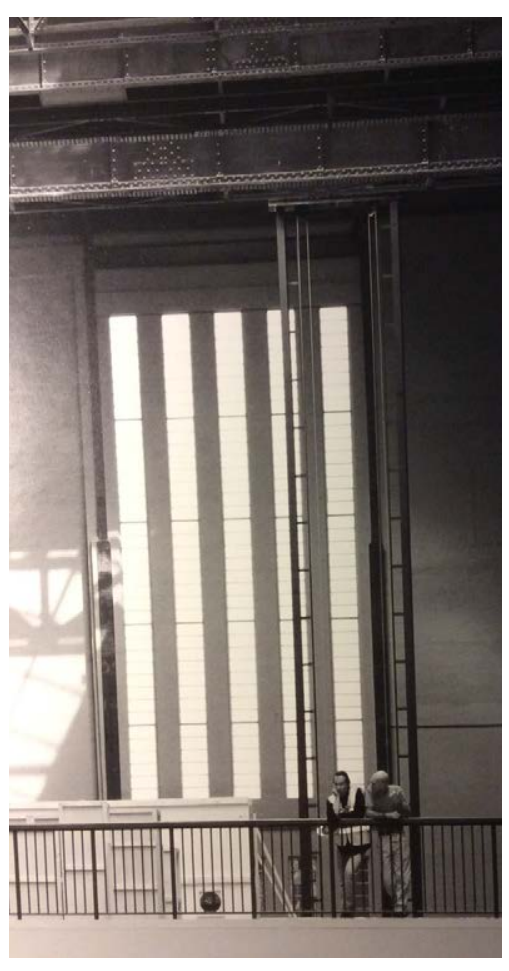

Juan Muñoz en la Tate Modern durante la instalación de Double Bind, Londres, 2001.

ordinarios que implícitamente aluden a la presencia humana. En los años ochenta, Muñoz comienza a trabajar con balcones como elementos urbanos que, a través de la descontextualización pierden su condición significativa para convertirse en elementos escultóricos ${ }^{5}$. La barandilla de los suizos en el turbine hall puede entenderse ahora como el balcón que Muñoz crea a partir de este elementos funcionales de protección y que le sirve ahora para asomarse al vacío. Del mismo modo en que Goya pinta a las majas y los chisperos en la cúpula de San Antonio de la Florida, asomándose al cielo para ver el milagro del santo, los personajes se asoman con gran realismo en el perímetro de la cúpula asomando sus cuerpos sobre una barandilla que se enfatiza por la perspectiva vista desde abajo. La barandilla se transforma así en la línea que separa lo terrenal de lo divino , lo medible de lo infinito, y lo accesible de lo que no lo es.

5 Observación hecha por Sheena Wagstaff en Un espejo de la conciencia en Juan Muñoz. Permítaseme una imagen. Turner, MNCARS, Madrid, 2009, p.27. 
El plano abstracto que continúa el nivel donde nos asomamos desde la barandilla a ese espacio tiene algo de urbano. El escultor procura un inmenso suelo en el que no se puede entrar, que se convierte en el horizonte, creando una imagen cargada de ausencia, obligando al espectador a quedarse fuera de él. El único punto de observación desde la barandilla produce una perspectiva que recuerda a los estudios que los pintores del Renacimiento hacían para representar la realidad. Una perspectiva con un marcado punto de fuga central a la altura de los ojos del observador. La retícula de huecos en el suelo no sigue la geometría de la sala sino que aparecen rotada, sin ser perpendicular a las paredes. Se enfrenta aquí la geometría de la sala, que es paralela al espectador, con un único punto de fuga. Los elementos que Muñoz añade, cuya posición respecto al espectador es oblicua, producen entonces dos puntos de fuga, estableciendo así la relación diferencial entre lo encontrado en la galería y lo añadido.

En la propuesta del concurso que ganan los arquitectos suizos, el turbine hall mantiene su condición de gran vacío en el edificio conservando sólo los elementos estructurales y añadiendo apenas algunos volúmenes que se asoman desde los niveles de las galerías. Muñoz utiliza para las guías de los ascensores una estructura de acero pintada de negro que ya había utilizado antes en otros proyectos. Parece que juega al despiste con el espectador al hacerla participar en el lenguaje del resto de elementos estructurales diseñados por Scott para la sala. Pero al fijar la mirada con un poco más de detalle en cómo esta nueva estructura viendo como en las cerchas originales, el visitante pronto comprueba que no forman parte de la sala original. Recurre a una estructura igual a la que había estudiado para diversas obras a mediados de los ' 80 , pero en una escala mucho menor. Esta pieza forma parte de la instalación A Place Called Abroad (Dia Beacon of the Arts, NY, 1996), donde aparece escondida entre muros, produciendo un cierto desconcierto en el espectador, por su localización y escala, y la curiosidad de comprender si es capaz de cumplir con la función que se le supone: ser un elemento dinámico de transporte vertical, que une generalmente al menos dos puntos, con el fin de transportar a alguien de uno al otro. En uno de los dibujos de su cuaderno de notas, hace un esbozo del ascensor que presentó en el Dia Centre of the Arts, y anota: 'Ascensor Dia. Usar cerca de una ventana de primer piso. Como memoria personal'. La memoria personal revive una experiencia propia relacionada con el yo consciente. Gadamer señala la importancia de volver atrás: "Hay entonces que volver la vista atrás. Pues toda mirada hacia atrás, hacia la profundidad 


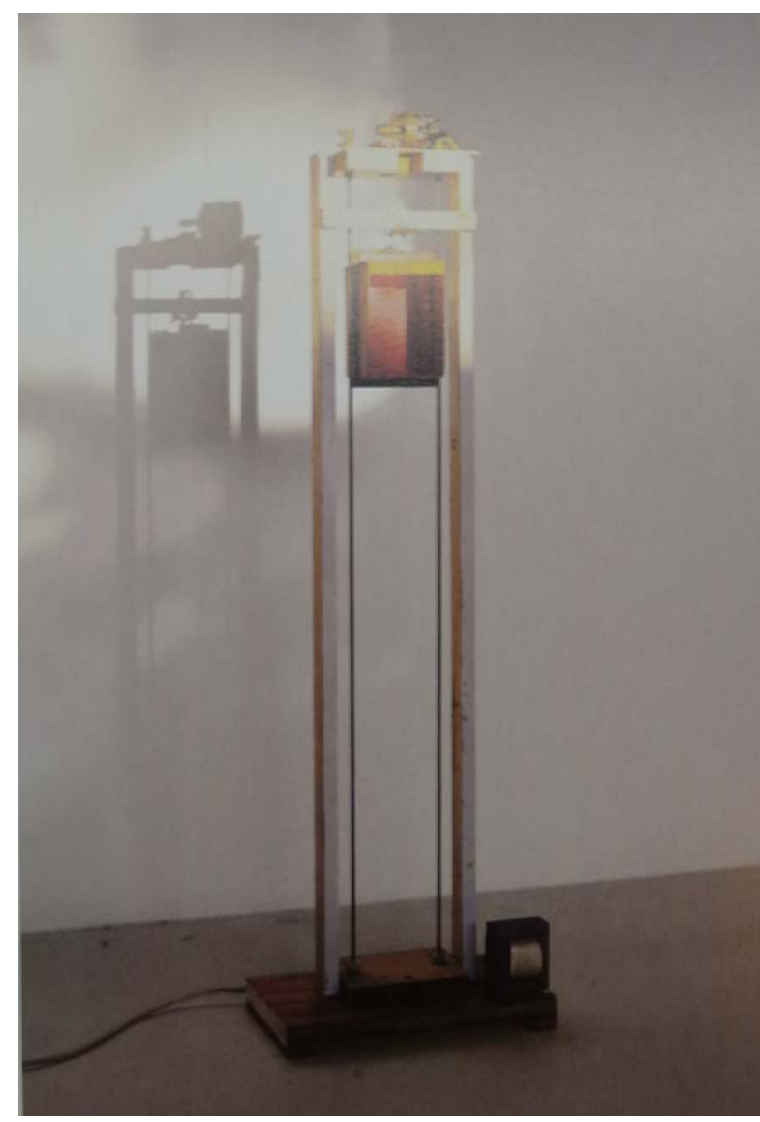

Elevator, Juan Muñoz, 1996.

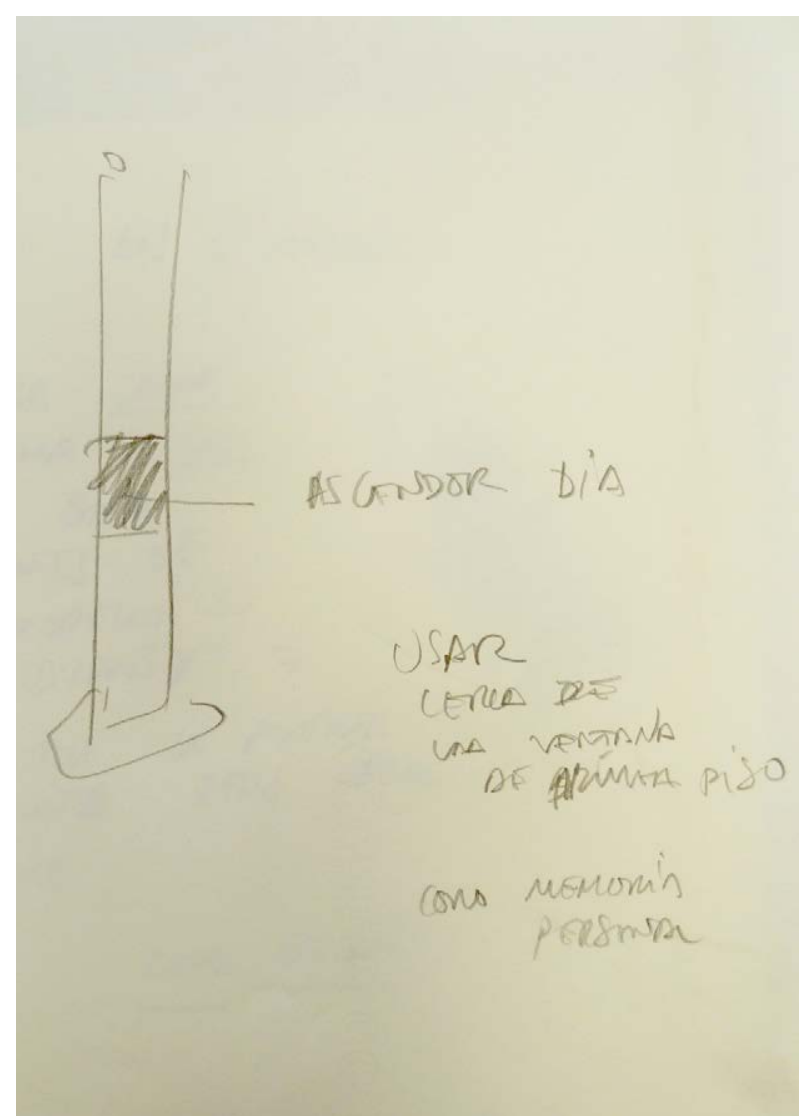

Cuaderno de notas del artista n¹9. 2000-2001 Cortesía del Estate de Juan Muñoz

histórica de nuestro presente, profundiza la conciencia del horizonte conceptual dispuesto hoy en nosotros." ${ }^{6}$ Muñoz no pretende que el espectador relacione el ascensor del Dia, con el que aquí presenta, pero sí que voluntariamente se propone hacer una reproducción del que allí presento, profundizando en su propio pasado.

Utilizando unos materiales que se adaptan al entorno de la Tate Modern, busca tanto en la forma como en el fin, el ascensor de su obra pasada, ahora a mayor escala, en correspondencia con el espacio de esta nueva instalación. Tomo prestadas algunas frases entresacadas del texto de Muñoz: Ilusionismo, percepción, proyecto $^{7}$, donde hablando de la percepción, centrándose en el muñeco del ventrílocuo escribe unas palabras que bien podrían describir la decisión tomada por el artista al repetir el elemento del ascensor en esta obra '...traer a la memoria lo ausente o repetir el mismo gesto que nada significa

6 Gadamer, Hans-Georg, Estética y Hermenéutica, Tecnos/Alianza, 2006, p.85.

7 Muñoz, Juan. Ilusionismo, percepción, proyecto en Juan Muñoz: Escritos/Writings, Ediciones de la Central. Barcelona, 2009, p. 71. Publicado por primera vez en Sur Express, 1, 15 Abril-15 Mayo, 1987, p. 35. 
ahora, en la confianza de que algún día significará. Aun sabiendo que lo que signifique será completamente distinto'. Insiste en el material que conoce, con el que ya ha tratado, pero trabaja su materialidad, y lo que es más importante en potenciar su poder narrativo.

Muñoz juega al despiste con los ascensores, del mismo modo que lo hace con los huecos en el plano gris abstracto. ¿Son huecos o son pinturas? ¿Los ascensores atraviesan el plano, o forma todo parte de una ilusión óptica? La técnica del trampantojo, utilizada por los artistas y arquitectos para conseguir engañar el ojo del espectador, se trae aquí para provocar al que se asoma desde la barandilla la sensación de lo que no es, o de ser de una manera distinta, al igual que los personajes que se asoman en la cúpula de Goya .

En Minarete para Otto Kurz ${ }^{9}$ de 1985 Muñoz coloca una alfombra sobre la que apoya el minarete , cambiando la visión que tiene de la misma "para mi el minarete también tiene otra dimensión; la alfombra era como el plano de una ciudad. Desde la primera vez que instalé la obra en mi estudio tuve la sensación de que la torre oteaba la ciudad"10 ... De nuevo un elemento, en este caso la alfombra, se convierte en lo que dará pie al componente horizontal de muchas de sus obras posteriores a este minarete. Como el escultor comenta en una conversación con James Lingwood en 1996: "Otras voces y otras vidas habitan ciertas piezas, $y$, con el tiempo, hay cosas que surgen de ellas. Creo que sin la alfombra no habría hecho esas piezas de suelo."

Probablemente lo que buscaba Muñoz incluyendo la alfombra bajo el minarete era rematar la obra, situándola sobre un pedestal. "A veces creo que soy capaz de hacer una obra sin una base, su pedestal"11.

8 Argan, Giulio Carlo dice "Una estatua realizada con la pintura tiene, además el prestigio del artificio, del engaño visual " Argan, Giulio Carlo. Renacimiento y Barroco I. Akal, p. 208.

9 Juan Muñoz visitó el Warburg Institute en Londres a finales de los años ochenta en busca de La imagen prohibida en Juan Muñoz: Escritos/Writings Ediciones de la Central. Barcelona, 2009, p. 159. Muñoz leyó el texto introductorio escrito por el entonces director del Instituto E.H. Gombrich de "La Leyenda del Artista" (Madrid, Cátedra, 1991) de Ernst Kris (psicoanalista) y Otto Kurz (bibliotecario del Instituto Warburg entre los años1944 y 1965). Kurz estudiaba la prohibición de las imágenes en el arte y buscaba una imagen que no consiguió encontrar, y que Muñoz planteó encontrar acudiendo al instituto el mismo. A raíz de esta investigación Muñoz denominó su obra El Minarete, explicando en su conversación con J. Lingwood en 1996 que no hay relación directa entre la obra y el título, considerándolo un "título muy privado..., ya que no suelo ir explicando las cosas". Si uno de los personajes del minarete fuera Otto Kurz, le estaría dando una posición alta, como permitiéndole seguir buscando esa imagen prohibida desde lo alto del minarete.

10 Juan Muñoz y James Lingwood. A Conversation. Septiembre 1996 en Monólogos y diálogos, MNCARS, 1997, p. 60 .

11 Ibíd. 


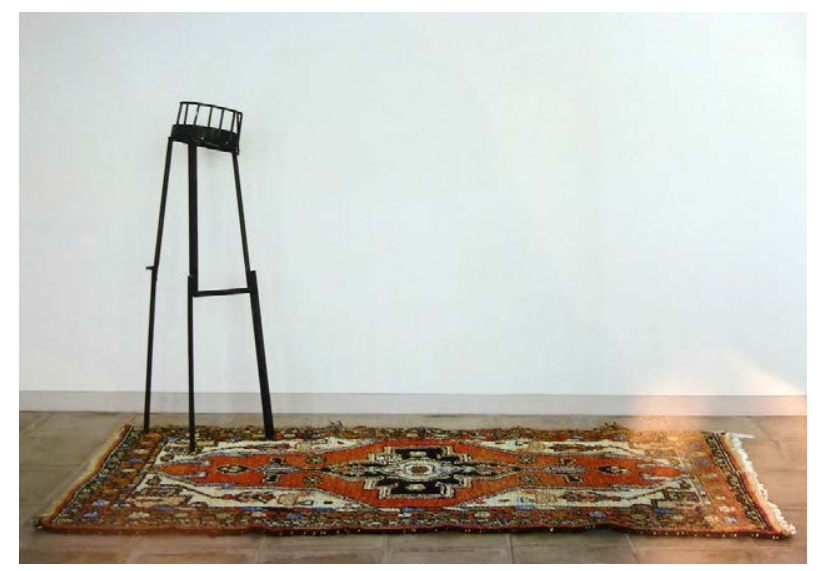

Minarete para Otto kurtz. Juan Muñoz, 1985.

Cuando Hal Foster cita a Serra en referencia a los pedestales en la escultura, dice "el principal avance en la historia de la escultura del siglo XX tuvo lugar cuando se prescindió del pedestal"12. Podemos entender que una vez retirado el pedestal, desaparece el concepto de monumento, y la escultura pasa a tener una relación directa con su emplazamiento estableciendo nuevas relaciones con él.

La idea de la alfombra evoluciona en Muñoz, y en The Wasteland (1986) comienza a incluir los suelos ópticos en su obra. Mediante piezas cerámicas (que más tarde cambiará por planchas de linóleo, más baratas y sencillas de montar) produce una superficie modular creando ilusiones ópticas similares a las utilizadas en los suelos barrocos. La obra se compone de una figura en bronce de un ventrílocuo sentada sobre una repisa anclada en la pared. Este suelo óptico se convierte en el fondo de la pieza, de nuevo una estrategia para reemplazar la base tradicional de una escultura. El suelo separa la figura del muñeco

12 Foster, Hal, El Complejo Arte-Arquitectura, Turner, 2013. 


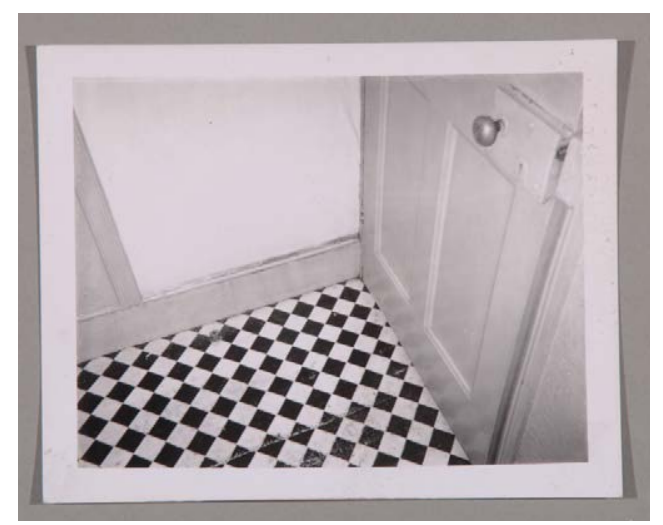

Fotografía tomada por Juan Muñoz. Suelo ajededrezado en Londres. Primeros años de los '80.

Documentación del artista.

Cortesía del Juan Muñoz Estate.

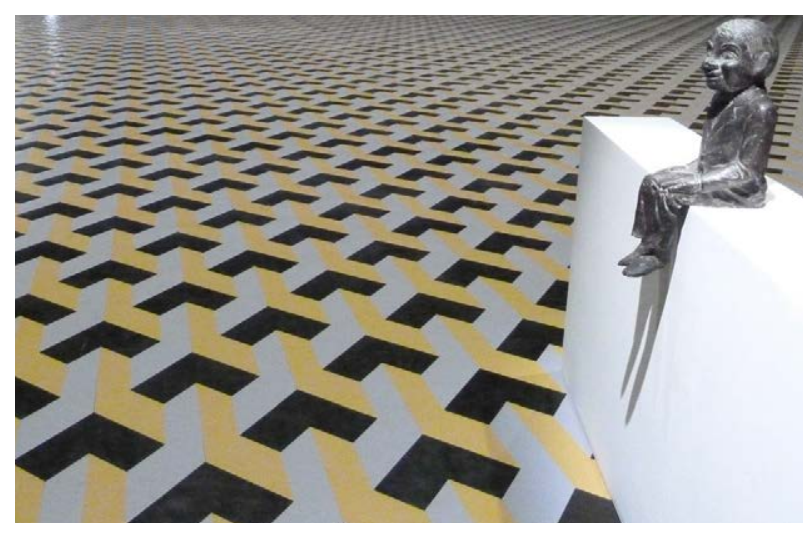

The Wasteland (1987). Juan Muñoz. Hangar Bicocca 2015

del ventrílocuo del espectador que queda contrariado frente al diseño de la superficie. A diferencia de Double Bind, estas piezas de suelo que Muñoz repetirá en varias de sus obras, son extensiones que el espectador puede cruzar, puede entrar en la obra, y acercarse al muñeco del ventrílocuo, convirtiéndose en un elemento participativo. En el caso de Double Bind, vuelve al concepto presente en sus primeras esculturas de los balcones donde se recalca la ausencia de la figura humana. Ya en sus años en Londres Muñoz fijaba la atención en los juegos del suelo ajedrezado frecuente en las entradas desde la calle en las viviendas de Londres, también utilizados en los baños. En uno de sus primeros cuadernos de notas, el escultor guarda una fotografía de uno de estos suelos.

La superficie horizontal tiene una apariencia lisa, dando la impresión de que si el plano cambiara de inclinación, la única manera de permanecer pegado a él seria agarrándose a los huecos, ya que si no, nos deslizaríamos. Parece como si ese plano que tanto usó Muñoz fuese una fachada que ha sido abatida y donde los huecos de las ventanas se tornasen ahora en huecos verticales. Esta sensación que produce en el espectador es de hecho 
un referente para Muñoz al de materialización de este suelo. El escultor fijó su atención huecos de fachadas, que fotografiaba, o recopilaba en revistas y luego recogía, ya girados, en sus cuadernos de notas. En una cuartilla de un hotel de Londres Muñoz escribe "la idea siempre la transparencia de un lado al otro" ... "este frontis copiar para muro Tate". Se fija así en uno de sus viajes en la fachada de un edificio junto al río en Londres que mucho tiene que ver con la Tate Modern, la Battersea Power Station. El cuerpo de la central había sido vaciado, quedando ya sólo la fachada de ladrillo con los huecos. Estos han perdido su condición útil y la fachada sólo mantiene la condición abstracta del plano de ladrillo perforado por una malla de huecos regulares, la abstracción que encontramos en el plano horizontal de Muñoz. En una serie de correspondencias con su amigo Bartomeu Marí ${ }^{13}$ quien le cuenta que en uno de sus viajes encuentra una casa en obras, sin cristales en las ventanas. "Desde la calle se veían los techos de los tres pisos a la vez. Era como mirar debajo de la fachada". Posteriormente le sugiere profundizar en el lenguaje de los elementos constructivos, seguramente para definir con mayor precisión los elementos que podrían posteriormente pasar a definir el espacio de la instalación. Busca un lenguaje arquitectónico que le lleve a lo más profundo de la misma, desde la forma de los elementos principales que mantienen una construcción en pie busca la abstracción. En su carta Mari propone indagar en el lenguaje arquitectónico aspirando a conceptualizar con precisión los elementos arquitectónicos a los que puede hacerse alusión en esta instalación (techo, ventana, columna, soporte, tragaluz, patios...).

Cuando piensa en llevar esta condición a la Tate, no cabe duda de que lo hace sobre el plano gris horizontal, abatiéndolo desde la vertical de la Battersea Power Station a la "alfombra" en la Tate. En Double Bind, ese plano horizontal se torna otra vez fachada, separando lo que bajo ella ocurre del espacio superior. Del mismo modo que cuando caminamos por la ciudad las fachadas aparecen a nuestro paso sin poder tocarlas, Muñoz retiene al espectador fuera de ella para contemplar pues si no fuera así perdería la condición de plano abstracto hacia el que mirar. Los huecos del edificio de Bankinter de la Castellana de Rafael Moneo y Ramón Bescós, la traba del ladrillo para su formación recuerda los huecos de Muñoz en Londres. Y del mismo modo que la fachada del edificio se ve desde

13 Cartas conservadas en el Estate de Juan Muñoz, Septiembre 2000. Bartomeu Marí, (Ibiza, 1966) Actualmente es el director del Comité Internacional de Museos y Centros de Arte Contempóraneo (CIMAM). Entre el año 1996 y el 2002 director del Centro de Arte Contemporáneo Witte de With en Rotterdam. 


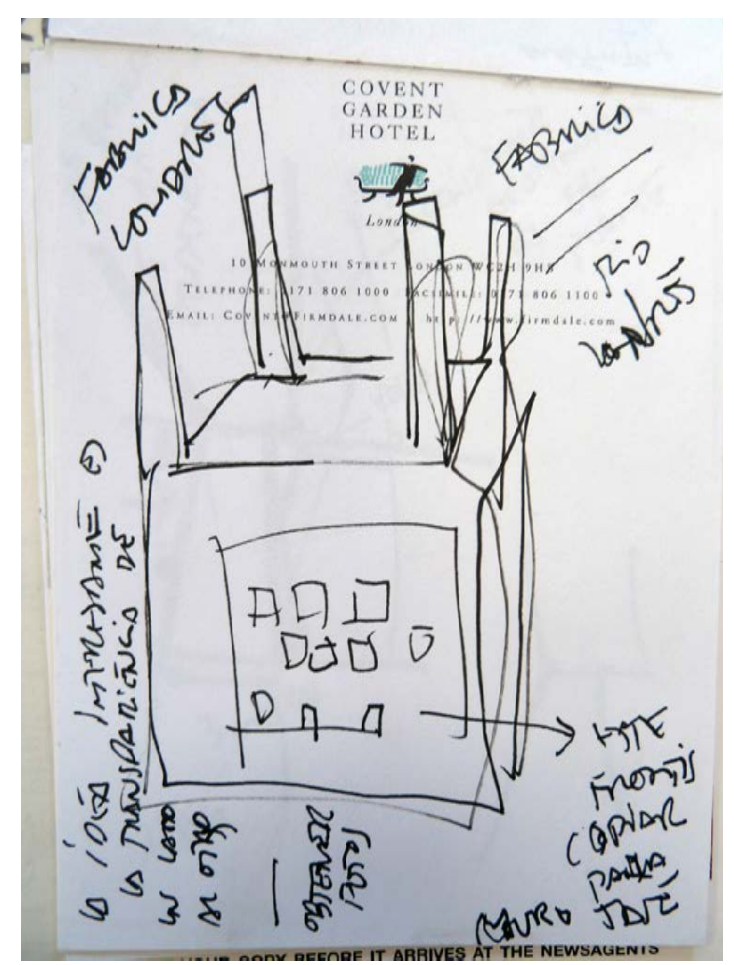

Dibujo de huecos de fachada, Battersea

Power Station. Londres. 2000.

Dibujo del artista.

Cortesía del Juan Muñoz Estate.

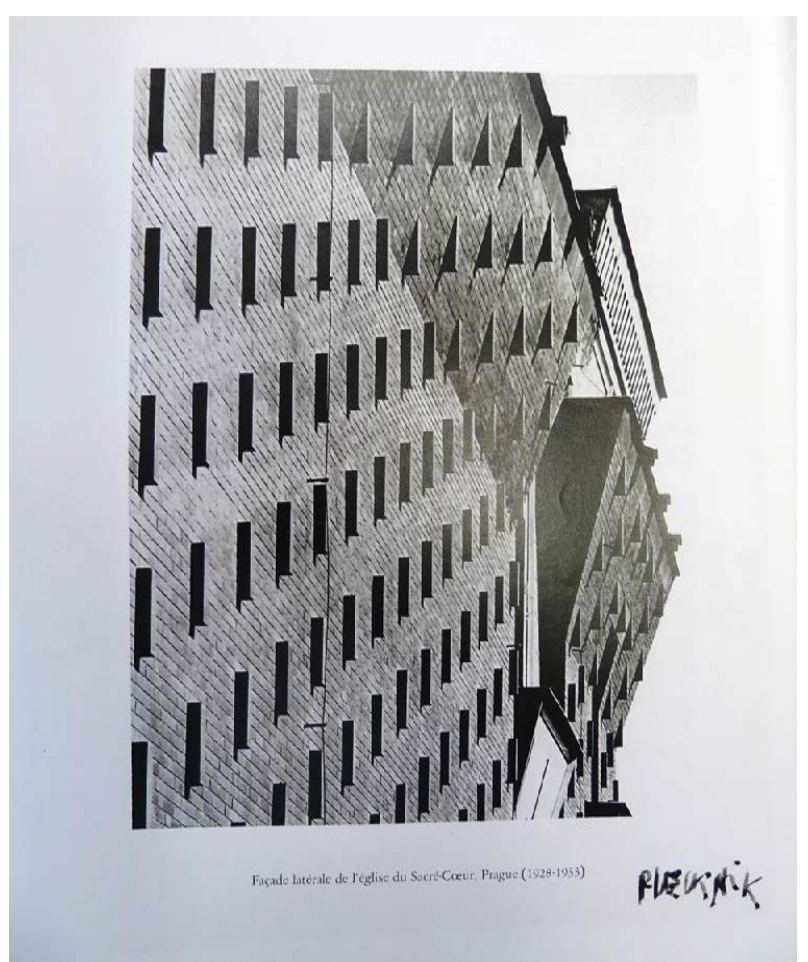

Fotografía (publicación) fachada lateral de la iglesia del Sacre-Coeur (Praga, 1928-1933) Documentación del artista.

Cortesía del Juan Muñoz Estate.

la Castellana, el plano horizontal en la Tate se verá desde la pasarela. Así escibía Muñoz en Construyendo Imágenes: Juan Muñoz ${ }^{14,}$ hablando del Museo de Merida de Moneo "Si se superpusiera el suelo sobre la pared, el ojo del espectador empezaría a dudar." Realizando la operación contraría, Muñoz superpone una retícula relacionada con los huecos de fachada sobre el plano horizontal.

De los veintidós "huecos" que se dibujan en el plano, dos de ellos son traspasados por sendos ascensores. Son idénticos y su movimiento discurre a lo largo de dos guías metálicas que soportan el desarrollo de los cables que suben y bajan toda la altura de la sala. Su posición respecto a las cerchas originarias de la sala hace que arriba se apoyen en una pieza cuadrada que recoge el desfase geométrico entre una y otra.

Dos poleas en la parte superior ayudan en el desplazamiento de las cuerdas metálicas que en la parte inferior se recogen en el cilindro acoplado al grupo tractor, funcionando

14 Muñoz, Juan, Construyendo Imágenes en Juan Muñoz en Muñoz: Escritos/Writings. Ediciones de la central, Barcelona, 2009 p. 155. 


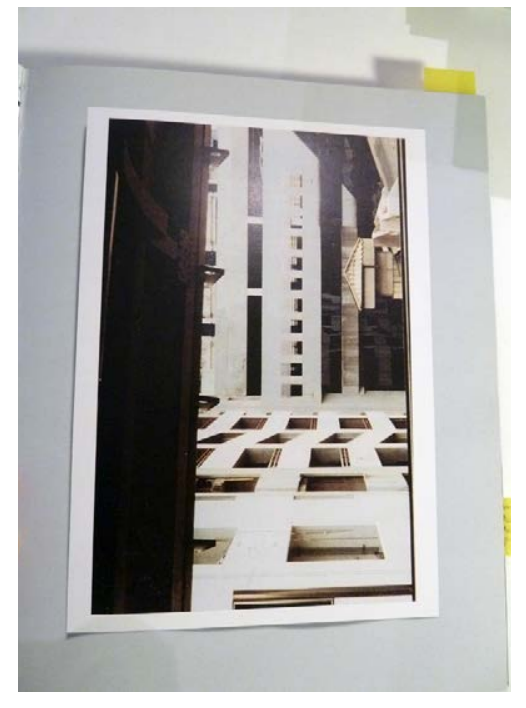

Huecos de fachada. Documentación del artista en preparación a Double Bind.

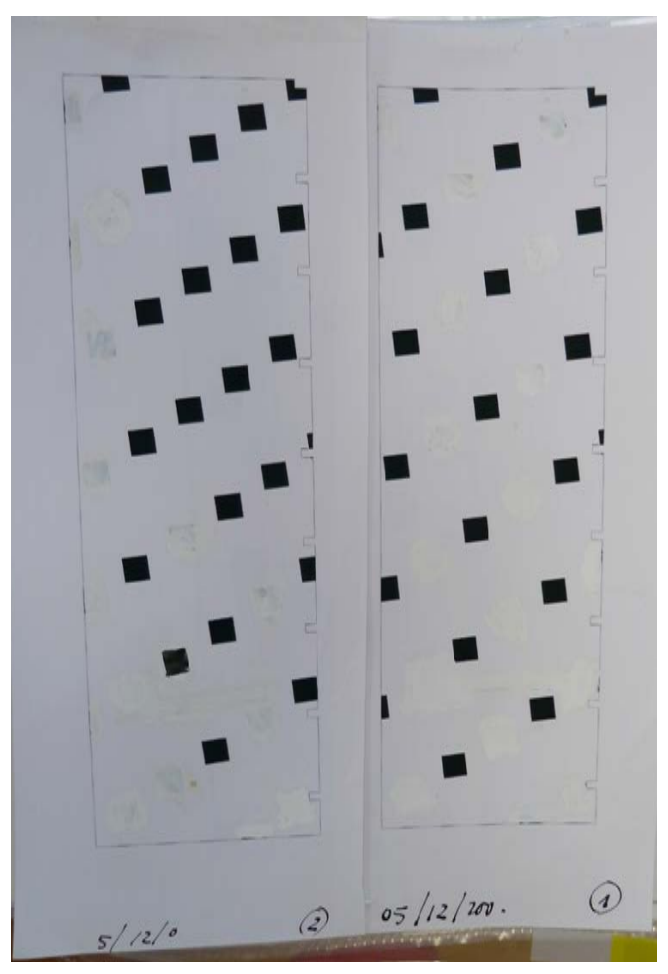

Double Bind. Dibujo de estudio composición de huecos en planta.

Dibujo del artista.

Cortesía del Juan Muñoz Estate.

alternativamente según se trate del ascenso o descenso de la cabina. La cabina del ascensor, de color blanco en su exterior y chapa metálica en su interior queda abierta en su parte frontal. Varios tubos fluorescentes iluminan el interior de la cabina produciendo una imagen en algunos casos destellante debido al color amarillo anaranjado de las luminarias reflejado sobre el metal.

El ascensor es el elemento que rompe con la horizontalidad de la obra. Así como el invento del ascensor moderno para pasajeros de Elisha Otis a mediados del siglo XIX transforma la verticalidad de las ciudades, en Double Bind su inclusión en la obra modifica la percepción del espacio en su cualidad vertical. Interrumpe la horizontalidad del plano, e introduce el espacio sobre él en la instalación. Al mismo tiempo, y sin ninguna otra presencia, es capaz de dar escala humana a la condición abstracta de los huecos. Los ascensores son también el acceso a un espacio, el cielo. Es posible imaginar que a través de ellos se alcanzase una altura tal que la densidad del aire podría ser diferente y pudiera ser posible flotar, o ser, sin más, el punto más alto desde donde mirar, como en una torre de vigilancia. 

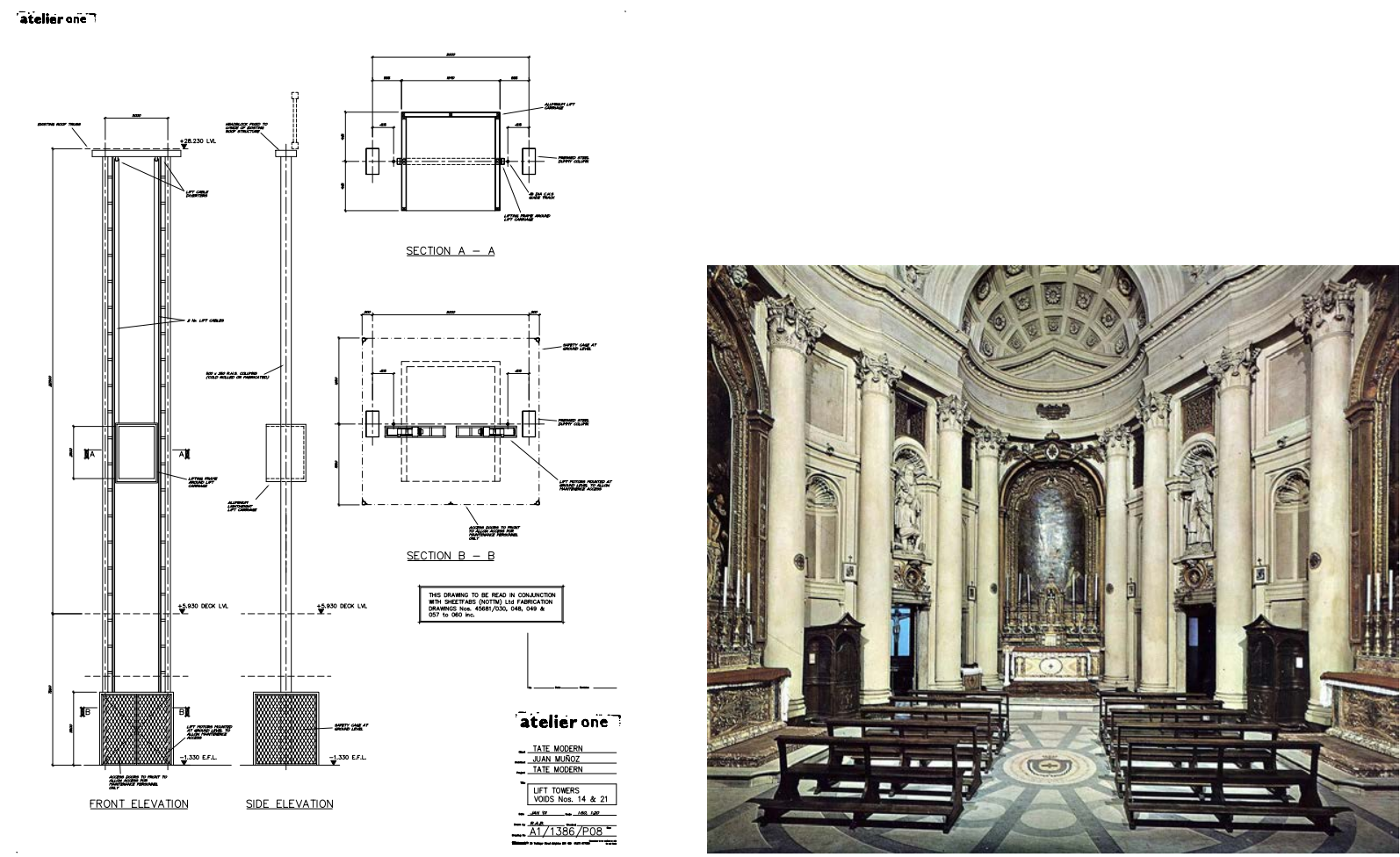

Alzaos Ascensores Double Bind.

Planos realizados por Atelier One.

Cortesía del Juan Muñoz Estate.

Interior de San Carlo alle Quattro Fontane. Roma, 1559-1667. Francesco Borromini.

Como las torres gemelas dei Salvucci en San Gimignano ${ }^{15}$ dominan el paisaje urbano medieval de la ciudad, los ascensores aquí no sólo se consideran objetos funcionales sino que también son símbolo. Las torres dei Salvucci fueron construidas como emblema de riqueza, aunque también eran utilizadas como fortalezas y centros defensivos para protegerse del enemigo. Pero eran ante todo una muestra de poder por parte de las familias que las habían construido, un paralelepípedo cuya altura estaba limitada por la economía y la destreza del constructor. En este caso, los ascensores no transportan a nadie, no tienen función, se muestran como elementos que dominan la escena imponiéndose en el espacio. Se refiere a ello también cuando habla de las columnas ornamentadas en las iglesias de Borromini. En San Carlos de las Cuatro Fuentes, encuentra cómo las columnas adosadas a la pared no cumplen función estructural alguna más que aparentar sujetar la cornisa

15 Muñoz expuso en San Gimignano en 1997 en la Galleria Continua su figura colgada "con la corda alla bocca", sus figuras descolgadas por cuerdas desde el techo. 
que sobre ellas se dispone. Muñoz dice refiriéndose a ellas: "En verdad, aquí la columna ni sujeta, ni sobre ella se apoya nada." 16

La inquietante escena no invita a adentrarse en este bosque de vacuidad, el espectador parece agradecer la barandilla de separación entre el mundo conocido y este paisaje absurdo y casi alucinante que provoca una sensación de desolación y misterio. ¿Quien querría adentrarse en él? Quizá sea mejor aceptar que es un lugar al que mirar, respetando el límite marcado por el autor. Es tiempo de observar, reflexionar y estudiar los misterios que se presentan ante el espectador en este nivel superior.

"A veces tengo la impresión de que mi obra reciente es sobre la espera, esperando algo que podría no ocurrir jamás, por otro lado temiendo que ocurra, incluso deseando que nunca pueda ocurrir. Es como mantener la obra en ese estado que llamaríamos de deseo; mantenerla en ese grado de deseo, simplemente aguantarla ahí, ese anhelo, esa incertidumbre, mantener la obra en ese punto preciso. 0 como observar una puerta que alguien puede abrir un día." ${ }^{17}$

La visión que se supone desde estos ascensores no es solo aquella cenital sobre la obra, también es la que nos permitiría ver a los espectadores y tener un control visual sobre todo el espacio. Aquel que viaje en el ascensor tendría una visión panóptica sobre la plaza, podría incluso descubrir que sucede dentro o bajo los huecos, podría tener acceso a otros estratos no perceptibles desde el balcón, encerrado en una caja suspendida que desde este balcón no se adivina a donde va. La luz otorga al ascensor una cierta divinidad, es la lucerna en la iglesia barroca, una lucerna en movimiento donde no hay Dios, un punto de referencia móvil que nos guía sin otorgarnos más luz “donde un dios va a aparecer o donde los dioses acaban de huir o donde la aparición de lo divino tarda demasiado"18

16 Muñoz, Juan, De la luminosa opacidad de los signos en Juan Muñoz: Escritos/Writings, Ediciones de la Central, Barcelona, 2009, p. 56.

17 Juan Muñoz, James Lingwood, Iwona Blazawick y Andrea Schlieker. Una conversación. Julio 1990 en Monólogos y diálogos, MNCARS, 1997, p.60.

18 Santiago Amón escribe en la revista Nueva Forma en el numero 49 de Febrero de 1970 una reseña del libro escrito por Martin Heidegger y Eduardo Chillida "El arte y el espacio". Muñoz incluye esta cita en su texto de 1985 que publica en la revista Figura llamado De la luminosa opacidad de los signos, donde el autor relaciona a Borromini con Kounellis, y donde lo que el autor dice puede ser aplicado a su propia obra. Santiago Amón hace también referencia al cuerpo del texto de Heidegger en su texto introductorio para la publicación Correspondencias: 5 Arquitectos, 5 Escultores, de la que Muñoz es comisario en 1982. 


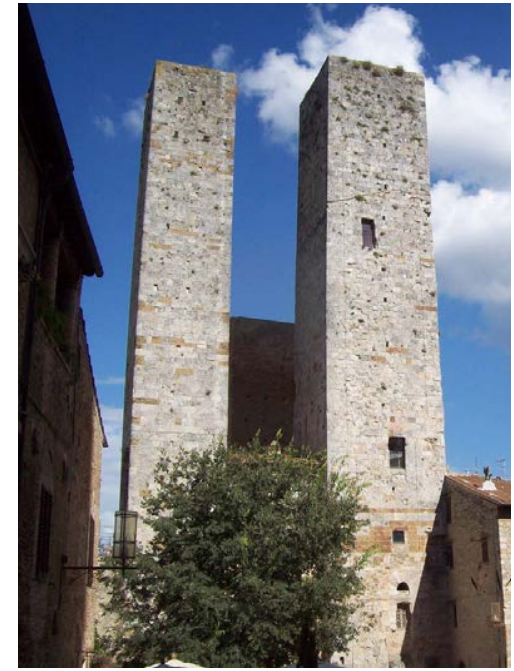

Torres gemelas de Salvucci. San Gimignano

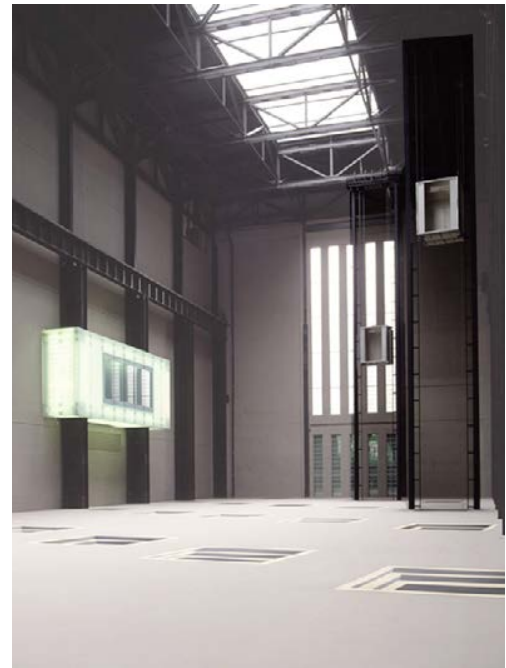

Double Bind. Nivel superior.

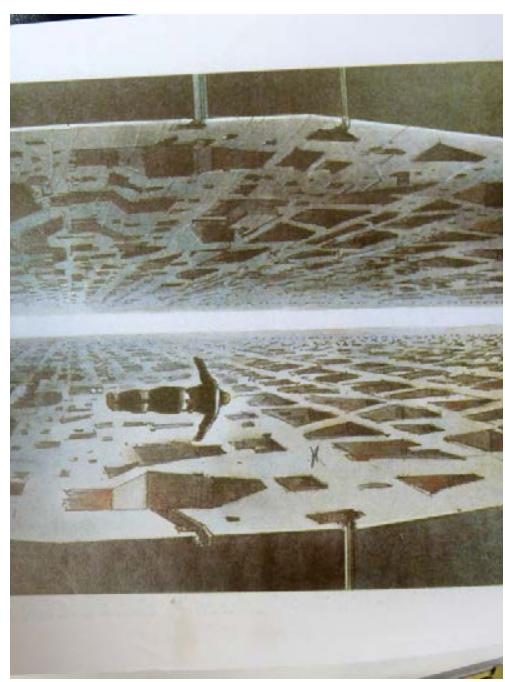

Documentación del artista Cortesía del Juan Muñoz Estate.

Estos ascensores son en realidad el mecanismo incompleto de un elevador que no esta preparado para llevar carga en la cabina, ya que no tienen contrapeso. Descubrir este detalle tecnológico, que es fácil pasar por alto cuando uno está sumergido en la poética de la obra, rompe con el sueño esperanzador de que ese ascensor conecte el espacio superior e infinito con en el que se sitúa el espectador, como si de una barca de Caronte se tratase. El ascensor tradicionalmente se ha entendido como un elemento que discurre a través de un hueco de las plantas de un edificio y que se encierra en un volumen protector que incluso tiene condiciones portantes. El ascensor de Juan Muñoz aparece desvestido, limitando su estructura a lo mínimo para permitir subir y bajar. Muñoz recoge el artículo de su profesor Santiago Amón "La exaltación del orden artificial en la arquitectura de Parent y Bloc"19 donde describe la Casa del Irán (Ciudad Universitaria de París,1968) y donde aparece una fotografía del edificio. Un prisma exento con dos grandes volúmenes

19 Amón, Santiago. La exaltación del orden artificial en la arquitectura de Parent y Bloc en Nueva Forma, Marzo, 1970. 


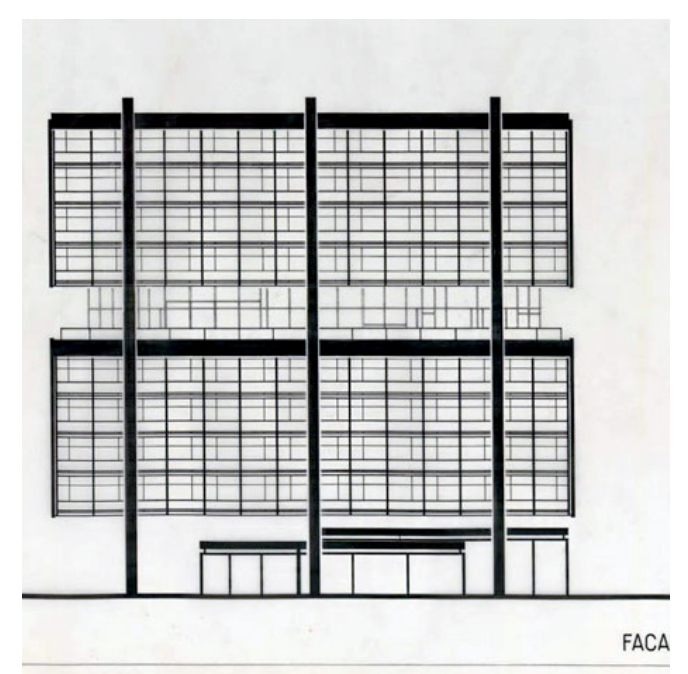

Parent y Bloc. Casa del Irán (Ciudad Universitaria de París,1968)

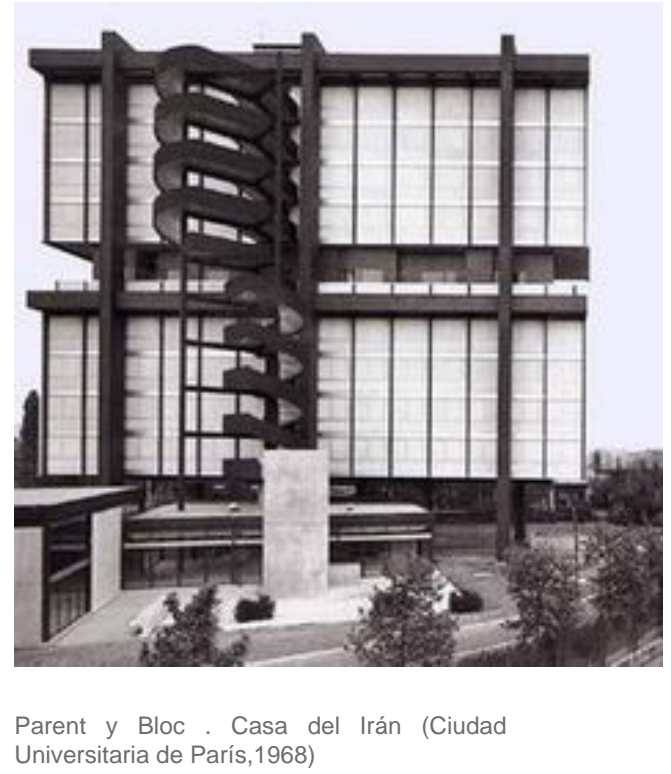

Universitaria de París,1968)

horizontales cuyos pisos quedan entrelazados mediante una escalera exterior totalmente abierta y situada a mitad de una de las caras principales del volumen. Muñoz anota bajo la imagen "ELEVATOR". En la casa del Irán los arquitectos ofrecen al usuario un contacto directo con la naturaleza y el entorno campestre desde todos los niveles. Situada en un punto central de la planta, para mitigar la presencia del volumen de la escalera sin sacrificar su posición, la desnudan consiguiendo una permeabilidad visual y relacionando su materialidad con los componentes visibles y estructurales del edificio. La escalera se descuelga de uno de los elementos verticales de la estructura vista. Los enormes pilares metálicos verticales recuerdan a los grandes perfiles metálicos de los muros laterales de la sala de turbinas, así como a los perfiles que sirven de guía de los ascensores.

La sala tiene un marcado punto de fuga definido por el plano horizontal. Las cajas de los ascensores que aparecen y desaparecen se convierten en un foco que distrae al ojo de la fuga, el ojo se mueve tras ellos, que en algunos casos se siguen y en otros se cruzan. En la instalación Fuochi (fuegos) de Jannis Kounellis expuesta en la Herbert Foundation en 


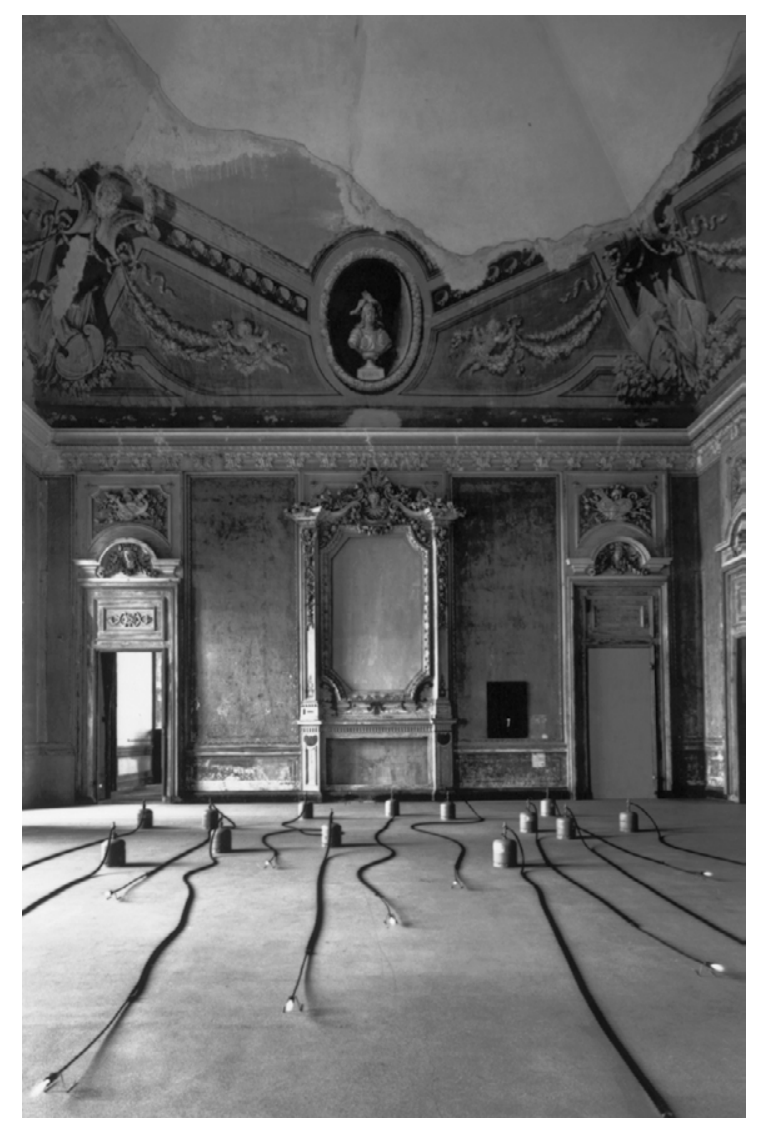

Jannis Kounellis "Fuochi" Herbert Foundation (1971)

1971 se disponen una serie de bombonas de gas en un extremo, de cada una de ellas sale un cable que en su punta muestra una luz azulada denominada por Muñoz "Ilamas de fuego." ${ }^{20}$ Juan Muñoz interpreta la bombona y la luz como los dos centros de una elipse imaginaria, lo que unido al juego con la luz, le lleva a relacionar la obra de Kounellis con la de Borromini diciendo que "El énfasis en la obra de ambos creadores está en hacer posible que tenga lugar algo, y ese algo es el acto generador de la luz"21. El haz de luz de la iglesia borrominiana se adentra por la lucerna atravesando el espacio interior chocando con los volúmenes y produciendo sombras. La luz en Fuochi "se dirige hacia un punto de fuga"22 donde las líneas tiene una dirección, al igual que las cornisas, al igual que los ascensores. "Es posible aventurar que Kounellis, como tan obsesivamente hiciera Borromini, ha

20 Muñoz, Juan, De la luminosa opacidad de los signos en Juan Muñoz: Escritos/Writings, Ediciones de la Central, Barcelona, 2009 p. 56.

21 Ibíd.

22 Ibíd. 
optado por la forma geométrica de la elipse. Dos centros y ninguno. La atención pasa de uno a otro. El ojo se mueve, pero ahora ya descentrado"23

Así como la arena desciende en el reloj marcando el tiempo, o la aguja en el metrónomo oscilando de un lado al otro define el ritmo musical ${ }^{24}$, los ascensores que suben y bajan organizan el paso del tiempo y son el compás de esta pieza. La diferencia de velocidad entre los dos ascensores, a los que hay que mirar durante un rato para darse cuenta de su ritmo desacompasado, marcan el pulso de la obra. La coreografía simétrica entre los dos ascensores se localiza en una posición lateral respecto al eje central de la sala, desplazado hacia el sur, disponiendo un ascensor por delante del otro. De nuevo la dualidad, en este caso dinámica, donde podría pensarse que un ascensor es el reflejo del otro. Pero, ¿qué sentido tiene que un ascensor suba y baje continuamente si no está en uso, ¿porqué habría un segundo ascensor haciendo el mismo movimiento?, ¿será otra ilusión óptica del escultor? En este caso no hay trampa, pero si misterio. De alguna manera, los ascensores marcan su propio tiempo, cada uno el suyo, y cuando se cruzan, los ojos del observador que habían estado siguiendo a uno de los dos ascensores, saltan al otro, que en lugar de bajar sube, produciendo un efecto casi hipnótico y de confusión.

La longitud vertical de la estructura de los ascensores es una vara con la que se puede medir el tiempo, distanciándola de ser entendida sólo como un objeto escultórico, y aportando el factor de movimiento y tiempo a la narrativa de la obra. Podríamos calcular el lapso de tiempo durante el cual los ascensores están ausentes, pero es al verlos subir y bajar cuando en palabras de Juan Muñoz: "lo que hay es una especie de detención del tiempo, y la metodología sutil de esos ascensores que suben y bajan y que van un poquitito cargados de ansiedad, porque van un poquitito despacio" ${ }^{25}$. La soledad que despierta este espacio en el nivel superior es inquietante, la velocidad contenida a la que se mueven los ascensores equilibra este efecto de desasosiego.

23 Ibíd.

24 Lévinas, Emmanuel, La realidad y su sombra. Arte y Crítica. Ed Trotta. Madrid 2001. p.48. "El ritmo representa la situación única en la que no se puede hablar de consentimiento, de asunción, de iniciativa, de libertad-porque el sujeto es asido y llevado por el ritmo".

25 Arranz, Manel y Solana, Anna. Documental Imprescindibles - Juan Muñoz, poeta del espacio, 2014. Imágenes y declaraciones de Juan Muñoz grabadas en el Centro Gallego de Arte Contemporáneo en Santiago de Compostela en 1996. 
Lento o rápido, están en movimiento perpetuo, una tema que atrae al artista desde principios de su carrera, como "una esfera del mundo: in perpetuum mobile"26 Un movimiento que parece eterno y que nunca se detendrá, como si la maquinaría produjera por si sola la energía necesitará para mantenerse en movimiento, como una dinamo que se cargara con el peso de los ascensores al caer, que utiliza la energía generada para volverlos a elevar, y que permitiese que nunca se interrumpiera su movimiento. No se pronostican cambios, el reloj sigue avanzando las horas y el escenario desértico e inhabitado que se observa desde la pasarela superior de la galería es siempre el mismo, nada más que el subir y bajar de los ascensores refleja el paso del tiempo. Sin principio ni fin, como el Libro de Arena de Borges "Me dijo que su libro se llamaba el Libro de Arena, porque ni el libro ni la arena tienen ni principio ni fin." ${ }^{27}$

Durante su estancia en Nueva York con una beca Fullbright, asiste en 1981 al Pratt Graphic Center, y trabaja como artista residente en el P.S.1 Contemporary Art Centre de Long Island City, asociado al MOMA. Muñoz era ya entonces gran admirador de la obra del escultor Richard Serra. A través de Carmen Giménez, con quien comisionaría la exposición Corrrespondencias: 5 arquitectos, 5 escultores ${ }^{28}$ pudo entrar en contacto con él. Ese mismo año entrevista al escultor americano ${ }^{29}$, que a finales de los sesenta había estado trabajando en videos con una cámara fija que graba en blanco y negro una imagen en movimiento. En una de ellas captura durante varios minutos una mano (la del escultor) que abre y cierra su puño intentando agarrar una hoja metálica en la parte izquierda de la imagen, que cae desde arriba sucesivamente por su propio peso (el espacio entre las láminas es constante, como si salieran de una maquina expendedora a un ritmo marcado), en algunos casos agarra la pieza soltándola inmediatamente y volviendo a abrir el puño en espera de que caiga la siguiente lámina (incluso podría pensarse que fuera la misma lámina la

26 Muñoz, Juan, De la precisión en las distancias en Juan Muñoz: Escritos/Writings, Ediciones de la Central. Barcelona, 2009 p.61 Publicado por primera vez en Piedras. Richard Long. Palacio de Velázquez. Ministerio de Cultura/ The british Council, Madrid, 1986 (cat.exp.).

27 Borges, Jorge Luis. El libro de Arena. 1975.

28 Benezra, Neal David. Sculpture and Paradox en Juan Munoz: March 6-June 15 1997. Smithsonian Institution.

29 La entrevista se centra en un interés común, en el arte en el espacio publico y la figura del viandante. Una porción de la entrevista se puede leer en el libro Juan Muñoz: Escritos/Writings. Sobre escultura pública. p.37. Una copia de la entrevista completa se conserva en el Juan Muñoz Estate. 


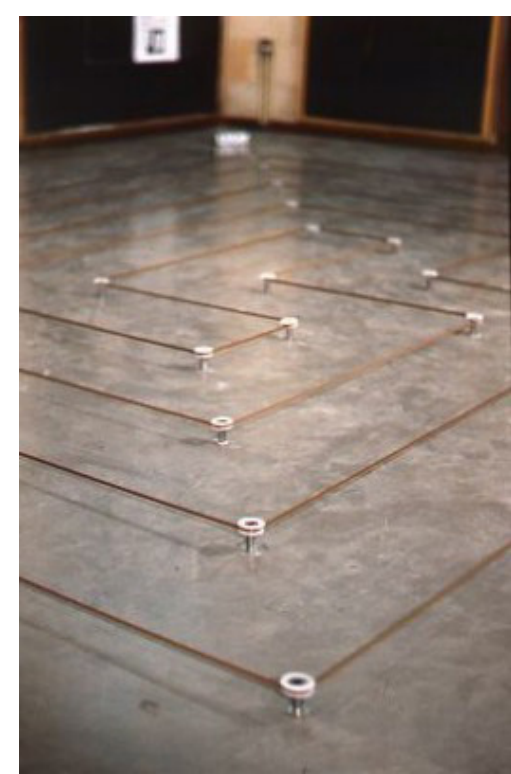

Untitled-1 Audio tape and tape recorders. 1980. Juan Muñoz

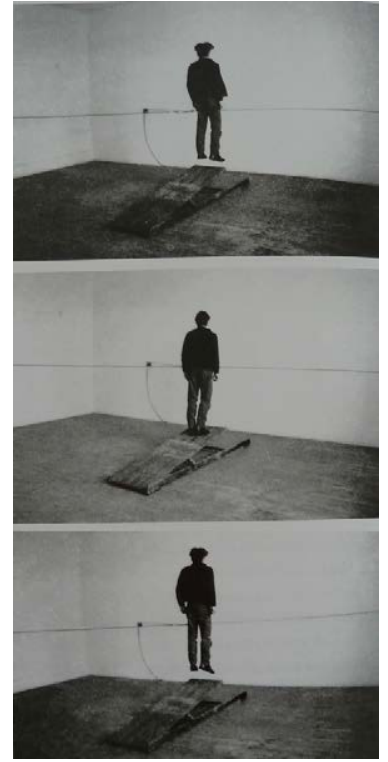

Performance. 1982. Juan Muñoz, PS1 Contemporary Art Center Long Islan New York

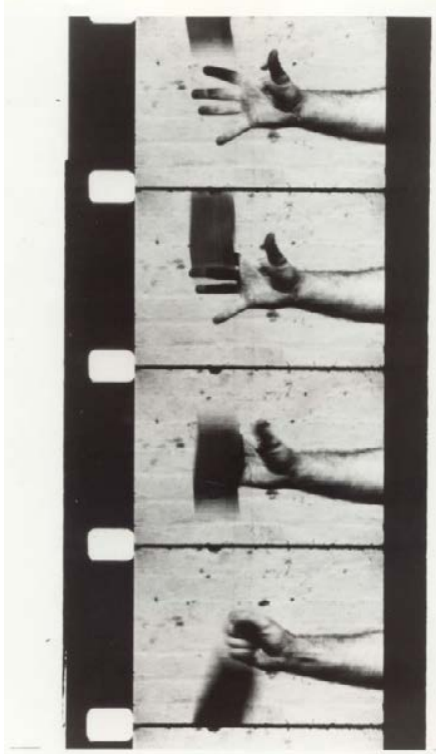

Hand catching lead, 1968, Richard Serra.

que repetidamente se suelta desde lo alto después de que haya caído ${ }^{30}$ ), en ocasiones cierra el puño sin lograr capturar la lámina, volviéndolo a abrir volver a intentarlo de nuevo. Es un claro ejercicio sobre la repetición en el estudio de la imagen en movimiento, pero también es un ejercicio del análisis espacio-temporal. La captura de varios fotogramas de la película permite percibir la continuidad temporal a través de la discontinuidad. De la misma manera, Juan Muñoz se retrata en el P.S.1. saltando sobre un trampolín capturando su imagen a distintas alturas, o sacudiendo un palo capturando el movimiento mediante una secuencia de imágenes fijas. Retratan una acción que se podría repetir hasta el infinito, donde no se sabe cuál es el principio y el final, como en el caso de los ascensores, que no adivinamos si suben primero y bajan después o viceversa, en algún momento empezaron a moverse, pero también puede ser que siempre se hubieran movido, y que nunca más se detendrán.

30 De acuerdo con Henrik Gustafsson, Asbjorn Gronstad que pese a parecer un movimiento mecánico propio de aquel realizado por un objeto, es el músico y compositor Philip Glass el que deja caer las laminas metálicas a intervalos regulares. La mano termina percibiéndose igualmente como si se tratara de un objeto mecánico al repetirse siempre el mismo gesto una y otra vez. 
El interés en Muñoz por el movimiento aparece en la década de los setenta. Al llegar a Londres, Muñoz comienza a estudiar historia del arte y cultiva el hábito de mirar y aprender. Son frecuentes sus vistas a la Tate y National Gallery. Más adelante consigue una Beca British Council para estudiar litografía avanzada en la Central School of Art and Design (hoy Saint Martins College of Art and Design). Sus estudios académicos se enfocan el la litografía, sin embargo su producción artística inicial se centra en obras donde se incorporan elementos mecanizados a una serie de objetos enlazados donde también trabaja con el sonido y el movimiento. A finales de los años 70 se sumerge en el mundo de la escultura experimental estando sus primeras obras ligadas al arte conceptual y procesual (o arte en proceso). Entra en contacto con artistas vinculados a estos movimientos y se interesa por el trabajo de Bruce Newman ${ }^{31}$ Experimenta con la recopilación y montaje de piezas, incorporando objetos mecanizados donde el sonido y el movimiento tienen un papel importante.

"The representation of movement and gestare within stillness is a Challenger that is endlessly fascinating"..."I think between stillness and the movement I try to find a place for my sculptures"32

En algunas obras anteriores, Muñoz trabaja con figuras que parecen intentar desplazarse pero que tiene movimiento limitados. Los ascensores parecen participar de ellos al tener un movimiento, que si bien no cesa, está condenado a ser siempre el mismo con la misma velocidad. Al introducirlos, además introduce el movimiento también en la forma de mirar la obra por parte del espectador que tiene que alzar la mirada y abandonar al horizontalidad del plano gris. Así, el dice: "dealing with the gigantic distortion that happens when you look up". ${ }^{33}$ Los ascensores son la referencia desde el plano superior que levantan la sospecha de la posibilidad de que algo esté ocurriendo más allá de lo que se ve en este nivel, sin saber a ciencia cierta qué ocurre una vez desaparecen bajo el plano gris.

"Al menos es claro que uno sospecha". ${ }^{4}$

31 Benezra, Neal, Juan Muñoz, Sculpture and Paradox, Hirshhorn Museum, 2001 p. 25.

32 Muñoz, Juan, Lingwood, James, A Conversation, May 2001, Unilever Series, Double Bind, Tate Modern 2001 p. 70.

33 Ibíd. p. 68.

34 Muñoz, Juan, Del oficio de ser visto en Juan Muñoz: Escritos/Writings, Ediciones de la central, Barcelona, 2009, p. 65, escrito en 1986-87. 


\subsection{De la precisión en las distancias ${ }^{35}$}

De la precisión de las distancias es el texto con el que Muñoz participa en el catálogo de la exposición de Richard Long , Piedras, que se celebró en 1986 en el Palacio de Velazquez de Madrid. Muñoz admiraba la obra del conocido artista brítánico cuya obra es referencia en el movimiento del land art. No se hace mención directa de Richard Long en el escrito, pero se entiende que su figura se ve reflejada en la del geógrafo. En el texto se narra una historia de ficción a través del cuadro de Vermeer "El geógrafo". Se desconoce la identidad del joven retratado por Vermeer, y Muñoz propone imaginar que se trata del geógrafo Mercator (1512-1594). Un flamenco que ideó una proyección cartográfica que permite trazar una ruta en línea recta entre dos puntos del mapa, una vez calculada la proyección mediante el sistema de Mercator, tan sólo se ha de ajustar la dirección del compás y mantenerla en línea recta sin necesidad de cambiar la dirección magnética de la brújula. ${ }^{36}$ Un año más tarde, Muñoz realiza estudios para una de sus obras más conocidas, The Prompter (El Apuntador). Muñoz señala que realiza la versión final de esta obra al recibir el encargo de Rudiger Schöttle para su proyecto Bestiarium. Este le pide una obra que tenga que ver con una ruina arquitectónica, y Muñoz, obsesionado por aquel entonces con la figura del enano, decide introducir la escultura dentro de la concha de un apuntador, busca darle un significado a la obra, y ahora ha encontrado la narrativa que responde a ello: que el apuntador es La casa de la Memoria, una ruina ${ }^{37}$, algo que no se ve, pero que siempre está ahí ${ }^{38}$. En el plano horizontal de este primer estudio del apuntador, donde aún no hay una escultura bajo la concha, si no un dibujo del rostro en el plano vertical, un plano horizontal elevado sostenido sobre puntales metálicos establece una relación con la figura de un enano que, apoyado en el suelo, asoma su cabeza a través de un tornavoz que se abre al plano horizontal. En él Muñoz dibuja una serie de juegos geométricos en los que crea una ilusión óptica a través de la representación de las curvas de nivel de un

35 Muñoz, Juan. De la precisión de las distancias en Juan Muñoz: Escritos/Writings. Ediciones de la Central. Barcelona, 2009 p. 61.

36 VV.AA. Mapas y Proyecciones, UNAM, 1998, p. 12.

37 Juan Muñoz, James Lingwood, Iwona Blazawick y Andrea Schlieker. Una conversación. Julio 1990 en Monólogos y diálogos, MNCARS, 1997, p. 62.

38 Ibíd. p. 61. 
terreno que pinta de color blanco, del mismo modo que aparecían en el mapa. Se centra en las geometrías más orgánicas del land art, que poco a poco va llevando a formas más ordenadas y rígidas.

El escultor utiliza la escritura como forma de reflexión, también para expresarse y experimentar. Escribe: 'Una tarde, hace semanas, comencé a escribir una debajo de otra las diversas formas que toma la geometría. Había acordado trazar, de abajo arriba, de izquierda a derecha, un sistema de coordenadas como una rejilla donde colocar un lugar cualquiera' ${ }^{39}$ El suelo de Double Bind al igual que en este relato de Muñoz, aparece como una rejilla en un lugar cualquiera; su repercusión especial es mucho más compleja que esta simple descripción, pero no deja de ser una bella forma de expresar la aparente simplicidad del gesto.

En la obra de arte, según Gadamer "(...)hay una aplicación vigorosa y siempre renovada de una energía que ordena espiritualmente."40 Se pueden tomar las palabras de Borges para hablar del orden geométrico en la obra de Muñoz: "La línea consta de un número infinito de puntos; el plano, de un número infinito de lineas; el volumen, de un número infinito de planos; el hipervolumen, de un número infinito de volúmenes... No, decididamente no es éste, more geométrico, el mejor modo de iniciar mi relato. Afirmar que es verídico es ahora una convención de todo relato fantástico; el mío, sin embargo, es verídico." ${ }^{4}$

Volviendo al plano abstracto y gris de Double Bind, el efecto dibujado en los huecos nos lleva a un mundo entre la bidimensionalidad y la tridimensionalidad. Las formas espaciales de las perforaciones se pueden transformar en un dibujo plano que resultara verdadero para el ojo siempre y cuando la posición entre el dibujo y el espectador permanezca inmutable. Muñoz, un apasionado de la magia y el ilusionismo, juega con la capacidad visual del espectador y el modo en que la mente procesa la imagen que percibe. Mediante trucos con la perspectiva, el plano y los volúmenes simula una apariencia real de una construcción ficticia. Desde los inicios de su carrera, siente fascinación por el trampantojo (trampa, confunde, equivoca al ojo, Trompe l'oeil en francés) que estudia primero a partir

39 Muñoz, Juan. Un objeto metálico en Juan Muñoz: Escritos/Writings, Ediciones de la central. Barcelona, 2009, p. 77. Publicado por primera vez como A Metallica Object en Jan van de Pavert and Juan Muñoz, Amsterdam Maatschappij Arti et Amicitiae, Amsterdam, 1988 (exh. cat.).

40 Gadamer, Hans-Georg, Estética y Hermenéutica, Tecnos/Alianza, 2006, p.92.

41 Borges, Jorge Luis, El libro de Arena, 1975. 


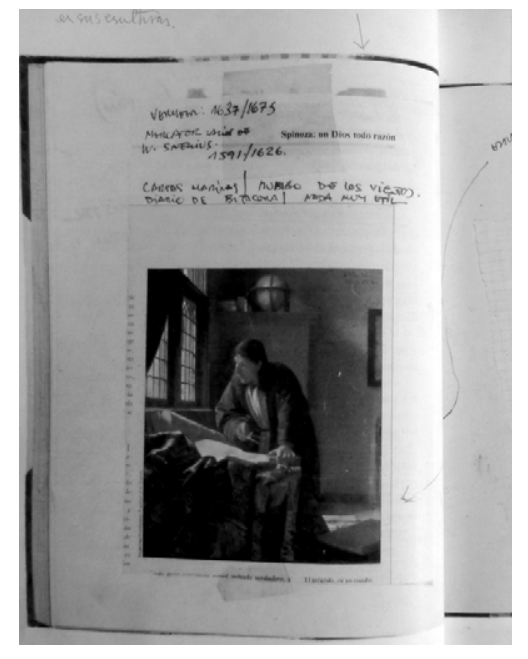

Cuaderno de notas del artista n 012, 1986. El geógrafo Johannes Vermeer entre 1668 y 1669 colección del Instituto Städel en Fráncfort del Meno

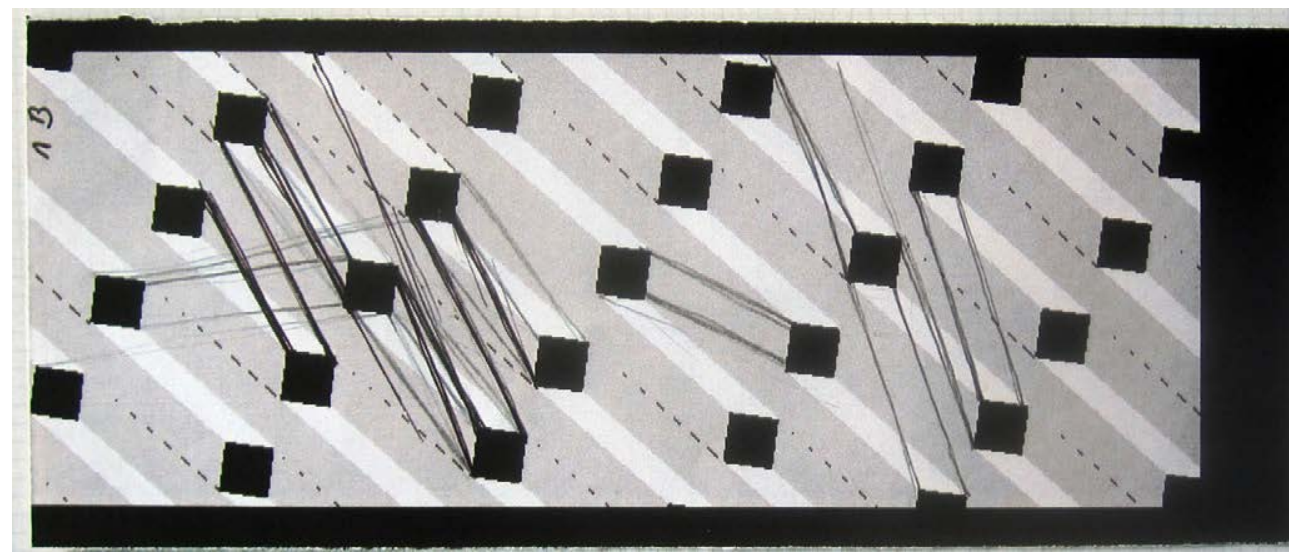

Double Bind. Estudio de planta. Dibujo del artista. 2000-2001

de los suelos, y después en toda forma pictórica o escultórica que utiliza este recurso, centrando la atención en artistas del periodo gótico, renacentista, y en especial en el barroco, sintiendo admiración por los techos y bóvedas de Borromini y los escenarios ilusorios del teatro del s.XVII.

El cerebro construye una interpretación de la realidad estableciendo relaciones entre lo que conoce y lo que ve. Los artistas fueron los primeros en explora la ciencia del ilusionismo buscando la profundidad, y utilizando la forma y el color para engañar al ojo. Íntimamente relacionado con la ciencia de la óptica, es también caso central en la psicología de la percepción, y de la neurociencia. Aún sabiendo que estamos frente a una ilusión óptica, nuestro cerebro genera una imagen que no se ajusta a la realidad geométrica de lo que se tiene ante los ojos, interpretando una imagen bidimensional como un elemento tridimensional. Muñoz utiliza este recurso creativo apoyándose en la geometría, el color y el movimiento (es la posición y el movimiento respecto a la pieza geométrica lo que hace que el efecto óptico funcione o no), el espectador tiene un papel dinámico ante la obra. 


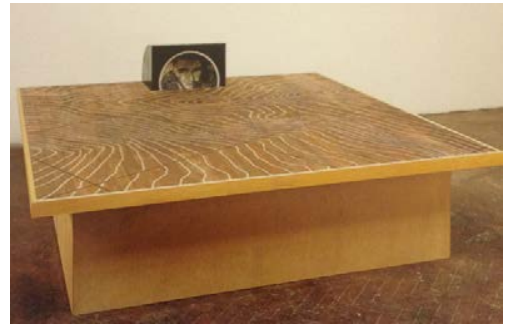

Estudio para The Prompter, 1987-1988. Juan Muñoz.

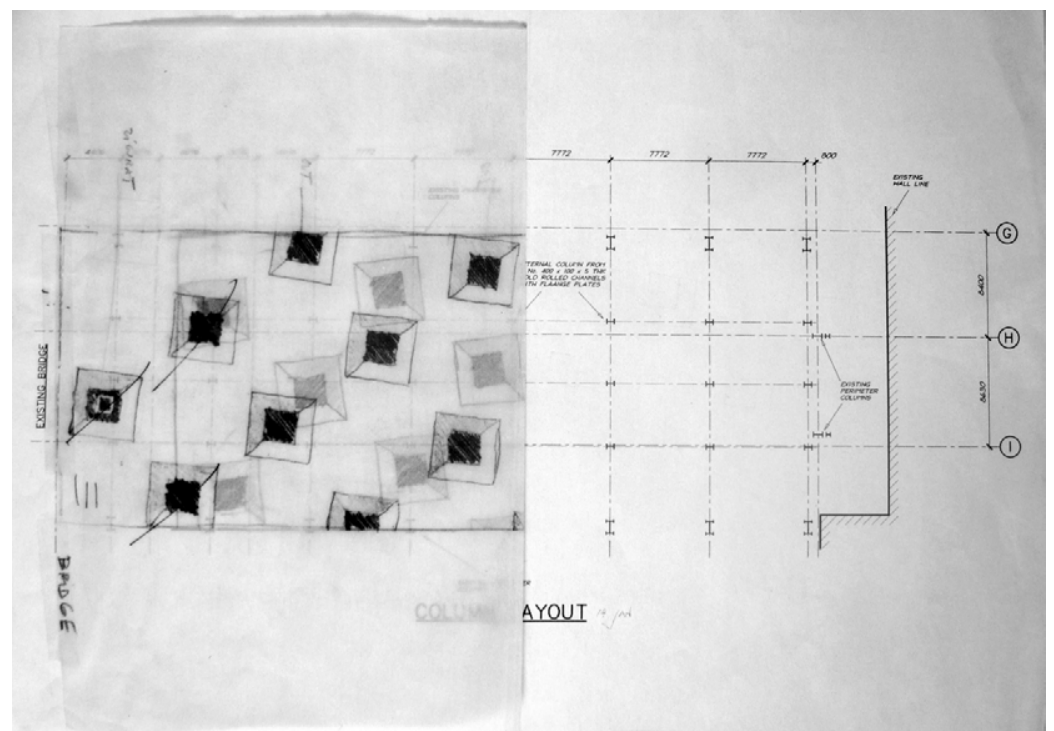

Estudios planta Double Bind. 2000-2001 Juan Muñoz.

Richard Serra habla sobre el ilusionismo en una entrevista en el que se le pregunta si el efecto de ilusión que se produce en sus obras debido a la geometría espacial de sus composiciones es un efecto improvisado, respondiendo: "cuando pienso en ilusión, siempre pienso en algo que significa otra cosa diferente de lo que es algo, o pienso en el Manierismo, donde hay una énfasis efectista de las formas." ${ }^{42}$ El efecto de ilusión en Double Bind es una combinación de estos planteamientos. Hay una voluntad de engañar al espectador, haciéndole creer que las pinturas en el suelo son en realidad huecos, estableciendo una estrategia de ambigüedad con el espectador.

Durante el tiempo que Muñoz pasa en Londres se interesa por un grupo de artistas, entre los que se incluye Carl Andre, un importante referente para el escultor, muy en particular en el tema de los suelos. La obra de Carl Andre se apropia del suelo como terreno en el que producir la obra de arte, y es también ahí donde se crea la extraña relación entre la pieza

42 Layuno, María Angeles, Richard Serra, Editorial Nerea, 2001, p.107. 
y el espectador. Este último puede transitar sobre las piezas de suelo, transportándose así a otro lugar. Del mismo modo funcionan los suelos de The Wasteland de Muñoz. Andre crea suelos modulares, una repetición de piezas del mismo material y de una geometría simple, menos barroca que los suelos de Muñoz, teniendo más que ver la relación entre ambos por el posicionamiento, la estrategia y la experiencia que por los juegos ópticos. Esta movimiento sobre la pieza lleva al espectador a experimentar la obra en un momento concreto, atendiendo a su propia historia y a su contexto. Como Double Bind, son obras que han de ser experimentadas para captar mediante los sentidos el conocimiento que de ellas se desprende. A diferencia del arte conceptual, el trabajo de Muñoz tiene un gran apego a la forma. En particular en Double Bind, donde los volúmenes internos definen espacios que puntualmente son habitados por sus figuras. Ambos escultores trabajan como coreógrafos, primero con las piezas, colocándolas en el lugar en dialogo con el contexto, adaptando las narrativas al espacio dado, que en muchos casos viene dictado por requerimientos ajenos al artista; después será la pieza la que defina el movimiento del espectador. Una convergencia de circunstancias cierran la pieza; las sensaciones de la localización de una misma obra en distintos espacios expositivos puede resultar muy diversa. Esta reflexión hace que exista una convergencia entre la experiencia del autor al resolver la localización de sus piezas en un espacio determinado, y la experiencia del espectador al acceder a la obra. El lugar escultórico es entonces la correspondencia entre el espacio común entre el cuerpo y la escultura En las obras previas de Muñoz, transitar sobre los suelos significa entrar en la obra. En Double Bind devuelve al espectador a esa relación perimetral con la obra, pero el tamaño de la misma es de tal envergadura que absorbe al espectador llevándolo dentro de ella, sumergiéndole no en el plano, sino en el espacio.

Juan Muñoz añade en sus obras que incluyen un suelo,, un factor óptico que distorsiona la percepción espacial. El engaño al que lleva al espectador no tiene un fin de escenografía teatral. La vinculación de Muñoz con el teatro aludiendo que sus obras son escenarios donde se mueven sus personajes debe ser matizada. Si es cierto que Muñoz tenía un profundo interés por contar historias, y por los libretos de teatro. Seis personajes en busca de autor de Luigi Pirandello era uno de sus libros preferidos, llegando incluso a copiar fragmentos y modificarlos para crear su propia narrativa. Pero nunca desarrolló un interés por la escena teatral, y declaraba haber ido al teatro en contadas ocasiones. 


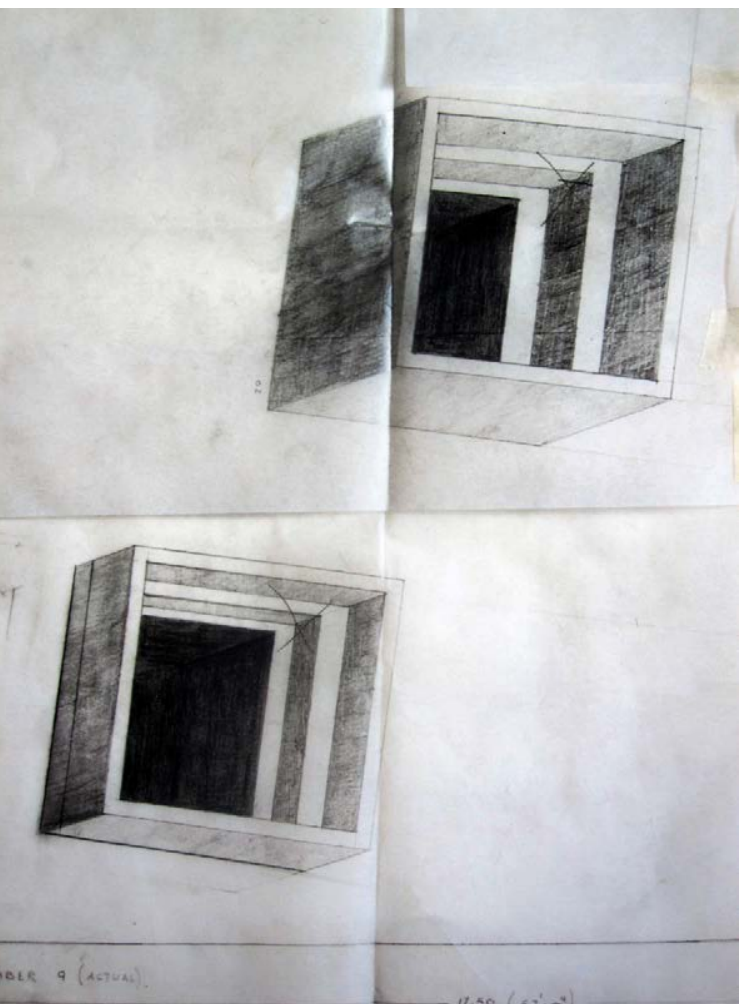

Estudios huecos e ilusiones ópticas. Double Bind. 2000-2001. Juan Muñoz.

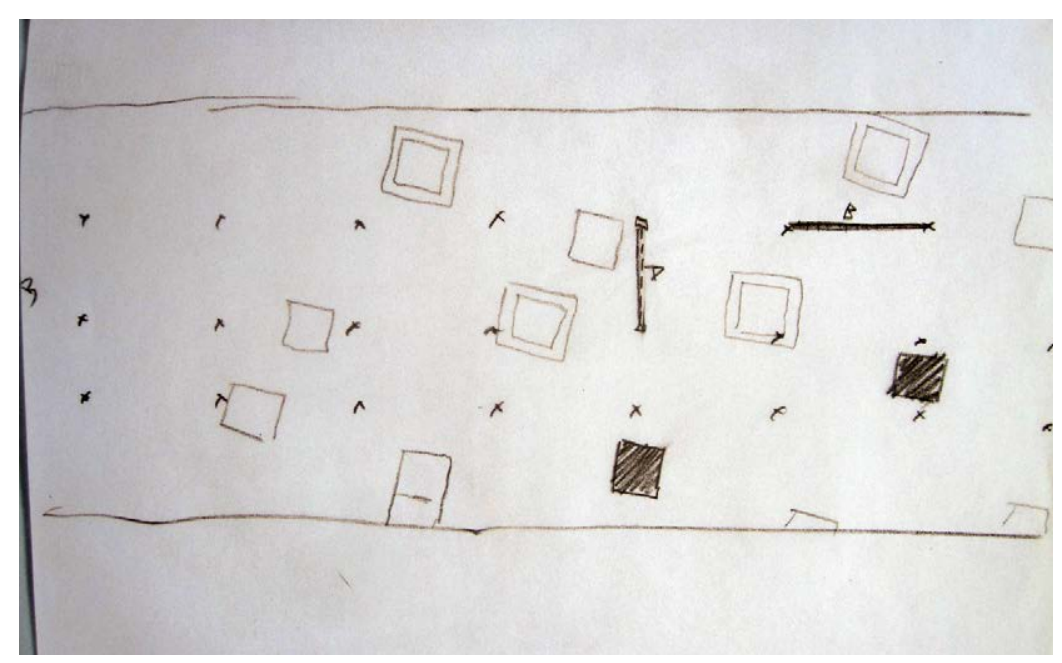

Estudios planta Double Bind. 2000-2001. Juan Muñoz.

Es cierto que el personaje de su obra El Apuntador establece una relación directa entre los dos mundos, pero las escenas posteriores de sus esculturas están más relacionadas con el paisaje pictórico y arquitectónico que con la escena teatral. El teatro puede existir sin escena, pero no sin personajes, las esculturas de Muñoz con un marcado componente escénico pueden existir sin personajes, son una ilusión a la que mirar, sin necesidad de un componente figurativo. 


\subsection{Tres imágenes o cuatro ${ }^{43}$}

Muchas de las ideas reflejadas en Double Bind parecen surgir de forma accidental:

"Many decissions are shaped by an accident encounter, by hearing or seeing something unexpected. The momento when my wife Cristina Iglesias said coming down the ramp at the Tate Modern made her feel as is she were going into a parking lot was important. It's surprising how slowly the piece started zapping itself, from the horizontality of the Bridges, to the need to deal with the verticality through the hanging figures, which was later substituded by the absence of the figures, to the displacement of other ideas that seemed more complete and more economical" 44

Este proceso narrado por Muñoz describe algunos de los acontecimientos que el denomina accidentados y que dan forma a la obra; algo que parece casual, es en realidad un recorrido de ida y vuelta a través de distintas opciones e ideas que se van formando a lo largo del tiempo y que comienzan muy atrás. En este proceso de ideación de la instalación se descartan o confirman estrategias conforme se va desarrollando el proyecto. Primero surge el encargo, más tarde, se conoce el lugar hay que familiarizarse con el espacio expositivo, después el tanteo y el cierre de la idea, finalmente la materialización, proceso en el cual se sigue dando forma conceptual a la instalación. Las expectativas también juegan un papel importante en este caso particular. La Tate Modern es el gran museo de arte contemporáneo de Londres, la nueva casa de la cultura que se espera desde su inauguración, tenga un fuente impacto en la cultura internacional. Las Unilever Series se estrenan con la instalación de la artista Bourgeois, y se plantean como el gran evento anual en el espacio central del nuevo museo. Este encargo era un gran reto para cualquier artista, el compromiso era el de hacer una gran obra.

No todas las ideas de Juan Muñoz prosperaron, acabamos de leer al principio de este capítulo un breve párrafo donde muestra las pinceladas de los conceptos más destacables que barajó. Entre las ideas que el escultor consideró para resolver el encargo de las Unilever

43 Muñoz, Juan. Tres imágenes o cuatro en Juan Muñoz: Escritos/Writings, Ediciones de la Central. Barcelona, 2009 , p. 105. Publicado por primera vez como Yotsu no imeiji. Brihuega, Jaime y Fernández-Cid, Mighel. Supein aatotoudi / Spain Art Today, The Museum of Modern Art, Tokonawa, Tokio, 1989 (exh. Cat.) 44 Muñoz, Juan, Lingwood, James, A Conversation, May 2001 en Unilever Series, Double Bind, Tate Modern, 2001, p. 69. 


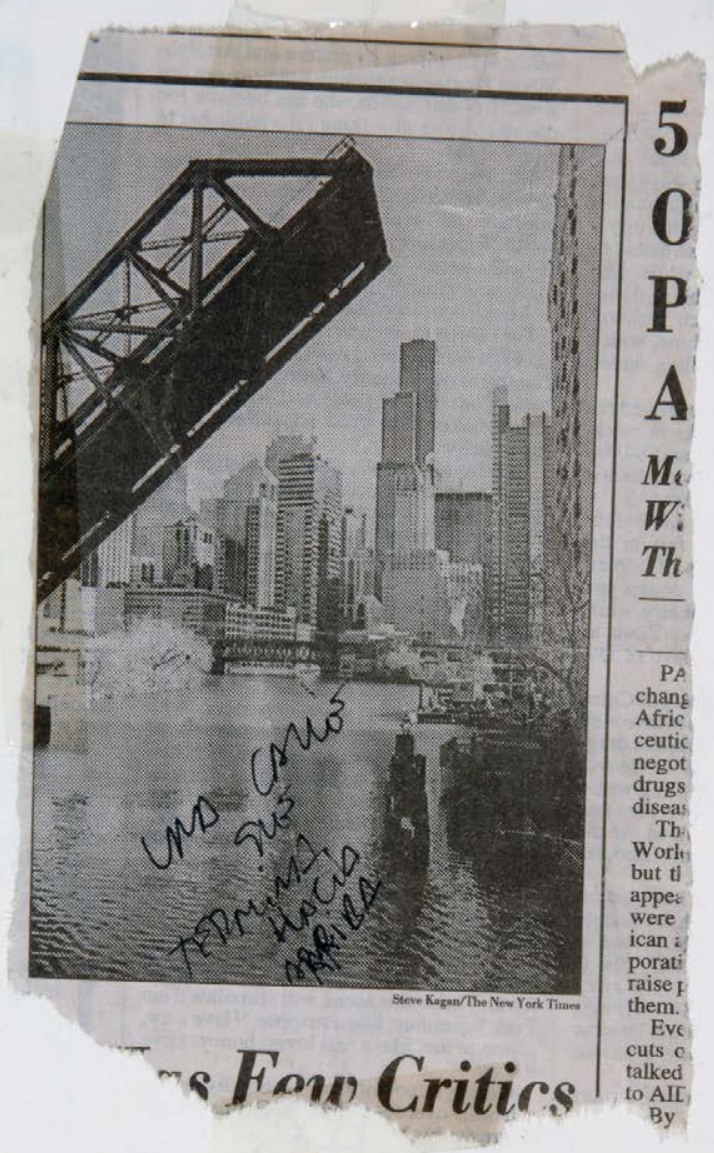

Cuaderno de notas del artista $n^{\circ} 20$.

2000-2001

Cortesia Estate de Juan Muñoz

Series, se pueden entresacar cuatro de ellas a través de la conversación que mantiene con James Lingwood en Mayo de 2001, algunas ilustradas en notas y bocetos en los cuadernos del escultor.

Cuando Paul Klee apunta: “La creación vive, en su condición de génesis, bajo la superficie visible, bajo la cobertura de la obra" ${ }^{45}$, se refiere a las opciones y estudios que se producen en torno a la producción de la obra y que son parte formante de la obra y materia para su conceptualización.....(la obra es su historia), se constituye durante el camino, en virtud de proporciones elementales que ligan las partes entre si y al conjunto. Toda labor es la relación de lo particular con lo general." ${ }^{\prime 4}$ Del mismo modo, en la parte superior de la obra se establece un diálogo entre lo elementos nuevos que integra Muñoz y los de la sala de turbinas, así como su la escala y proporción.

45 Klee, Paul. Teoría del Arte Moderno, Filosofía de la Creación, Argentina, Ediciones Caldén, Colección el hombre y su mundo, 2007, p.92.

46 Ibíd. 


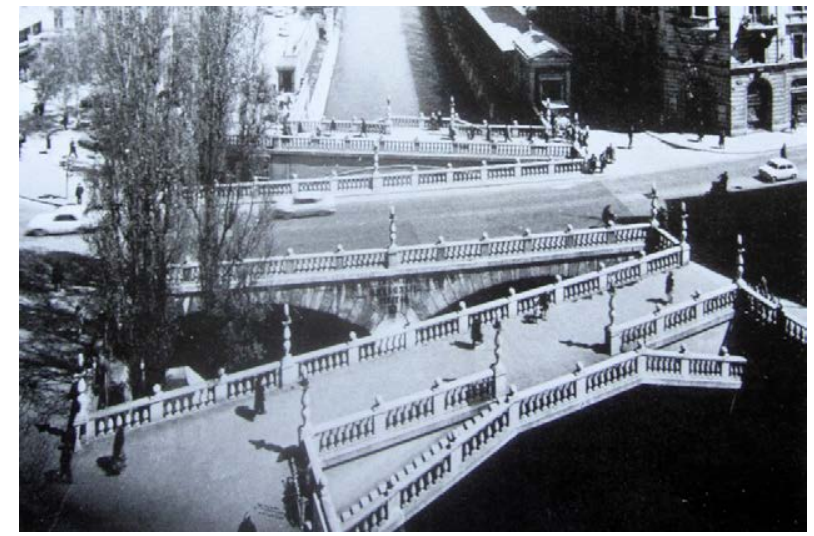

Puente triple de Ljubljana. Documentación del artista.

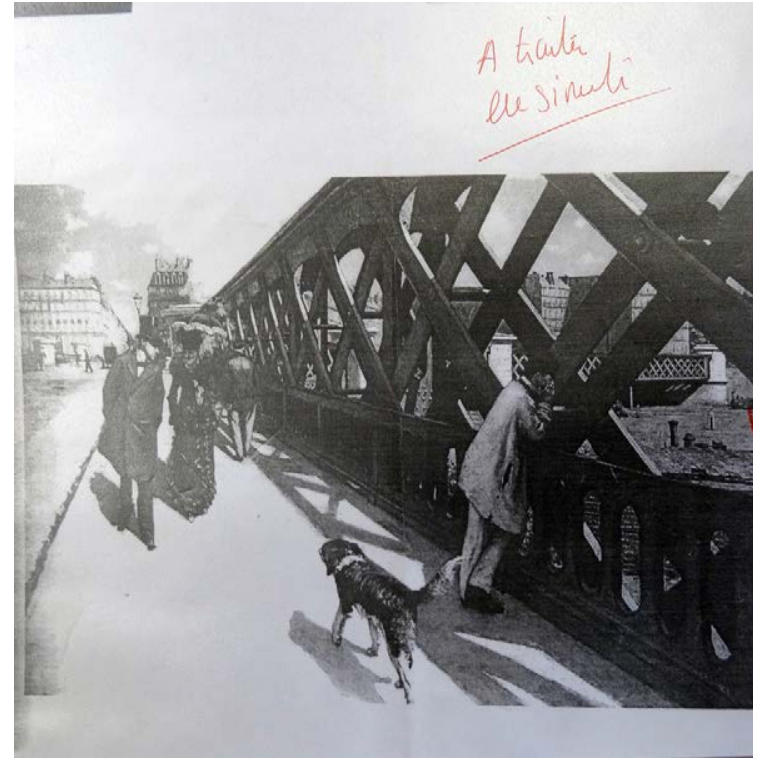

Documentación del artista. Cortesia Estate de Juan Muñoz

Tres de las primeras ideas de entre los cuatro acercamientos que se planteo Juan Muñoz como posibles instalaciones, y de las que hablaré más adelante, pueden descubrirse en la obra final. Una de ellas es diferente, y no tiene una relación formal fuerte con sus obras anteriores. Se refiere a los puentes que no llevan a ningún sitio y se pierden en el vacío. “My first idea, or image if you like, was to build two successive bridges. I don't know why - it just came in a very intuitive way: two Bridges tilted into the horizon, disappearing into the distance. There was a photograph of two Bridges in Ljubljana that I found very interesting on a spatial level. That was the very first idea: standing on a bridge - or a Plateau - and looking at something that was leading nowhere to nowhere." 47

Muñoz habla de que le interesa la idea de estar en un puente, mirando a algo que lleva a ningún sitio. Esto nos lleva a enlazar el concepto con el uso que finalmente da a la pasarela existente en la sala de turbinas. La utiliza para crear ese juego con el horizonte y el no

47 Muñoz, Juan, Lingwood, James, A Conversation, May 2001 en Unilever Series, Double Bind, Tate Modern, 2001, p. 67. 
lugar. Una plataforma desde la que mirar a un horizonte que no lleva a ningún sitio, y a un lugar al que además no se puede acceder más que con la vista. La barandilla ofrece un apoyo donde descansar, como invitando a que la contemplación sea larga y meditativa, no es solo un lugar de paso. La fotografía de los puentes de Ljubljana (llamado Puente de los Dragones) muestra una estructura de puente triple, que se abre en distintos ángulos, pero que como todo puente, al final conecta dos puntos. Esta situación hace que el viandante deba decidir que camino tomar, y de algún modo reflexionar sobre la elección, eliminando el comportamiento autómata al desplzarse en un entorno urbano.

Muñoz recorta una imagen de un periódico donde aparece un primer plano de un puente con un fuerte carácter industrial. El puente levadizo aparece alzado en la fotografía, al fondo Chicago, sobre la fotografía una nota de Muñoz: “Una calle que termina hacia arriba”. Es fácil pensar que los puentes llevan a establecer una relación directa con la calle. Un recorrido entre dos puntos flanqueado por muros laterales. La calle es el tema central en su obra $A$ Place Called Abroad (Nueva York, 1996, instalada como Streetwise en Santa Fe en 1998). La obra que se plantea Muñoz tiene un fuerte componente visual, esta estrechamente ligada con la fuga y el punto de vista. Lograr ese efecto en un lugar cerrado, que aunque amplio, tiene un volumen limitado, y una estructura que compromete a la obra. Muñoz conoce las ciudades americanas, y esta familiarizado con las imágenes de Rodchenko, señala en 1996: "Ha sido en los últimos meses cuando me he dado cuenta de lo que admiro algunas de las fotografías de las décadas de 1920 y 1930, como las de Rodchenko y algunos de los clásicos americanos. Ellos realmente volvieron a situar el punto de vista, y lo consiguieron gracias a la arquitectura moderna y a los rascacielos" ${ }^{48}$ Centrado en el punto de vista, y en una visión desde un punto elevado, se encuentra entre sus documentos relacionados con Double Bind una fotografía aérea de la ciudad de Chicago. Sobre el río Muñoz dibuja lo que podría interpretarse como una serie de puentes, y entre ellos profundos huecos, pozos sin fondo, similares a los que comenzará a esbozar sobre el plano horizontal que finalmente introduce en Double Bind. En los croquis recogidos en sus cuadernos de notas recurre a l perspectiva y a la vista aérea para representarlos. Cuando la idea esta ya más avanzada, se apoya también en el dibujo en sección. Entre sus recortes, una alusión al libro de Jonathan Swift, Los Viajes de Gulliver, podría servir para una relación entre la figura y la escala.

48 Muñoz, Juan, Lingwood, James, Una conversación, Septiembre 1996 en Monólogos y diálogos, MNCARS, 1997 p. 35. 


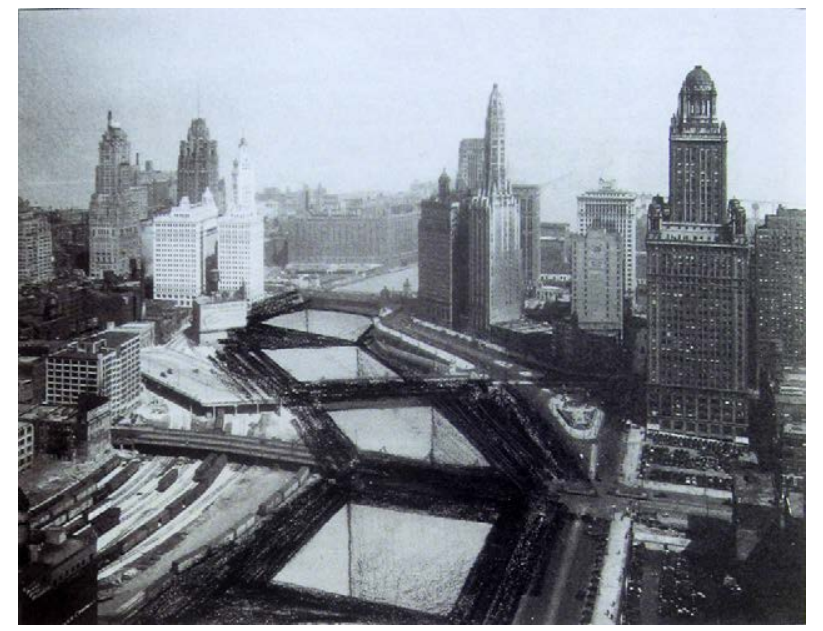

Dibujo del artista sobre fotografía de la ciudad de Chicago.

Muñoz se aleja de la idea de los puentes como tal, aunque hemos visto que en este primer comienzo ha mostrado intenciones que llegan a formalizarse en Double Bind. Rodchenko vuelve a formar parte del cuerpo de referencias del artista. En un intercambio de cartas con Susan May, comisaría de la Tate Modern en aquel momento, ésta le envía unas fotografías del artista, además de una imagen de Miss la la at the Cirque Fernando de Degás entre otras. Probablemente Muñoz le había comenzado a presentar la idea de descolgar ciertas figuras del techo, en la línea de las Hanging Figures que había empezado a trabajar años antes. La segunda idea que se plantea el escultor es la de suspender algunas figuras colgantes en el espacio. Entre los documentos de Muñoz quedan archivadas imágenes de acróbatas, el cuadro de Man on a Rope (1858) de Honoré Daumier que recorta de la revista Art in America, ${ }^{49}$ e incluso una imagen de la famosa escena de la película Misión Imposible, donde Tom Cruise aparece descolgado en una habitación.

49 Art in America, May 2000, p.117. 
"My second idea was to suspend a great number of figures in the space. These are some of what I would call the habitual errors along the way."50

Está idea no prosperó, aunque los fuertes intereses por la verticalidad y por forzar un punto de vista que lleve al espectador a mirar a lo alto son estrategias fundamentales en Double Bind.

En la tercera idea continúa trabajando con las figuras colgadas, pero incluye un plano horizontal suspendido del techo donde las figuras se apoyan (varias figuras en conversación) y del que además se descolgarían otras figuras con la cuerda en la boca. Respecto a esta idea, Muñoz señala que produciría dos mundos distintos arriba y abajo, sin existir una relación vertical entre los dos. Propone un plano horizontal de espejo, jugando con la dualidad de las figuras, y bajo este, en uno de sus bocetos, propone otro juego de espejos, una de las figuras descolgadas (en este caso del pie) sostiene un espejo, donde se refleja la otra figura.

"Actually, one of the many momentary images I had as an idea for intersecting the space was of a suspended carpet - with people above it, and people below it. But the cut would just have been a horizontal one, not a vertical one. The associations weren't right, but anyway it pushed me towards the idea of having two separate spatial experiences, above and below. So the carpet evolved into a floor. This gives two quite different kinds of space - and the dialectic between the two is important" 51

Finalmente, la cuarta idea ya incorpora los ascensores como elemento fundamental de la pieza. Aparece en los bocetos un plano horizontal a la altura de la pasarela existente de la sala de turbinas. Comienza con la idea de jugar con muchos ascensores que suben y bajan, que puede relacionarse con la idea de varias figuras colgadas a distintas alturas. Las figuras colgadas de Muñoz incorporaban en algunos casos un motor para hacerlas rotar, pero esta rotación se producía en un plano horizontal, ahora el movimiento de los ascensores es vertical. La reducción a sólo dos hizo entonces que se estableciera la relación dual de movimiento entre ellos.

Dentro de este esquema también baraja la idea de presenciar la escena desde balcones laterales queda esbozada en varios croquis que el artista realiza durante el proceso de creación de la obra, teniendo ciertas similitudes con la instalación en el Palacio de

50 Muñoz, Juan, Lingwood, James, A Conversation, May 2001 en Unilever Series, Double Bind, Tate Modern, 2001, p. 67.

51 Ibíd. p. 68. 


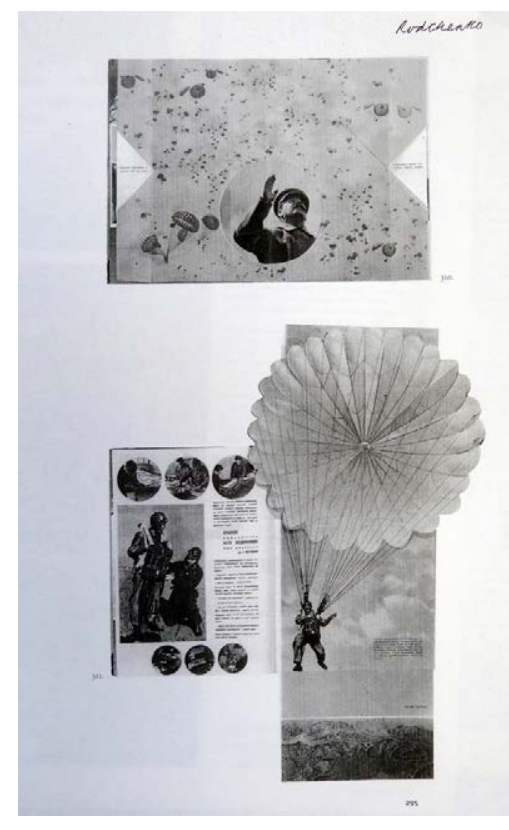

Rodchenko

Documentación del artista. cortesia Juan Muñoz estate.

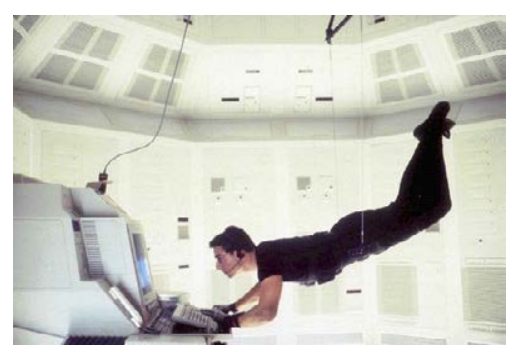

Misión imposible. Referencia localizada en documentación del artista

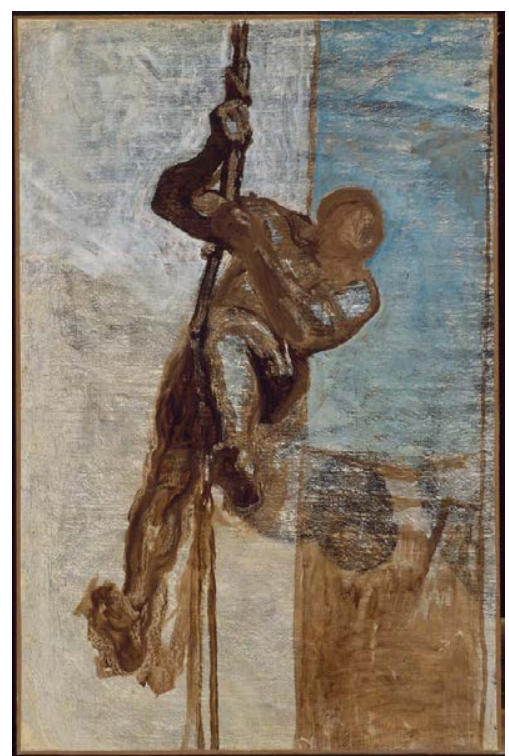

Man on a Rope about 1858 Honoré Daumier (French, 1808-1879) Referencia localizada en documentación del artista

Velázquez en Madrid, donde las figuras se observan desde una balconada superior. En 2001, realiza el ejercicio inverso en Thirteen Laughting at each other. Sitúa a los personajes en gradas laterales, y el visitante recorre la sala pasando por delante de ellos, que parecen estar criticando lo que ven, y riendo a carcajadas sin casi poder mantener la compostura. En los croquis revierte el concepto, volviendo a poner la obra en el punto de mira y al espectador en esa posición de detenerse antes de llegar a ella, en la barandilla. Le permite mirar desde una posición central pero no pasar, estableciendo el límite entre el espectador y el espacio abstracto y apenas escalado sobre la plataforma. Del mismo modo, se plantea la posibilidad de incluir un pasillo lateral de columnas junto a una de las paredes de la Tate a la altura del primer nivel. Bien puede recordar a sus obras donde enanos circulan a lo largo de un pórtico de columnas ( I saw it in Bologna, 1991)

Pasando de la historia a la acción, finalmente Muñoz comienza a desarrollar la estrategia a seguir en los huecos planteados en el forjado horizontal que es traspasado por dos ascensores y que llevan a pensar en la Teoría del Doble Vínculo (The Double Bind Theory). 

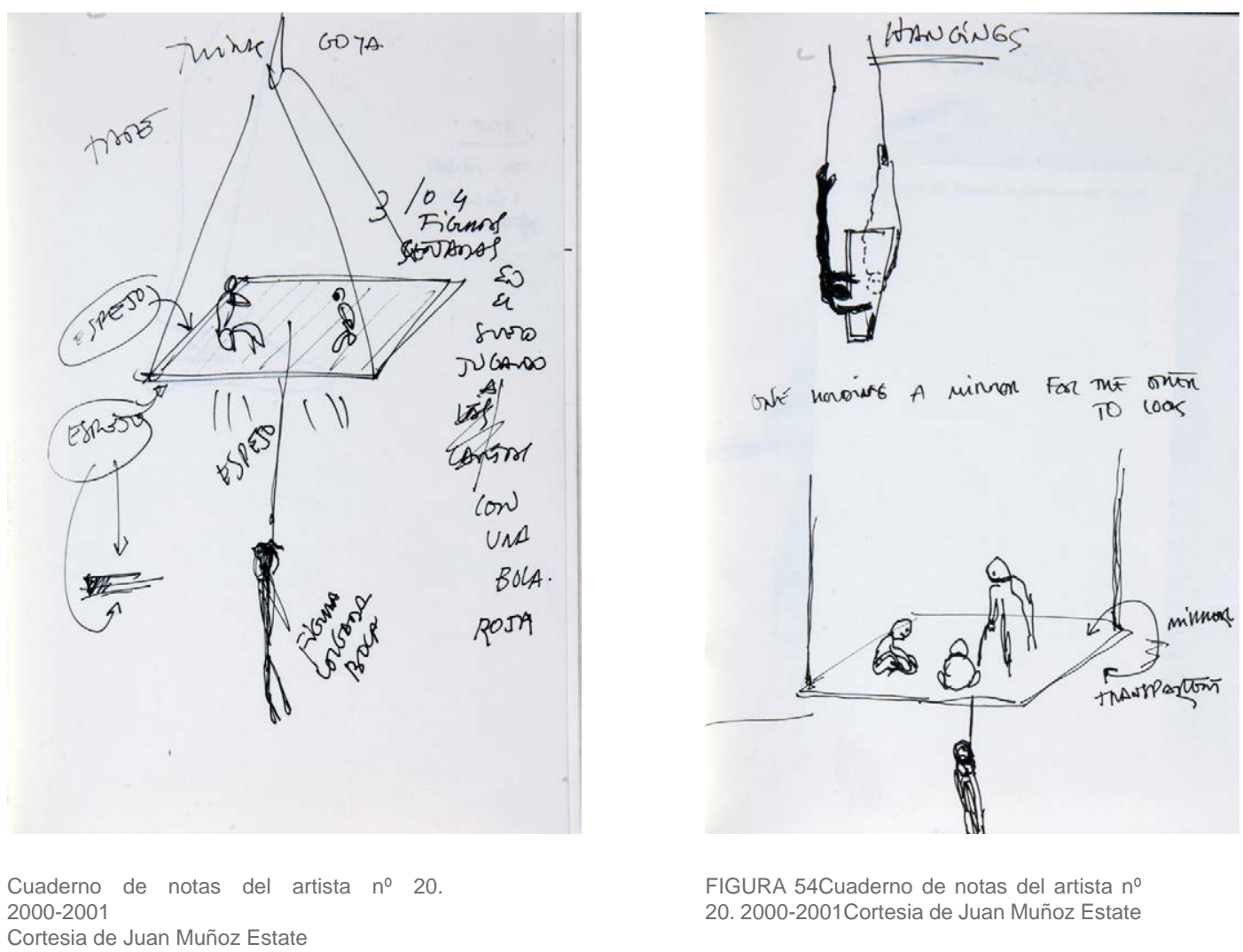

FIGURA 54Cuaderno de notas del artista $n^{\circ}$ 20. 2000-2001Cortesia de Juan Muñoz Estate

Encuentra en el plano intermedio, lo que llamaremos purgatorio, un habitat para sus figuras, personajes que no dejan representarle a él mismo, sus muñecos de ventrílocuo. En esta obra Muñoz vuelve a reproducir una atmósfera confusa para el espectador; apoyado en ciertos elementos arquitectónicos, y buscando la abstracción de un contexto urbano, lleva al espectador a situarse entre la realidad y la ilusión, entre la ausencia y la presencia. Muñoz buscaba decir lo que es indecible, esto sólo se puede lograr mediante el misterio y el enigma. Crea un lugar casi místico, de contemplación, de luz y de oscuridad. Una obra abarrotada de autorreferencias.

Dentro del universo de lo posible queda el resucitar una obra que fue ideada para un espacio determinado respondiendo a una instalación temporal. Después de ser expuesta, Double Bind se desmontó y guardó con la idea de poder volver a ser devuelta a la vida en un futuro. En Mayo del 2015, después de dos años de trabajo en el proyecto, el Hangar Bicocca expone la obra en su gran nave industrial de Milán como parte de la exposición Double Bind and Around, comisarizada por Vicente Todolí. El Hangar es una nave con unas 


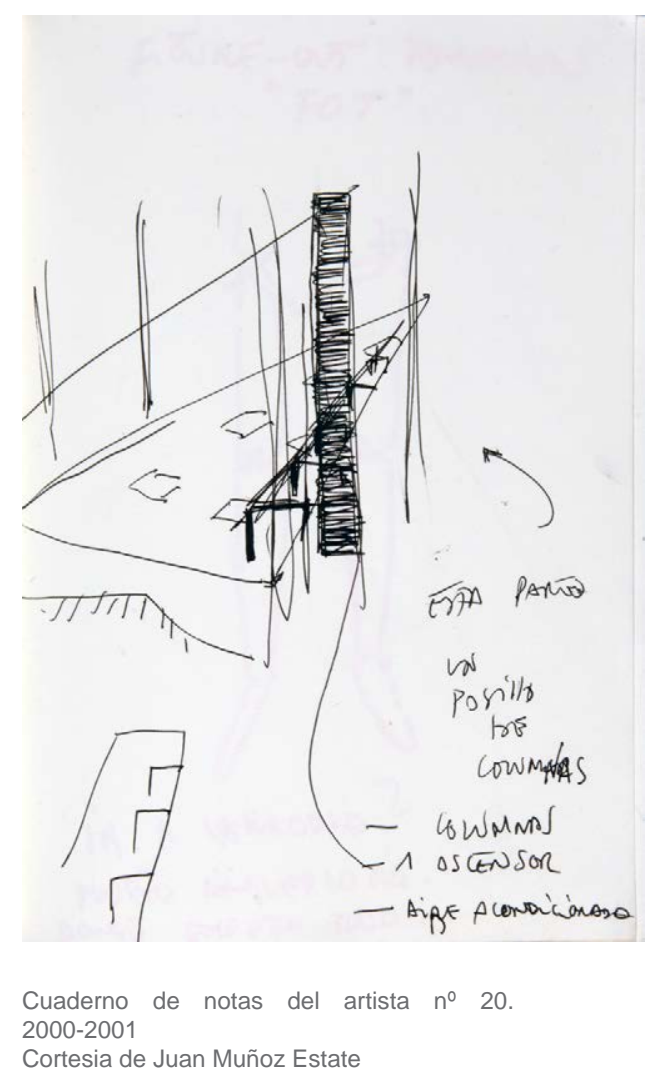

2000-2001

Cortesia de Juan Muñoz Estate

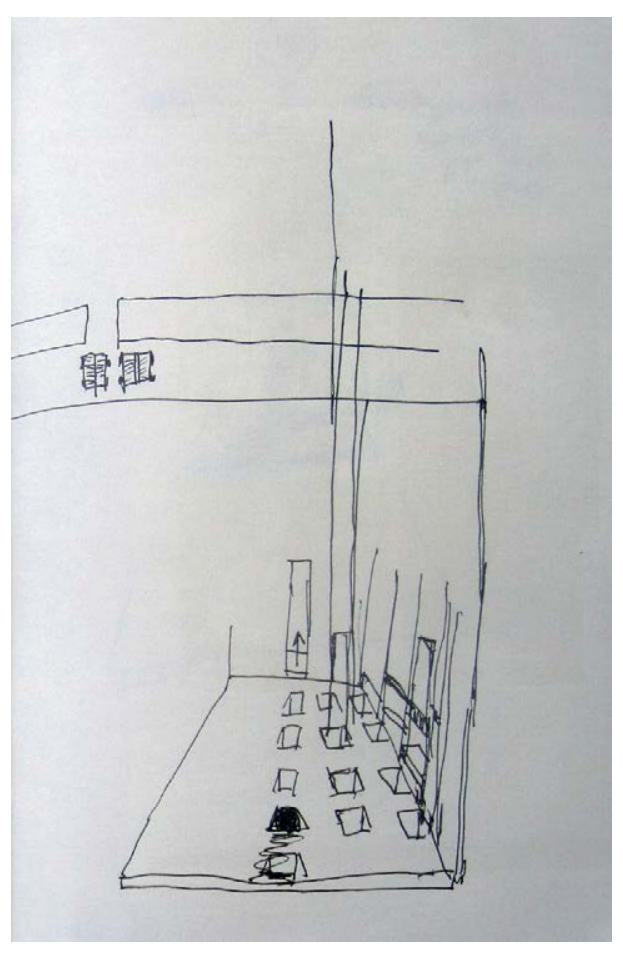

Cuaderno de notas del artista $n^{\circ} 20$. 2000-2001

proporciones muy distintas a la Tate. La instalación de Double Bind se adapta a la sala de turbinas, se apoya en sus paredes, coincide con los planos existentes, se mimetiza con su estructura y juega con los elementos existentes. El Hangar Bicocca es una amplia nave de proporciones vastas y menor altura que la Tate. Bajo el criterio de Cristina Iglesias, Vicente Todolí y James Lingwood ${ }^{52}$, se procura una adaptación de la instalación que mantenga toda la esencia de Double Bind, no se búsca la réplica exacta, se busca adaptar la obra a este nuevo espacio, y que cobre sentido aquí, en el Hangar. Muñoz pensaba que al volver a sacar una obra de una caja, había que repensar su condición, darle una nueva vida. Reproducir literalmente Double Bind en este espacio hubiera limitado la capacidad de sorprender de la obra. Era más interesante explorar las cualidades espaciales del Hangar e instalar aquí Double Bind, explotándola al máximo.

52 Colletta, Federico The Hangar Bicocca Variant en Juan Muñoz, Double Bind and Around, Mousse Publishing, Milan, 20015, p. 168. 

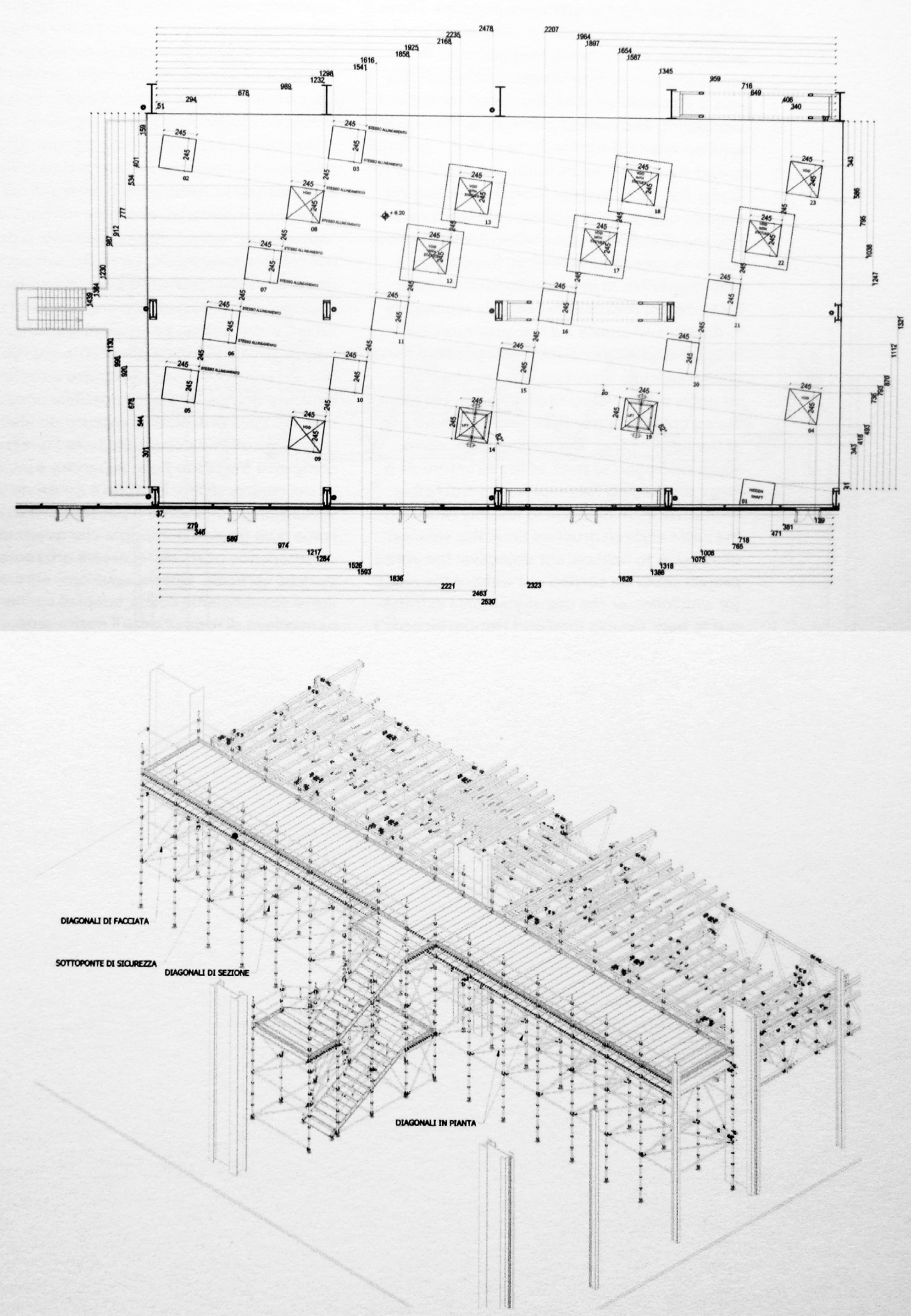
En cuanto a la estructura, se construye un gran plano horizontal mediante una estructura modulada, que se descuelga de los grandes pilares metálicos existentes. Con este sistema estructural, no es necesario incluir ningún apoyo bajo el forjado, por lo que el espacio inferior es, en el Hangar, un oscuro estrato con huecos de luz en el techo, y una circulación libre, tan solo interrumpida por las dos grandes columnas existentes, y las cajas de los dos ascensores. Esta nueva condición no tiene una repercusión negativa en la experiencia de la obra, es diferente, pero la sensación en el nivel inferior sigue siendo oprimente, y los huecos de luz crean la confusión necesaria para que el recorrido sea laberíntico. Aquí la luz parece salir del intestino de la obra, la nave es opaca y se ha procurado mantener una atmósfera tenebrosa en toda la sala de la exposición. La imposibilidad de leer una retícula en el piso inferior, lleva a un recorrido desordenado, y el espectador no es capaz de recordar si se ha asomado ya por ese hueco. La sensación es la de una ciudad infinita. La instalación queda delimitada en uno de sus lados por una pared existente de la nave, otros dos se cubren con grandes cortinas negras, y el frente se deja abierto; es el acceso al piso inferior. En este caso, el acceso es único, la Tate Modern ofrecía la posibilidad de acceder directamente a la sala a través de la entrada norte del museo, o, desde el nivel inferior de la galería, decidir si subir por las escaleras a la plataforma existente, o alternativamente continuar en este nivel inferior introduciéndose en la oscuridad. No existe en el Hangar una estructura parecida, todo ha de construirse desde cero. Se recurre a una estructura de andamiaje (que se deja vista) para construir una escalera que lleva al piso superior. El número de huecos es el mismo, sin embargo, la disposición es algo diferente (como lo es la geometría del plano). Se consigue de este modo el mismo efecto, tanto desde el plano superior como desde el nivel inferior. En el Hangar no existe el dramatismo vertical, pero los ascensores siguen teniendo un importante papel formal y narrativo en la composición. La instalación de Double Bind en la Tate Modern y en el Hangar Bicocca tiene una resolución diferente, sin embargo, la dinámica que transmite la obra se mantiene intacta. Muñoz buscaba no repetirse, pero de algún modo reivindicaba ciertos temas. "Permítaseme una y otra vez" insistía Muñoz. 

4 EL INFIERNO 


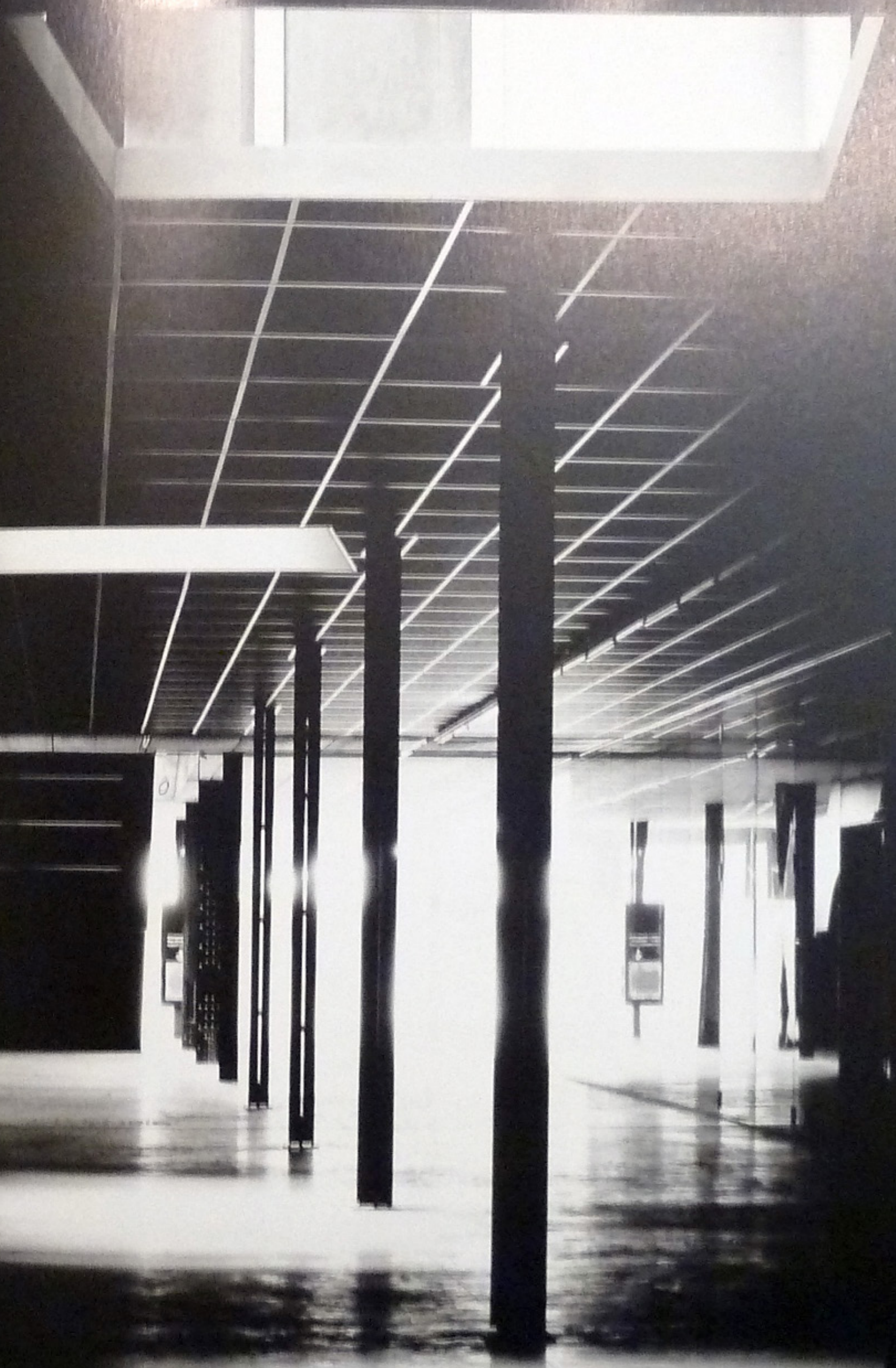


"Per me si va ne la città dolente,

Per me si va ne l'etterno dolore,

Per me si va tra la perduta gente.

...Lasciate ogni speranza, voi ch'intrate"

Divina Comedia. Infierno. Canto III. Dante Alighieri.

“ ...Vosotros que entráis, abandonad toda esperanza.” , escribió Dante a las puertas del infierno. El infierno es la primera de los tres Cantos de la Divina Comedia. Está formado por nueve círculos, en los que son sometidos a castigo los condenados. El poeta accede a él a través de un vestíbulo en forma de bosque. En el infierno encuentra sepulturas, pozos, pantanos y arenales. Los condenados: los lujuriosos, los glotones, los avariciosos, los coléricos, los herejes, los violentos, los fraudulentos y los traidores, viven allí, agrupados según los pecados cometidos, sin mezclarse. Un lugar variado, como variados son los pecados. La cuarta zona del último círculo del infierno de Dante es un pozo profundo con un gran lago de hielo, tan ardiente como el fuego, frío y silencioso. En la Edad Media el infierno se concebía como un lugar subterraneo y por lo tanto, oscuro. En la mitología griega, el infierno o Hades se sitúa al oeste, hasta que se concibe una tierra redonda y pasa a ubicarse en el subsuelo. En este inframundo se sitúa el Tártaro, que tiene una mayor equivalencia con el infierno cristiano, el lugar más profundo y tormentoso. El Hades es el 
lugar de los muertos, el Tártaro, un lugar de castigo. El Averno romano corresponde a este mismo inframundo del Hades griego, un lugar igualmente húmedo y oscuro.

Cuando nos adentramos en la oscuridad que plantea Muñoz bajo el plano gris, entramos en un bosque de pilares donde perdemos la orientación hasta que nuestra vista se acostumbra a la oscuridad y, como si hubiéramos entrado en el infierno de Dante, empezaremos a encontrar a los individuos que lo habitan organizados en patios que, quizás tengan algo que ver con los círculos del poeta florentino. 


\subsection{La imagen prohibida ${ }^{1}$}

Si al subir a la pasarela nos encontramos frente al espacio vacío sobre el plano abstracto desde donde elevamos la mirada hacia lo alto, bajo ella nos adentramos en un espacio oscuro en el que el visitante no sabe lo que se va a encontrar. Como quien se mete de un cueva dejando la claridad del día, el contraste hace que surja una sensación de incertidumbre y a la vez de sorpresa. La pasarela del museo continúa por un volumen que mantiene sus cotas inferior y superior y que se apoya sobre esbeltos pilares metálicos en el espacio de oscuridad inferior. Al poco de entrar el ojo se habrá acostumbrado a la oscuridad y podrá distinguir algunos huecos dejan entrar un poco de luz. Al fondo, casi desdibujadas por la oscuridad, se advierten las dos cajas de los ascensores que desde ya habíamos visto desde la pasarela. De este modo, nos encontramos aquí con la realidad y el origen de los elementos que parecían estar, sin ninguna certeza, en el cielo.

Cuando nos acercamos a los huecos y elevamos la mirada, se nos descubren fragmentos de una ciudad suspendida, ventanas y puertas crean un entorno urbano en este mundo intermedio donde habitan algunas figuras que se relacionan entre sí, independientes de lo que sucede a su alrededor.

La sensación es completamente diferente de la que se tiene arriba, en el cielo, no solo por lo que se ve, sino por cómo se experimenta, sin la posibilidad de saber que nos dirigimos hacia el centro de la pieza. Nos adentramos en la oscuridad, atraídos por la luz que atraviesa las perforaciones del forjado, y nos encontramos con lo inesperado. Como en $A$ Place Called Abroad (DIA, Nueva York, 1996) nos introducimos en de un espacio que en una ciudad podría ser un aparcamiento, una sala de maquinas o un almacén vacío. Cuando Muñoz visito la sala de turbinas junto a su mujer, la escultora Cristina Iglesias, antes de la instalación, le intereso cómo, para ella, entrar en la sala a través de la rampa y adentrarse

1 Muñoz, Juan, La imagen prohibida en Juan Muñoz: Escritos/Writings. Ediciones de la central. Barcelona, 2009 p. 159. Públicado por primera vez como A imagem proibida. Tarantino, Michael, Juliao Sarmento, Fundaçao Serralves, Oporto, 1992 (cat. Exp.). 


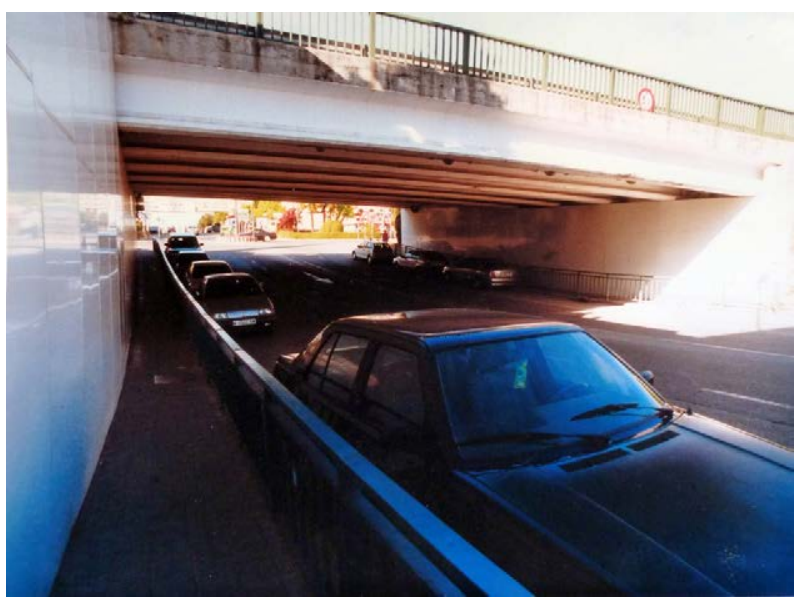

Documentación del artista. Cortesía del

Estate de Juan Muñoz.

Documentación del artista

Cortesia del Estate de Juan Muñoz
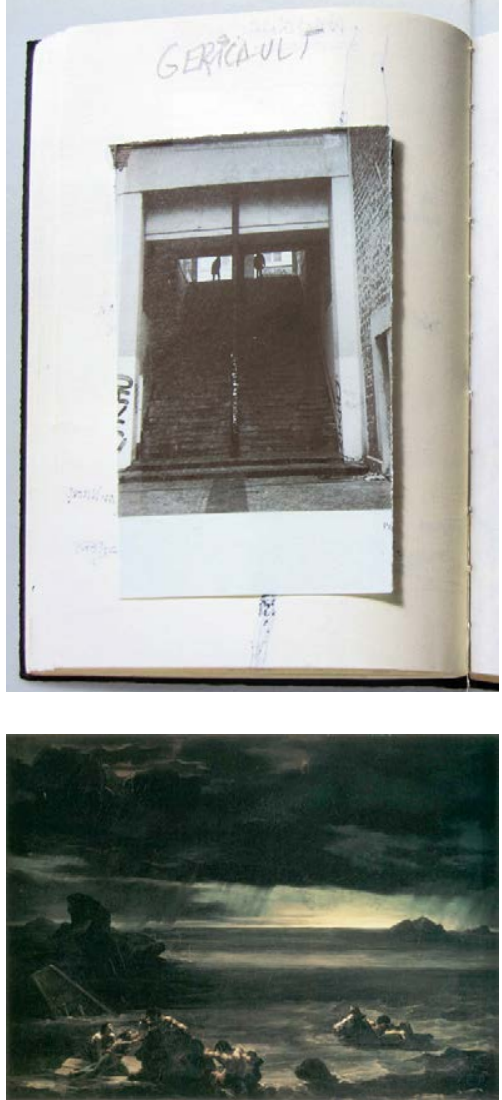

Cuaderno de notas del artista. 2000-2001

en este espacio le recordaba la entrada en los aparcamientos de la ciudades ${ }^{2}$, espacios a los que accede desde la calle con luz. Se abre ante nosotros sin apenas ornamentación y la luz se reduce a mínima, la necesaria para orientarse y llegar a la plaza de aparcamiento. El modo en que el visitante experimenta esa transición le interesó a Muñoz, que cambió la forma en la que había mirado la sala hasta entonces. Le ofrecía una nueva oportunidad para jugar con las sensaciones del espectador, poner en jaque su confianza y sacarlo de lo convencional para introducirlo en lo desconocido.

“GERICAULT," escribe Muñoz en su cuaderno de notas. El pintor francés (1791-1824) es conocido por sus imágenes dramáticas. La enfermedad, al final de su corta vida le lleva a tener una visión pesimista, dedicando sus últimos años a retratar enfermos mentales.

2 Muñoz, Juan. Lingwood, James. A Conversation, May 2001 en Juan Muñoz, Double Bind at Tate Modern. Tate Publishing, London, 2001. p. 69. Juan Muñoz: "The moment when my wife Cristina (the artist Cristina Iglesias) said that coming down the ramp at Tate Modern made her feel as if she were going into a parking lot was important.' 
En muchas de sus obras la muerte acecha y se retrata el sufrimiento físico y psíquico del hombre. Como en las obras de Gericáult, Muñoz buscaba esa carga emocional al límite de lo aterrador y desconocido, sin sentimentalismos, con fuerza desgarradora de la que se desprende la unión de calor y frío que desata una escena de tensión. En la escena del diluvio (aproximadamente 1818) de Gericault, un cielo oscuro y amenazante oprime el espacio de la misma manera que sucede en este piso inferior de Double Bind. Se respira una sensación de ausencia, incluso ante la presencia de otros espectadores, la sensación de oscuridad y frío lleva al aislamiento, a sentirse perdido, envuelto en un silencio que no está relacionado con la ausencia del ruido. Los otros espectadores se ven sólo como siluetas, sin poder desenmascarar sus gestos, la sensación es de intranquilidad y sospecha. Esa ausencia planteada por Muñoz en los balcones resurge en esta obra: "La figura estaba implícita en el balcón vacío, por eso era innecesario ponerla”3.

Tanto en el cielo como en el infierno la figura escultórica permanece ausente, el espectador circula por un espacio donde el espectador es la figura. James Lingwood destaca este hecho en una obra pasada de Muñoz en el Irish Museum of Modern Art, en una sala con un suelo pintado, Muñoz instala algunos colgadores en la pared y todo lo demás es ausencia. Muñoz dice "Para mí era importante llegar a una conclusión no figurativa. Conseguir una ilusión enorme, de forma que no hubiera nada que mirar sino la ilusión misma." ${ }^{4}$ La ilusión va más allá en este espacio, cuando el espectador se encuentra con las figuras donde nunca esperaría encontrarlas, asomando alrededor de los huecos que quedan sobre su cabeza. Podríamos utilizar las propias palabras de Muñoz de un escrito de 1990 para describir la sensación de ausencia y presencia tanto en los balcones, como en el nivel superior de Double Bind, o aquí, en este piso inferior: “Este lugar aloja en su interior esa tensión entre la suspensión de la presencia humana y su posible aparición. Entre su ida y su posible vuelta" 5

3 Muñoz, Juan. Lingwood, James. Una conversación, Enero 1995. en Monólogos y diálogos. MNCARS. 1997. P. 124.

4 Muñoz, Juan. Lingwood, James. Una conversación, Enero 1995. en Monólogos y diálogos. MNCARS. 1997. p.125.

5 Muñoz, Juan, Segment, en Juan Muñoz: Escritos/Writings. Ediciones de la central. Barcelona, 2009 p. 139. Públicado por primera vez en Juan Muñoz, The Renaissance Society at the University of Chicago, Chicago / Center d'Art Contemporain, Genéve, 1990 (exh. cat.). 


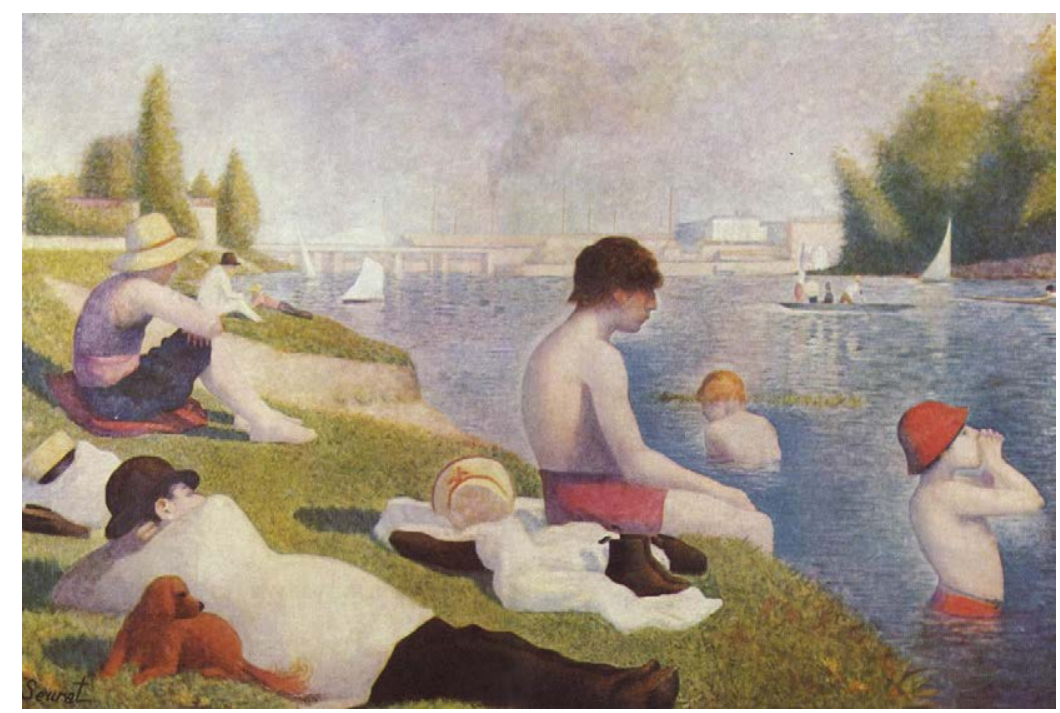

Bañistas de Asnières, 1884. Georges Pierre Seurat

La sensación de soledad y aislamiento en el espectador le lleva a percibir la ausencia, una ausencia entendida como la separación de un lugar y de una realidad conocida. Un aislamiento mental, impenetrable, abstracto, el del vacío dentro de uno mismo, donde sólo se escucha el eco. Muñoz reflexiona ante el cuadro delos bañistas de Seurat en la National Gallery de Londres: "esos espacios entre toda esa gente que mira al río..., entre ellos sólo hay distancia; todos permanecen quietos, silenciosos, y a su vez cada uno parece ocupar un espacio de silencio.(...). Al mirarlos me di cuenta de que no me interesaba la formulación que escondía la obra. Me interesaba la soledad increíble de los personajes(...) Pensé en la imagen del alma mirando al desierto (...); la indiferencia de la tarde soleada es paralela a una tensión enorme. Me va a costar muchos años alcanzar esa claridad.”6 La oscuridad, los huecos de luz, la mirada elevada, llevan al espectador a esa soledad, a ese aislamiento que le deja en contacto con el espacio físico presentado pero que le distancia

6 Muñoz, Juan. Lingwood, James. Blazawick, Iwona y Schlieker, Andrea Una conversación, Julio 1990. en Monólogos y diálogos. MNCARS. 1997. p.63. 
de otros individuos. Pasando inmediatamente a conectar con la obra, estableciendo el ansiado diálogo entre el espectador y la obra, en la intimidad del aislamiento psicológico.

A finales de los años ochenta, Muñoz realiza varias esculturas donde el tema central es el muñeco del ventrílocuo, figura que se presenta ante el espectador en ausencia de un ventrílocuo, como un cuerpo mudo al que Muñoz sigue atribuyendo cualidades que van más allá de un ser inanimado. El muñeco del ventrílocuo era entonces la pieza central de la obra, pero desde aquellos ejercicios, podría decirse que sus obras son muñecos de ventrílocuo; todas ellas son el medio de transmisión del mensaje del artista, congeladas en un momento determinado, en ese punto en el que el artista las da por terminadas y las presenta en un instante y las abandona delante del espectador sin añadir ya más palabras. Dice del muñeco del ventrílocuo que "Coloca al espectador entre la luz y la realidad, entre el artificio y la pared. Devuelve a la mirada la sombra que en su cuerpo proyecta" ${ }^{7}$

El escultor ofrece al espectador un recorrido por un espacio de extrañeza sorprendiendo de nuevo cuando al situarse bajo los huecos observa al mirar hacia arriba y se encuentra con un mundo diferente. Algunos huecos están cerrados en sus cuatro lados perimetrales, otros con retranqueos que muestran un tercer paisaje insospechado que da un vuelco al entendimiento del espacio superior y de la obra en su conjunto. Es un espacio de transición para el espectador, el medio en el que confluyen la apertura del espacio superior y lo que ocurre en el interior del estrato intermedio. Estratos de una misma fase, que dialogan en sus formas y se complementan pero que ofrecen visiones totalmente diferentes.

Descolgados en el forjado, patios de manzana con paredes blancas y persianas metálicas aparentemente cerrando ventanas, parece que todo esta dormido. Hacia el fondo de la sala, la ciudad de este mundo suspendido comienza a abrirse, los muros de ciertos huecos se retranquean un poco, y en estas pasarelas aparecen los "ciudadanos", esculturas realistas en resina gris, muy semejantes unas a otras, y que realizan actividades distintas, algunas interaccionando entre sí, dando la sensación de que este lugar habitable ha existido desde siempre, y llegando a resultar extrañamente familiares.

7 Muñoz, Juan. Ilusionismo, percepción, proyecto. Juan Muñoz: Escritos/Writings. Ediciones de la Central. Barcelona, 2009, p. 71. Públicado por primera vez en Sur Express, 1, 15 Abril-15 Mayo, p. 35, 1987. 

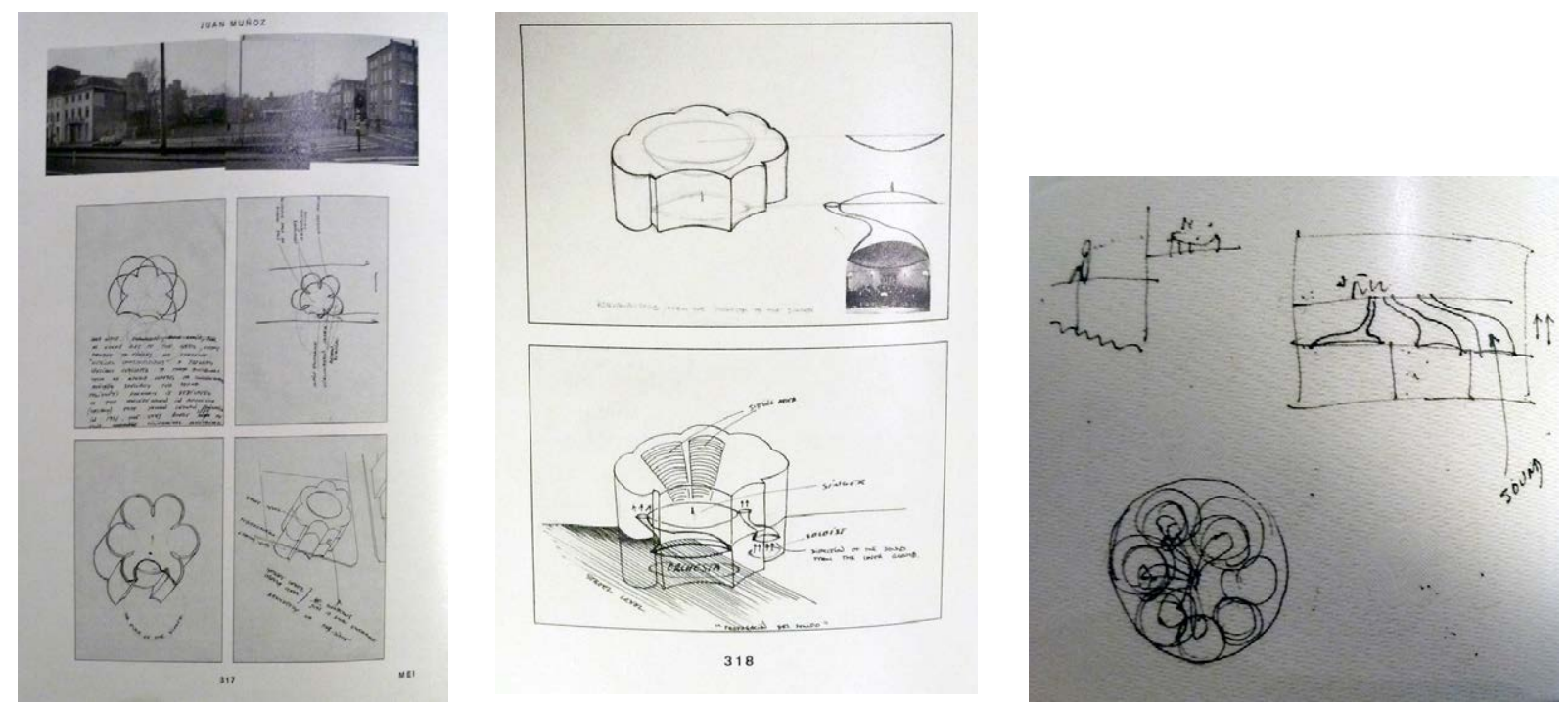

A Building for Muisc. 1993. Juan Muñoz

Como en un aparcamiento, la escala de este espacio no es urbana. Este nivel se percibe como un interior, dentro de otro espacio interior, el del museo. Los ascensores que llegan al nivel inferior ayudan a enfatizar esta idea. Los huecos quedan en un lugar ambiguo, difícil de clasificar como dentro o fuera, y siendo así, al mirar hacia ellos, seguimos localizándonos en un interior, o quizás en un nivel bajo tierra, un submundo. Al mirar a través de los huecos nos sentimos expuestos a un espacio exterior. Se establece la conciencia de estar debajo, de comprender los distintos estratos que componen la obra, y saberse situado en el espacio oprimido bajo el peso volumétrico de lo que queda encima.

La concepción de espacios y la composición arquitectónica han formado parte de la obra escultórica del artista, y han sido también tema central de otros medios de expresión artística producidos por el escultor. Building for Music es una obra en colaboración con el compositor Alberto Iglesias realizada para Sonsbeek 93 (Arnheim, Paises Bajos) y promovida por Valerie Smith, quien le invitó a participar en esta exposición tras 
escuchar a Muñoz presentar unas ponencias durante un congreso en Eindhoven en el Van Abbemuseum en $1991^{8}$. Entre los tres acordaron realizar una pieza sonora que sería presentada como un programa de radio similar a los producidos junto a compositor Gavin Bryars en los estudios de la BBC en 1992 (A Man in a Room, Gambling), un texto leído en inglés por el escultor acompañado de música y sonidos y presentado como si se tratara de un programa de radio en directo grabado en un coche en movimiento (teóricamente dirigiéndose a un solar en Arnhem). Lo que aquí interesa es la configuración espacial de la descripción que el narrador hace sobre un proyecto ficticio realizado para una sala de conciertos en Arnhem. La trama narrada por Muñoz, que a su vez pone voz al arquitecto, explica como el edificio había desaparecido tras los bombardeos en la ciudad durante la Segunda Guerra Mundial y describe lo que en realidad es un diseño de Muñoz. Una sala polilobulada (a base de circunferencias que se intersectan), genera varios espacios que engendran uno de mayor tamaño. Subdividida en dos niveles "Uno subterráneo para los músicos y la parte superior para el público...dos auditorios en uno"9 , el sonido asciende mediante unas trompas a la parte superior. El cantante se sitúa en el medio del espacio central y en el nivel inferior, la orquesta, invisible al público. Sin duda un proyecto radical para una sala de música. La estrategia de estratificar las diferentes secciones de una sala de música tradicional en una distribución vertical recuerda a los niveles de Double Bind. Separa los niveles de interacción de los distintos grupos de individuos, clasificándolos según su función en distintos niveles, unos sobre otros. La orquesta en el subsuelo, los cantantes en el nivel inmediatamente superior, y los espectadores en gradas ascendentes alrededor del espacio central. Ahora en la Tate, Muñoz define donde el espectador puede entrar y donde solo debe observar, mientras que las figuras quedan aisladas en un espacio reservado solo para ellas. Además, Muñoz ilustra el relato con unos dibujos a mano alzada de plantas, axonometrías e incluso un collage donde sitúa a la orquesta en el nivel inferior y mediante una cornucopia situada en el techo del piso inferior, el sonido asciende a la escena y coloniza el espacio principal donde se localizan los espectadores en gradas perimetrales. “...un sonido que venia de lejos...un sonido que venia de abajo"10

8 Smith, Valerie. Una voz sin Brújula en Juan Muñoz La voz sola. Esculturas, dibujos y obras para la radio. La Casa Encendida 1992 p.63.

9 Muñoz, Juan. Building for Music en Juan Muñoz: Escritos/Writings. Ediciones de la Central. Barcelona, 2009, p. 55. El texto fue escrito en 1993.

10 Ibis p 239. 


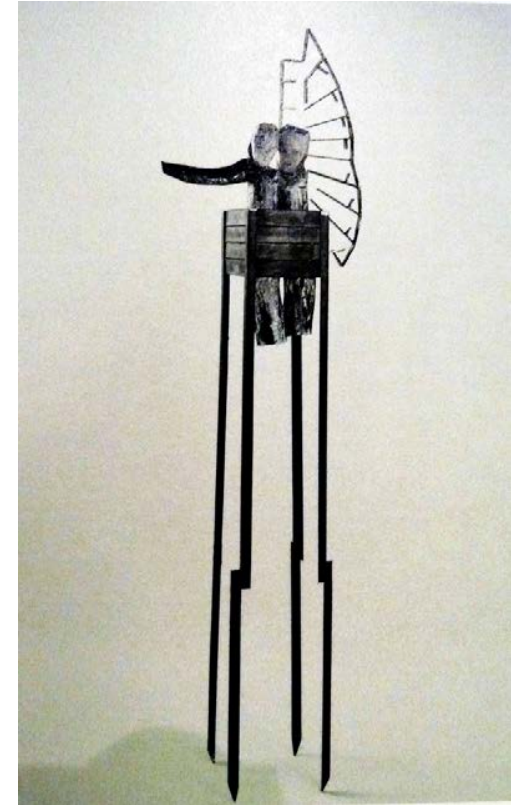

Pieza con Alvar Aalto, 1984. Juan Muñoz

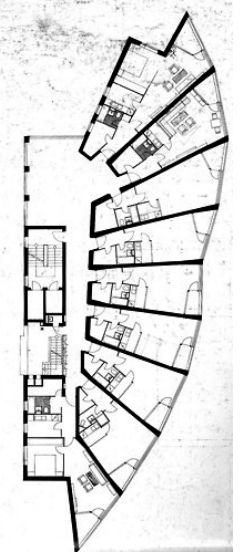

viviendas Neue Vahr'. Alemania. 1959-1962. Alvar Aalto

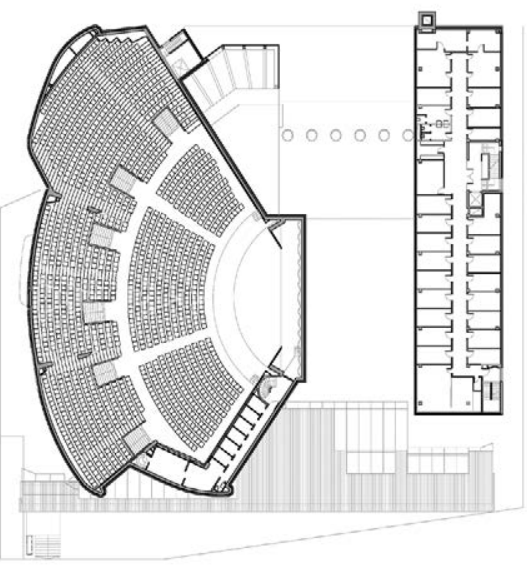

Casa de Cultura. Helsinki. 1952-1958. Alvar Aalto

Imágenes de A Building for Music. La sección que muestra los dos espacios inferor de la orquesta y el superior

Tiene también interés apuntar como Muñoz menciona el Kulttuuritalo Hall de Helsinki de Alvar Aalto y el pabellón Philips de la Feria Mundial de Bruselas de 1958 de Le Corbusier y Xenakis anotando que el primero fue pensado para tener un "tiempo de resonancia muy bajo", mientras que el segundo, se presentaba como "una clara construcción para la música”. No pasa desapercibido el estudio que realizó Muñoz para escribir este texto, para el cual investigó sobre distintas salas de música y profundizó en patentes de materiales y técnicas de construcción para evitar el eco. ${ }^{11}$ En 1984 presenta en la Galería Pedro Vijande de Madrid uno de sus minaretes, bajo el título de Pieza con Alvar Aalto. Dos figuras en madera subidas sobre un minarete de hierro, a modo de bandera aparece en hierro los muros de la planta del edificio de viviendas 'Neue Vahr' (Bremen, Alemania, 1959-

11 Mari, Bartomeu. Emitiendo...El uso de la radio en la obra de Juan Muñoz en Juan Muñoz La voz sola. Esculturas, dibujos y obras para la radio. La Casa Encendida. 1992 p.63. 
1962). La planta tiene una similitud geométrica con la de la Casa de la Cultura de Helsinki (Kulttuuritalo en finés. 1952-1958), también de Alvar Aalto, que presenta una sala para conciertos. A la misma serie pertenece la obra de Minarete para Otto Kurtz (1985). Dos esculturas con una materialización similar, pero con narrativas muy diferentes, cada una de ellas orientada a distintos intereses del artista relacionados con otros ámbitos de la cultura, como son la arquitectura y la historia del arte. Aquí se demuestra como Muñoz arrastra estos intereses a lo largo de su vida, y vuelve a ellos en distintas situaciones, los estudia y los exprime.

Parece posible encontrar casi siempre una narrativa detrás de todas las obras de Muñoz. En sus piezas para la radio mezcla música y narrativa, escondiendo esta vez al ventrílocuo detrás de las ondas, y dejando que el sonido llegue a través de la radio. Esas obras de difusión tienen también un cierto carácter temporal. Aunque eran piezas grabadas, se procuraba que respondiesen a un momento preciso de la emisión de un programa concreto, aunando ficción y realidad, momento presente con momento futuro y pasado. Al oir las piezas, se escucha "en el programa de hoy" o "en el programa de ayer". Este tipo de narrativa de ficción atada a un momento preciso despierta un juego que traslada a la audiencia a otros tiempos y otras realidades. ¿Nos transporta la pieza al pasado o quizás este ocurriendo en el presente? El sonido, la voz, el lenguaje, otra manera de conquistar el espacio y el tiempo, otra forma de experiencia para el espectador, que es ante estas piezas sonoras, oyente.

La parte inferior de Double Bind se asemeja a aquella que reserva en A Building for Music para la audiencia, la inferior, y de menor altura. En oposición a la amplitud volumétrica que encontramos en el piso superior de Double Bind, aquí la altura es mucho más reducida y queda agudizada por la oscuridad. En este nivel, el plano del techo, de color gris oscuro, oprime el espacio bajo él. Está sostenido por delgados pilares metálicos que producen un efecto de perspectiva que se rompe con la desordenada entrada de luz a través de los huecos. La altura del espacio inferior compromete la altura del estrato intermedio. La base superior del forjado viene dada por la altura existente de la plataforma, por lo que el escultor debe decidir cual es el espesor del volumen intermedio y la altura restante del nivel inferior. Muñoz juega por un lado a mimetizarse con el espacio y ,por otro, a apoderarse de él utilizando todos sus registros. Es un diálogo entre la galería y el 
escultor: 'La escultura es espacio por negación. Al aparecer en el espacio hábil, se apodera de los poderes que ya existían allí y los conjuga. La escultura moderna quiere ser espacio irreconocible por cotidiano.' En este texto de 1982, Dejar una inscripción en el espacio, Muñoz escribe las bases de lo que acontecerá en la sala de turbinas. Un espacio existente, conocido por muchos, espacio que quedará sometido a su obra por un tiempo. Para que esto suceda, Muñoz mimetiza partes de su obra con la sala siguiendo el lenguaje arquitectónico existente, resolviendo los pilares con una estructura similar a la del edificio. Consigue así que la instalación y la sala colaboren a la par en esta provocación para los sentidos que se mueven entre lo cotidiano y conocido (el museo) y lo desconocido (la instalación). Esta provocación crea una extraña sensación de olvido, un olvido realmente inexistente. El espectador que conoce la sala, percibe la anomalía, pero el engaño despista, los recuerdos se emborronan, se difuminan los límites entre lo que era y lo que es ahora, en ese momento en el tiempo en que Double Bind extiende ese nivel central hasta chocar con la fachada oeste de la sala. Con esta secuencia de pilares, según la posición del espectador, se puede apreciar una ordenada retícula, o un bosque desorganizado, de elementos verticales. En su texto Segment, donde Muñoz vuelve a demostrar su conocimiento e interés por la historia de la arquitectura escribe: "Geoffrey Scott, posiblemente en calidad de alumno de Berenson, quiso resumir los valores específicos de toda construcción. Scott decía que al entrar en una iglesia y confrontados desde el fondo de la nave con una larga perspectiva de columnas, el espacio mismo nos sugería el caminar hacia delante, hacia la conclusión de este movimiento, hacia el altar. < Porque un movimiento sin motivo y que no conduce a un punto culminante, contradice nuestros impulsos: no es humano $>$...Cruce de caminos, lugar de tránsito. Espacio inscrito en su propio exilio."12. Hemos establecido en el segundo capitulo de esta tesis, al describir la sala de turbinas, alguna relación de similitud entre esta galería de la Battersea Power Station y la nave central de una catedral gótica. Con la instalación de Muñoz, desaparece la clara lectura de esta semejanza. Tiene más que ver con una iglesia barroca, que no necesariamente culmina en un altar, y que con todos los elementos decorativos, la continuidad de sus cornisas, la multiplicidad de las columnas, lleva al ojo de un lado a otro. En el piso inferior de Double Bind no hay un delante, la

12 Muñoz, Juan, Segment, en Juan Muñoz: Escritos/Writings. Ediciones de la Central. Barcelona, 2009 p. 127. Públicado por primera vez en Juan Muñoz, The Renaissance Society at the University of Chicago, Chicago / Center d’Art Contemporain, Genéve, 1990 (exh cat.). 
retícula de pilares se vuelve laberíntica, la conclusión del movimiento lleva hacia la luz, en este caso, a la luz que proviene de los huecos en el techo. Múltiples focos que generan múltiples recorridos. Según donde se fije la atención del espectador, tenderá a aproximarse a ese foco, pero no existe orden no hay principio ni fin.

Volviendo a los bosques de pilares, Muñoz escribe en Construyendo Imágenes: Juan Muñoz ${ }^{13}$ una visión personal sobre el Museo de Mérida de Moneo. El edificio le recuerda a la arquitectura ficticia de Piranesi, escribe "A veces pienso que este edificio es una gran mentira. Una mentira necesaria, Un inmenso escenario que nos permite acceder al interior de una ilusión - hasta el tamaño es engañoso, parece mucho más grande de lo que es en realidad." Del mismo modo esta retícula de delgados pilares, probablemente no todos ellos estructuralmente necesarios, resulta también engañosa, según la perspectiva se dificulta la lectura del espacio, resultando en un lugar enmarañado, multiplicando así su extensión, a modo de laberinto.

Segment es un extenso texto de Muñoz alrededor de una arquitectura efímera llamada 'La posa' en Zurite, una construcción levantada con palos altos, finos troncos y cuerdas. Esta construcción recuerda a la obra que realiza dos años más tarde en Barcelona: Una habitación donde siempre llueve (Barcelona, 1992). ("Yo quisiera hacer una habitación así, sin esperanza, llena de una lluvia irrefutable, cayendo sobre una conversación indiferente"14). En el cuerpo de este texto, Muñoz entrelaza la historia de la construcción y derribo de esta pequeña habitación sin paredes ni techo al mismo tiempo que intercala reflexiones sobre el habitar. Recopila comentarios de Rossi, E. Lévinas, o Francesco Dal Co e identifica La Posa como la "primera casa, el primer lugar construido para habitar... todo surge de la necesidad de esconderse del exterior"15. Muñoz relata que en un escrito se narra como en una ciudad, los carmelitas construyeron una iglesia tomando una calle de pared a pared, ${ }^{16}$ casi de la misma manera que el toma la sala de turbinas de pared a

13 Muñoz, Juan, Construyendo Imágenes: Juan Muñoz en Juan Muñoz: Escritos/Writings, Ediciones de la Central. Barcelona, 2009 , p. 155.

14 Muñoz, Juan, El rostro de Pirandello en Moure, Gloria, Urban Configurations, Pligradía, Barcelona 1994, p.118.

15 Muñoz, Juan. Segment en Juan Muñoz: Escritos/Writings. Ediciones de la Central. Barcelona, 2009, p.129. Públicado por primera vez en Juan Muñoz, The Renaissance Society at the University of Chicago, Chicago / Center d'Art Contemporain, Genéve, 1990 (ext. Cat.).

16 Ibíd. p. 133. 


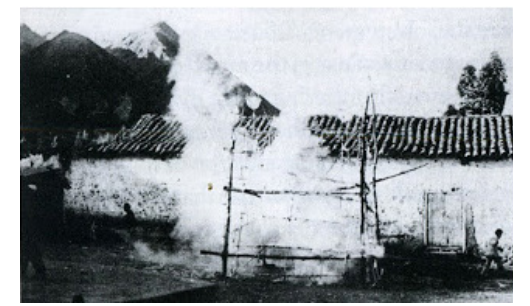

La Posa en Zurite

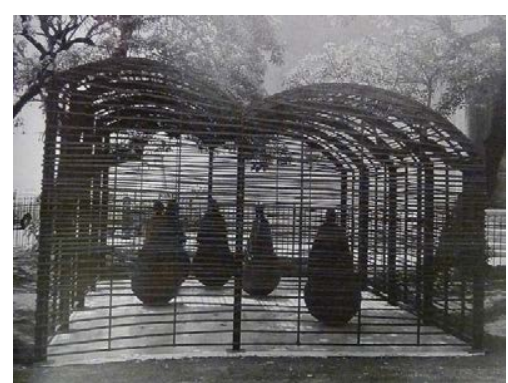

A House Where It Always Rains. Plaça del Mar, Barcelona. 1992. Juan Muñoz.

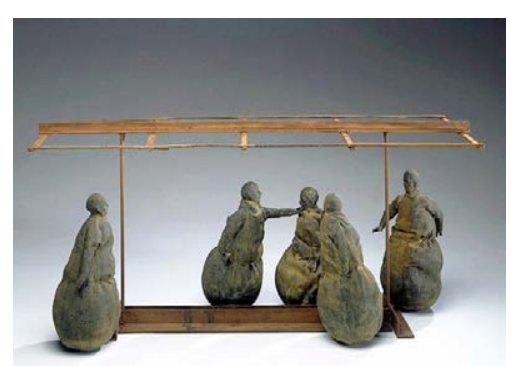

Untitle-maqueta para Last Conversation Piece. 1994. Juan Muñoz

pared para crear este espacio inferior. De igual modo que La posa, Double Bind es una estructura efímera, y cómo en ésta 'en el transcurrir del tiempo, la única permanencia es su descripción.'17

En la galería Matt's de Londres, la artista Melanie Counsell realiza en 1995 una instalación en la que crea un falso techo a lo largo de toda la galería, una planta libre con una retícula de pilares, reduciendo la altura a un tercio de la original. Muñoz conserva la imagen de esta intervención junto a los recortes que recopiló durante el proceso de creación de Double Bind. El efecto producido en el espacio interior de la galería guarda grandes semejanzas con el resultado final de Double Bind. Como coincidencia, en la Matt's Gallery, uno de los planos laterales de la sala esta compuesto por grandes ventanales, única entrada de luz en la sala, que con los techos más bajos, ha resultado en un espacio algo tenebroso. De la misma manera, el observador situado en el piso inferior de la instalación de Double Bind, y

17 Ibíd.p. 133. 


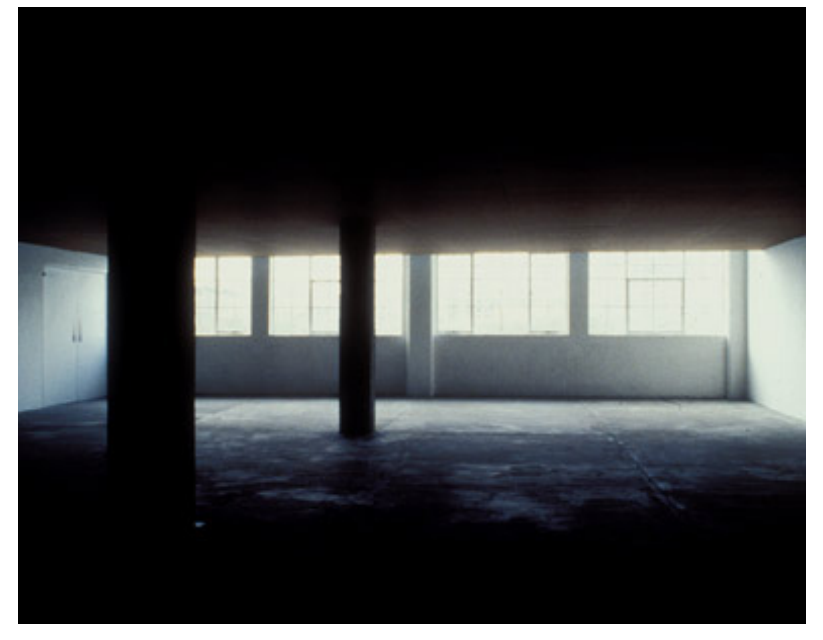

Matt's Gallery,Intervención de Melanie Counsell, 1995. Londres.

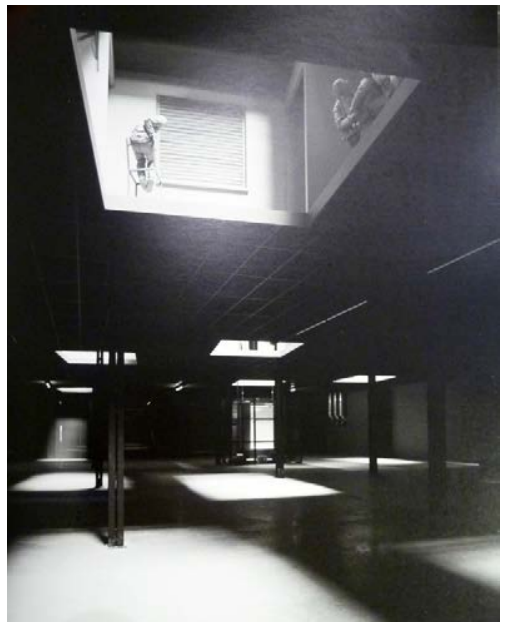

Nivel inferior de Double Bind.

que sumergido en él dirija su mirada hasta la entrada oeste de la galería que va da desde la calle a través de la rampa, tiene una visión similar, todo el plano vertical queda inundado por un foco de luz a modo de pantalla, al fondo del espacio interior. La luz en este espacio se reduce a la de esta entrada, que es la que el espectador deja a su espalda al adentrarse en el piso inferior y a la que penetra por las aperturas verticales a través del forjado.

Los huecos vistos desde el nivel inferior nos permiten descubrir, tanto lo que hay en el nivel superior, como lo esconde el espesor del volumen. Esta vista recuerda a las obras de Gordon Matt-Clark, sobre el cual, Muñoz inventa un pasaje en su texto "Notas afines a tres $^{\prime 18}$ donde busca un precedente en el recuerdo infantil de Matta-Clark como fuente de inspiración para lo sus futuras obras , dice así:

18 Muñoz, Juan, Notas afines a tres, en Correspondencias: 5 arquitectos 5 escultores. Madrid. Ministerio de Obras Públicas y Urbanismo, Dirección General de Arquitectura y Vivienda, 1982, p. 17. 


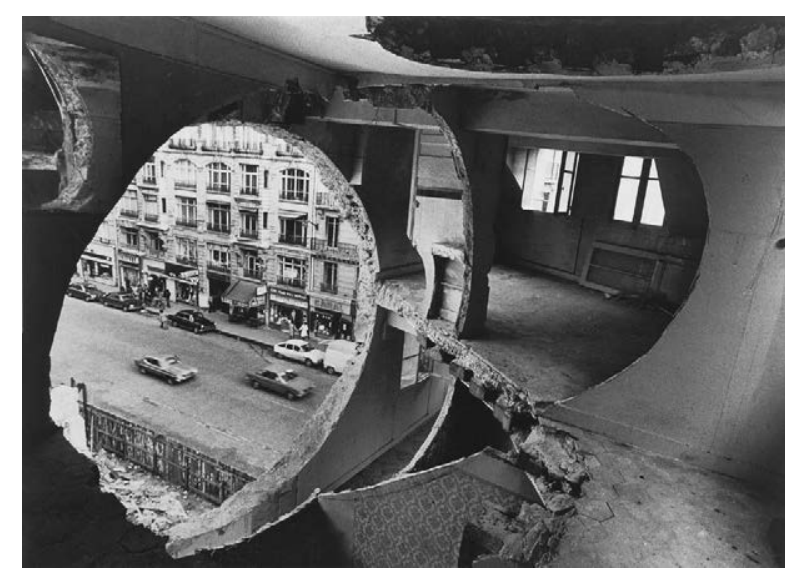

Conical Intersect. 1975. Gordon Matta Clark

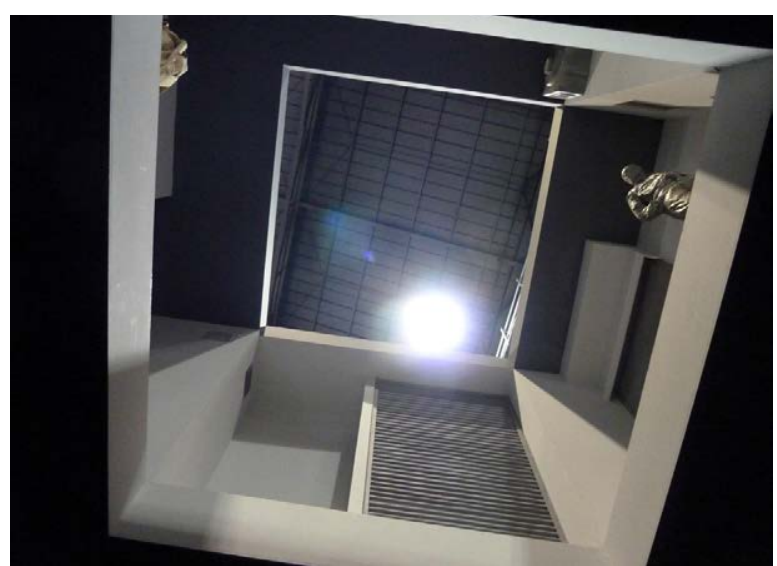

Interior Double Bind

"Es posible imaginar que el gran pintor de origen chileno, Roberto Mata, llevara a pasear a su hijo por las calles de París, donde residió temporalmente. Es igualmente posible o ficticio imaginar que en uno de estos paseos mostrara un interés especial por la complejidad de los arbotantes y arcos de la iglesia del Sacre-Coeur. Permítasenos, en la lícita desmesura de toda ficción, imaginar el momento en el que, una vez dentro, el muchacho observó con especial devoción el rosetón que, a manera de epicentro, aúna y divide a la vez la luz interior de dicha iglesia. Años después, Gordon Matta-Clark, ex estudiante de arquitectura, concibió la actividad escultórica como el acto de abrir en el vientre de varios edificios abandonados una serie de círculos a través de suelos y muros. Esta acción, que permitía la entrada de la luz de un lado a otro y desde un quinto piso hasta el sótano a lo largo de elipses y círculos vaciados en la edificación, bien podría haber sido señal de alarma para aquellos que concibieran un posible dialogo entre los practicantes de ambos oficios" 19 
Esta acción de Matta-Clark, como los huecos de Muñoz, propone una realidad oculta abriendo una nueva perspectiva de visión. Matta-Clark mediante las perforaciones en arquitecturas existentes, y Muñoz proyectando estructuras con una cualidad similar, descubren espacios que están físicamente conectados, pero en los que la conexión visual entre ellos queda impedida por paredes y techos. Mediante la perforación se articulan los espacios ofreciendo una visión casi surrealista. A través de la rotura del sólido, se ofrece una nueva visión de una realidad común. Aunque el trabajo y los intereses de los dos artistas son distintos, ambos muestran una fascinación por el entorno construido y encuentran la necesidad de diseccionar las estructuras físicas dejando al descubierto la realidad social que encierran. 


\subsection{De la luminosa opacidad de los signos ${ }^{20}$}

“el espectador debe de ser colocado en la sombra. Por eso Borromini centra el compás de la iglesia en el tragaluz"

Los distintos estratos y la situación de espectador a distintas alturas respecto de la obra, producen visiones en picado y en contrapicado. Bajo el título del capítulo The View from Above del libro Reflections on Barroque ${ }^{21}$ anota Muñoz "the view from below". En la arquitectura contemporánea al mirar hacia arriba en cualquier espacio interior, uno se encuentra con el plano liso y mudo del techo. En otros tiempos, los techos estaban repletos de cosas a las que mirar, lámparas, molduras, frescos, espejos. Mirar hacia arriba era como mirar más allá de los limites del espacio, muy particularmente en el barroco, donde se intentaba enmascarar la geometría plana del techo llegando incluso a fingir hacerlo desaparecer mediante el dibujo de un cielo abierto. Decorando los techos a menudo se conseguían ilusiones espaciales y eran también un soporte en el que contar historias.

La vista desde abajo es la del espectador, que conecta elevando la mirada con lo que ocurre arriba. La vista desde arriba propuesta por el barroco responde al posicionamiento de la iconografía que se representa en techos planos o abovedados. Si pensamos el fresco de La Apoteosis de San Ignacio (1685-1694) que realiza Andrea del Pozzo ${ }^{22}$ en la iglesia de San Ignacio de Roma, nos encontramos con un techo plano donde se presenta una impresionante perspectiva ilusionista donde es difícil diferenciar que elementos arquitectónicos son reales y cuales no. La luz viene de un Dios situado en el centro, que mira directamente hacia abajo, donde su mirada se encuentra con la del espectador.

En la arquitectura moderna los techos se convirtieron en paramentos horizontales, generalmente blancos que participaban como un plano mas en la configuración de las cajas abstractas con las que se resolvían todos los programas. Hoy en día, los techos son

20 Muñoz, Juan, De la luminosa opacidad de los signos en Juan Muñoz: Escritos/Writings. Ediciones de la central, Barcelona, 2009, p. 55. Públicado por primera vez como De la luminosa opacidad de los signos: Borromini-Kounellis. Figura, 6 , 1985 pp. 93-95.

21 Harbison, Robert, Reflections on Barroque, Ed. Reaktion 2000 p.60.

22 Andrea del Pozzo escribió el manual Perspectiva pictorum atque architectorum-Perspectiva para pintores y arquitectos. (volumen 1:1693, Volumen 2:1698) 


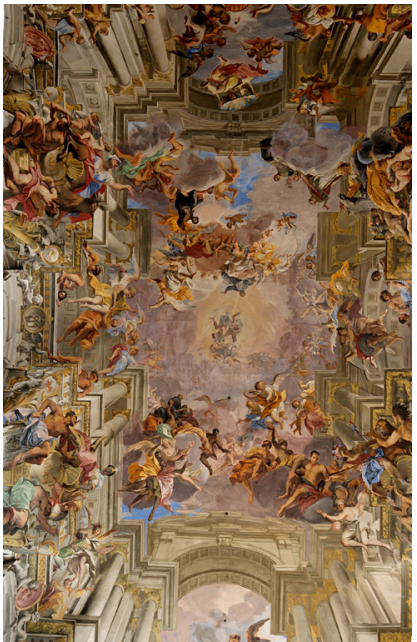

Apoteosis de San Ignacio. 1685-1694. Andrea Pozzo

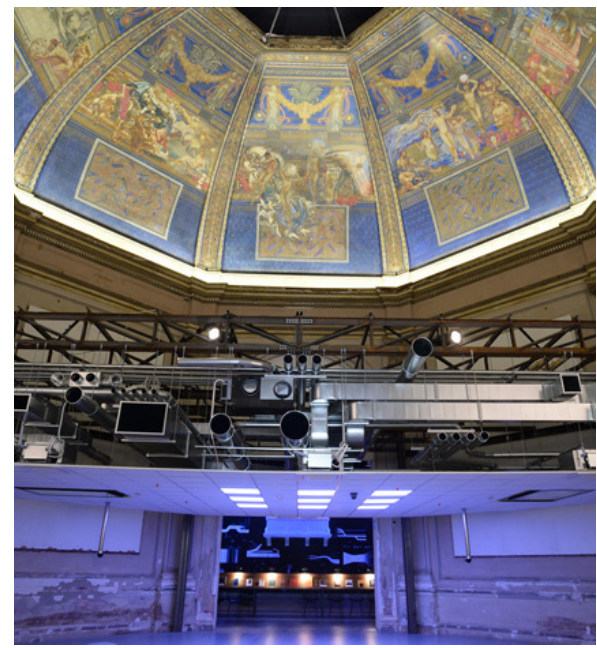

Fundamentals. 14 International Architecture Exhibition. La Biennale Di Venezia. Rem. Koolhaas

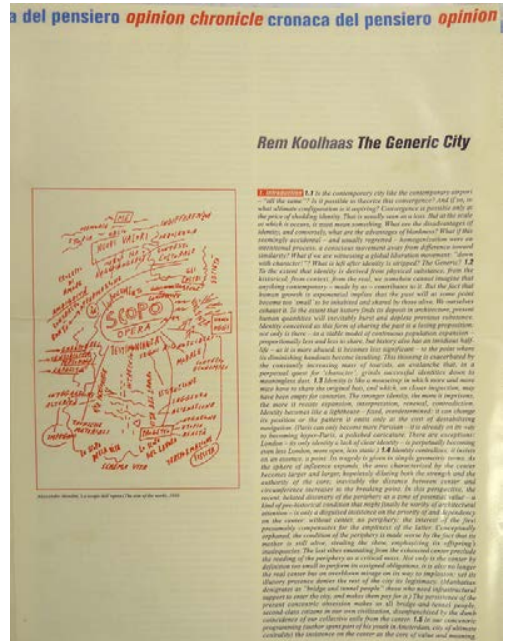

La ciudad generica. Rem Koolhaas Documentación del artista,

Cortesía del Estate de Juan Muñoz

elementos meramente funcionales. De encontrar algo, son las luminarias y una retícula que subdivide el falso techo registrable. Los techos ya no son atractivos de mirar, además sabemos que tras ellos se encuentra lo que Koolhaas llama el "espacio basura", "que es la suma total de nuestro éxito actual”23, donde se aglomeran tubos de aire acondicionado, mecanismos eléctricos, cables y toda una serie de elementos que hacen que el edificio funcione, y que se quieren mantener ocultos. "The ceiling has become a thick volume full of machinery, of which the architect has very little to say. The expression has been reduced to that of a grid."24 El espesor de la sección necesita además de albergar la estructura,

23 Koolhaas, Rem, Espacio basura, 2002, en Walker, Enrique. Lo Ordinario. Editorial Gustavo Gili, 2010, p. 119.

24 Koolhaas dirige la 14 Edición internacional de la Bienal de Venecia en el 2014, llamada Fundamentals. Una visión global sobre la historia de la arquitectura de los últimos 100 años en contraste con la arquitectura histórica. La pieza central de la exposición mostraba un falso techo registrable suspendido bajo una cúpula restaurada y decorada con frescos. Sobre el techo registrable y visible en el perímetro, todos los conductos mecánicos que se utilizan hoy en día en arquitectura. 


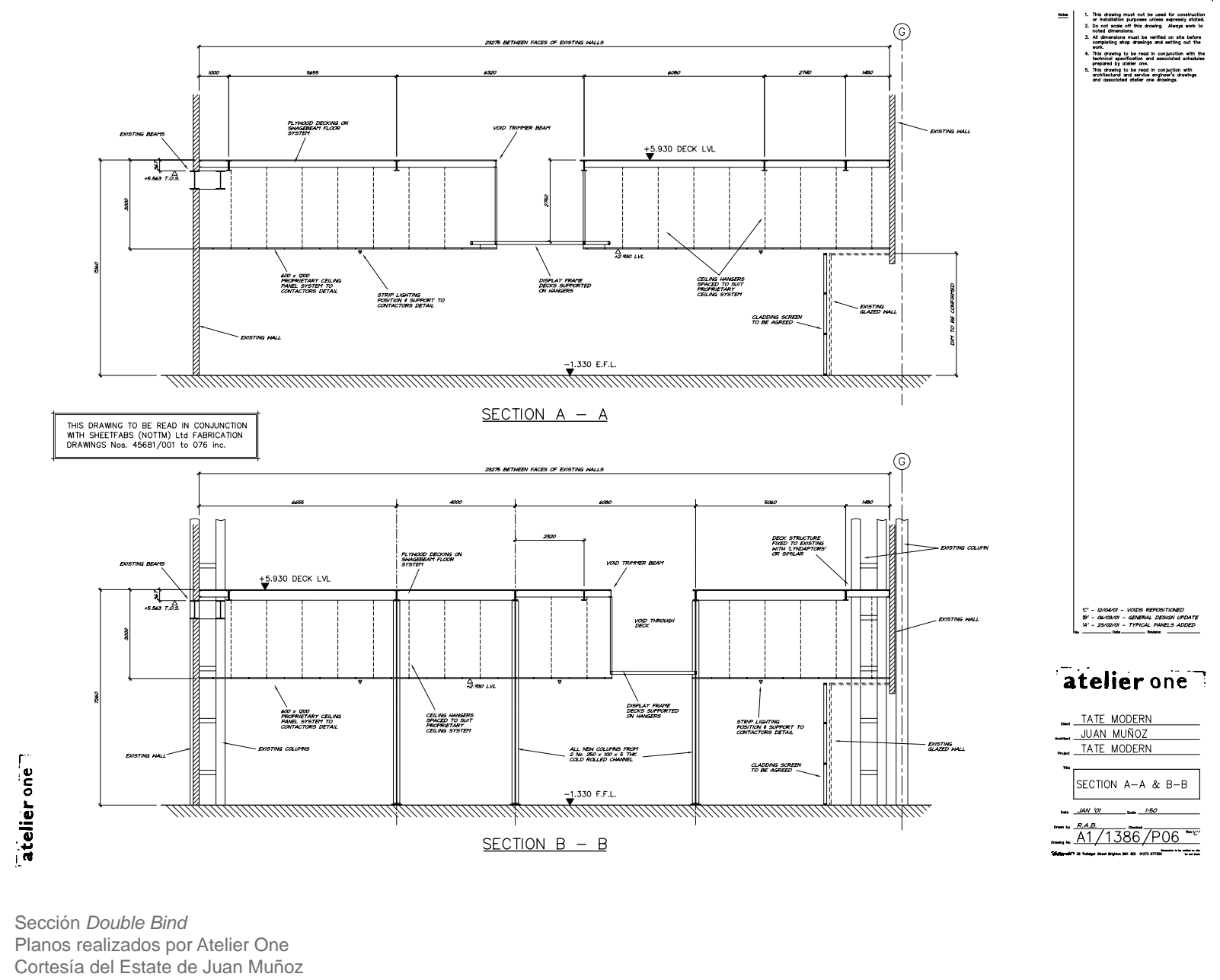

tener capacidad para cobijar el compendio de mecanismos funcionales que responden a las necesidades actuales de los espacios habitables, y que son generalmente accesibles.

Entre los documentos que Muñoz recopiló durante su preparación de Double Bind, y que quedan conservados en el Archivo de Juan Muñoz, aparece una copia del texto de Khoolhaas La Ciudad Genérica(1995) ${ }^{25}$. En el punto 14 dedicado a la historia, Koolhaas hace una referencia que bien podría describir el tipo de lugar que Muñoz presenta en Double Bind: "Una ciudad es un plano habitado del modo más eficaz por gente y procesos, y, en la mayoría de los casos, la presencia de la historia no hace más que aminorar su rendimiento..." Muñoz se despoja de todo lo innecesario, quedándose con los elementos y estrategias mínimas que le permiten describir visualmente el lugar ambicionado. Un espacio definido por los mínimos elementos, resaltando así su capacidad organizativa del mismo. La geometría pura de los volúmenes que lo definen sin distracciones, resulta en

25 En OMA, S, M,L,XL, Rotterdam, 010 Publishers, 1995, p. 1247-1254. 
un espacio cuyo único cometido parece ser encerrar el vacío, contener. Este espacio está a medio camino entre la ciudad que no existe, la ciudad que pudo ser, o la que podrá llegar a ser.

Volviendo al techo, este piso inferior de la instalación de Muñoz también necesita de un cierto espesor. Se presenta una superficie con una retícula modular cuadrada y apariencia de techo registrable, de color oscuro. No invita a ser observado, no es bello, no tiene interés, sólo los huecos de luz llevan a fijar la vista en él. Del mismo modo que los tubos mecánicos invaden las tripas de los edificios, la escultura de Muñoz se aloja de manera inesperada en las tripas de este techo de piel oscura y áspera. Entre la retícula registrable se dispersan entradas de luz que atraviesan todo su espesor. Bajo esta estructura de apariencia vulgar surge la emoción que podía encontrase en la iconografía barroca. Los huecos de luz se desvelan como patios de manzana cerrados por los que se puede mirar a través, y pequeñas estructuras interiores donde habitan las figuras del escultor. Súbitamente el techo ha dejado de ser una piel que esconde los elementos indeseables de una arquitectura, para convertirse en el refugio de unos individuos que colonizan el espacio entre forjados.

Surge aquí de nuevo la necesidad de recordar que toda esta estructura de forjado es escultura. No responde a requerimientos arquitectónicos, pero podría hacerlo. El espacio destinado a las instalaciones es tan profundo en la arquitectura contemporánea que compite con los espacios a los que sirve. Las necesidades técnicas se adueñan de los intramuros de los edificios, la cavidad entre la piel exterior y la piel interior es cada vez mayor, creándose entre estas dos capas un espacio que el arquitecto ha de empezar a tener en cuenta de otra manera, si no quiere que su arquitectura se vea doblegada a la técnica y que escape de sus manos el grueso mundo que dista entre las caras interior y exterior de los forjados o de los muros verticales.

Como en los techos pintados del barroco, se crea, a través de una arquitectura fingida, un volumen espacial profundo y distinto del plano horizontal, en algunos casos, incluso representa aperturas al cielo abierto. Durante su estancia en Roma, visitó los interiores de las iglesias, con gran interés en el juego de los volúmenes entre la luz y los trampantojos. El óculo central en las cúpulas de las iglesias, una apertura circular en el punto más alto y central de la cúpula, tiene su origen en el Panteón de Agripa, desde entonces el circulo se asocia a la divinidad, y este hueco de luz establece la conexión entre el interior y exterior, 


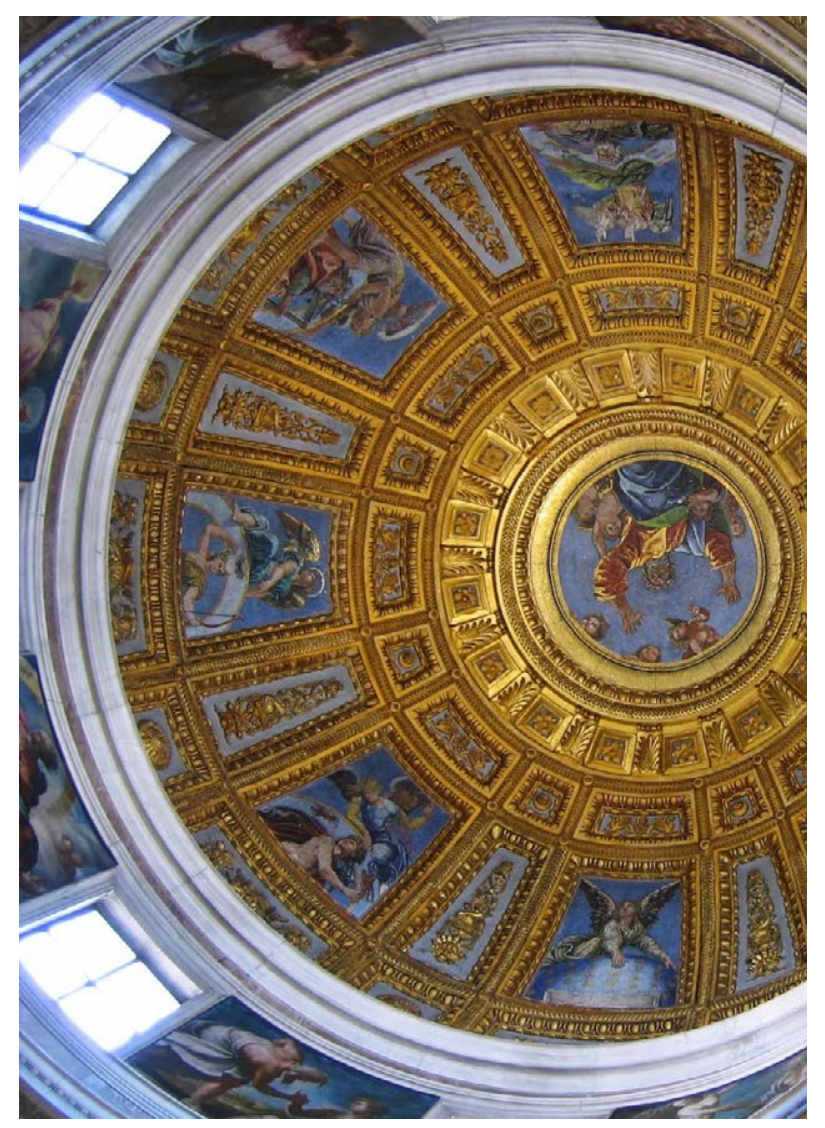

Santa Maráa del Popolo. 1516. Capilla Chigi. Rafael Sanzio

vinculando lo divino con lo terrenal. Esta idea no siempre se lleva a cabo de manera material, en muchos casos se recurre al trampantojo para representar el cielo en la posición central de la bóveda. En la Iglesia de Santa María del Popolo (Roma), en la capilla Chigi (futuro papa Alejandro VII) cuyos cartones para la realización de los frescos fueron realizados por Rafael en 1516, aparece en escorzo, y con gesto de poder, el Dios Padre, al mismo tiempo abre los brazos en señal de acogida, tiene en definitiva una postura dominante, también conseguida por su posición elevada, donde su figura es la que supervisa el paso de lo que ha de ascender a un mundo controlado por Él. Es característico que, en este tipo de obras, uno o varios personajes establezcan conexión con el espectador, dirigiendo su mirada hacia abajo, en lugar de hacía el cielo, o hacia la escena que esta teniendo lugar.

De la misma manera, existen una serie de personajes en la obra de Muñoz que se asoman con seguridad al vacío, dando la impresión de mantener la mirada de aquel que se permita detenerse a observarlos. El espectador se ve atraído por la apertura de luz y el 
espacio abierto, se encamina hacía él, mira a través, se encuentra en un primer plano a los personajes de la escena, algunos continúan con sus actividades, y otros, como los ángeles de las escenas de los frescos, miran hacia el espectador, haciéndoles formar parte de la escena.

El escultor se enfrontaba a la verticalidad de manera formal, pero también simbólica. Un punto de vista bajo para el observador, obligando a este a elevar la mirada, le sitúa en una posición de inferioridad. El elemento que queda en un plano superior cobra grandeza y crea una sensación de opresión. Al igual que sucede en las grandes iglesias barrocas donde se marca un punto de luz en la zona más alta, o una grandiosa decoración que cautiva la mirada del espectador y le hace mirar arriba remarcando la profundidad y la perspectiva. En Double Bind sitúa al espectador ante un espacio con una marcada verticalidad que subraya mediante los dos ascensores que guían al observador a llevar su mirada arriba, a percibir todo el volumen espacial e incluso provocar una cierta sensación de vértigo, una estrategia que exploró en la serie de sus figuras colagadas: hanging figures.

En 1997 expuso en una galería de San Gimignano una de sus primeras figuras colgadas. La figura se mantiene suspendida mediante una cuerda que sostienen con la boca; Miss La la at the Cirque Fernando, de Degás, pintada en 1879 y expuesta en la National Gallery de Londres, lugar frecuentado en su juventud por Muñoz, es seguramente un referente para dicha $\operatorname{serie}^{26}$. La obra de Degás, de la que hay varías versiones utilizando diversas técnicas, representa a una joven acróbata suspendida de una cuerda a la que se agarra con la fuerza con la mandíbula, que sostiene todo su peso. Es la única figura que aparece en el cuadro. Semejante punto de vista, no da a lugar a que nadie le robe el protagonismo, ni siquiera la colorista carpa circense. Como en el cuadro de Degás, las figuras de Muñoz se agarran a la cuerda mediante la boca, y flexionan las pernas entrelazando los pies. Muñoz estaba intrigado con ciertas figuras circenses, como los enanos, o los acróbatas. Profundizó en

26 Ver Benezra, Neal. Sculpture and Paradox en Juan Muñoz. Catálogo de la exposición. Hirshhorn Museum and Sculpture Garden, Art Institute of Chicago, Museum of Contemporary Art (Chicago, Ill.), y Contemporary Arts Museum. Washington, D.C. : Chicago, Ill: Hirshhorn Museum and Sculpture Garden, Smithsonian Institution ; Art Institute of Chicago, University of Chicago Press. p. 39. 2001. 

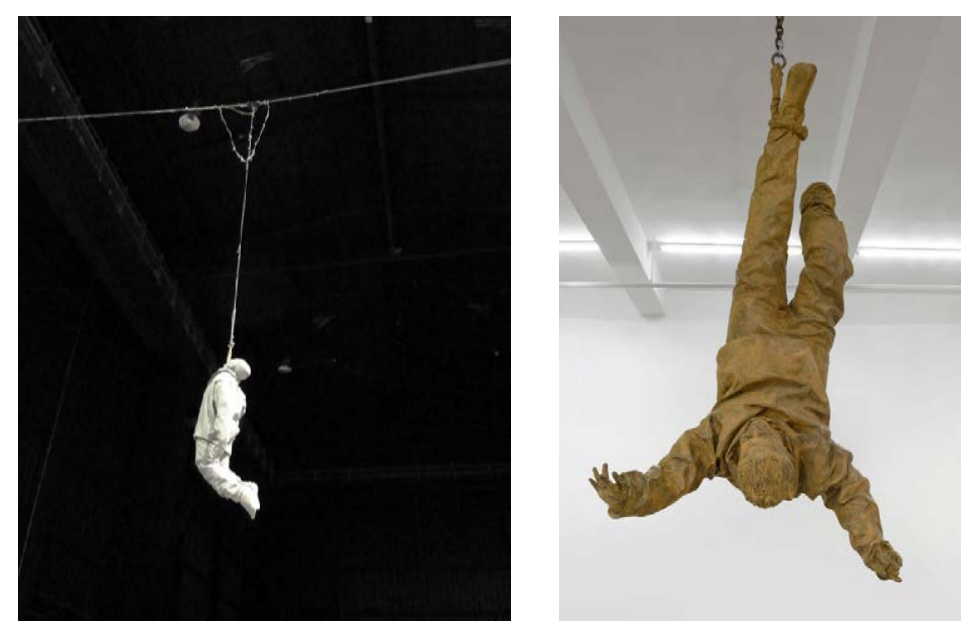

Hanging Figure. 1997. Juan Muñoz.

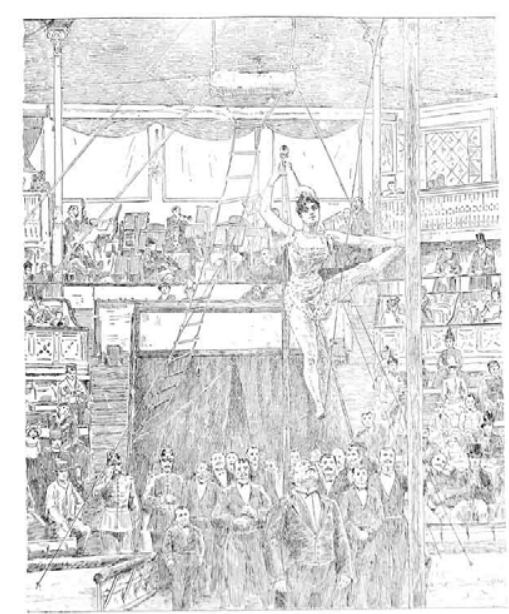

Acrobats and Mountebanks

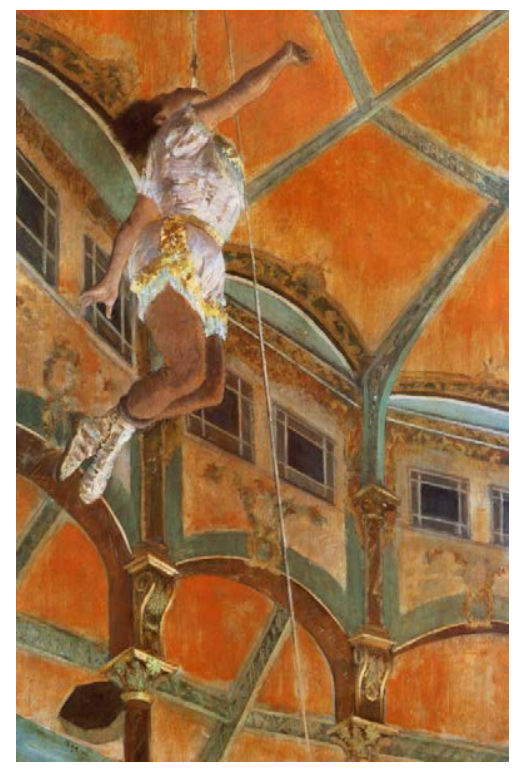

Miss La La at the Cirque Fernando. 1879 Edgar Degas
Hanging Figure. 2001. Juan Muñoz.

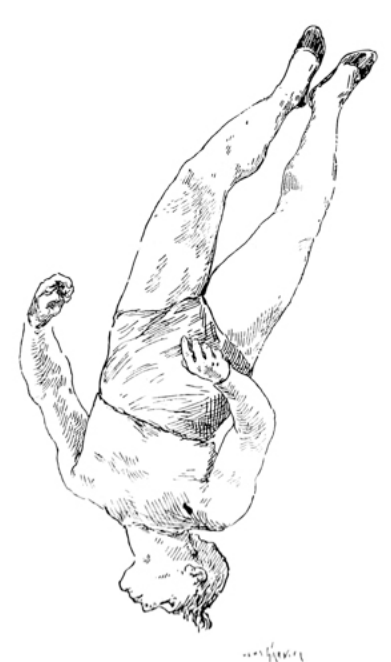

Acrobats and Mountebanks
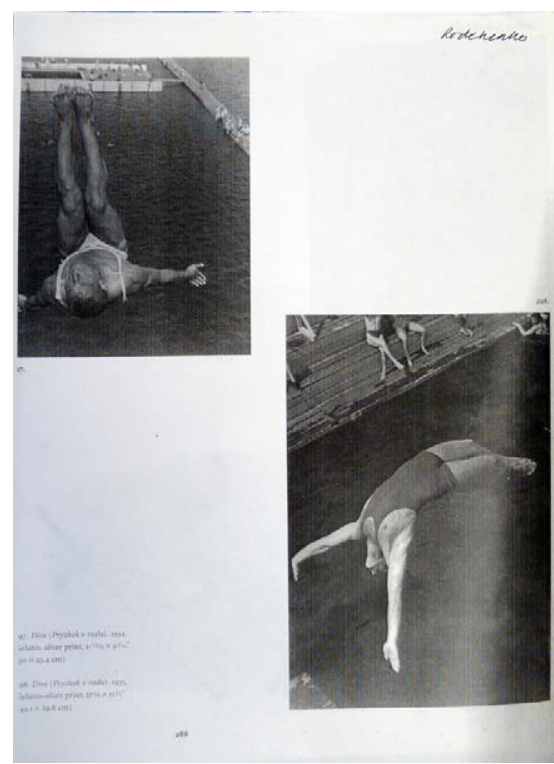

Imágened de Rodechenko

Documentación del artista.

Cortesía del Estate de Juan Muñoz

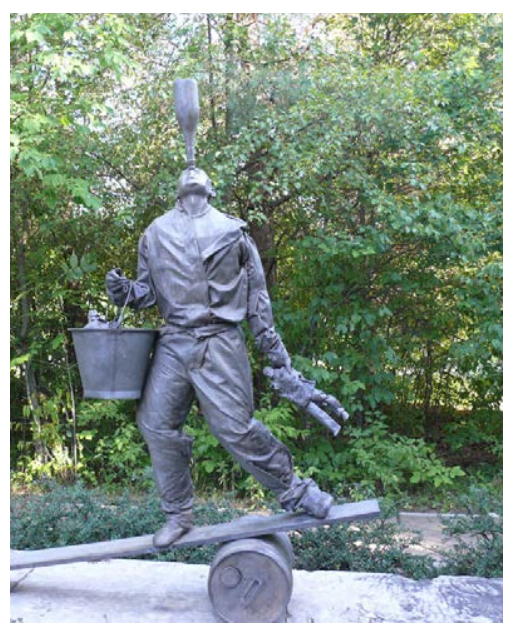

Broken Nose Carrying a Bottle', 1999. Juan Muñoz

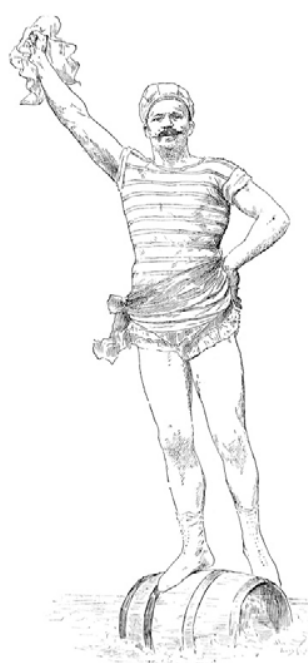

Acrobats and Mountebanks 
los personajes acróbatas estudiando el libro ilustrado Acrobats and Mountebanks ${ }^{27}$ donde se pueden ver descripciones e ilustraciones de acróbatas en distintas situaciones. En una de las escenas, la acróbata, descolgada en una cuerda proveniente del techo es observada por la audiencia, que eleva la cabeza centrando su atención en ella. Se podría retratar a los observadores de Double Bind en este piso inferior obteniendo una imagen donde muchos de ellos se encuentren parados, con la mirada elevada y dirigida a los huecos de luz. Esa luz que invita a mirar arriba como los rayos dorados en la escultura el Éxtasis de Santa Teresa de Borromini.

La cuerda de las figuras (en bronce o resina) colgadas es el eje que marca el centro de la pieza en su verticalidad. La vista se centra en la figura colgada, el espacio que la rodea se difumina a su alrededor. Los marcados detalles de la figura, su grado de definición, borran la posibilidad de que la atención se centre a otro lugar. El movimiento libre y lento de rotación de las figuras hipnotiza al espectador. Algunas figuras incorporan un pequeño motor que las mantiene en movimiento, de nuevo el perpetuum mobile. En Double Bind se reclama de nuevo una mirada hacia $\operatorname{arriba}^{28}$, la misma posición requerida para recrearse en la ausencia, en los balcones del Hotel Declerq, pero está vez para encontrarse con una pintoresca comunidad suspendida en un espacio con cavidades.

27 Le Roux, Hugues, Acrobats and Mountebanks, Charleston: Nabu Press, 1980. Rubén Polanco (Asistente colaborador con Juan Muñoz ) comenta "esto me lo trajo, y realmente de aquí han nacido muchísimas ideas ("Acrobats and Mountebanks" un libro de Huguea de Roux y Jules Garnierde 1980) creo que me lo trajo de un Mercado de estos de segunda mano, es antiguo, es inglés. Aquí hay enanos, ventrílocuos..." en Arranz, Manel y Solana, Anna. Documental “Imprescindibles - Juan Muñoz, poeta del espacio” 2014.

28 Muñoz, Juan. Lingwood, James, A Conversation, May 2001 en Juan Muñoz, Double Bind at Tate Modern. Tate Publishing, London, 2001. p. 68. James Lingwood: "Maybe you only have two possibilities - to keep very close to the ground - as many sculptors have done since 190's, or something to engage with the verticality. The horizontal expanse isin't so intimidating."

Juan Muñoz: "It is true that the horizontality was never the biggest challenge. You can talk about verticality in formal terms but also in symbolic terms. The verticality of the hanging figures that I started to think about in the beginning was certainly a way of dealing with the gigantic distorsion that happens when you look up. Probably the image of the elevator that came later on is a resolution of how to engage verticality". 


\subsection{Construyendo imágenes ${ }^{29}$}

A través del trabajo de Richard Serra y Robert Smithson, Muñoz descubre la capacidad de la escultura para activar el espacio. El espectador está al mismo tiempo dentro y fuera de la escultura. El espacio engendrado dialoga con el espectador, su percepción de la obra varía según su posicionamiento y movimiento, se puede ver desde fuera o desde dentro, la pieza se experimenta mientras se recorre su interior o se deambula alrededor. Este tipo de escultura trata con el espacio, y la condición del objeto como elemento queda en un segundo plano.

Según Muñoz el encuentro entre las disciplinas de arquitectura y escultura se da en el espacio, cada una con una visión diferente del mismo y coincide con Serra en que es la utilidad social de la arquitectura y la inutilidad de la escultura lo que diferencia el concepto espacial en cada una de ellas. ${ }^{30}$ En "De los materiales a la arquitectura"31 Moholy-Nagy , vinculado a la Bauhaus durante los años veinte, señala que "cada periodo cultural tiene su propia concepción del espacio". Define el espacio como una realidad de la experiencia sensorial ligada a la vista, el oído, el equilibrio y el movimiento. El espacio "es la relación entre la posición de los cuerpos". Explica cómo se experimenta la arquitectura, pero sin embargo tiene una visión muy diferente sobre la escultura, que la entiende como "volumen" y no como espacio.

La obra de Muñoz requiere el movimiento del espectador a través de ella para poder acceder visualmente a todas sus partes. Generalmente, el espectador en un museo, se sitúa frente a un cuadro, mirando al plano de una pared, y dando la espalda a lo que ocurre tras de sí o en el caso de un objeto escultórico, se sitúa generalmente en una zona que permite rodearlo para ver todas sus caras. El espectador, acostumbrado a un modo de ver,

29 Muñoz, Juan, Construyendo imágenes en Juan Muñoz. Juan Muñoz: Escritos/Writings. Ediciones de la central. Barcelona, 2009 p. 155

30 Muñoz, Juan Notas afines a tres. En Juan Muñoz: Escritos/Writings. p.45. "Digamos que se entiende por espacio la multiplicidad del arriba y el abajo, el dentro y el afuera, lo ocupado y lo vacío, la sombra y la luz, la derecha y la izquierda, la opacidad y la transparencia, así como la dificultad y el asombro. En última instancia, el conflicto entre ambas actividades reside en la necesaria utilidad social de la arquitectura y en la justa inutilidad de la escultura. Sin embargo, digámoslo una vez más, entre todas las artes, éstas dos comienzan y terminan en su preocupación por el espacio.".

31 Textos de Arquitectura de la Modernidad. Editorial Nerea. p.243. 
puede llegar a ausentarse al pasar delante de las obras de arte. Muñoz tiene una posición frente a los espacios museísticos tradicionales, y es consciente que la rutinaria disposición de las obras puede llevar al espectador a la apatía. En Double Bind obliga al espectador a recorrer la instalación, y en efecto, a ver todas sus caras, pero no se trata de rodear la pieza, tiene que ver con sumergirse en ella, como cuando se habla de entrar en un cuadro, Muñoz busca introducir al espectador en la escultura, hacerle participe de ella. Sumergirse en una escultura conlleva alterar la concepción del mirar tradicional en el museo. Una situación impredecible rompe con la preconcepción del espectador acostumbrado a que las cosas funcionen de una cierta manera dentro del espacio expositivo, volviéndolo más receptivo a percibir y detenerse en la obra así presentada. En este caso, no se produce una interacción entre la obra y el espectador, la obra no se ve alterada si no hay nada que la visite, es el espectador el que recibe unas señales distintas al verse expuesto a determinadas condiciones físicas respeto a la pieza. Cambia el espacio expositivo y la manera de recibir la obra. Pienso que en algunos casos, donde el espectador no conozca la sala de exposiciones, habría espectadores que no se plantearan que el forjado que se extiende más allá es una pieza completamente independiente de la sala, fundiendo el espacio expositivo con la obra.

La intervención de Muñoz transforma el espacio expositivo y la relación del espectador con la obra de arte. Esta obra no es un objeto, si no un conjunto de objetos y situaciones que crean un ambiente, una atmósfera, una ilusión, un paisaje.

La obligada mirada hacía arriba desde el nivel inferior aísla al espectador de otras personas que puedan circulan por la sala, convirtiéndolo así en una visita solitaria. El espectador se ausenta de su realidad introduciéndose de manera individual en lo presentado ante él. Es aquí cuando se activa la participación del espectador, cuando la necesidad de mirar hacia arriba modifica la concepción de su entorno. La conciencia y la memoria individual juegan un papel importante en este nivel. Según su manera de comprender el espacio del piso superior (el cielo) y de su entendimiento sobre el significado y funcionamiento de los huecos su reacción será única y personal.

Los habitantes están en un mundo que resulta desconocido y al mismo tiempo familiar, que podría asemejarse a ningún sitio o a todos los lugares. Como en A Place Called Abroad (Un Lugar Llamado Extranjero), la abstracción urbana esta ligada al exilio y a la propia 


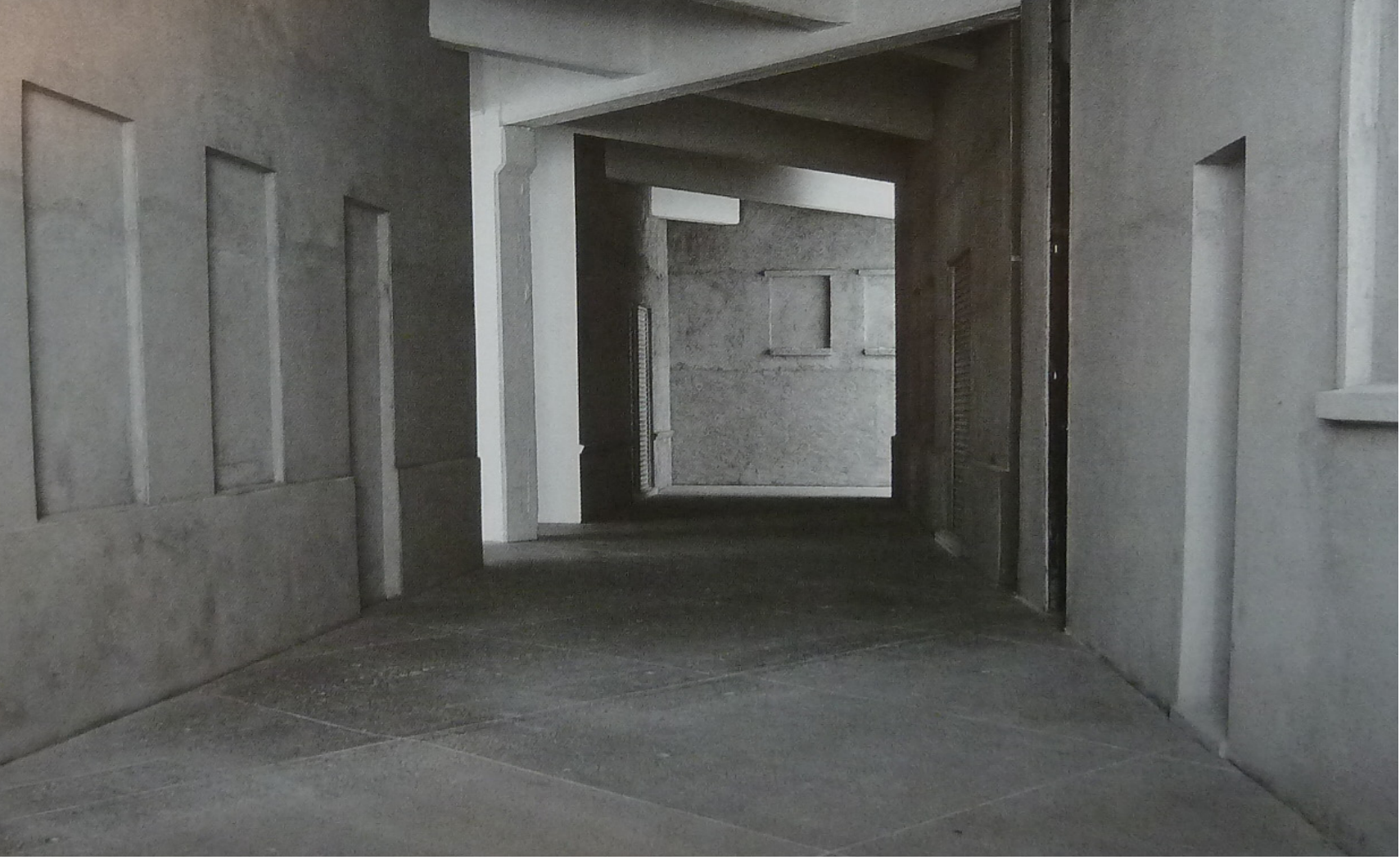

A Place Called Aborad. Dia Center of the Arts, NY. 1996. Juan Muñoz

experiencia del artista que emigró a finales de los años 70 a Londres, y posteriormente a Nueva York. Como en tantos otros textos del artista incluye reflexiones personales al tratar distintos temas. En 1982, tras su vuelta de Nueva York escribe en un texto referido al trabajo de Mario Merz en el que habla sobre el exilio desde su experiencia personal: "Y ahora te cuelgas los abalorios del arte y dices que no recuerdas con exactitud si fue el encubrir o el descubrir lo que te hizo pasar disfrazado de ciego la frontera inglesa y vivir estos últimos años como un nómada” ${ }^{32}$. En el exilio se aprende sobre la individualidad al mismo tiempo que se extienden los límites de lo global. El individuo se sitúa fuera de su contexto, perdiendo toda compañía y descubriendo la condición de un nuevo entorno y el interior de uno mismo. El exilio, que se puede encontrar también en la mente, puede ser consecuencia de una necesidad. William H. Gass dice que la vida es en si un exilio ${ }^{33}$, un lugar de extrañeza. El exilio puede ser buscado conscientemente por necesidad, para

32 Muñoz, Juan, Phiby, Juan Muñoz: Escritos/Writings. Philby.1982, p. 53.

33 Gass. William H. "life is itself an exile" en Finding a form. Essays. Cornell University Press 1996.w 


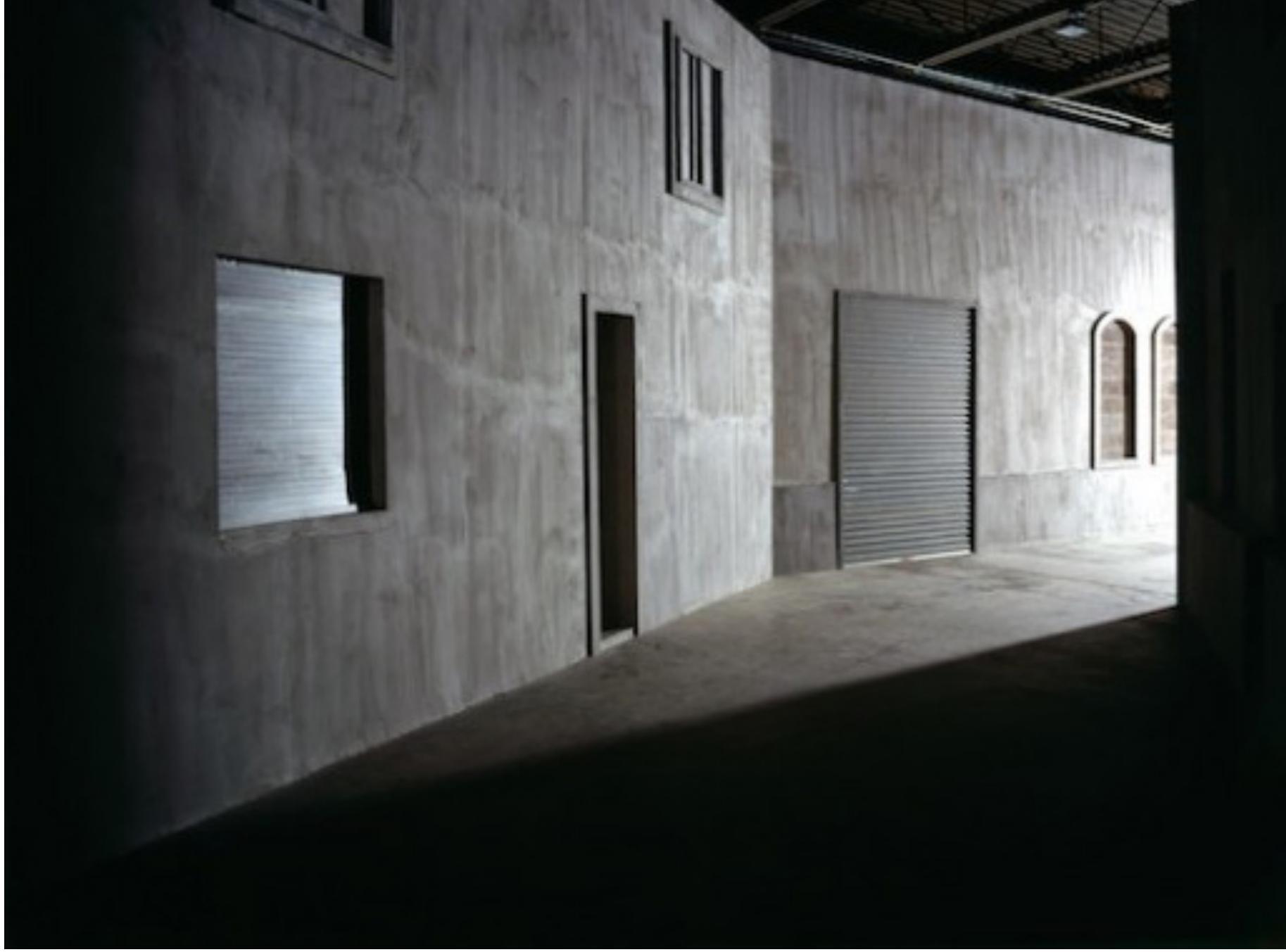

Streetwise.SITE Santa Fé, 1998. Juan Muñoz

defenderse de la prisión de lo familiar o por sentirse desterrado de lo conocido, cuando la vida no basta. El cambio de lugar, el emigrar, conlleva un desequilibrio del universo personal. En este estado de desorientación se inicia la búsqueda de fuerzas que devuelvan el equilibrio a su centro y que dan como resultado nuevos argumentos.

Como en A Place Called Abroad y en Streetwise el espectador se convierte en un paseante que camina dentro de y entre la escultura. Un camino por una calle definida por sus fachadas laterales con huecos de puertas y ventanas sellados, todo bajo una misma tonalidad de colores tierra y grisáceos, los colores de la ciudad occidental. La sensación de abandono hace que el paseante constituya una relación fantasmagórica con lo que le rodea. Se consigue un aislamiento del espectador, sometiéndolo a las sensaciones del entorno en el que esta inmerso. Del mismo modo que en Double Bind el espectador desconecta de su entorno familiar aislándolo con una obligada mirada desde el piso inferior a los huecos suspendidos, en A Place Called Abroad consigue el mismo efecto introduciéndole en un 


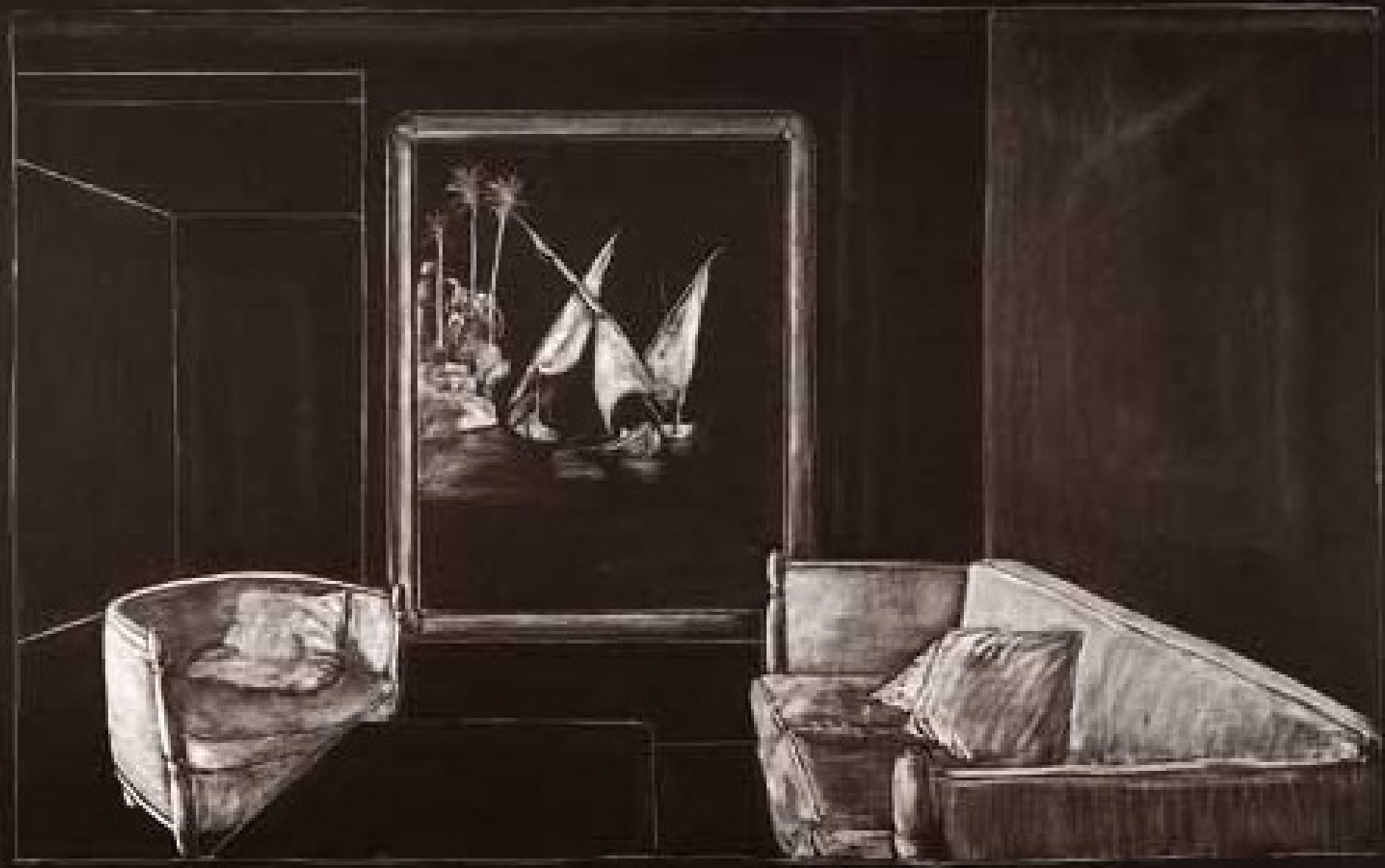

Dibujos de Gabardina. 1988-1999. Juan Muñoz

mundo material apartado de lo conocido. El espectador se sitúa físicamente en el territorio de lo desconocido, mientras que en Double Bind el conocimiento de todos los estratos se produce a través de la mirada. El camino a lo largo de las calles de su primera escultura se abre en distintas salas donde aparecen figuras, anónimas y despersonalizadas, todas con el mismo carácter y la misma resolución, que están dentro de su mundo, ajenas al visitante, exactamente con el mismo carácter y comportamiento que en Double Bind. La relación con los personajes es algo diferente entre los dos casos. En el primero, el visitante puede acercarse a las figuras y establecer una relación de escala. En Double Bind la distancia es imperativa, la separación entre personajes y espectador aumenta la distancia psicológica entre ambos mundos resaltando la absoluta independencia de los personajes, agudizada aún más por su posición elevada en el espacio. En el primer caso se produce un enfrentamiento frontal, en Double Bind, oblicuo. El recorrido lleva al espectador a experimentar el destierro, literal y metafóricamente, despertando una sensación de inseguridad y duda, sin dejar claro hacia donde ha de dirigirse. No hay un 


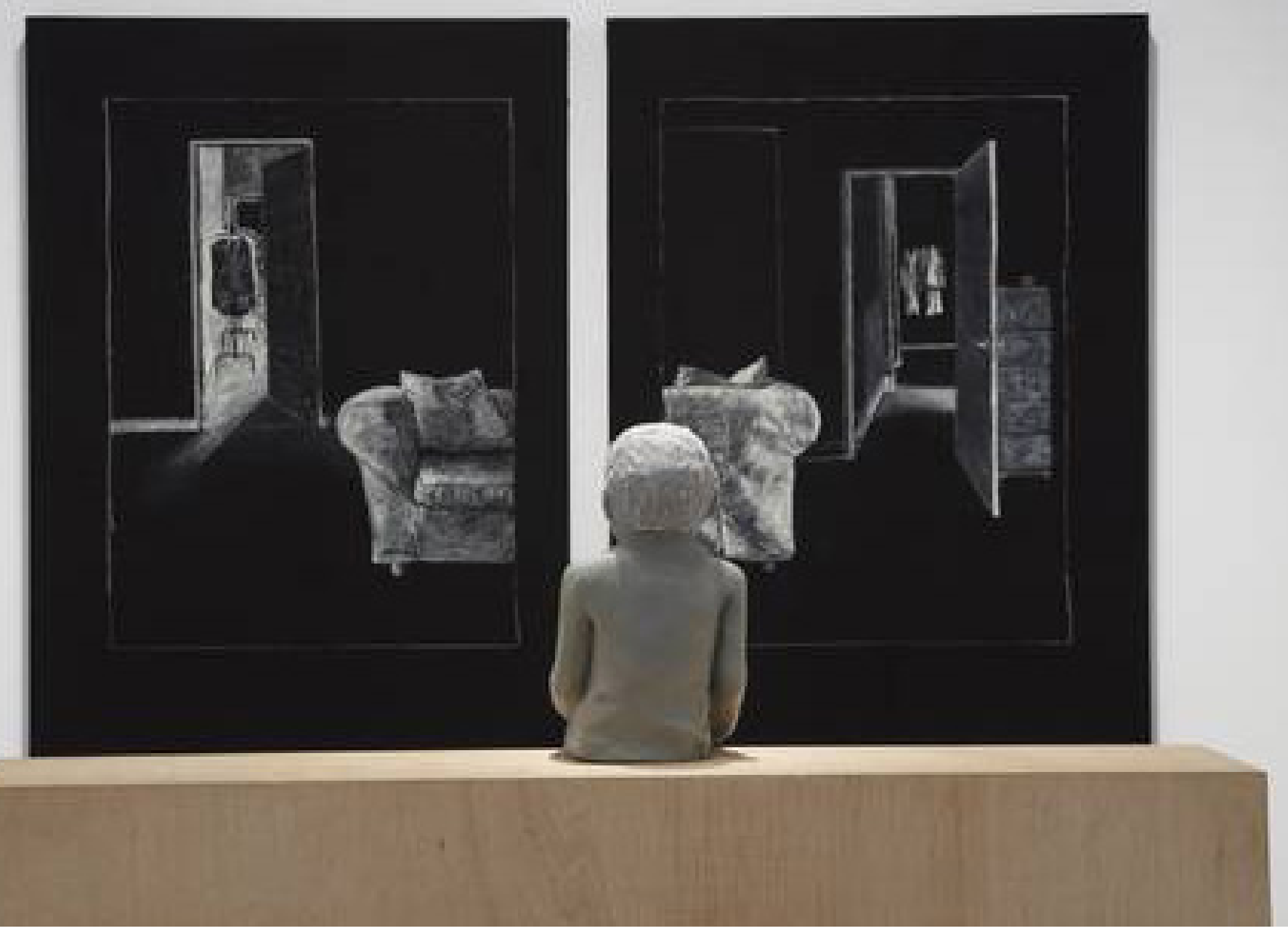

Ventriloquist Looking at a Double Interior. 1988-2000. Juan Muñoz

recorrido establecido, el recorrido es nómada. El espectador decide la dirección de su desplazamiento, como quien se encuentra en un cruce de caminos, elegir llevará a un lugar u otro, diferentes unos de otros. Se produce una confrontación entre el mundo interno y el externo, navegando paralelamente por un mundo material y a través de la mente que busca respuestas.

En Double Bind se puede circular por la planta inferior libremente, una autonomía que puede resultar extenuante. En busca de hallazgos con la mirada puesta en los huecos de luz, se hace un camino sin ruta seducido por la entrada de luz y el deseo de descubrir la naturaleza de todos los vacíos. La alienación urbana del piso superior no ayuda a orientarse en este nivel. Cada hueco ofrece una visión diferente, y la disposición oblicua de la retícula tan clara en el piso superior se manifiesta caótica y desordenada en la oscuridad del piso inferior. Santiago Amón se preguntaba en el texto introductorio que escribió para la exposición comisarizada por Muñoz en 1982, Correspondencias: 5 arquitectos, 5 
escultores $^{34}$ : “¿Qué espacio resulta más laberíntico? ¿El que a través de una compleja y tortuosa sucesión de galerías conduce a una salida única y de difícil hallazgo, o aquel otro que, espejo de sí mismo en todas sus orientaciones, no tuviera ni salida ni entrada?”. A continuación Amón pasa a resumir el cuento de Borges Los dos reyes y los dos laberintos ${ }^{35}$, en el que un rey de las islas de Babilonia mandó construir el más complejo de los laberintos, lleno de muros, puertas y escaleras. Cuando el rey de los Árabes le visitó, a modo de burla, le invitó a entrar en el laberinto, del que solo consiguió salir al implorar socorro divino. Años más tarde el rey de los Árabes hizo cautivo al de Babilonia, y en venganza le introdujo en un laberinto obra de Dios, donde no hay galerías, ni muros, ni puertas ni escaleras, le abandonó sólo en medio del desierto, donde murió de hambre y de sed. De algún modo, A place Called Abroad y Streetwise tienen más que ver con la obra propia de la creación humana, con muros, puertas, escaleras y galerías que recorre. Double Bind se simplifica, el laberinto es una extensión donde el espectador tiene dificultad para orientarse por la falta de referencias, la repetición confusa de huecos en el techo por donde entra la luz, donde no existe un orden ni una jerarquía, donde no hay principio ni fin, ni en el tiempo ni en el espacio.

La illusion que Muñoz representa, tanto en A Place Called Abroad como en Double Bind surge de un estudio del contexto urbano. Un estudio que contiene un valor perceptivo muy alto, pero también un fuerte componente formal. Comenta en 1996, trás haber realizado $A$ Place Called Abroad: "Ahora me doy cuenta de que he pasado muchísimo tiempo mirando paredes, mirando cómo están construidas y cómo colaboran en crear la calle”36

Hasta llegar a la forma física de la exploración de la calle en A place Called Abroad, o a la alegoría del espacio urbano de Double Bind, Muñoz explora los espacios interiores en el

34 Amón, Santiago, Laberinto espacial del arte en Correspondencias 5 Arquitectos, 5 Escultores, Madrid. Ministerio de Obras Públicas y Urbanismo. Dirección General de Arquitectura y Vivienda. 1982. p. 11. El propósito de Amón al introducir el cuento de Jorge Luis Borges Los dos reyes y los dos laberintos, es para introducir lo que a su parecer tienen en común los cinco escultores y los cinco arquitectos cuyo trabajo forma parte de la exposición. A su parecer el común denominador entre todos ellos "la totalidad del vacío como campo de operaciones". 5 Arquitectos: Emilio Ambasz, Peter Eisenman, Frank 0. Gehry, Leon Krier, Venturi, Rauch \& Scott Brown. 5 Escultores: Eduardo Chillida, Mario Merz, Richard Serra, Joel Shapiro, Charles Simons.

35 Borges, Jorge Luis, Los dos reyes y los dos laberintos en El Aleph, 1949

36 Muñoz, Juan. Lingwood, James. Una conversación, Septiembre 1996. en Monólogos y diálogos. MNCARS. 1997. p. 154 
plano en los llamados dibujos de gabardina. Grandes lienzos negros de tela de gabardina sobre los que pinta generalmente con tiza blanca y que realiza a finales de los años '80. Retrata interiores domésticos con puntos de vista forzados. Al contrario que en las obras anteriores, donde se abstraen componentes que definen la calle, como ventanas o puertas, y se llevan a un mundo de indefinición, estos dibujos se llenan de detalle. En las instalaciones escultóricas el espectador es plenamente consciente de que la calle es una ilusión, se encuentra dentro de un interior, y quiere ser una calle, pero de algún modo no termina de serlo. El espectador es participe del doble juego, del artificio que le hace percibir el engaño y participar en él. La exagerada perspectiva de los dibujos de gabardina, invitan a entrar, y también a pensar quien se esconde tras las puertas entreabiertas, o los largos pasillos. Como en tantas otras obras la ausencia marca el clima de la escena. Los dibujos captan una escena de lo que podría corresponderse con cualquier interior domestico, pero el color, y las puertas entreabiertas vuelven a darle un toque de misterio tan presente en sus obras. En la larga serie de los dibujos de gabardina se repiten los mismos espacios, en algunos casos desde distintos puntos de vista, de tal manera que se localizan los mismos elementos, pero en distintas posiciones. Cuando se observan al mismo tiempo el espectador se siente desconcertado, hasta que consigue hacerse una visión mental del espacio completo. Resulta confuso observar uno junto al otro la vista interior de un solo espacio desde dos puntos distintos.

En Double Bind, mostrando cierta indiferencia a la organización espacio temporal, el espectador se ve obligado a comprobar en su camino errante si ya se ha asomado a todos los huecos, recayendo en algunos de ellos por segunda vez de manera que, el espectador, desorientado, permanece en movimiento. El espacio tenebroso y el aislamiento que produce la visión oblicua de los espacios superiores sumerge al espectador en el mundo de Juan Muñoz, se produce una desconexión del mundo real. Como en su primera exposición en solitario en 1984 en la Galería Fernando Vijande de Madrid, donde expuso sus primeros balcones abrazados a las columnas de la sala, Juan Muñoz convierte un interior en un exterior, y de manera anticipatoria comienza a explorar sobre el mundo suspendido. 

5 EL PURGATORIO 


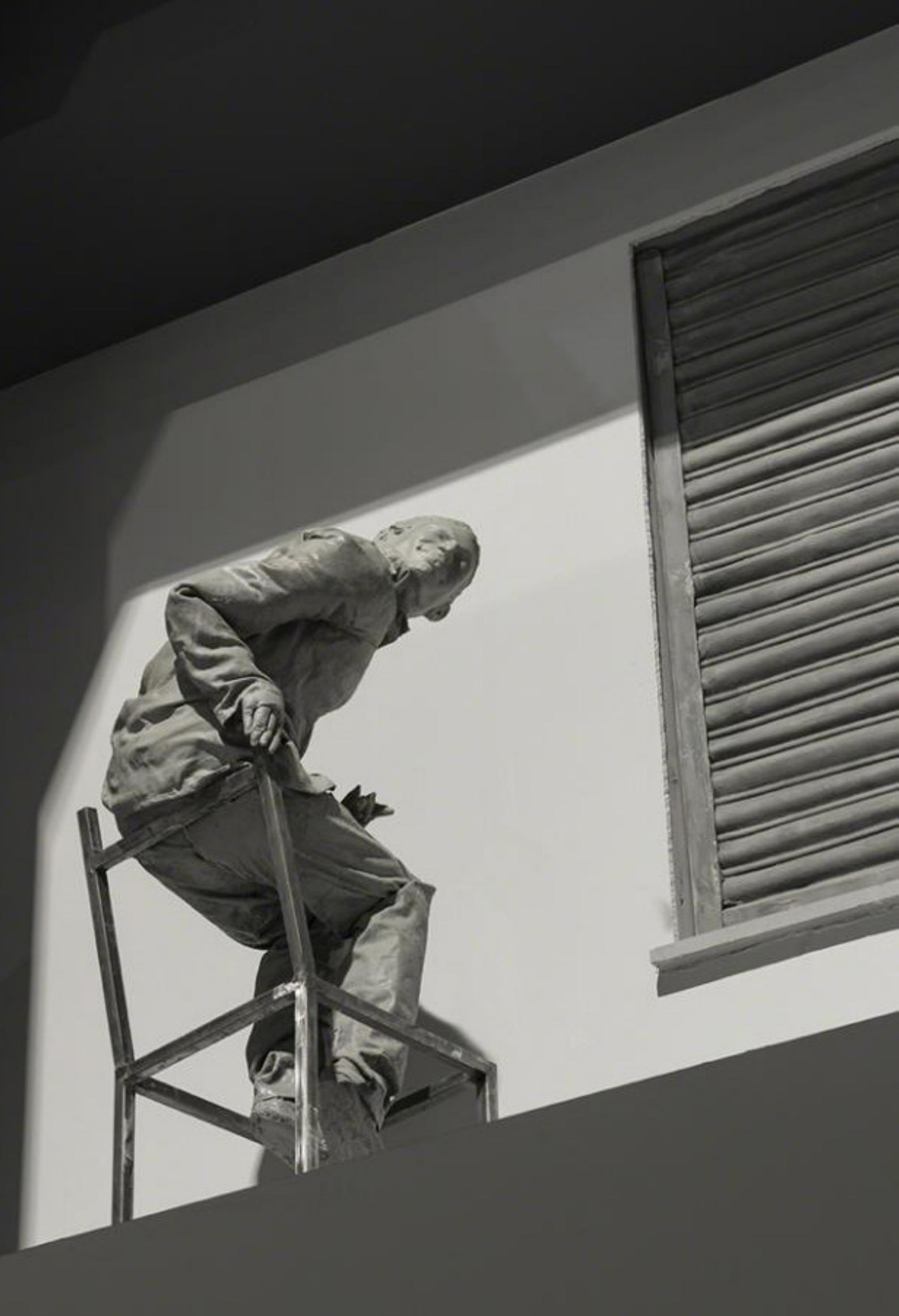


"Volsersi verso me le buone scorte

e Virgilio mi disse: "Figliuol mio,

qui può esser tormento, ma non morte."

Dante Alighieri. Divina Comedia. Purgatorio. Canto XXVI.

Este espacio se crea para ser observado desde la plataforma del museo y la oscuridad que se produce al bajar las escaleras y adentrarse en el bosque de perfiles metálicos, se extiende un volumen misterioso que no adivinamos a entender ni desde arriba, donde se nos engaña con el juego de los huecos reales e irreales, ni desde abajo, donde solo desde los huecos adivinamos su espesor. Esta frontera, (purgatorio), separa dos mundos muy diferentes, el cielo y el infierno.

Las esculturas de Muñoz habitan en torno a los huecos del purgatorio, que parecen surgir de la oscuridad desde arriba y llevar un poco de luz a la desorientación bajo su volumen. Este purgatorio es el centro de la creación de Muñoz con figuras desorientadas que no se sabe muy bien a cual de los dos mundos pertenecen y resulta ser la transición entre ellos, del mismo modo que para San Agustín el purgatorio era una respuesta piadosa para los inocentes que escapaban de las penas del infierno. 


\subsection{La mejor escultura es un caballo de Troya ${ }^{1}$}

Bajo la plataforma central de la sala de turbinas, el visitante descubre por completo la narrativa escultórica de Double Bind. Como si se tratara de un contador de historias, Muñoz hace pasear al espectador por una serie de secuencias sin un orden especifico. Desde el infierno se alcanza a ver esta serie de perforaciones en el volumen en la que en cada una hay una historia diferente pero dentro de la misma narrativa. A través de los huecos descubrimos la pequeña comunidad que habita este espacio suspendido. La arquitectura de cada uno de los huecos responde a un espacio que podría contener vida detrás de las paredes que lo conforman. Según nos adentramos en el piso inferior, las perforaciones verticales ganan profundidad en el volumen, creándose estructuras espaciales más complejas, donde aparecen distintas figuras de personajes de un uniforme color gris ${ }^{2}$, de carácter realista, y todas con el mismo rostro pero distinta gesticulación. Las impresiones que se han podido tener en el piso superior dan un giro, transformándose y redefiniéndose por lo que ahora vemos, y de alguna manera, descubrimos, ya que, lo que aquí ocurre era impredecible. Este es el purgatorio.

Descubrimos un espacio inesperado en el interior de una plataforma con espesor en el que se manifiesta una parte de la narrativa que probablemente no hubiésemos ni imaginado que pudiera tener lugar. Como si se tratara de una escultura de Matta-Clark, el escultor nos da una visión de lo que queda oculto cuando habitamos un edificio, aquello que sucede sobre nosotros. Mediante la forma plástica, Muñoz crea espacio habitable que podría corresponderse con una realidad ignorada si se piensa en que es solo mediante las perforaciones como establecemos conciencia de que el espesor de ese forjado puede ser habitado, y esto aparece ante nosotros casi como algo fortuito. Que no veamos ciertas cosas no significa que no existan, y descubrirlas causa extrañeza y sorpresa. Nos fiamos de lo que ven nuestros ojos, y tomar conciencia de un engaño perceptivo, donde no se puede necesariamente culpar a otro, produce una sensación de cierto temor. Si no podemos

1 Muñoz, Juan. Domus 659. Marzo 1985. p. 77.

2 Para Paul Klee, "La forma más reducida de equilibrio total queda representada por el gris, armonía sin vida”. Veasé Klee, Paul. Teoría del Arte Moderno. Una Teoría de los Colores. Argentina, Ediciones Caldén. Coección el hombre y su mundo. 2007. p.98. 


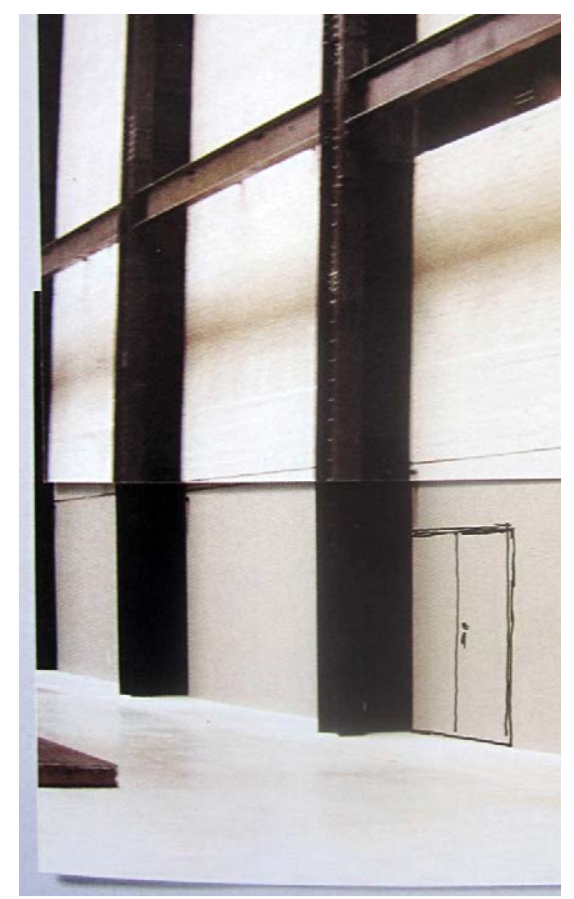

Dibujo del artista sobre fotografía de la sala de turbinas.

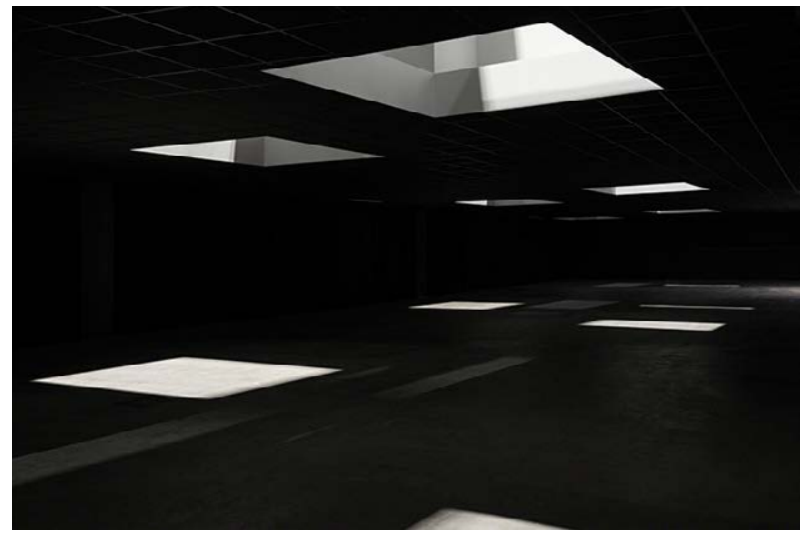

Nivel inferior Double Bind \& Around. Hangar Bicocca Miñán, 2015

fiarnos de nuestra propia vista, ¿que nos queda?, se despierta una sensación de inseguridad y un estado de alerta, pero también de curiosidad. Muñoz ha ganado, mediante su juego espacial ha conseguido su objetivo; ahora el espectador toma conciencia de toda la escena, su mente ha comprendido los juegos ópticos, y toma control y conciencia de su vista, ya no volverá a traicionarle; solo le queda recorrer este espacio y saciar su curiosidad mientras intenta asentar la nueva información recibida.

La existencia de los huecos es la que desvela el secreto que esconde el interior del volumen. De no existir las perforaciones, el observador permanecería ignorante de lo que pudiera estar teniendo lugar en el estrato intermedio, entre el amplio espacio superior y la oscuridad bajo él. Sólo se hace visible aquello que se alcanza a ver desde el espacio inferior hacia el interior de los huecos. No se sabe si el desarrollo de la comunidad continúa, ni si es posible la conexión entre ellos a través de las entrañas del volumen. La experiencia física del espacio ha dado un vuelco. El artista consigue que el espectador 
acepte como posible lo que el ha creado. En las iglesias de Borromini el creyente entra con la intención de acercarse a Dios, Borromini le lleva a convencerse en creer en lo que quiere creer mediante artilugios que le hacen verse más cerca de Dios. El espectador que quiere sumergirse en el mundo de Muñoz, acepta, no sin sorpresa, este mundo elevado, y esto desata numerosas preguntas. Durante los estudios de la sala de turbinas, Muñoz dibuja sobre una fotografía una doble puerta. Ahora que he entrado a creer en el mundo que me propone Muñoz, me pregunto si al colocar una puerta en un muro, del que no me he planteado al verlo nada más que su condición de limite, significaría ofrecer una conexión entre dos mundos, el que conozco y el que ni imagino. Cómo saber cual es el espesor de este muro, si solo veo su frente... empiezo a imaginar más allá de lo que ven mis ojos, se abren infinitas posibilidades... quizás el arte es una trampa para evidenciar la ignorancia. Del no existir al existir, del objeto al espacio, de la luz que creemos verdadera a la invisible luz de la verdad que nos abre a otras realidades. Algunos dicen que es escenografía, en cualquier caso, es arte: “... mientras una obra eleva aquello que representa, a una nueva conformación, a un nuevo y diminuto cosmos, a una nueva unidad de lo tensado en sí, de lo unido en sí , de lo ordenado en sí, es arte."3

Las perforaciones o huecos se convierten en el vacío en torno al cual se desarrolla un espacio habitable. El emplazamiento de este espacio habitable resulta muy intrigante. Santiago Amón habla del emplazamiento en la obra de Heidegger que es entendido como “el despliegue de lo abierto, capaz de admitir, entre otras cosas, la aparición de las cosas que posibilitan la morada del hombre y congregarlas a través de una pertenencia recíproca, cada una en su lugar y a partir de él" y "En el despliegue de este emplazamiento tiene lugar lo que hace posible todo lugar." ${ }^{4}$ El desarrollo tridimensional escultórico crea un lugar que es emplazamiento de ciertas figuras y elementos. El emplazamiento hace al lugar como el lugar al emplazamiento. Así mismo, los espacios crean vacío, que es según Heidegger “Una incorporación que en su acto creador aporta lugares, y con ellos una apertura de encuentros para una posible morada del hombre y un reposo de las cosas protegidas y concertadas en el ámbito creado por ellas".

3 Gadamer, Hans-Georg, Estética y Hermenéutica, Tecnos/Alianza 2006 p.92.

4 Amón, Santiago, Laberinto espacial del arte en Correspondencias 5 Arquitectos, 5 Escultores. Madrid. Ministerio de Obras Públicas y Urbanismo. Dirección General de Arquitectura y Vivienda. 1982.p. 13. 
Hablamos en el capítulo de el cielo sobre La Casa de la Memoria a la que Muñoz se refiere cuando habla de su obra El Apuntador. En respuesta a un encargo en el que se le pidió hacer una obra relacionada con una ruina. Muñoz no conocía la ruina de los jardines de Nymphenburg y rechazando elaborar una obra para recordar algo que a él le resultaba desconocido, ideó El Apuntador. Ese personaje de la escena teatral que es capaz de recordarle a un actor que debe decir, ante el olvido de algo que todavía no ha dicho. El paradójico trabajo de este personaje, le sitúa además físicamente en un lugar que se construye de un modo inverso a la casa tradicional. En lugar de construir un volumen sobre un terreno, esta surge en un hueco, en un vaciado. El apuntador desaparece bajo la tierra, como los recuerdos se sumergen en la mente a la espera de ser necesitados. La descripción de la casa del apuntador forma parte de uno de sus relatos: “(...) debió de ser antes de la caída de la tarde cuando empecé a contarle lo de la casa en medio de la calle... lo primero era cavar un agujero...no levantar la tierra o hacer un hueco en la tierra, sino construir una casa como un agujero...que...que debería ser lo que yo decía: una casa donde sólo hay un agujero...y en ella, viviendo en ella, un enano de pie, inmóvil. Puedo verlo todo y todo está frente al agujero... encima (sobre una superficie inmensa desprotegida, el deleite de los encuentros romántico y la entonación calida de la voz, alfombras y pasos furtivos."

Según Bernard Rudofsky ${ }^{6}$, una de las soluciones más radicales dentro del campo de los refugios son las ciudades y pueblos al norte de China en un cinturón de loess, un material geológico formado por la sedimentación del limo (material ligero y compacto de color amarillento transportado por las tormentas de viento). El loess es un terreno profundo y próspero para el cultivo. Debido a su condición ligera y compacta, es también un material que resulta fácil de excavar. Según Rudofsky, hasta diez millones de personas viven en este tipo de viviendas excavadas. En Tungkwan, cuya fotografía aérea Muñoz conservó durante el proceso de documentación de Double Bind, vive una organizada comunidad que ha dispuesto en una legible retícula sus unidades de vivienda. La fotografía aérea muestra una distribución de oscuros pozos de proporciones cuadradas y de unos 8 metros de altura. Son los patios de las viviendas a las que se accede desde la superficie mediante

5 Muñoz, Juan. El apuntador [2] en Escritos/Writings. Ediciones de la central. Barcelona, 2009 p. 113

6 Rudofsky, Bernard, Architecture without architects, Doubleday \& Company, Inc., Garden City, New York, 1964, p.16 
Se produce así en Double Bind un encuentro entre las cualidades de la obra escultórica y las condiciones que impone la arquitectura. El mismo Muñoz define este espacio en su texto Notas afines a tres $^{7}$ : "Digamos que se entiende por espacio la multiplicidad del arriba y el abajo, el adentro y el afuera, lo ocupado y lo vacío, la sombra y la luz, la derecha y la izquierda, la opacidad y la transparencia, así como la dificultad y el asombro." Piensa en ella desde su condición especial, cómo espacio habitado por sus esculturas, pero también como espacio para mirar y recorrer, con la idea de promenade architectural a través del recorrido por sus estratos.

7 Muñoz, Juan, Notas afines a tres, en Correspondencias 5 Arquitectos, 5 Escultores, Madrid. Ministerio de Obras Públicas y Urbanismo. Dirección General de Arquitectura y Vivienda. 1982.p.18. 


\section{2. "Una correspondencia sobre el espacio"8}

Los variados intereses de Muñoz incluyen la pintura, que practica y estudia. Está particularmente cautivado por la pintura de los siglos XIII al XV, siglos de exploración en los modos de expresión pictóricos, donde la geometría, la perspectiva y el ilusionismo tienen un importante papel, en paralelo a la narrativa ilustrada en las obras. En sus años de juventud, Santiago Amón introdujo a Muñoz la obra de Mondrian, y le provocó para que intentase 'meterse dentro"9. "Es difícil escapar de la gran lección formal del modernismo, porque una y otra vez me acabo deteniendo en las rayas escalonadas que el campesino dibuja en la tierra con su arado"10. El texto de donde se han extraído estas frases, Tres imágenes o cuatro, es un relato en el que Muñoz se sitúa a si mismo en una habitación de un hotel en Nuevo México. Dentro de este espacio, recorre todas las paredes analizando la decoración, lo que le lleva desde Gainsborough a Turner, pasando por Brueghel, y llegando a la casa de Robert Ventury en Chestnut Hill. Unos pensamientos se encadenan con otros. Una reproducción del cuadro atribuido a Brueghel, "Paisaje con la caída de Ícaro” (1554), le hace recordar que es después de la lectura del poema de Auden, cuando presta atención a las piernas de Ícaro que sobresalen del agua al caer a causa de la salida del sol. El arte tiene la capacidad de transmitir muy distintos mensajes, a Muñoz le interesa a narrativa, las cualidades espaciales y la resolución formal. Es el terreno que ara el campesino de Brueghel el que le lleva de los viejos pintores a la formalidad de la pintura modernista. Una habitación puede ser un espacio lleno de profundidad, donde viajar en el tiempo y en el espacio mediante la imagen, mediante los textos, mediante la imaginación. Una reflexión al terminar el relato: "La luz seguía iluminando el cuarto, pero algo sustancial

8 Muñoz, Juan. Berger, John. Una correspondencia sobre el espacio. Arte y Parte No 32. España. Abril-Mayo, 2001. pp.50-61.

9 "For years as a kid I had a private tutor called Santiago Amón who was a brilliant acholar as well as a writer on art. One afternoon, as he was showing me a book of Mondrian's paintings, he just said to me 'Drown'. I did not understand then, but he was write. That's all that you can do. Either you drown or not. John Berger once said that the chair of Rietveld is not a chair but an act of faith" en Muñoz, Juan, Lingwood, James, A Conversation, May 2001 en Unilever Series, Double Bind, Tate Modern 2001 p. 74

10 Muñoz, Juan. Tres imágenes o cuatro en Escritos/Writings. Ediciones de la central. Barcelona, 2009 p. 107 Públicado por primera vez como Yotsu no imeiji, Brihuega, Jaime y Fernandez-Cid, Miguel, Supein aatotoudi / Spain Art Today, The Museum of Modern Art, Tokonawa, Tokio, 1989 (exh. cat.) 


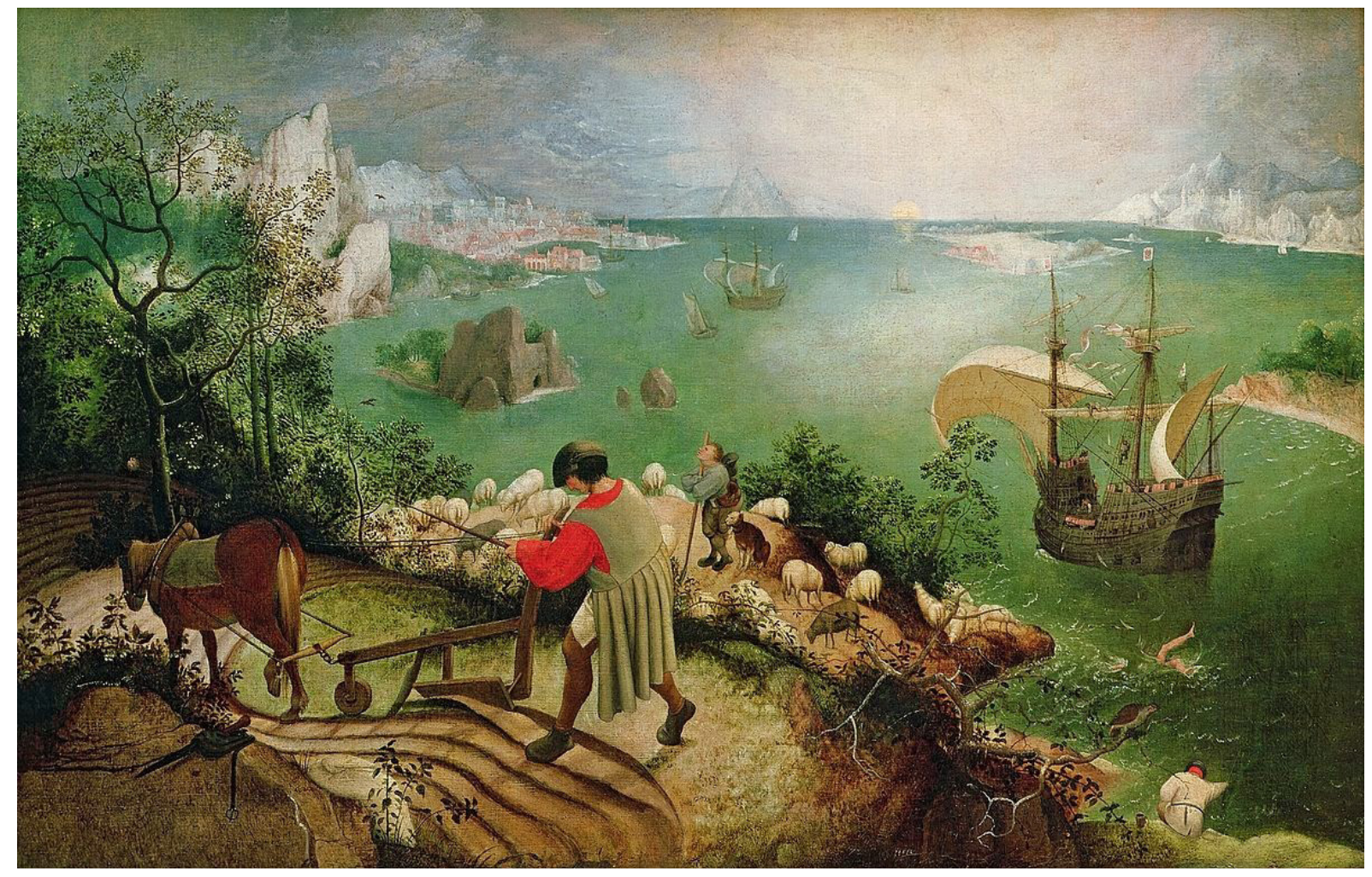

"Paisaje con la caída de Ícaro", 1554. Breughel

había cambiado. La casa de Chestnut no era una escultura. En algún lugar dentro de ella alguien, no ya la vieja señora que muriera hace años, sino otro, habitaba el ruido que hace un tenedor al caer al suelo."11 Muñoz se cuestiona los límites entre la escultura y la arquitectura, parece aún convencido de su reflexión temprana, en que admite la convergencia en la preocupación por el espacio de ambas actividades, alejándose una de la otra en materia de utilidad. La obra de Muñoz evoluciona hasta diluir los límites entre arquitectura y escultura.

“In Breughel’s Icarus, for instance: how everything turns away

Quite leisurely from the disaster; the ploughman may

Have heard the splash, the forsaken cry,

But for him it was not an important failure; the sun shine As it had to on the white legs disappearing into the green 


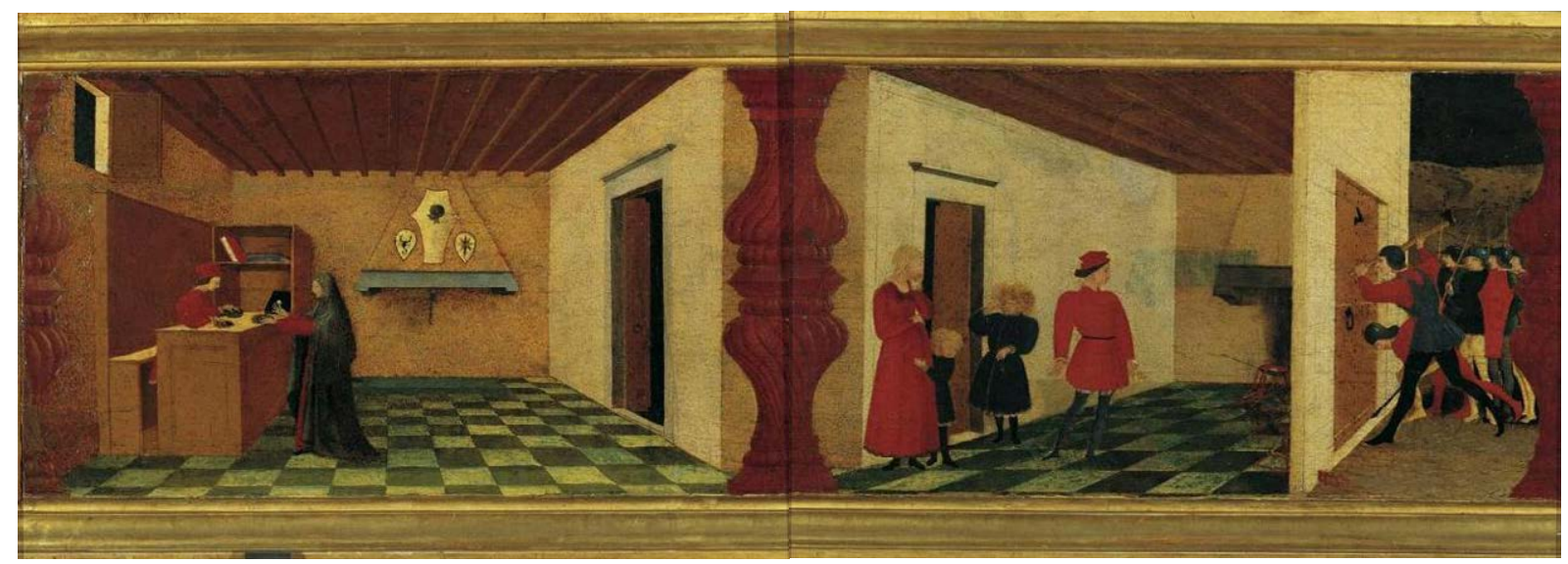

Predela del Palacio Ducal de Urbino. 14651468. Paolo Uccello

Water, and the expensive delicate ship that must have seen

Something amazing, a boy falling out of the sky,

Had somewhere to get to and sailed calmly on. ${ }^{12 "}$

Entre las anotaciones del escultor encontramos una referencia a la predela de Paolo Uccello del Palacio Ducal de Urbino (1465-1468) ${ }^{13}$ a la que se refiere como "el cuadro de Uccello de los judíos". Uccello, acusado por Vasari de prestar más atención a la perspectiva

12 Auden, W. H. Poéma Musee des Beaux Arts

13 La tabla se encuentra en el Hermitage de Leningrado. Representa el milagro de la hostia profanada en seis escenas diferentes. Las dos primeras son escenas interiores. En la primera se representa un banco de préstamo, un judío (los símbolos del escorpión, la cabeza de moro o la estrella sobre la pared así lo indican) recibe una hostia de una mujer, dándole este a cambio una bolsa de dinero. En el segundo panel, el interior de la casa de la mujer hebrea, sobre un cazo la hostia sagrada inundada en sangre y manchando el suelo, la mujer con el hombre y los dos hijos permanecen en el interior de la casa, mientras que al otro lado de la puerta, un ejercito intenta acceder a la misma. En este caso la secuencia se da de manera lineal, en cada una de las escenas se muestran sucesos consecutivos que tienen como protagonistas principales a la familia hebrea. 


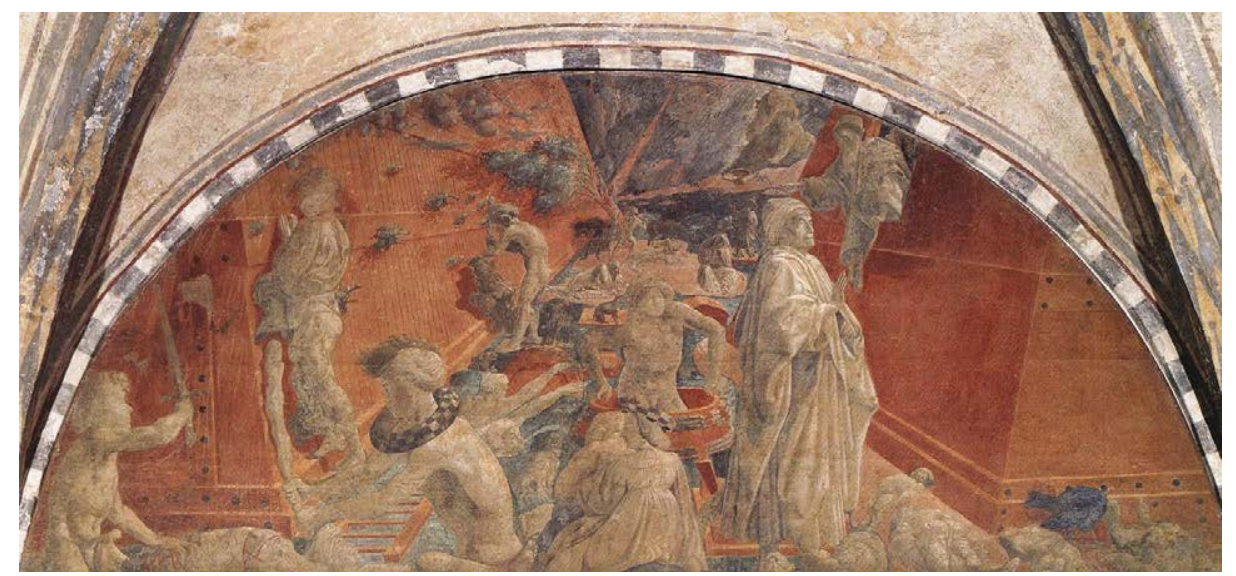

El Diluvio de las Aguas. Santa Maria Novela. 1447. Paolo Uccello

que a las figuras, ${ }^{14}$ y apasionado por la geometría y el estudio de la perspectiva, presenta en esta obra varios espacios de gran amplitud, situando a los personajes sobre los planos de suelo. En las dos primeras escenas, las que seguramente interesaron a Muñoz, utiliza una perspectiva frontal. Cinco planos definen el espacio interior. Ambos espacios quedan unidos por un mismo diseño en el suelo, un ajedrezado (o suelo en escalera).

Las perspectivas muestran un punto de fuga elevado, aún lo es más en otro fresco de Uccello, también mencionado en las notas de Muñoz, El Diluvio y la Retirada de las

14 Vasari, Giorgio, Las Vidas de los más excelentes pintores, escultores y arquitectos: Paolo Uccello. 
Aguas (1447) ${ }^{15}$ Con un punto de vista central muy profundo y donde la geometría de los volúmenes laterales definen la escena, no solo espacialmente, si no también a nivel de contenido, ya que en cada uno de los lados se representan dos acontecimientos que tiene lugar consecutivamente. Uccello experimenta con dos puntos de fuga, en lugar de hacer uso de la perspectiva pictórica con un solo punto de fuga carácteristicos de Brunelleschi o Alberti y consigue obtener un efecto más expresivo, cargando la narración de acción y en este caso de dramatismo. Como en Double Bind, para observar este fresco del Claustro Verde de Santa María Novella hay que elevar la mirada, ya que se encuentra en la parte alta de la nave, agudizándose aun más la fuga de la perspectiva.

Junto a estas notas, aparece otra a la que me refiero de manera más libre, ya que la información que aporta es limitada, pero con relevancia para lo que aqui se trata: "study german female friend of Mies Van der Rohe"16. Es posible pensar que Muñoz se refiere aquí a Lilly Reich. En la casa Tugendhat que ella diseña junto a Mies Van der Rohe en 1929 se utiliza como en el Pabellón de Barcelona del mismo año, una fina plancha de ónix, de suelo a techo para separar la zona de estar del comedor. Esto produce un efecto muy similar a la imagen de la segunda escena interior de la predela de Uccello, un efecto cercano al de una sección fugada de un espacio interior.

En los últimos cuadernos de notas del artista, aparece en numerosas ocasiones la cita 13 Rue del Percebe $e^{17}$ Una de ellas al lado de una fotografía de la maqueta de El Lissitzky donde muestra la sección de su proyecto de interior para la vivienda de Tipo F. La viñeta de 13

15 Florencia, Santa Maria Novella, Claustro Verde. La composición representa dos momentos consecutivos en un mismo plano, a un lado el diluvio con aguas turbulentas, al otro, el arca de Noe aparece ya anclada tras la evacuación de las aguas. La inusual perspectiva es participe de la subdivisión de los dos instantes narrados en una única escena, la perspectiva con dos puntos de fuga era practicada por el maestro de Uccello, Ghiberti. Escribe Vasari, Giorgio, Las Vidas de los más excelentes pintores, escultores y arquitectos: Paolo Uccello.: "Representó con tanto empeño y tanto arte a los muertos, la tempestad, el furor de los vientos, la caída del rayo, los árboles arrancados de cuajo y el pavor de los hombres, que no es posible alabarlo bastante... trató las figuras mediante las líneas perspectivas y pintó "mazzocchi” y otros elementos, por cierto bellísimos." "mazzocchi": anillos de varias caras que se utilizan para base de tocados y utilizadas en pruebas de pintura debido a su complejidad para ser representadas.

16 Cuaderno de notas de Juan Muñoz, año 2000.

17 Título de la popular macro viñeta cómica del ilustrador Francisco Ibáñez que se comenzó a publicar en la revista Tio Vivo en 1961. El edificio se compone de una planta baja, donde hay una tienda de ultramarinos, la portería, una alcantarilla y el ascensor, tres plantas, una azotea y una escalera paralela al hueco del ascensor. 


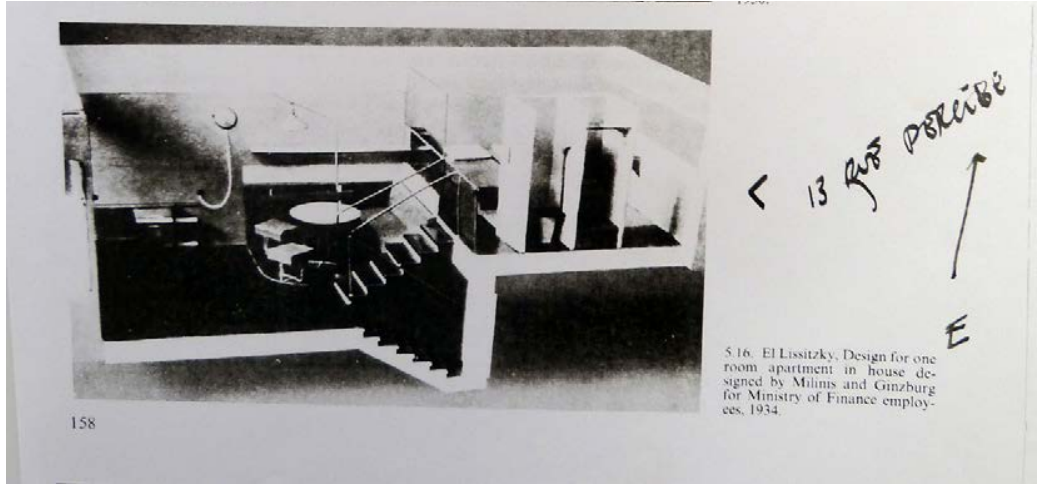

Flat in a House of the Commune. El Lissitzky.

1930. International Hygiene Exhibition.

Documentación del artista.

Cortesía del Juan Muñoz Estate

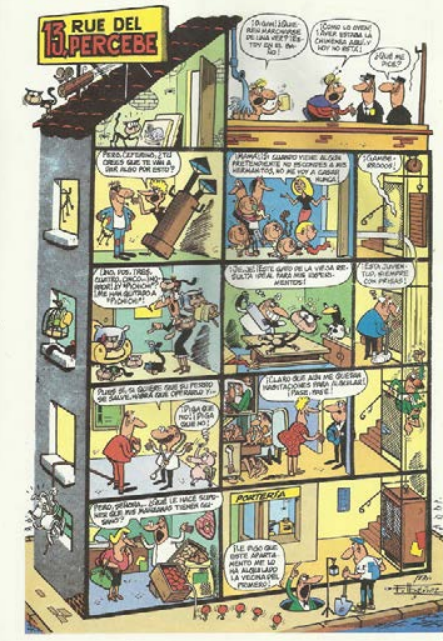

13 Rue del Percebe

Rue del Percebe muestra una sección de un edificio de apartamentos y la comunidad que lo habita, en cada una de las casillas se ilustran una serie de chistes aislados referidos a lo que ocurre exclusivamente en ese habitáculo, una caricatura de los aspectos sociales de la época, y la picaresca. No es necesario hacer una lectura lineal, las situaciones se muestran en una única trama espacia no secuencial. Como en la ventana indiscreta, la película de Hitchcock, (Rear Window, 1954) el observador puede ver desde fuera las acciones que ocurren simultáneamente e independientemente en el edificio opuesto, centrándose en la que desee en cada momento. 13 Rue del Percebe no es un chiste aislado, se convierte en una publicación periódica, y como en un edificio real, las anécdotas se extienden en el tiempo. Ibáñez trabajaba sobre una plantilla del edificio (cargada de ausencia esperando a que los personajes invadan sus calladas paredes, como los balcones de Juan Muñoz) las peripecias de los personajes, siempre los mismos, todos ellos incrustados en pequeños cubículos, siempre en el mismo sitio e ignorantes de que sus acciones, en muchos casos vergonzantes, estaban siendo observadas y transcritas. 


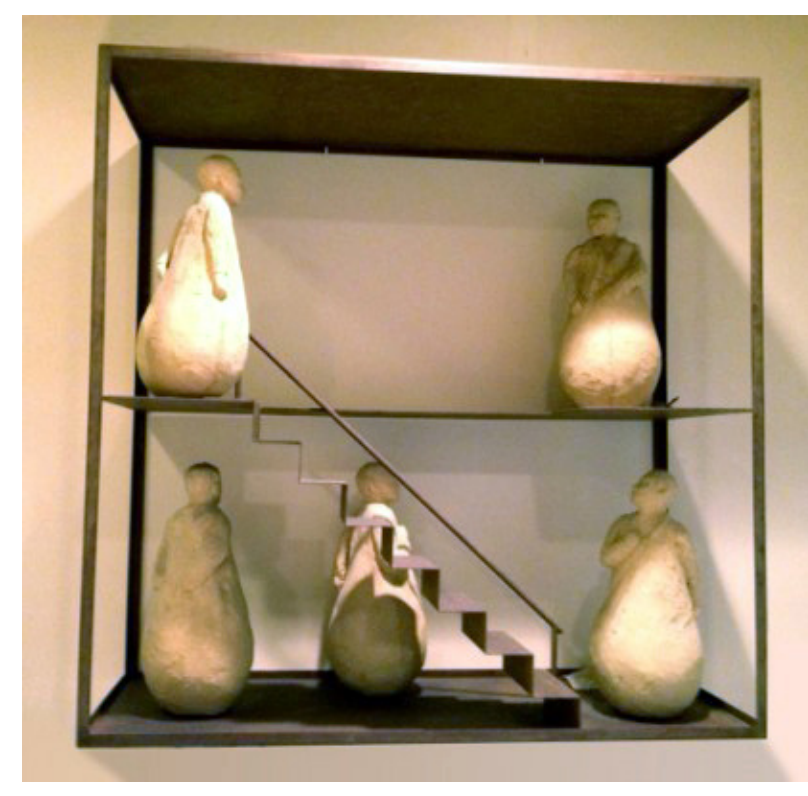

Conversation Piece. 1993. Juan Muñoz

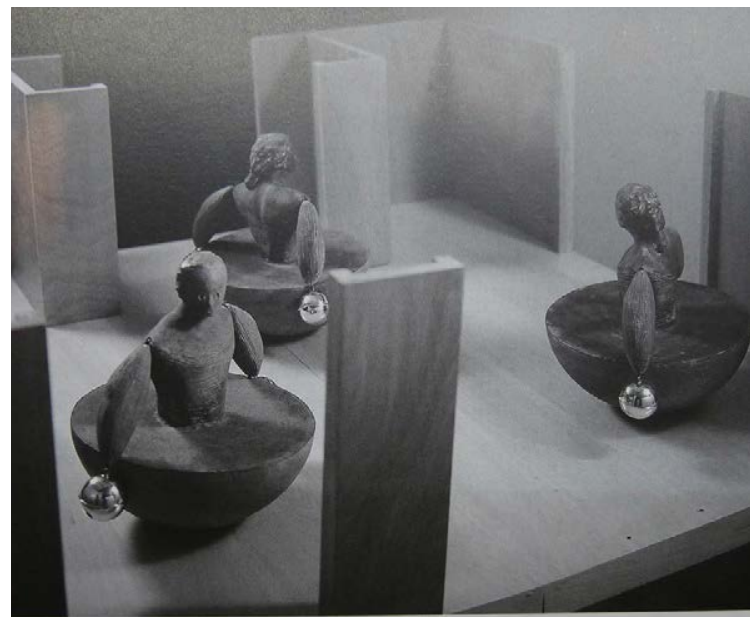

Bailarinas en Apartamento. 1990. Juan Muñoz

De un modo parecido, Perec imagina en La vida, instrucciones de uso (La Vie mode d'emploi 1978) un edificio parisino donde la fachada ha desaparecido, dejando visibles de manera simultanea todos los espacios internos del inmueble. Tanto 13 Rue del Percebe, como en La ventana indiscreta o en La vida, instrucciones de uso, tiene mucho que ver con el arte de mirar, la capacidad de observar la conducta humana sin ser visto, un análisis sociológico en el que el objeto a estudiar ignora la situación a la que ha sido expuesto. A Muñoz le interesa mostrar un plano de visión similar, la sección fugada, la capacidad de entrar en un interior permaneciendo en el exterior, va buscando "construir un muro de vivienda

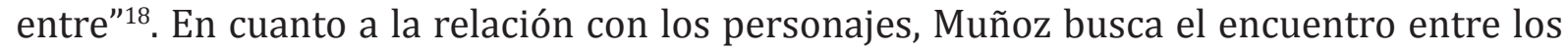
dos protagonistas que activan la historia en el plano sección, el personaje que habita el lugar, y el personaje que observa la escena. Quiere comprometer al espectador y hacer participe al protagonista que es observado. Confronta a los dos individuos, creando una situación de incomodidad en la que el curioso espectador es también percibido por la

18 Cuaderno de notas de Juan Muñoz 2000. 


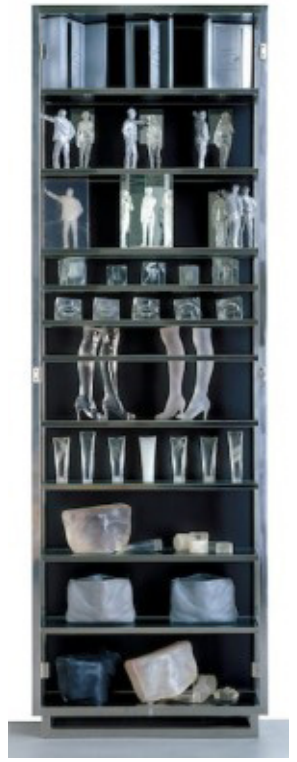

Crossrail Cabinets October. 1999. Juan Muñoz

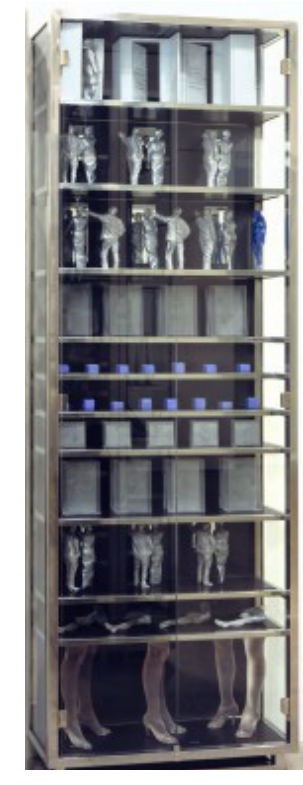

Crossrail Cabinets February. 1999. Juan Muñoz
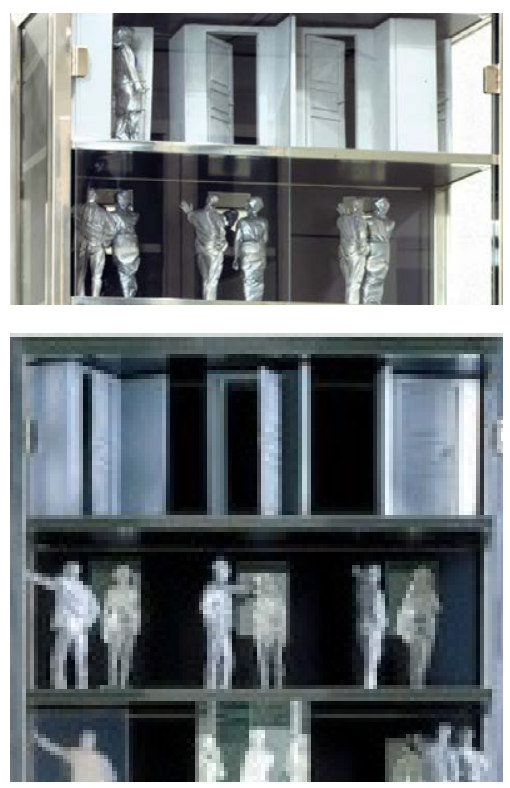

Crossrail Cabinets October and February. 1999. Juan Muñoz

figura observada. Este tipo de composiciones perspectivas nos recuerda a la manera en que en algunos retablos góticos o renacentistas se cuenta de forma dinámica la vida de un Santo, de Cristo o de la Virgen, a través de la sucesión de escenas con figuras pintadas o bajorrelieves. En cada una de ellas se establece un espacio propio, una escena que muestra incluso una perspectiva independiente.

Como en los once Crossroads Cabinets que el escultor realiza en 1999, cada uno bajo el nombre de un mes del año, Muñoz expone en una serie de vitrinas miniaturas de algunos de los objetos más característicos de su producción. Una colección de 'cabinet of curiosities', que bien podrían leerse como una serie de protagonistas dispares llevando a cabo sus actividades independientes, sobretodo en los estantes donde aparecen figuras humanas, en algunos casos jugando con puertas. Los estantes quedan encerrados mediante unas puertas de vidrio, que permiten una relación visual entre el interior y el exterior: "The 


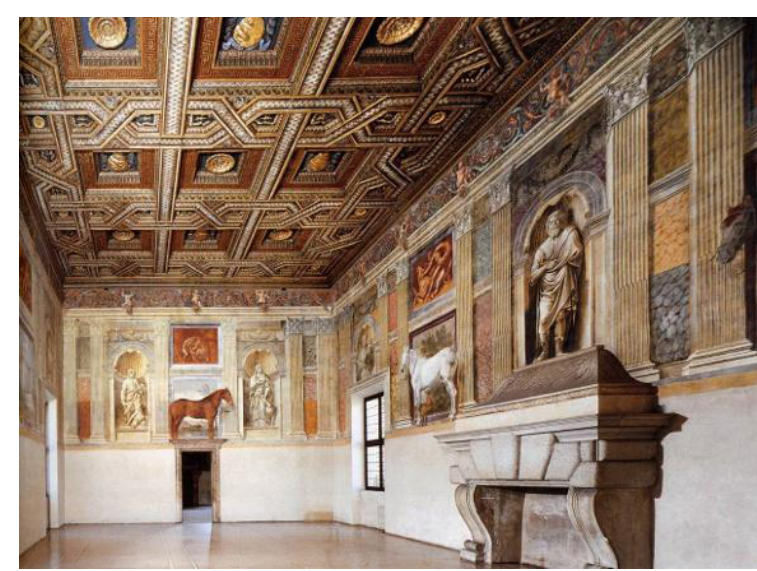

Palazzo Te. Sala dei Cavalli. Mantova 152634 Giulio Romano

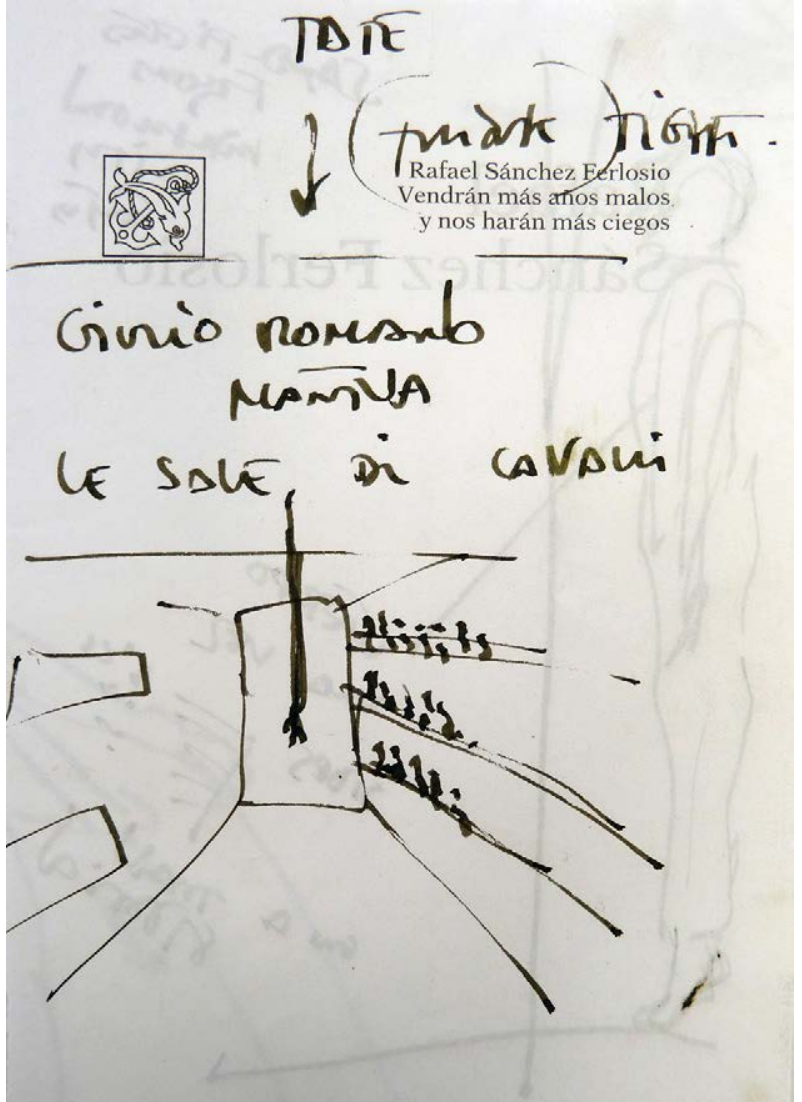

Estudio para Double Bind

Dibujo del artista.

Cortesía del Juan Muñoz Estate

spectator becomes very much like the object to be looked at, and perhaps the viewer has become the one who is on view" 19

Pensemos ahora en el Palazzo Te, construido en 1534 en la ciudad de Mantua (Italia) como un palacio de recreo suburbano de planta rectangular con un generoso patio central. La mayor parte de sus paredes están decoradas con escayolas y frescos, trabajos dirigidos por el arquitecto Giulio Romano. En el vestíbulo de la entrada principal, aparecen unos frescos que representan los más hermosos caballos y perros. Dibujos que, como cuenta Giorgio Vasari, fueron ejecutados por Benedetto Pagni y Rinaldo Mantovano de un modo tan realista que no parecen pinturas. Además del repetido punto de vista, la atención de Muñoz en esta pieza tiene, en mi opinión, dos focos de interés, por un lado la composición en nichos de los elementos representados, y por otro, el relieve. Mediante elementos arquitectónicos pintados sobre la pared se crean una serie de casilleros donde en cada 19 Entrevista de P. Schimmel a Juan Muñoz, en Juan Muñoz en Sculptures et Dessins, exh. cat. Musée de Grenoble, ed. G. Tosatto, 2007, p. 31. 
uno de ellos se trata un tema particular e independiente, se representa una escultura de un torso, un caballo, un pasaje de la mitología griega, etc. El estilo pictórico es el mismo, pero la escala de cada una de las representaciones queda acorde a lo que en ella se quiere representar y abarcar, resultando de muy diferentes tamaños. El relieve pintado, los elementos arquitectónicos y decorativos de carácter volumétrico organizan el conjunto, a la vez que están creando un plano de fondo para la sala. Mediante análisis ópticos y aplicando juegos perspectivos se logra representar un relieve. En el caso de la Sala dei Cavalli, que interesó a Muñoz, tanto los elementos decorativos como los figurativos responden a la perspectiva. Otras referencias que atrajeron al artista y que menciono más adelante corresponden a periodos anteriores de la historia de la pintura, donde las figuras tiene un aspecto más plano y los objetos y elementos arquitectónicos responden a la perspectiva confluyendo la prolongación de sus líneas en un punto central dotando a la imagen de profundidad (siguiendo las leyes de la perspectiva formulada por Alberti en 1453 valiéndose de la geometría euclidiana).

Los recursos que busca Muñoz en la pintura son los del sistema de representación cónico. La escultura le aporta todo lo que necesita para conseguir una visión real, pero Muñoz quiere obtener un cierto enfoque pictórico tanto el plano superior de la obra como dentro de los nichos queriendo engañar al ojo, jugar con la realidad y la ilusión, y la relación entre el tamaño y la distancia.

Generar esos recovecos, esas fugas de planos que en la pintura se entienden como reales pero que se ven pintados. Conseguir el juego inverso o compartido de ver una imagen plana que fuga, creada por objetos tridimensionales, exagerando la realidad de las fugas. Lo más importante para lograrlo es elegir el punto de vista y el interior adecuado en los que apoyar la escultura.

Cuando pensamos en la escenografía, tiene aquí sentido referirnos a la descripción que Hal Foster hace de la escultura de Richard Serra, aun teniendo claro la distancia que separa el tipo de escultura minimalista del escultor americano de la obra de Muñoz "el objeto minimalista involucra al sujeto pero permanece externo a él o a ella, mientras que en la arquitectura barroca, los listones y torques envuelven al sujeto y el efecto es a menudo 
extraordinario: un aplastamiento espacial del sujeto y una deformación subjetiva del espacio." ${ }^{20}$

En el barroco los huecos de luz, sugieren en quien los ve una ascensión. Muñoz utiliza este efecto, pues también quiere provocar esa mirada elevada, pero a diferencia del barroco, detiene al espectador a observar un plano intermedio. Ese plano intermedio es horizontal y bien podría entenderse como si de una fachada abatida se tratase que separase el interior del exterior y en el que al mirar a través de los huecos la mirada se detuviera.

La idea de abatir el plano vertical con sus huecos, y entenderlo como un plano horizontal surge por un lado de la visión frontal de un elemento, y por el otro de la contemplación de la calle y la configuración formal de las fachadas. La gente pasea por las calles como si no viera nada, no se detiene a mirar las fachadas que flaquean los caminos, es el escenario habitual y se sabe de memoria. Se convierten en una escenografía no penetrable. Como en las galerías comerciales que describe Walter Benjamin, en las calles creadas por Muñoz en sus obras A place called Abroad presentada en Dia Center of the Arts en 1996, y dos años más tarde expuestas en SITIO Santa Fe bajo el nombre de Streetwise, el tráfico desaparece quedando solo una abstracción de las fachadas laterales :"comercio y tráfico son los dos componentes de la calle. Pero resulta que el segundo ha desaparecido en los pasajes;"21. Las calles se asemejan a los pasadizos que crea Richard Serra en algunas de sus esculturas entre planchas verticales, aislando también al espectador y obligando a experimentar una cierta perspectiva, con un definido punto de vista. En el caso de Serra, los espacio se ven distorsionados por complejas curvaturas, en el caso de Muñoz en Double Bind, el espacio se distorsiona por su localización y su materialidad; abstrae elementos que se encuentran en el espacio de la calle, reduciendo su expresión y funcionalidad al mínimo, que dispone en un "purgatorio" inaccesible al espectador que lo contempla mirando hacia arriba asomándose a los huecos de luz.

En 1988, casi como un guión de lo que sería su obra ocho años más tarde, Muñoz escribía en su texto Un objeto metálico"22

20 Foster, Hal, El Complejo Arte-Arquitectura. Turner 2013 p.199.

21 Benjamin, Walter, Libro de los Pasajes, 1950 p.77.

22 Juan Muñoz: Escritos/Writings. Barcelona. Editado por Adrian Searle. Ediciones de la Central. MNCARS. 2009. p. 77 

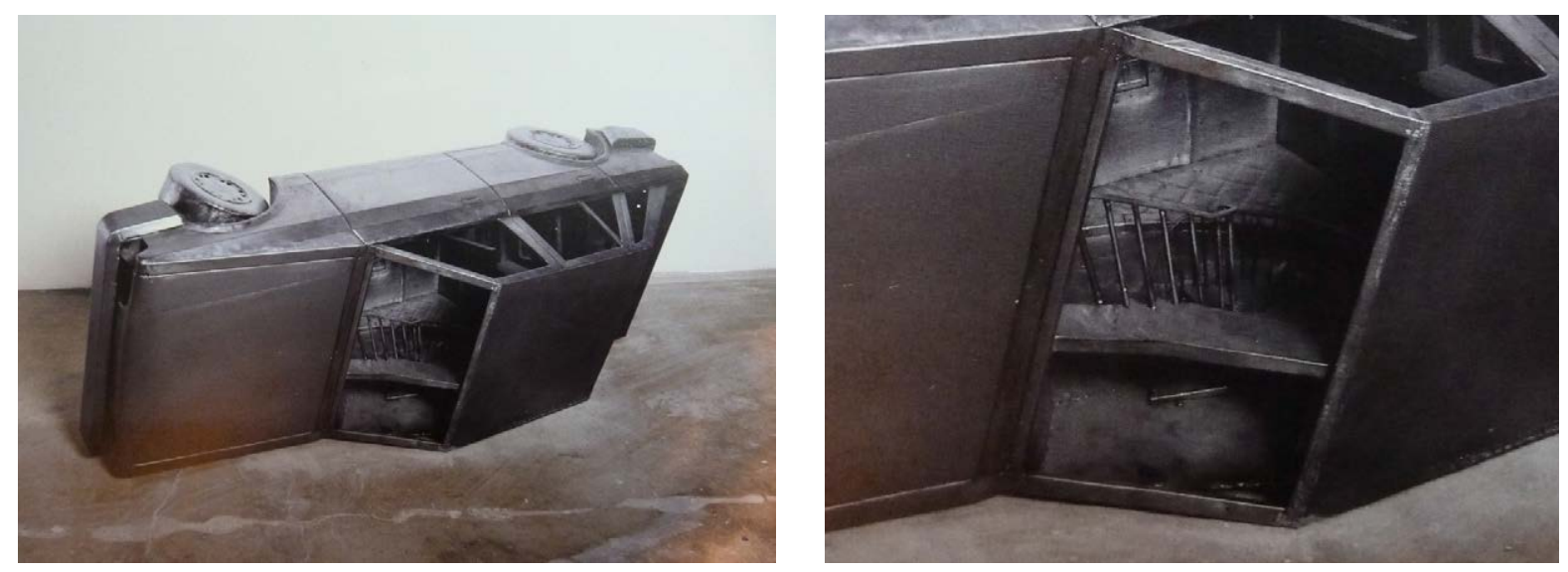

Loaded Car. 1996. Juan Muñoz

"Al final de la calle una plaza.

Encontrar en esta ciudad cuando se apaga

$Y$ es asaltada por estatuas

Que bajan de sus peanas...

...Una ciudad atravesada por pasillos interiores"

La exploración del mundo urbano forma parte del repertorio de Juan Muñoz desde el inicio de su carrera. Primero aislando partes de él, tales como los balcones, escaleras o puertas. Más adelante unificando varios componentes urbanos. En A Place Called Abroad y Streetwise configura falsas perspectivas de calles creadas con escayola gris. El espectador camina flanqueado por puertas y ventanas ciegas que evocan la memoria de lugares conocidos, pero donde ya no se puede vivir porque son impenetrables. De alguna manera se niega al espectador el conocer lo que ocurre tras esas paredes, el mundo oculto. En una de las salas que se abren en el recorrido de la obra Streetwise aparece Loaded Car, un 


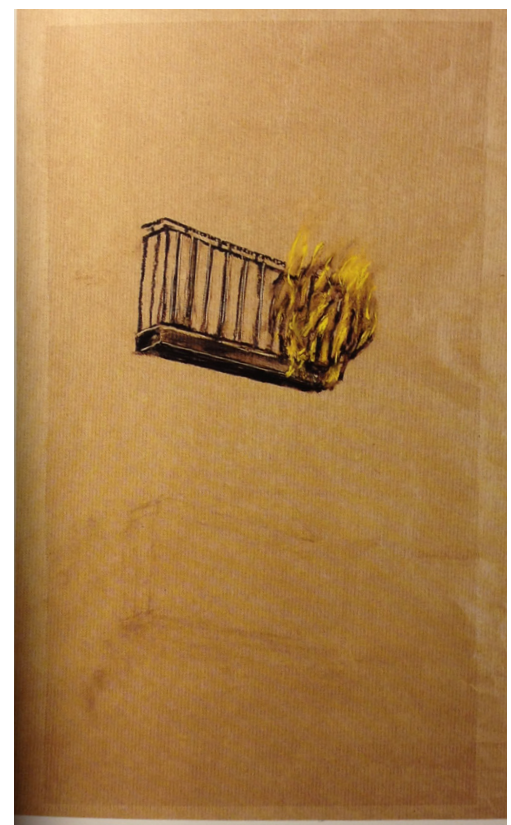

Untitled (Balcony with Fire), 1984. Juan Muñoz

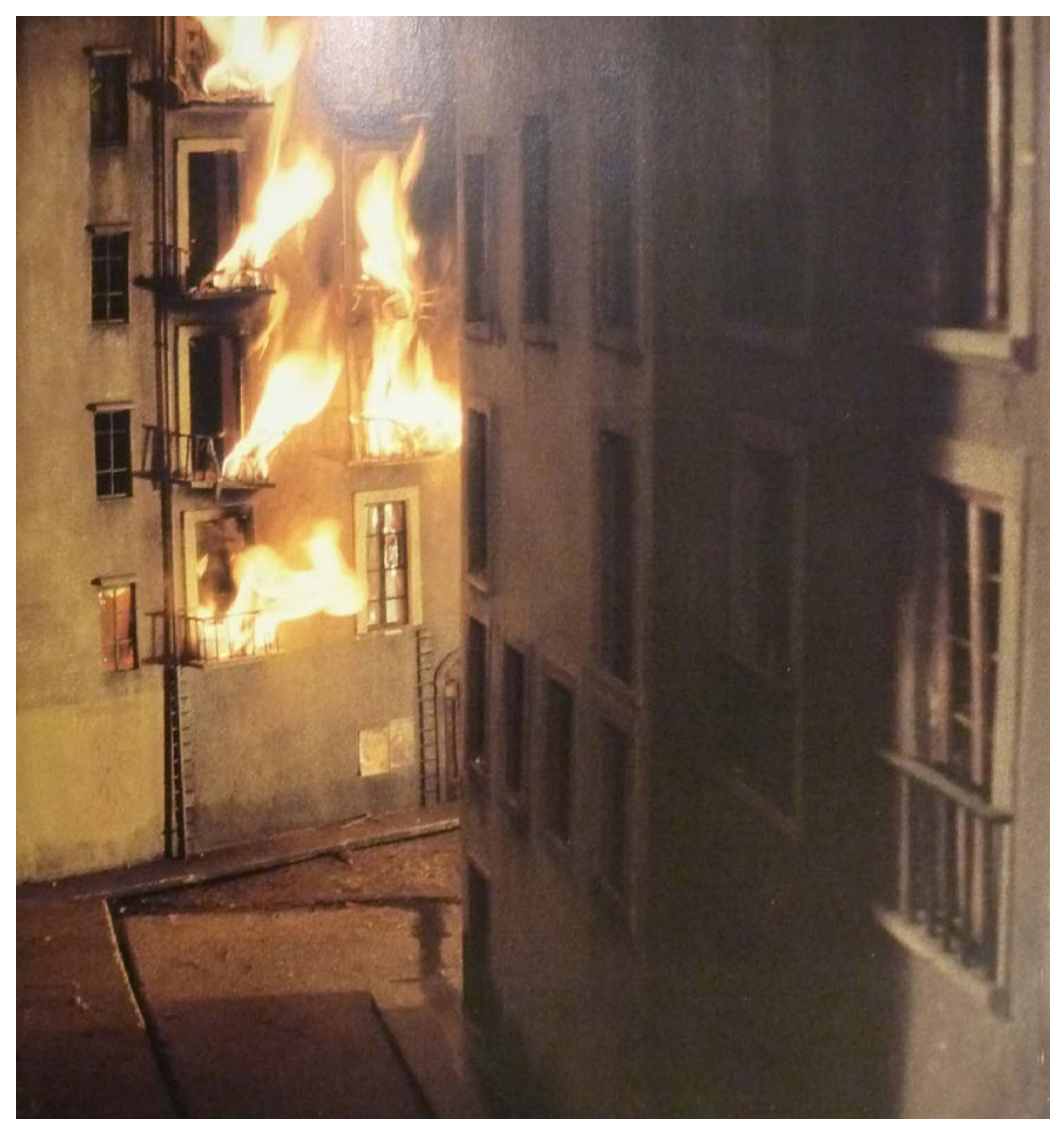

The Burninf of madrid as Seen from the Terrace of My House, 1999. Juan Muñoz

coche esculpido en acero que en su interior contiene una ciudad en miniatura, escaleras que entrelazan de manera laberíntica avenidas donde se levantan edificios con ventanas y puertas selladas. Recuerda de algún modo a las cárceles de Piranesi donde se entremezcla lo real y lo imaginario, y donde la desolación es latente. Ofrece una visión distinta del mismo entorno que ha recorrido a pie el espectador, ahora extrañamente contenido en el interior de un coche. Aparece la escultura dentro de la escultura, algo que como hemos visto es una de las características de Double Bind.

Posteriormente Muñoz realiza una maqueta muy detallada de una zona urbana, muy similar al que se representa en el interior del coche. Edificios con ventanas, molduras, distintos acabados en las fachadas, cornisas, etc. en definitiva, todos los elementos que podríamos encontrar en cualquier calle de Madrid, salvo gente. Tras terminar la pieza, le prende fuego, y captura el proceso en una serie de imágenes tomadas por su amigo el fotógrafo Attilo Maranzano. Títula la obra The Burning from Madrid as Seen from the Terrace 
of My House (1999). En el año 2001, al mismo tiempo que expone Double Bind, Juan Muñoz continúa desarrollando el juego de la muñeca rusa en su escultura Descarrilamiento. Un tren con varios vagones apoyando unos sobre otros tiene en su interior un detallado entorno urbano similar al del vehiculo. Un entorno solitario de aquello que podría ser visto solo si se pasara con un coche o un tren a través de una ciudad. A diferencia de todas estas esculturas donde las fachadas son impenetrables, en Double Bind algunos huecos abren a un mundo que resulta de alguna manera interior por su configuración espacial, sin embargo, el marco narrativo de cada uno de los huecos tiene los accesorios y elementos arquitectónicos necesarios para ofrecer una imagen de ficción de una la calle, una calle exterior y carente de suelo en su parte central "an interior without floor"23.

Repasando las fotografías que Muñoz toma de la sala de turbinas, aparece una de unas puertas metalizas en las que el dibuja otras similares junto a ellas. Parece que el artista quisiera aprovechar los elementos arquitectónicos que allí encuentra pero que, después de su estudio, necesitara otros que intenta introducir para contextualizar sus figuras y generar su narrativa.

Este exterior - interior se percibe como una cavidad en el interior de la plataforma, idea que se liga al concepto de la arquitectura como refugio. De alguna manera, Juan Muñoz decide proporcionar un cobijo, un nicho para sus figuras, mediante una estrategia escultórica que puede ser entendida como arquitectura. La asociación explicita que el escultor establece entre el espacio y la inclusión de elementos arquitectónicos hacen que el simbolismo no deje otra alternativa al observador que entenderlo como arquitectura. Es casi imposible separar forma de significado. Durante las últimas décadas del siglo XX la frontera entre escultura y arquitectura se diluye. La escultura comienza a proponer cambios en el espacio a partir de la manipulación de éste. La voluntad de crear un espacio que englobe las figuras, en este caso de manera lateral, ya que el espacio habitable se encuentra en el equivalente a la proyección interior de las caras que genera el hueco, nos lleva a buscar referentes espaciales en el imaginario del escultor. Sabemos de su predilección por los interiores barrocos recargados y de geometrías curvas. Pero, en cambio, el espacio que aquí se propone es sobrio, escaso en ornamentación, y de marcados planos ortogonales.

23 Cuaderno de notas de Juan Muñoz, año 2000. 


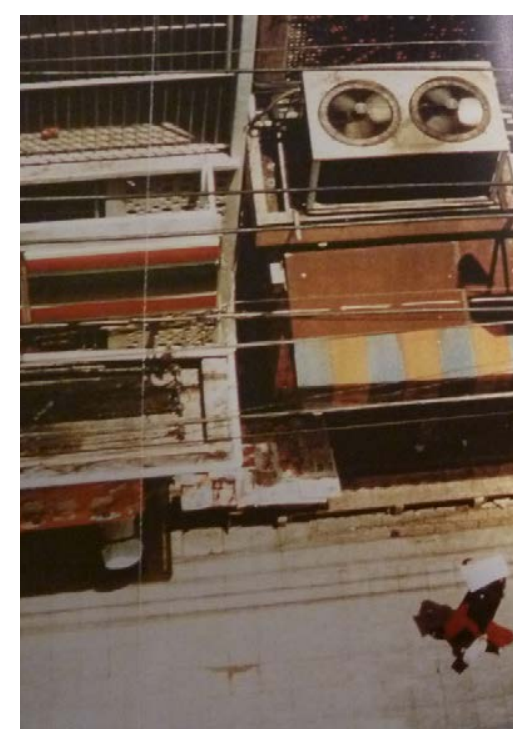

Ciudad Este Asiatico

Documentación del artista.

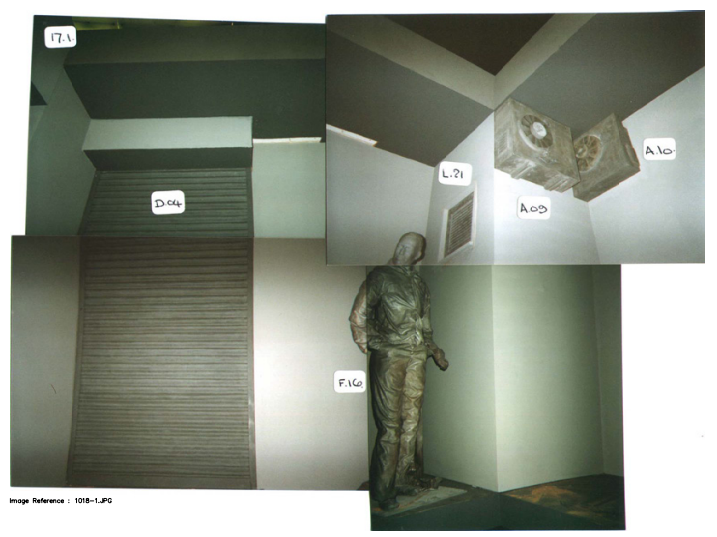

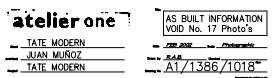

Double Bind

Planos realizados por Atelier One. Cortesía del Estate de Juan muñoz

En la sala de turbinas apenas encontramos elementos que nos ayuden a entender la escala arquitectónica del espacio. Muñoz se siente liberado de las referencias que puedan entrar en dialogo con el lenguaje que se quiere proponer. No hay nada de lo existente que tapar u ocultar pero tampoco mucho a lo que agarrarse. Herzog \& de Meuron apenas actuaron en el espacio de la sala de turbinas, apenas hay gestos de los suizos, salvo los elementos necesarios para el museo. La sala no ha perdido su lenguaje original, quedando un volumen con un espacio ensordecedor que aturde, en parte, por ese carácter aséptico que recalca aún más la densidad de este vacío. Juan Muñoz incorpora los artificios necesarios que le permiten caracterizar el contexto que busca construir. Desde los años ochenta, Muñoz empezó a recuperar elementos arquitectónicos separados de sus funciones, vinculado todavía al arte postminimalista de la década de los setenta.

La representación escultórica de los aparatos de aire acondicionado (construidos con el mismo material que las figuras), las falsas persianas metálicas (hechas con telas), las 
ventanas (de madera), etc., no son más que símbolos, la iconografía de su obra. Muñoz, en lugar de recoger los elementos arquitectónicos existentes e introducirlos en su obra, decide moldearlos. A diferencia del ready made de Duchamp, que idealiza un producto sacándolo de su contexto, Muñoz esculturiza el producto para contextualizar el proyecto. Robert Venturi señala que cada generación tiene su propia definición de arquitectura, y que para él, "la arquitectura es un refugio con símbolos superpuestos"24 . La escultura trabaja con el espacio y produce espacios, pero el identificar estos espacios como lugares o cavidades habitables es algo que en muchos casos queda a merced de la capacidad apreciativa e interpretativa del observador. En este caso Juan Muñoz quiere hacer reconocible el espacio que propone como aquel que podría ser encontrado en un rincón de cualquier ciudad. Utiliza símbolos que definen un contexto urbano. Estos elementos son también objetos con los que estamos familiarizados y de los que conocemos sus proporciones, por lo que inmediatamente nos dan una sensación de escala de lo proyectado. La caracterización del espacio con estos elementos escultóricos de carácter arquitectónico nos lleva a focalizar las posibles sensaciones que la obra nos pueda producir a un entorno humano y urbano. Reconocemos la naturaleza del medio que se plantea, y no solo eso, nos identificamos con el individuo que lo habita e incluso, ya que creemos poder manejarnos en el entorno urbano propuesto por verlo como algo semejante a lo ya conocido, como si nos fuera posible ocupar el lugar de esos personajes.

En Double Bind se utilizan elementos que evocan un paisaje urbano cotidiano (ventana, puerta, caja de aire acondicionado...). Mediante la expresión escultórica de estos elementos el artista crea un espacio cargado de condiciones existentes similares a las de un entorno de ciudad, que podríamos denominar genérica, donde lo hallado, lo banal, lo cotidiano, es el denominador común. Los elementos que pertenecen al mundo cotidiano u ordinario se convierten en extraordinarios por su premisa surrealista. En esta extraña ciudad donde el carácter está definido por la naturaleza formal de los elementos que la configuran, todos ellos producto de un taller de escultura donde han sido construidos con maderas o telas, se crea un habitat con un potencial realista sorprendente. Este efecto no es debido a su

24 Venturi, Robert, Una definición de la arquitectura como refugio con decoración superpuesta, y otro alegato a favor de un simbolismo de lo ordinario en la arquitectura: Robert Venturi 1978 en Walker, Enrique, Lo ordinario, Editorial Gustavo Gili, S.L. 2010. p.67. 
parecido con la realidad, que existe en cuanto a su forma, sino por la instrumentalización de dichos elementos como símbolos que definen la caracterización urbana de un espacio. Las figuras que habitan este espacio transitorio entre el cielo y el purgatorio se perciben como fugitivos dentro de esta ciudad cautiva, pero la intromisión del espectador en esta ecuación y frente a la impasibilidad de las figuras ante su presencia y el descaro de su pose ante el cruce de miradas, el espectador se convierte en la figura del flâneur de Charles Baudelaire. El encuentro fortuito entre las figuras y el espectador produce una tensión deliberada donde uno puede llegar a preguntarse si esta queriendo mirar a un lugar dentro de la escala de lo privado y del que quizá deba retirar la mirada para no ser indiscreto.

Al espectador le resulta muy difícil percibir que las figuras no miden más de 1,40 metros, y que los elementos arquitectónicos no son reales ni escalados ,si no reproducciones artísticas realizadas con el mismo material que las figuras y con una medida proporcional a las figuras que habitan el espacio. 


\subsection{El ventrilocuismo es una forma de polifonía ${ }^{25}$}

"Since I lack of voice of my own, the voices of others invade me as if I were a silent ventriloquist"26

Desde sus orígenes, la figura humana ha sido el tema dominante en la escultura. Durante las vanguardias el arte se resistía a la forma figurativa, sin embargo, es inevitable la relación de la escultura con el cuerpo humano, aunque no sea por una directa representación antropomórfica, la relación de la escultura con el cuerpo humano va más allá de los limites de lo representado, es la unidad de medida. En los años ochenta y noventa se recupera la temática figurativa por artistas como Robert Gober, Mike Kelly, Thomas Schutte, Katharina Fritsch, Paul McCarty, Stephan Balkenhol, Charles Ray and Kiki Smith. ${ }^{27}$

Para Muñoz el espacio se define a partir de las dimensiones del cuerpo humano. "toda forma en el espacio es comprendida a partir de las dimensiones del cuerpo humano. Cada objeto en torno al cual y en cuyo entorno nos movemos es percibido a partir de la extensión de nuestro propio organismo y sus limites". ${ }^{28}$ Muñoz es conocido internacionalmente por sus figuras, sin embargo tardó varios años en incluir en sus trabajos una figura humana con cierta definición. Comenzó componiendo partes de figuras de maniquís, o porciones del cuerpo, una pierna, una oreja. Más adelante, en los minaretes de los años 80 incluirá pequeñas modelos en madera, similares a los tótems, y pintados de un único color uniforme. Tras realizar diversas esculturas mas cercanas a los juguetes que al humano, como los muñecos de ventrílocuo, o las bailarinas, el escultor salta a representar figuras de mayor escala con rasgos poco definidos y donde las extremidades inferiores son sustituidas por sacos.

A mediados de los noventa crea un molde de un enano (George), que después repetirá en su versión femenina (Sara). Con estas esculturas da un salto en la definición realista de los

25 Muñoz, Juan. Juan Muñoz. El ventrilocuismo es una forma de polifonía. Escritos/Writings. Ediciones de la Central. Barcelona, 2009 Pág. 97. Escrito en 1990.

26 Hoffman, Eva, Lost in Translation: A Life in a New Language, Vintage 1998, p. 220.

27 Juan Muñoz: a retrospective / edited by Sheena Wagstaff. Tate 2008 p.95.

28 Mu;oz, Juan, Notas afines a tres en Juan Muñoz: Escritos/Writings, Ediciones de la Central. Barcelona, 2009 , p.47. 
rasgos. Continúa con esta técnica, realizando rostros a partir de moldes y reduciéndolos en escala para que la cabeza mantenga una proporción adecuada con el cuerpo. Las extremidades siguen siendo centro de su atención, continuando con los sacos, o eliminando los pies en algunas de ellas. Las últimas esculturas, que son las presentadas en Double Bind, responden a un molde de la cara de su hermano, con un alto grado de definición, pero, otra vez, reduciendo su escala. "No creo que se puedan hacer cosas de tu mismo tamaño, han de ser más grandes o más pequeñas. Yo las hago más pequeñas, porque me da la sensación de que crea una distancia mayor, tanto física como conceptual, entre el espectador y el objeto"29.

La escala de las figuras en Double Bind, como sucede en gran parte de sus obras anteriores, es más reducida que la humana, generalmente alrededor del $1.40 \mathrm{~m}$ de estatura. Juan Muñoz necesitaba una altura determinada en el estrato intermedio para encajar las figuras en un espacio proporcionado a su escala, pero también era necesario calibrar el espacio inferior restante, que permita la mirada oblicua del espectador hacia el piso superior. La obra se beneficia de la distancia entre el espectador y las figuras, los huecos parecen tener más profundidad, y la distancia a los personaje parece mayor. El hecho de que los personajes sean de una escala menor, y que el espectador no pueda acercarse a ellos, da la sensación de que están a más distancia, obteniendo el resultado buscado.

El muñeco del ventrílocuo es un hablador silencioso, la figura que externaliza la voz de otro hombre, su álter-ego, la figura desdoblada del ventrílocuo. Las figuras se convierten en habladores silenciosos. Insinúan ciertas ideas y externalizan su interior más profundo mediante el lenguaje gestual y corporal. Se produce una interacción casi telepática entre la pieza y el espectador. Este último puede percibir el rechazo de la figura y sentirse incomodo al mirarla, o empatizar con ella, y entender con complicidad la actitud de la figura. Y tras el espectáculo y el dialogo entre la pieza y el espectador el ventrílocuo, el escultor que transfiere sus palabras a través de la pieza.

Identificar al personaje como una figura humana fortalece las relaciones de cercanía entre el grupo escultórico y el espectador. La participación del espectador en la escena errando por el piso inferior y la coherencia visual que la analogía de la imagen presenta con el

29 Juan Muñoz, James Lingwood, Iwona Blazawick y Andrea Schlieker, Una conversación. Julio 1990, en Monólogos y diálogos. MNCARS. 1997. p. 62. 
mundo real hace aparecer la disyuntiva entre el enigma de identificarse con el personaje y la extrañeza de asociar con la vida un cuerpo escultórico. La puesta en escena confronta al personaje con un posible álter-ego. En esta obra, al contrario que en otras de Muñoz, no aparece el espejo que genera el doble de la figura, el doble es ahora el espectador. Su estado mental y su capacidad para identificarse con las figuras del purgatorio determinaran sus reacciones y su relación con el conjunto escultórico. Se activa la memoria filogenética del espectador, que establece una relación de parentesco con las figuras sin llegar a comprender el orden en la cadena evolutiva. El encuentro en la claridad que se abre en medio de la oscuridad provoca un impacto en el estado mental que altera la comprensión del momento presente, el descubrimiento destapa el lado oscuro de la personalidad en el conflicto de sentirse identificado con los personajes o renegar de ellos. El espectador navega por un circuito de la mente que confronta el mundo exterior que ve ante sus ojos y su mundo interno.

Double Bind es, entre otras cosas, un grupo de esculturas repartidos en varias escenas. El escultor comienza a explorar las composiciones de figuras escultóricas con las llamadas Conversation Pieces. Según contaba el mismo, estas composiciones parecen surgir de manera casual en su estudio, donde trabajaba principalmente las figuras por separado. La acumulación de ellas en el espacio de trabajo llevó al artista a observar la relación entre ellas y la fuerza de la tensión espacial que se crea en torno al conjunto de piezas.

En sus grupos escultóricos se crea una relación muy particular entre las figuras, casi un equilibrio tenso. En estas composiciones escultóricas observamos que entre las figuras se da una separación que las mantiene gravitando en conjunto pero con la imposibilidad de aproximarse más unas a otras (las figuras no tiene pies, sus extremidades se ven sustituidas por un saco, etc.).

En muchas de sus composiciones anteriores, el observador puede moverse y acercarse a las figuras cuanto quiera pero una distancia psicológica que deriva del lenguaje gestual de las figuras establece una relación de extrañeza entre el observador y las piezas. Como ha sucedido en obras anteriores tales como Plaza en el Palacio de Velazquez en 1996, donde el conjunto de figuras se observaba desde una balconada, o en Vivir en una caja de zapatos de 1993, donde se sitúa a las figuras en un rail que recorre la parte superior de la galería, en Double Bind el artista también coloca al espectador a una distancia insalvable 
de las figuras. A la distancia psicológica se suma en estos casos una distancia física. En Double Bind las figuras se observan desde un punto inferior, se debe mirar hacia arriba para verlas. Podría entenderse que el artista busca un encuadre pictórico, que enmarca un forzado punto de vista, sin embargo, el lenguaje corporal de las figuras, que en algunos casos parecen llevar a cabo una actividad sin percatarse de los mirones visitantes, y que en otros casos cruzan sus miradas con las nuestras esbozando una media sonrisa con un gesto que nos domina y descoloca, haciéndonos dudar de si realmente ese cruce de miradas es una ilusión, o una casualidad, hace que no sea posible simplificar este juego del artista a un encuadre pictórico. La distancia entre las figuras y el observador es la que separa al observador del mundo de las figuras, que queda inaccesible a él, y del que parece que solo puede ver una parte.

La figura antropomórfica de Muñoz quiere alejarse de la escultura como monumento, Muñoz llama a sus figuras estatuas, concepto que puede relacionarse con el deseo de imitar la figura humana natural, o con mostrar ese momento de la parálisis de un individuo. Se aleja de la escultura como objeto, y se rinde al espacio envolvente como parte de la narrativa.

Los habitantes sin identidad de Double Bind son iguales unos a otros, cada uno realizando una actividad diferente, pero todos caracterizados con la misma ropa, el mismo rostro. En su conjunto crean una narrativa silenciosa sin un propósito aparente. No parecen tener ningún deseo de socializar más allá de su mundo, con esta indiferencia llevan al espectador hasta lo más profundo de su alma. El estado de animo del espectador cambia, donde están las figuras escucha el silencio que se establece a través del lenguaje mudo de las figuras. El espectador interpreta con su voz las palabras mudas de las figuras convirtiéndose en el ventrílocuo.

La expresión de los rostros en la obra de Juan Muñoz evoluciona a lo largo de su obra casi siempre en busca de un gesto con un atrevimiento impenetrable que no invita a la interacción de la figura con el observador. En su exploración escultórica el cambio de modelo es muy escaso y se concentra en la variación de expresiones de un mismo rostro en lugar de en la variedad a través de personalizar las distintas figuras. En su conversación con James Lingwood en septiembre de 1996 Juan Muñoz cuenta que hasta aquel momento solo ha utilizado un repertorio de unas seis caras. Caras donde ha trabajado la expresión, pero 


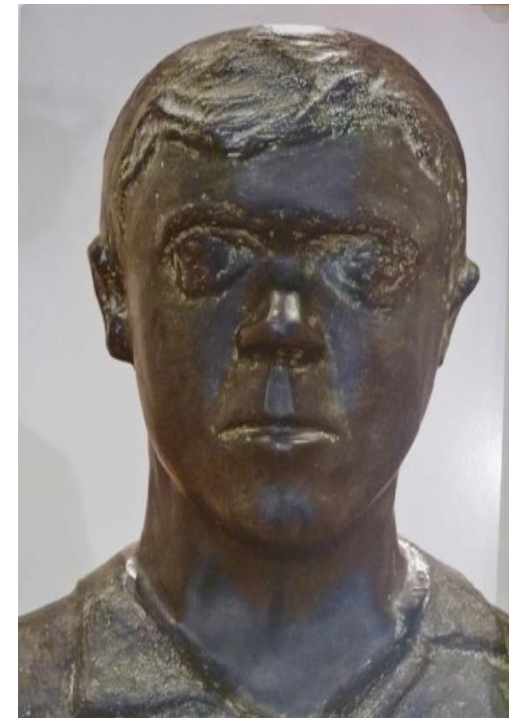

Krefeld Dwarf. 1989. Juan Muñoz

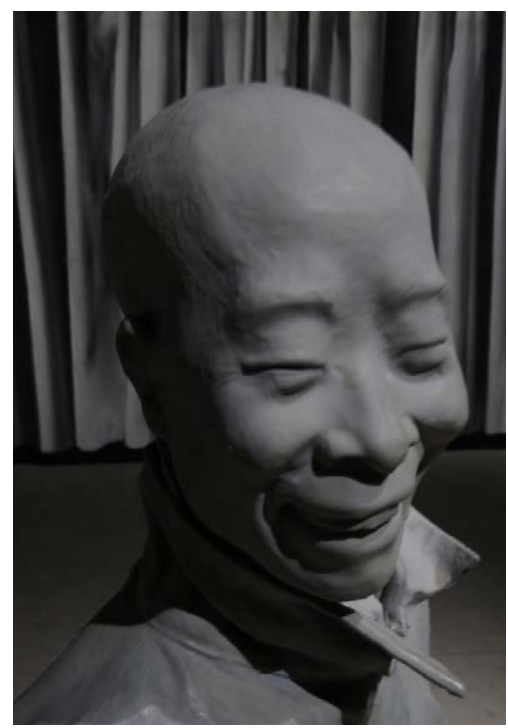

The Nature of Visual Illusion, 1994-1997. Juan Muñoz

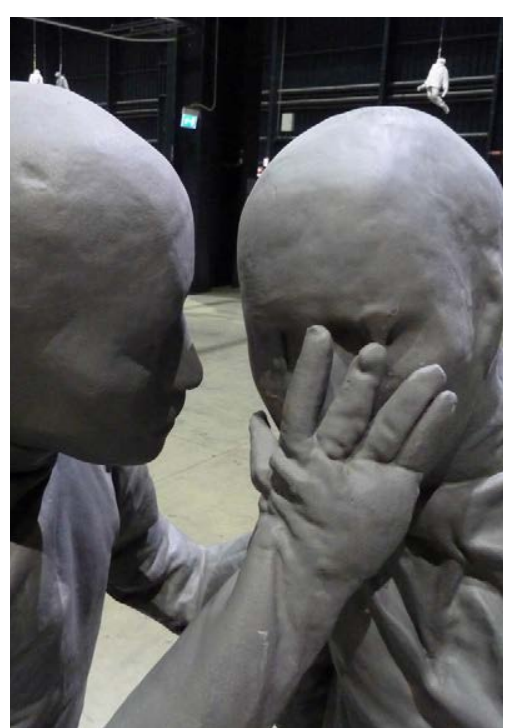

Conversation Pieces, 1994-1996. Juan Muñoz

intentado evitar el sufrimiento de encontrar el rostro perfecto. Eludiendo frustraciones como las de Giacometti ante la imposibilidad de atrapar el gesto insondable, su atención se centra en la composición y en la relación entre la figura y el conjunto. Muñoz no tiene el afán de otros artistas que buscan un repertorio de semblantes mediante distintos modelos, sino que a través de un mismo modelo y variando su visaje, centra su atención en la expresión corporal y en el dialogo de la figura con el entorno. En algunos casos, la repetición del modelo puede incluso crear una confusión momentánea en el espectador que ve multiplicado al mismo individuo en mas de cincuenta posiciones distintas en un mismo espacio, como si el movimiento de la figura se produjera tan rápido que se percibe en todas las posiciones por las que pasa en un único instante. "no es que quiera crear un símbolo, más bien es una imagen definitiva".

Desde los inicios de su carrera, antes de centrar su obra en las figuras, mostraba una preocupación por la figura humana en el campo de la escultura. La figura antropomórfica 


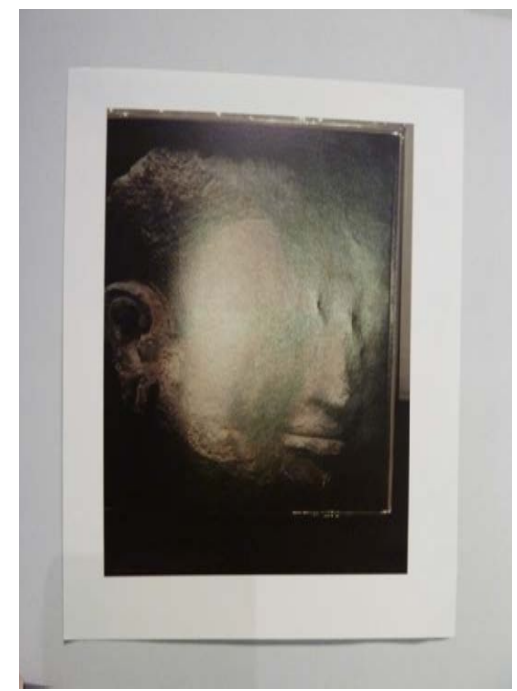

Documentación del artista. Juan Muñoz

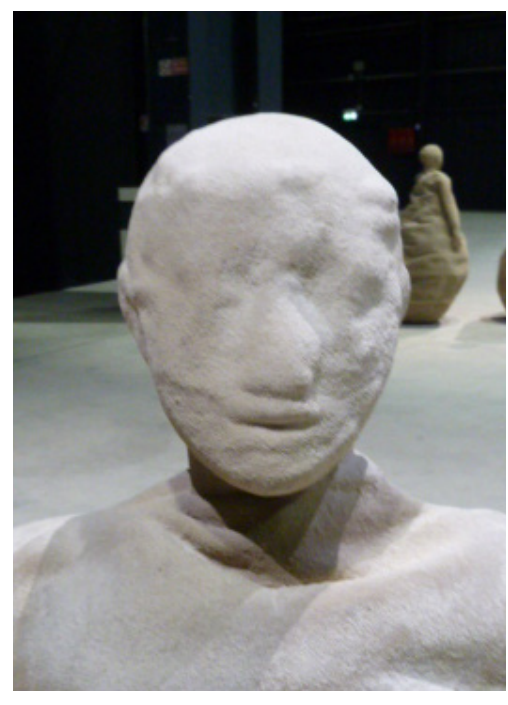

Conversation Pieces, 1994-1996. Juan Muñoz

acerca la escultura al observador por tratarse de una relación directa con lo conocido. "El Cristo, más enjuto que divino, toma su medida del cuerpo humano, y es esta dimensión , tomada de lo común y no su mero emplazamiento, lo que le da a la escultura su adjetivación pública." ${ }^{30}$ Esta preocupación sobre la medida del cuerpo humano que demuestra en sus primeros escritos, en este caso en la entrevista que le hizo a Richard Serra en Nueva York en 1981 y las asociaciones directas entre el cuerpo humano representado y el observador seguirán formando parte de sus exploraciones escultóricas. La búsqueda de la extrañeza a través de lo común es una constante en el artista como muestra en sus esculturas de enanos como en Dwarf with Three Columns de 1988.

La obsesión de Juan Muñoz por el Autoretrato en un espejo convexo (1523-24) del artista italiano Parmigianino parece arrancar de una conversación durante la instalación de una obra delartista Mario Merz, probablemente en el montaje dela exposición Correspondencias,

30 Muñoz, Juan, Sobre escultura pública en Juan Muñoz: Escritos/Writings. Ediciones de la Central. Barcelona, 2009, p.37. 
5 Arquitectos, 5 Escultores, comisariaza por Juan Muñoz y Carmen Giménez el mismo año en el que escribió su texto no publicado Philby ${ }^{31}$ (1982). "En el interior de un gran palacio, vi desde la puerta dos medias esferas, una dentro de otra; mientras alguien hablaba del pintor Parmigianino, un italiano colocaba ensimismado piedras y cristales rotos sobre un armazón de acero".

Parmigianino (Francesco Mazzuoli , Parma 1503- Cremona 1540) realizó este autorretrato en una media esfera para demostrar sus cualidades pictóricas. Tras su llegada a Roma, necesitado de una tarjeta de presentación para el Papa Clemente VII , que demostrará su virtuosismo, decide realizar su autorretrato inspirándose en las imágenes distorsionadas que producen los espejos convexos de los barberos. Encarga una esfera de madera cortada por la mitad sobre la que pinta su autorretrato , mientras ve su imagen reflejada en un espejo convexo. El efecto permite una visión de 180 grados en lugar de una imagen plana, donde los objetos cercanos están muy aumentados, como su mano que reposa delante de él y que es mas grande que su cabeza , que al estar en el centro de la imagen no está distorsionada , como también lo está la ventana que se curva en el fondo de la habitación.

« As Parmigianino did it, the right hand

Bigger than the head, thrust at the viewer

And swering easily away, as though to protect

What it advertises $\ll^{32}$

Queda en la memoria el trabajo de Parmigianino, basándose en este soporte y en el tema, Muñoz realiza en 1985 una serie de cinco piezas tituladas Portraits sobre medias esferas huecas. Pinta en ambas caras de la media esfera detalles de un rostro, en la parte cóncava y en la convexa, sin que la geometría del soporte le lleve a someter el dibujo a la distorsión del pintor italiano. Obsesionado con los trucos de cartas, y con Parmigianino en el recuerdo, Juan Muñoz descubre su autorretrato en una chincheta sobre su dedo. En 1995 captura una imagen doble, en un primer plano una baraja de cartas sostenida

31 Muñoz, Juan, Philby.(1982), en Juan Muñoz: Escritos/Writings. Ediciones de la Central. Barcelona, 2009, p.53.

32 Ashber, John, Self portrait in a convex mirror, Poema galardonado con el premio Pulitzer en 1975 en http://www.poetryfoundation.org/poetrymagazine/browse/124/5\#!/20596528/0 


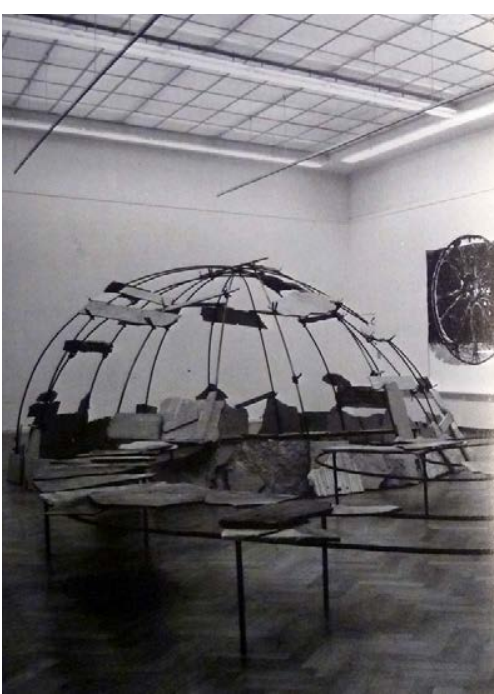

Iglú De Gennazzano, 1979-81.Mario Merz

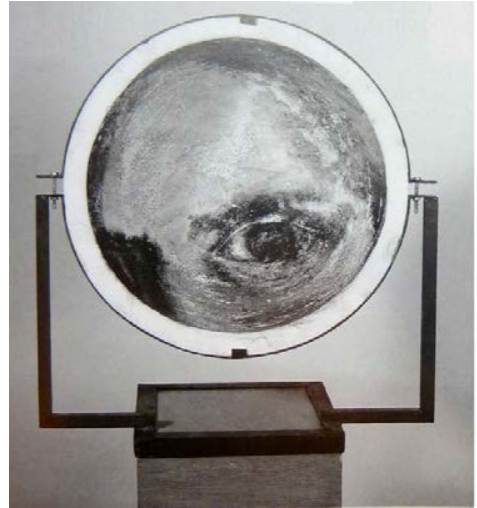

Autorretrato en un espejo convexo. 1985 Juan Muñoz.

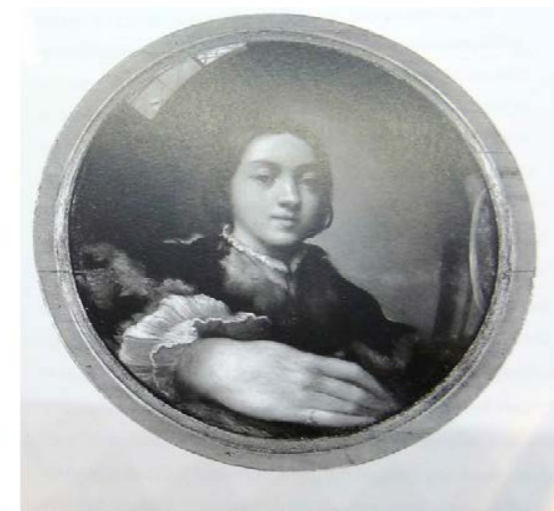

Autorretrato en un espejo convexo. 1523-24. Parmigianino.

entre sus manos, en el dedo anular derecho apoya una chincheta, que refleja las cartas deformadas y en la parte superior central, al fondo y por detrás de las cartas, su rostro, también deformado por la curvatura del objeto, rotula sobre la fotografía SELF PORTRAIT IN A CONVEX MIRROR.

La agudeza de Parmigianino y su capacidad de manipulación pictórica captaron la atención de Muñoz, que incluyó algunas notas del texto de Vasari sobre el artista en el texto introductorio del catalogo para la exposición en el Palacio de las Alhajas de Madrid Correspondencias, 5 Arquitectos, 5 Escultores (Notas afines a tres) en 1982. En "El tiempo de Posar"33, compara una obra de Parmigianino, Camilla Gonzaga, condesa de San Segundo y sus hijos (1533-35), con la fotografía de Agustí Centelles: Elecciones de Febrero de 1936. Represión de la alegría. Concluye que ambas imágenes están estrechamente ligadas al manierismo por las poses, lo exagerado de las vestimentas, los personajes anexos, o

33 Muñoz, Juan, El tiempo de posar, en Escritos/Writings, Ediciones de la Central. Barcelona, 2009, Públicado por primera vez como "Die Zeit der Pose" 1988 p. 89. 


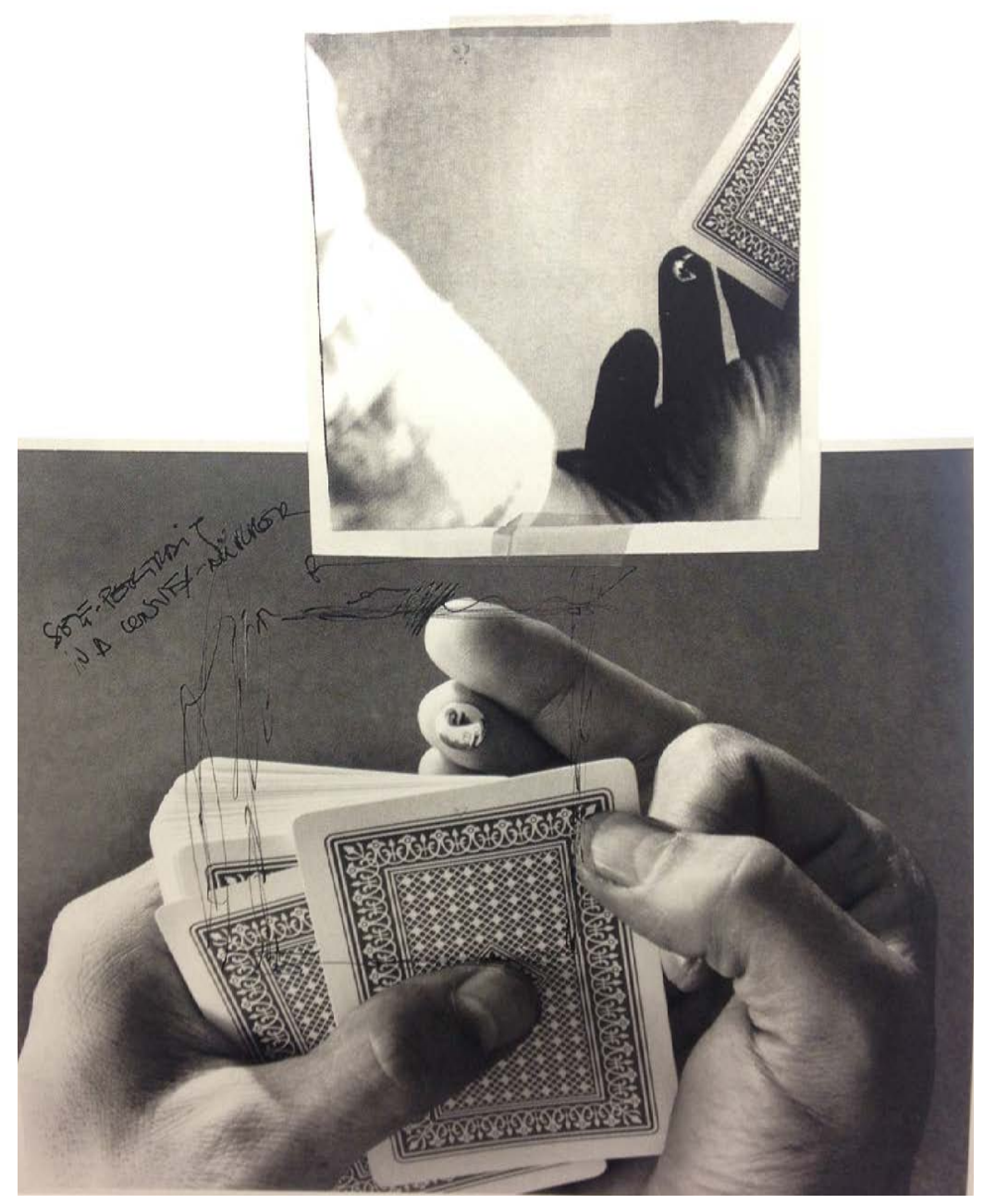

Untitled 1995. Juan Muñoz.

la expresividad de las manos. Vuelve al Autorretrato en un espejo convexo para tratar el carácter ilusorio de los tres guardias, que bien podrían ser el reflejo de una imagen central ausente. El ejercicio de pintar en un espejo, donde el cuadro imita al imitador le hace dudar de la imagen. Los tres guardias con el mismo gesto, en rotación alrededor del obrero, como los tres niños alrededor de Camilla Gonzaga podrían ser el resultado de una ilusión óptica, una imagen que proviene de un único individuo.

En Double Bind además de los 22 huecos que se observan desde la parte superior, tiene en su parte inferior un hueco mas, secreto, "the secret shaft" que se descubre al fondo del piso inferior. En él, una tríada de figuras en penumbra, aparentemente iguales al resto, se reúnen alrededor de un tubo fluorescente, como si estuvieran mirando un juego de planos, o su imagen especular saliera de ese centro. Casi como en un cuadro de Caravaggio la luz descubre el autorretrato de Juan Muñoz, muy parecido al rostro del resto de las figuras 

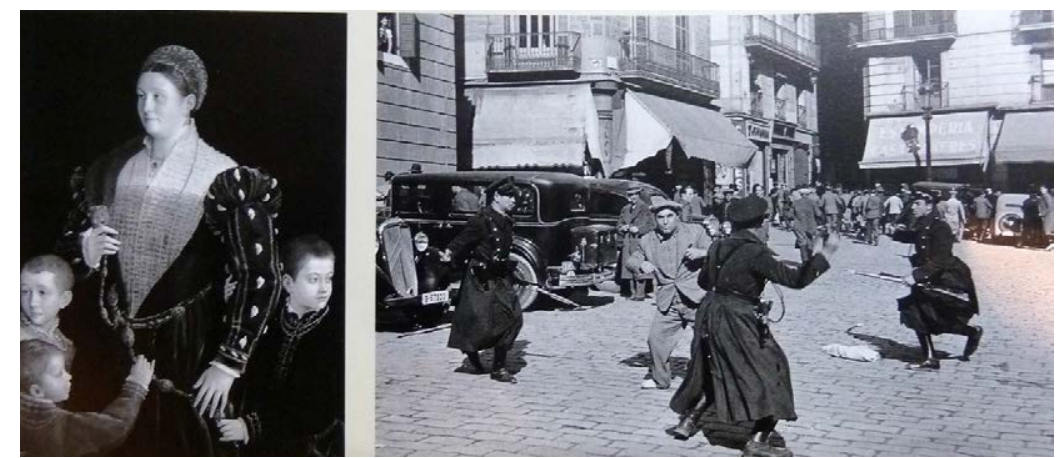

Camilla Gonzaga, condesa de San Segundo y sus hijos. 1533. Parmigianino

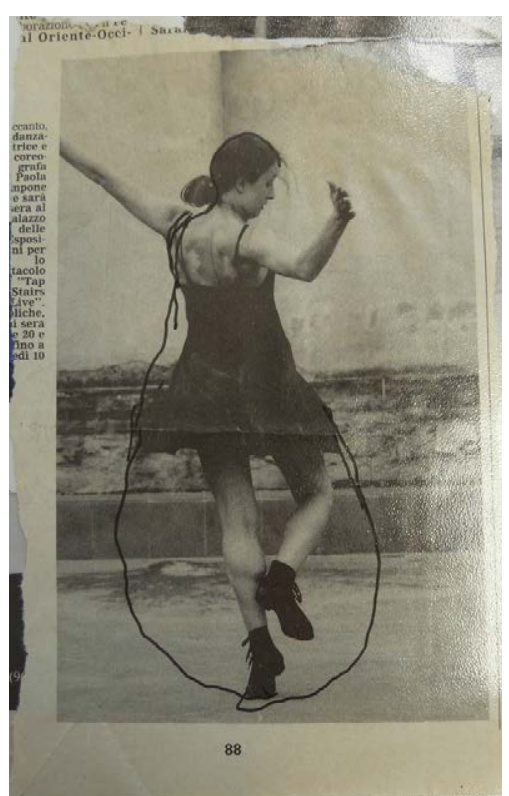

Dibujo del artista

Cortesía del Estate dw Juan Muñoz

de la obra, que se corresponden al de su hermano Vicente, aparece ahora en la posición central el rostro del artista.

Las figuras de Double Bind, tan distintas y a la vez tan parecidas a nosotros, nos hacen cuestionarnos nuestro propio yo, dudar de la realidad, dudar de ellos y dudar de uno mismo. Quizás se han quedado quietas, congeladas en un instante, porque saben que si se quedan quietas, si no se mueven, la gente pasará de largo. Con ellas, daremos un paso más en el conocimiento, cumpliéndose de este modo la idea de continuidad, en palabras de Gadamer, sobre la obra de arte: "El antiquísimo concepto de mímesis, con el cual se quería decir presentación (Darstellung) de no otra cosa que de orden. Testimonio de orden: eso parece ser válido desde siempre, en cuanto a toda obra de arte, también en este mundo nuestro que se va transformando cada vez más en algo serial y uniforme, sigue testimoniando la fuerza del orden espiritual que constituye la realidad de nuestra vida. En la obra de arte acontece de modo paradigmático lo que todos hacemos al existir: 

6 CONCLUSIÓN 

El proceso creativo está en continua evolución, no sigue una trayectoria lineal, sufre idas y venidas pero siempre la memoria y los recuerdos juegan un papel fundamental. Como hemos visto, en el imaginario de Juan Muñoz observamos una recurrencia de temas y exploración de variaciones de ideas y conceptos que resurgen reiteradamente a lo largo de su carrera. Muchos de ellos tienen una influencia concreta o se validan mediante un referente preexistente.

Sin proponerse necesariamente hacer historia, en el creador surgen ideas que perduran, rehaciéndose o difuminándose a través de sí mismo o mediante el quehacer de otros, en el camino de tiempos futuros. Estas son la base para nuevos conceptos, donde la idea generadora no tiene porque encontrarse explícitamente reflejada pero cuya matriz circunscribe sus actos. Entendemos que la creación es un hecho individual que se articula a través de la experiencia y del recuerdo, donde se engloban acontecimientos que anteceden al propio creador, pudiendo considerarse entonces como un bien común y de relevancia 
universal. Sin embargo, las cosas no siempre transmiten su cómo y su porqué. Ante el deseo de profundizar en el nivel de comprensión, es necesario ahondar en el conocimiento que aporte datos de los episodios que originan la idea.

Las huellas del pasado se reflejan de algún modo en la obra final, pero no es fácil identificarlas sin conocer los referentes. Averiguar e indagar en el tejido constituyente de la obra, es entender de qué manera la obra ha llegado a ser lo que es. El ideograma de la obra de Muñoz se ve afectado por lo hallado en el camino, las ideas descartadas o los nuevos impulsos, de manera que conocer todos ellos es conocer las raíces y el esqueleto de la obra. Con esta tesis me propuse estudiar cómo las capas de la memoria conforman la creación, evidenciando las convergencias entre los caminos de búsqueda y su materialización final. Juan Muñoz es un caso de estudio con el que ofrecer una mirada profunda de lo creado. Se pueden entender las cosas por lo que son, pero una perspectiva poliédrica sobre una obra abre nuevos caminos de entendimiento.

La tabula rasa es un estado imposible. Es la capacidad del creador, su sensibilidad ante el entorno circundante, la que le permite ofrecer nuevas visiones, pero siempre partiendo de lo conocido. La preocupación por investigar las influencias nos ofrece una visión más global de la mirada de un creador, proponiendo nuevos caminos de comprensión y un análisis diferente de una mente creadora. Como se expone en el primer capítulo de esta tesis, la memoria se conforma según unos determinados procesos de asimilación y tiene gran peso en los comportamientos presentes y futuros.

Conocer el pensamiento creativo de Muñoz, cuya obra comenzó a exponerse en los años 80 y que forma ya parte de los libros de historia del arte contemporáneo, supone la oportunidad de presentar las referencias y las constantes en su obra ligadas al proceso de la creación y no solo desde la perspectiva final del objeto. Los estudios de arte sitúan a Muñoz en su contexto social e intelectual que es indiscutiblemente un marco referencial necesario. $\mathrm{Su}$ selección personal de referentes va mucho más allá de su entorno inmediato, se extiende a sus viajes a los libros o cuadros, que entre otros, le llevan a distintos periodos históricos y muy diversos ámbitos culturales. Este acercamiento nos permite escribir una historia de la obra que proporcione una aproximación a la misma y prolongue la continuidad entre dicha obra y el pensamiento del artista. 
Esta investigación nos ha acercado a documentar e interpretar el recorrido del proceso creativo, que en muchos casos se considera espontáneo e independiente de cualquier otra fuente, pero que tiene, sin embargo, un origen y un desarrollo, que no siempre puede ser encontrado o evidenciado, ni es necesario que así sea, pero es desde luego existe y es determinante. Esta perspectiva proporciona un conocimiento histórico que se puede añadir a aquel que ofrece la obra desde la experiencia. Los dos modos de conocer se complementan entre sí.

Los tres puntos de partida de Juan Muñoz para responder al proyecto de la sala de turbinas son, según él mismo describe, su experiencia, su lenguaje y el espacio propuesto ${ }^{1}$. A través de estos tres puntos se desarrolla el proceso creativo -que tiene a su vez tres fases determinadas, la pre-creación o concepción de ideas que darán forma a la obra, la creación o producción de la obra y recreación o experimentar la obra propuesta. En la imaginación de Muñoz ante el encargo de la sala de turbinas no existe una idea predeterminada, necesita responder a situaciones y estímulos particulares y lo hará mediante su lenguaje y apoyándose en su experiencia para producir estas respuestas.

Decíamos al comienzo de la tesis que Juan Muñoz vuelve, como sucede en Double Bind, a ideas que maneja constantemente en varias de sus obras. La innovación en esta última obra radica en la necesidad de fabricar un espacio que genere un contexto que envuelve al espectador y a sus figuras. Al inventar el espacio alrededor de las figuras surge una nueva historia que sumerge al espectador en una instalación que es alegoría de la vida en la tierra, donde se localiza un cielo, un infierno y un purgatorio. La extrañeza que nos provoca el lugar inventado, el posicionamiento de las figuras en el espacio, la relación del observador con el espacio y lo que ocurre en él, es capaz de producir un amasijo de interpretaciones personales que enriquece la visión artística, pero que no necesariamente

1 Antes de que Double Bind este completamente instalada, el comisario James Lingwood pregunta a Muñoz sobre la las partes del proyecto que estaban latentes en su mente cunado fue invitado a realizar el trabajo. Muñoz no cree que sea posible tener algo en su imaginación esperando para responder a un volumen como el de la sala de turbinas. JL"How mucho of this Project was latent in your mind before you where invited to work in the Turbine Hall?" JM “I don't think is possible to have anything waiting in your imagination for a space and volumen of this kind. The space is there, it's a given. Then I have my language and my experience, that's it. These ar the starting points. I don't think anybody can really shape a work like this prior to being asked. You have to come, to look, to despair and smile." En Muñoz, Juan, Lingwood, James, A Conversation, May 2001 en Unilever Series. Double Bind, Tate Modern.2001, p. 67. 
responden a la propia reflexión del artista. Por lo que el resumen cognitivo de la obra que aquí se ha presentado ofrece un acercamiento al artista, a su obra y a la memoria que acompaña el proceso.

Como dice T.S. Eliot, la capacidad del presente de alterar el pasado es tan relevante como la imposibilidad de entender el presente sin la dirección del pasado. ${ }^{2}$ El espacio escultórico acoge al observador como cuerpo activo dentro del mismo, de esta situación resulta una experiencia personal que otorga un sentido determinado a la obra según su propia vivencia. No hay un mensaje que descifrar, la relación del espectador con la obra es un diálogo capaz de producir nuevas historias. Esta tesis ha mostrado un análisis interpretativo de dicha obra pretendiendo situarse en el punto de vista de su autor, tratando de evidenciar todo aquello que se ha interpretado y rescatando imágenes de la memoria del artista que preservan los lazos entre la obra y su origen.

La creación artística genera sensaciones en el espectador. Muchas de las obras de Muñoz llegan a desafiar los límites de lo escultórico y requieren de un observador activo, que se desplaza por una instalación que modifica el propio espacio. Muñoz orienta y divide el espacio respondiendo a las necesidades de su narrativa, jugando entre lo sensible y lo inteligible, -cuya comprensión depende de la experiencia del observador. Se liga aquí la cuestión de la importancia del estudio del proceso creativo para una mejor interpretación de la obra con la necesidad de dar a conocer el resultado de esta investigación. El observador conocedor de dichas circunstancias tiene una mayor capacidad para enfrentarse a las obras del artista desde el punto de vista de lo inteligible. Crear el vínculo necesario entre el cuerpo de pensamiento del artista y la obra producida ofrece una perspectiva al margen de lo sensible.

Juan Muñoz refleja en su última obra el perfeccionamiento de su pensamiento creativo. Mostrar explícitamente algunas ideas, como pueden ser las relaciones entre Muñoz y el barroco, o ilustrar como Muñoz encuentra en huecos de fachadas la retícula que plantea para el plano horizontal del espacio superior de la obra. 0 mirar atrás y encontrar la idea del perpetuum mobile (presente en los ascensores que suben y bajan incesantemente en Double Bind) en su texto de 1986 De la precisión de las distancias, son sólo algunos

2 Eliot, T.S. Tradition and individual talent (1919). En: Eliot, T.S. Selected Essays. London: Faber and Faber, 1951. p.15. (Traducción de la autora) 
ejemplos de entre otros muchos presentados en esta tesis, que nos hacen percibir nuevas y, en algunos casos, inesperadas relaciones entre la obra y los referentes del artista. Esta investigación nos ofrece la posibilidad de releer a través del tiempo, encontrando en la unidad de una instalación lo múltiple, la relación entre lo representado y el imaginario del artista. Es interesante mirar, pero saber nos proporciona un conocimiento complementario de lo percibido por nuestros sentidos.

El estudio del proceso creativo a través de la memoria muestra cómo la obra tienen una relación directa con la experiencia del propio artista. La memoria es un almacén de información, una herramienta para la imaginación en el presente- que es pasado y futuro. 



\section{CONCLUSION}

The creative process is always in continuous evolution, as it is nonlinear, with comings and goings where memory and memories play a key role. As we have seen, there is a recurrence of themes and an exploration of variations of ideas and concepts in the imaginary of Juan Muñoz that reappear repeatedly throughout his career. Many of them have a definite influence or are validated by a pre-existent reference.

Without having necessarily the intention of making history, the creator produces things or ideas that endure. Through him or the work of others, these ideas are remade or blurred, on the path towards the future. These ideas are the basis for new concepts, in which the generating idea does not need to be explicitly reflected. However, its original circumscribes their actions. This leads us to the understanding of creation as an individual act articulated through experience and memory, where events preceding the own creator are included. Therefore, creation can be considered as a common good and of universal relevance. However, things do not always convey their how and why. Given the desire to 
deepen the level of understanding, it is necessary to delve into the knowledge that can provide information about the episodes that originate the idea.

In some way, vestiges of the past are reflected in the final work, but it is not easy to identify them without knowing the references. Discovering and delving into the fabric that makes up the work is to understand how the work has become what it is. The ideogram of Muñoz's work is affected by what was found on the way, discarded ideas or new impulses. In this sense, knowing all these is to know the roots and the skeleton of the work. The aim of this thesis was to study how memory layers shape the creation, showing the convergences between the paths of search and its final materialisation. Juan Muñoz is a case study that offers a deep look at what has been created. One can understand things for what they are, but a multifaceted perspective of a work opens up new ways of understanding.

The tabula rasa is an impossible state; it is the ability of the creator, his sensitivity to the surrounding environment which enables him to offer new visions, but always starting from the previously known. The concern for investigating influences offers a broader picture of the creator's vision, proposing new ways of understanding and a different analysis of a creative mind. As discussed in the first chapter, memory is formed according to specific processes of assimilation and weighs heavily on present and future behaviour.

Getting to know the creative thinking of Muñoz, whose work began to be exhibited in the 80s and is now part of the history books of contemporary art, is an opportunity to provide the references and the constants in his work related to the process of creation and not only from the object's final perspective. Art studies place Muñoz in his social and intellectual context, which is undeniably a necessary referential framework. His personal selection of references goes far beyond his immediate surroundings, it extends to his travels, books, or paintings, which lead him, among others, to different historical periods and very diverse cultural fields. This approach makes it possible to write a history of the work that provides an approximation to it and prolongs the continuity between the same and the artist's thoughts.

This research has allowed us to document and interpret the trajectory of the creative process, which in many cases is considered as spontaneous and independent from any other source. However, the creative process has a source and a development that cannot 
always be found or evidenced, nor is it necessary to do so, but it does exist and is decisive. This perspective provides a historical knowledge that can be added to that offered by the work from experience. Both ways of gaining knowledge complement each other.

The three starting points that Juan Muñoz uses to respond to the Turbine Hall project are, as he describes; his experience, his language and the proposed space ${ }^{1}$. Through these three points the creative process is developed, which, in turn, has three specific phases; the pre-creation (or conception of ideas that will shape the work), the creation (production of work) and the recreation (the experiment of the proposed work). There is no predetermined idea in the imagination of Muñoz for the Turbine Hall project; he needs to respond to particular situations and stimuli, and will do so by using his language and relying on his experience to produce these responses.

At the beginning of the thesis, it was stated that Juan Muñoz returns, as in Double Bind, to ideas that he constantly uses in several of his works. The innovation in this latest work is the need to make a space that creates a context that involves viewers and their figures. By inventing the space around the figures, a new story emerges, one that plunges the viewer in a facility that is allegory of life on earth, where heaven, hell and purgatory are located. The strangeness that the place invented provokes, the positioning of the figures in space, the relationship of the viewer with space and what happens in it is capable of producing a medley of personal interpretations that enrich the artistic visions, but that do not necessarily respond to the artist's own reflection. Therefore, the cognitive summary of the work presented here provides an approach to the artist, his work and memory that accompany the process.

1 Before Double Bind is fully installed, the commissioner James Lingwood asks Muñoz about the parts of the project that were dormant in his mind when he was invited to carry out the work. Muñoz did not think it possible to have anything in his imagination waiting to respond to a volume such as that of the Turbine Hall. JL"How much of this Project was latent in your mind before you where invited to work in the Turbine Hall?" JM "I don't think it is possible to have anything waiting in your imagination for a space and volume of this kind. The space is there, it's given. Then I have my language and my experience, that's it. These are the starting points. I don't think anybody can really shape a work like this prior to being asked. You have to come, to look, to despair and smile". In: Muñoz, Juan, Lingwood, James, A Conversation. May 2001, in: Unilever Series. Double Bind. Tate Modern. 2001 p. 67. 
In the words of T.S. Eliot, "the past should be altered by the present as much as the present is directed by the past"2. The sculptural space receives the viewer as an active body within it. This situation results in a personal experience that gives a certain sense to the work according to the experience of each one of them. There is no message to decipher; the relationship between the viewer and the work is a dialogue capable of producing new stories. This thesis has offered an interpretative analysis of this work aiming to be placed on the point of view of the author, trying to show everything that has been interpreted and retrieving images of the artist's memory which preserve ties between the work and its origin.

Artistic creation generates feelings in the viewer. Many of the works of Muñoz even challenge the limits of the sculptural and require an active observer, who moves through a set installation that modifies the space itself. Muñoz orientates and divides the space in accordance to the needs of his narrative, playing between the sensitive and the intelligible, and whose understanding depends on what the observer experiences. Therefore, the importance of the study of the creative process for a better understanding of the work is linked to the need of publicising the results of this research. The viewer, aware of these circumstances, has a greater capacity to deal with the artist's works from the point of view of what is intelligible. Creating the necessary link between the artist's line of thought and the work produced offers a perspective separated from sensitivity.

Juan Muñoz's latest work reflects the refinements of his creative thinking. To explicitly show the relationships between Muñoz and the Baroque, or to illustrate how Muñoz finds in the openings of a façade the grid that he envisages for the horizontal plane of the upper space of the work, or to look back and find the idea of perpetuum mobile in elevators that rise and descend incessantly in Double Bind in his text from 1986 De la precisión de las distancias -Precision of distances- , are some examples, among many other presented in this thesis, which makes us perceive new and, in some cases, unexpected relationships between the work and the references of the artist. This research offers the possibility to reread over time, finding multiplicity in the unity of an installation, the relationship

2 Eliot. T.S.Tradition and individual talent (1919). In: Eliot, T.S. Selected Essays. London: Faber and Faber, 1951, p. 15. 
between what is represented and the imaginary of the artist. It is interesting to observe, but knowing provides a complementary knowledge of what is perceived by our senses.

The study of the creative process through memory shows us how the work has a direct relationship with the artist's own experience. Memory is a storehouse of information, a tool for imagination in the present, which forms part of the past and the future. 



\section{BIBLIOGRAFÍA}





\section{Bibliografía general}

AMÓN, Santiago. 1970. “El arte y el espacio” en Nueva Forma, № 49.

AMÓN, Santiago. 1970. "La exaltación del orden artificial en la arquitectura de Parent y Bloc" en Nueva Forma, № 50.

ANDRÉ, Carl, Christophe Cherix, y Michelle Piranio. 2014. Carl André. New York, NY : New Haven ; London: Dia Art Foundation : Yale University Press.

ANDRÉ, Carl, Dan Flavin, Donald Judd, Ellsworth Kelly, Sol LeWitt, y Robert Mangold. 2002. American Beauty: 23 May-13 July 2002: Carl André, Dan Flavin, Donald Judd, Ellsworth Kelly, Sol LeWitt, Robert Mangold, Agnes Martin, Isamu Noguchi, Robert Ryman, Richard Serra, Joel Shapiro, Tony Smith. London: Annely Juda Fine Art.

ARGAN, Giulio Carlo. 1987. Renacimiento y Barroco I. Madrid: Ediciones AKAL.

Art And Illusion. A Study In The Psychology Of Pictorial Representation. 2013. London; New York, NY: Phaidon.

ASIMOV, Isaac. 2015. “Essay by Isaac Asimov on Creativity 1959.” MIT Technology Review. Accessed August 24. http://www.technologyreview.com/view/531911/isaac-asimovasks-how-do-people-get-new-ideas/.

Atlas, ¿cómo llevar el mundo a cuestas? 2010. Madrid: Museo Nacional Centro de Arte Reina Sofía.

BACHELARD, Gastón. 2000. La poética del espacio. Madrid. Fondo de Cultura Económica.

BADDELEY, A. D. 1998. Memoria humana: Teoría y práctica. Madrid: McGraw-Hill Interamericana de España.

BARRAL, Paulino Rodríguez. 2008. La imagen del judío en la España medieval: el conflicto entre cristianismo y judaísmo en las artes visuales góticas. Barcelona: Edicions Universitat Barcelona. 
BARTHES, Roland. 2009. La cámara lúcida: Nota sobre la fotografía. Barcelona: Ediciones Paidós.

BATESON, G., D. Jackson, J. Haley y J. Weakland. 1956. 'Toward a Theory of Schizophrenia', Behavioural Science 1, pp251-254. En Bateson, G. 1972. Steps to an Ecology of Mind: a Revolutionary Approach to Man's Understanding of Himself. New York: Ballantine Books. BAUDELAIRE, Charles. 1989. Edgar Allan Poe. Editorial Antonio Machado. BENJAMIN, Walter. 2005. Libro de los Pasajes. Madrid: Ediciones AKAL. BENJAMIN, Walter. 2009. Estética y política. Buenos Aires: Las cuarenta. BERGER, John. 2000. Modos de ver. Barcelona: Editorial Gustavo Gili. BERGER, John. 2001. Mirar. Barcelona: Editorial Gustavo Gili.

BERGER, John. 2011. Sobre el dibujo. Barcelona: Editorial Gustavo Gili. BERGSON, Henri. 1991. Matter and Memory. Cambridge: MIT Press. BERGSON, Henri. 2008. La evolución creadora. Buenos Aires: Cactus. BLOOM, Harold. 1973. La ansiedad de la influencia. Una teoría de la poesía. Oxford University Press

BORGES, Jorge Luis. 2011. Funes El Memorioso. Barcelona: Debolsillo.

BORGES, Jorge Luis. 2011. El Aleph. Barcelona: Debolsillo.

BORGES, Jorge Luis. 2011. Ficciones. Barcelona: Debolsillo.

CHAMBERLAIN, John, Suzanne Harris, Gordon Matta-Clark, Dennis Oppenheim, Richard Serra, Robert Smithson, y Holly Solomon Gallery (New York, N.Y.), eds. 1991. Chamberlain, Harris, Matta-Clark, Oppenheim, Serra, Smithson, Weiner. New York: Holly Solomon Gallery.

CHASTEL, André. 1988. El arte italiano. Madrid: Ediciones AKAL.

Christa Dichgans, Lili Dujourie, Marlene Dumas, Lesley Foxcroft, Kees de Goede, Frank van Hemert, Cristina Iglesias, Harald Klingelhöller, Mark Luyten, Juan Muñoz, Katherine Porter, 
Julião Sarmento, Barbara Schmidt Heins, Gabriele Schmidt-Heins, Didier Vermeiren. 1985. Catálogo de la exposición.Eindhoven : Stedelijk Van Abbemuseum.

COMPANY, Federico Ruiz. 1997. Kant. Prólogo e introducción de la crítica de la razón pura. Valencia: Ediciones Tilde.

DIAZ PADILLA, Ramón. 2013. Arte, magia e ilusión. Madrid: CSIC.

DIDI-HUBERMAN, Georges. 2013. La imagen superviviente. Madrid: Abada.

DIDI-HUBERMAN, Georges, y Rosario Ibañes Jalón. 2009. Ser craneo. lugar, contacto, pensamiento, escultura. Valladolid: Cuatro Ediciones.

FERNANDEZ ARENAS, A. 1964. La imagen espiritual de la catedral gótica. Tierras de León. Revista de la Diputación Provincial, Vol. 4. №5.

FLEMING, John, y Hugh Honour. 2004. Historia mundial del arte. Madrid: Ediciones AKAL. FLÓREZ CASTRO, Fernando. 2005. El espacio inquietante del hombre: el lugar del ventrílocuo : unas reflexiones sobre la obra de Juan Muñoz. CENDEAC.

FOSTER, Hal. 2013. El Complejo Arte-Arquitectura. Madrid: Turner.

FRIED, Michael. Arte y objetualidad ensayos y reseñas. Madrid: Antonio Machado Libros. GADAMER, Hans-Georg. 2006. Estética y Hermenéutica. Madrid: Tecnos/Alianza. GADAMER, Hans-Georg. 2007. Verdad y método I. Salamanca: Ediciones Sígueme. GADAMER, Hans-Georg. 2012. Verdad y método II. Salamanca: Ediciones Sígueme. GASS, William H. 1997. Finding a Form: Essays. Ithaca: Cornell University Press. STEINER, George. 1984. A Reader. Oxford: Oxford University Press.

GIBNEY, Paul. 2006. "The Double Bind Theory: Still Crazy-Making After All These Years", Psychotherapy in Australia, Vol. 12, N. 3.

GIEDION, Sigfried. 2008. Space, Time \& Architecture: The Growth of a New Tradition. Cambridge: Harvard University Press. 
GLAHN, Philip. 2007. Estrangement and Politicization: Bertolt Brecht and American Art, 1967-1979. Ann Arbor: ProQuest.

GOMBRICH, Ernst Hans. 2013. Lo que nos cuentan las imágenes. Barcelona: Elba.

GUSTAFSSON, Henrik, y Asbjorn Gronstad. 2014. Cinema and Agamben: Ethics, Biopolitics and the Moving Image. Londres: Bloomsbury Publishing USA.

HARBISON, Robert. 2000. Reflections on Baroque. Londres: Reaktion books.

HEIDEGGER, MARTIN. 2000. Tiempo y ser. Madrid. Editorial Tecnos.

HERREU, Pere, Josep María Montaner y Jordi Oliveras. Textos de Arquitectura de la Modernidad. San Sebastián: Editorial NEREA.

HIPONA, San Agustín. 1824. Las Confesiones de San Agustín: enteramente conformes a la edición de San Mauro.

HOFFMAN, Eva. 1998. Lost in Translation: A Life in a New Language. Londres: Random House.

HUYSSEN, Andreas. 2003. Present Pasts: Urban Palimpsests and the Politics of Memory. Stanford, California: Stanford University Press.

KLEE, Paul. 2007. Teoría del arte moderno. Buenos Aires: Editorial Cactus

KRAUSS, Rosalind E. 1981. Passages in Modern Sculpture. Cambridge: MIT Press.

KRIS, Ernst, y Otto Kurz. 2007. La leyenda del artista. Madrid: Cátedra.

KOOLHAAS, Rem. 1978. Delirious New York. New York: The Monacelli Press.

LAYUNO, María Ángeles, y Richard Serra. 2001. Richard Serra. San Sebastián: Editorial Nerea.

LEE, Pamela M., y Gordon Matta-Clark. 2001. Object to Be Destroyed: The Work of Gordon Matta-Clark. Cambridge: MIT Press.

LE ROUX, Hugues. 2012. Acrobats and Mountebanks. Charleston: Nabu Press.

LÉVINAS, Emmanuel. 2001. La realidad y su sombra. Madrid: Editorial Trotta 
LISTA, Giovanni. 2006. Arte Povera. Abscondita.

LLEDÒ, Emilio. 2000. El silencio de la escritura. Madrid: Espasa.

LÓPEZ EIRE, Antonio, Ma Henar Velasco López, La Mitología Griega: lenguaje de dioses y hombres. Arco Libros

LÓPEZ SILVESTRE, Federico. 2013. Los pájaros y el fantasma: una historia del artista en el paisaje. Salamanca: Ediciones Universidad de Salamanca.

MADRID, Silvia, Arturo Olvera y Jorge Viveros. Mapas y proyecciones. 1998. México DF: UNAM.

MARINA, José Antonio. 1994. Teoría de la inteligencia creadora. Pamplona: Anagrama.

MARSHALL, Christopher R. 2011. Sculpture and the Museum. Ashgate Publishing.

MATHEWS, Timothy. 2014. Alberto Giacometti: The Art of Relation, Timothy. I. B. Tauris.

MELERO MONEO, María Luisa. 2005. La pintura sobre tabla del gótico lineal: frontales, laterales de altar y retablos en el reino de Mallorca y los condados catalanes. Barcelona: Edicions Universitat Barcelona.

NATSUME-DUBE, Sachiko. 2013. Giacometti y Yanaihara: trabajo como una mosca. España: Elba.

O’DOHERTY, Brian. 2000. Dentro del cubo blanco la ideología del espacio expositivo. CENDEAC.

PAOLETTI, John T., and Gary M. Radke. 2003. El arte en la Italia del Renacimiento. Madrid: Ediciones AKAL.

PAREYSON, Luigi. 1988. Conversaciones de estética. Madrid: A. Machado Libros.

PEREC, Georges. 1988. La vida, instrucciones de uso: novelas. Anagrama.

PEREC, Georges. 2003. Especies de espacios. Editorial Montesinos.

PIRANDELLO, Luigi. 1999. Seis personajes en busca de autor. Madrid: MESTAS, Ediciones Escolares. 
PROUST, Marcel. 2011. En busca del tiempo perdido, 1: Por el camino de Swann. Madrid: Alianza.

RASO MADERUELO, Javier. 2008. La idea de espacio en la arquitectura y el arte contemporáneos, 1960-1989. Madrid: Ediciones AKAL.

RILKE, Rainer Maria. 1997. Cartas a un joven poeta. Barcelona: Ediciones Obelisco.

ROMÁN LAPUENTE, Francisco, María del Pino Sánchez López, y María José Rabadán Pardo. 2012. "Tratado de Neuropsicología Clínica”, en Memoria y Amnesias, Tema 6, p.1. Universidad de Murcia.

RUDOFSKY, Bernard, y Museum of Modern Art. 1987. Architecture Without Architects: A Short Introduction to Non-Pedigreed Architecture. Albuquerque: University of New Mexico Press.

RUIZ VARGAS, Jose María. 1997. Claves de la memoria. Madrid: Editorial Trotta.

RUIZ VARGAS, Jose María. 2002. Memoria y Olvido. Perspectivas evolucionista, cognitiva y neurocognitiva. Madrid: Editorial Trotta.

RUSKIN, John. 2014. La lámpara de la memoria. Editorial Taurus.

RYAN, Raymund. 2000. Building Tate Modern: Herzog \& De Meuron. Harry N. Abrams.

SARAMAGO, Jose. 2010. Ensayo sobre la ceguera. Madrid: Punto De Lectura.

SARLO, Beatriz. 2007. Tiempo pasado. Cultura de la memoria y giro subjetivo. Una discusión. Siglo XXI.

SEARLE, Adrian. 2015. "If There's a Joke, It's on Us: Juan Muñoz's Playful Optical Illusions." The Guardian. Accessed April 11. http://www.theguardian.com/artanddesign/2015/ apr/10/juan-munoz-installation-retrospective-playful-optical-illusions-review.

SEGUI, Javier, PLANELL, Joaquin, BURGALETA $i$ Pedro M. 1996. La interpretación de la obra de arte. Madrid: Editorial Complutense.

SERRA, Richard. 1994. Writings/Interviews. Chicago: University of Chicago Press.

SILVERMAN, Kaja. 2009. El umbral del mundo visible. Madrid: Akal. 
SMITHSON, Robert, y Jack D. Flam. 1996. Robert Smithson, the Collected Writings. California: University of California Press.

STEINER, George. 1987. A reader. Oxford University Press.

STRATTON, Michael. 2003. Industrial Buildings: Conservation and Regeneration. Taylor \& Francis.

The Unilever Series: 2000-2012. 2012. Londres: Tate.

TIRAPU-USTÁRROZ, J. y J.M. Muñoz Céspedes. 2005. “Memoria y funciones ejecutivas”, Rev Neurol 41 (8): 475-484.

VALÉRY, Paul. 2010. Escritos sobre Leonardo da Vinci. Madrid: Antonio Machado Libros.

VASARI, Giorgio. 1998. Las Vidas de los más excelentes pintores, escultores y arquitectos, escritas por Giorgio Vasari, pintor aretino. Madrid: Tecnos.

VENTURI, Robert. 1992. Complejidad y contradicción en la arquitectura. Barcelona: Editorial Gustavo Gili.

VILA-MATAS, Enrique. 2015. Kassel no invita a la lógica. Booket.

WALKER, Enrique. 2010. Lo ordinario. Editorial Gustavo Gili.

WELLS, Rachel. 2013. Scale in Contemporary Sculpture: Enlargement, Miniaturisation and the Life-Size. London: Ashgate Publishing.

WORDSWORTH, William. 2000. Oda: Atisbos de inmortalidad en los recuerdos de la primera infancia. Ediciones elaleph.com

YATES, Frances Amelia. 2005. El arte de la memoria. Madrid: Siruela.

ZABALBEASCOA, Anatxu. 1999. Miralles Tagliabue: arquitecturas del tiempo. Barcelona: Gustavo Gili. 


\section{Bibliografía específica sobre la obra de Juan Muñoz}

COOKE, Lynne, Jan Avgikos, Alberto Iglesias, Juan Muñoz, Justo Navarro, Luc Sante, Adrian Searle, y Sheena Wagstaff. 2009. Juan Muñoz: Permítaseme Una Imagen. Londres: Turner; Madrid: Museo Nacional Centro de Arte Reina Sofía.

Entre el objeto y la imagen: escultura britanica contemporanea. 1986. Catálogo de la exposición. Enero-abril 1986, Palacio de Velázquez. Madrid: Ministerio de Cultura.

Correspondencias: 5 Arquitectos, 5 Escultores. 1982. Madrid. Ministerio de Obras Públicas y Urbanismo. Dirección General de Arquitectura y Vivienda.

FLÓREZ, Fernando Castro. 2005. El espacio inquietante del hombre: el lugar del ventrílocuo : unas reflexiones sobre la obra de Juan Muñoz. CENDEAC.

Juan Muñoz: La Voz Sola: Esculturas, Dibujos y Obras Para La Radio. 2005. Madrid. La casa Encendida. Editorial Obra Social Caja Madrid

Juan Muñoz, Double Bind \& Around. 2015. Hangar Bicocca. mousse Publishing, Milan. Koening Books, London.

Juan Muñoz. 2012. Will It Be a Likeness / Radioartnet. June 7. http://radioartnet. net/11/2012/04/04/juan-munoz-will-it-be-a-likeness/.

Juan Muñoz: A Retrospective. 2008 Catálogo de la exposición. London: Tate

Juan Muñoz. 2014. Madrid: La Fábrica.

LINGWOOD, James. 1996. Juan Muñoz: monólogos y diálogos/Monologues \& Dialogues. Madrid: Art Data.

MAY, Susan. 1700. Juan Muñoz: Double Bind at Tate Modern (The Unilever Series). London: Tate.

MUÑOZ, Juan. 1983. La Imagen Del Animal. Arte Prehistórico. Arte Contemporáneo. Catálogo de la exposición celebrada en la Casa del Monte en Madrid, diciembre 1983 enero 1984. Madrid: Caja de Ahorros y Monte de Piedad. 
MUÑOZ, Juan, e IVAM Centre del Carme (eds.). 1992. Juan Muñoz: IVAM Centre Del Carme, 10 Abril - 28 Junio 1992. Catálogo de la exposición. Valencia: IVAM Centre del Carme.

MOURE, Gloria. 1994. Urban Configurations. Barcelona: Ediciones Poligrafia.

MUÑOZ, Juan, Hirshhorn Museum and Sculpture Garden, y Smithsonian Institution (eds.). 1997. Juan Muñoz: March 6-June 15 1997. Catálogo de la exposición. Washington, D.C.: Smithsonian Institution.

MUÑOZ, Juan. 1999. Juan Muñoz. New York: Dia Center for the Arts.

MUÑOZ, Juan. 2001. Juan Muñoz. Catálogo de la exposición. Hirshhorn Museum and Sculpture Garden, Art Institute of Chicago, Museum of Contemporary Art (Chicago, Ill.), y Contemporary Arts Museum. Washington, D.C. : Chicago, Ill: Hirshhorn Museum and Sculpture Garden, Smithsonian Institution ; Art Institute of Chicago, University of Chicago Press.

MUÑOZ, Juan, y Tate Modern. 2001. Juan Muñoz. Double Bind at Tate Modern. London: Tate Publishing.

MUÑOZ, Juan, Tate Modern, Museo Guggenheim Bilbao, and Museu Serralves (eds.). 2008. Juan Muñoz: A Retrospective. London: Tate.

MUÑOZ, Juan. 2009. Juan Muñoz: Escritos/Writings. Barcelona: La Central.

MUÑOZ, Juan, y Sterling and Francine Clark Art Institute. 2010. Juan Muñoz at the Clark. Williamstown, Mass.: New Haven [Conn.]; London: Sterling and Francine Clark Art Institute.

MUÑOZ, Juan, y Irish Museum of Modern Art (eds.). 1996. Silence Please!: Stories after the Works of Juan Muñoz. Zurich: Scalo.

MUÑOZ, Juan, y Tim Adams. 2013. Juan Muñoz: Sculptures. New York: Skarstedt Gallery. TOSATTO, Guy. 2007. Juan Munoz: Sculptures et Dessins. Actes Sud-Papiers. 

ANEXOS 



\title{
ANEXO 1. Conversaciones con James Lingwood
}

\author{
04.05.2015 Milan. Hangar Bicocca
}

Marta González Ruiz. In your conversation with Juan Muñoz on May 2001 around Double Bind, you ask him about the power of the subconscious. He responds: "I am so happy you point to the subconscious. It is a word that has been removed from the language of modernism. I am surprised you even mention it. It seems as if we forget that there are hidden reasons..."

James Lingwood. I was pushing him about the history of his brother. Vicente suffered from psychological problems and he came to London for a therapeutic procedure for schizophrenics. I was trying to push him to talk more about the figure of his brother and the schematic understanding of the Double Bind. It can't be a coincidence that he asked his brother to be the model for the figure in Double Bind thirty years later. There is always a well thought through economy in all of his work, taking things away, and making the absence palpable.

MG. Juan Muñoz titles one of his articles “The best sculpture is a Trojan horse” I see Double Bind as this Trojan Horse, both in concept and content.

JL. That is interesting, the Trojan horse surprises, the content is revealed only gradually. He was trying to play with the viewer through the dynamics of perception and deception.

MG. I am interested in knowing better Munoz's references. You have put together some images that Muñoz gathered during the process of creation of Double Bind. Which are the Oriental cities that are represented in some of the images?

JL. He visited several cities in South East Asia. Those images are probably Bangkok and Cambodia.

MG. Why did Juan Muñoz reproduce architectural elements with sculptured materials instead of borrowing them as already built elements? 
JL. He was not interested in creating a realistic environment. His environments are fictions, constructed scenarios. He occasionally used found elements in his work, but he wanted to build the form, build the space with highly controlled elements. It would have had a very different feeling if he had used assemblage.

MG. Do you know which material did Muñoz get from the Tate Gallery in order to understand the Turbine Hall space? Did he get any plans of the original scheme of the Power Station? The openings on the new platform have a parallelism with Scott's first level, with the openings for the engines.

JL. He would have reviewed a lot of material, and probably the original plans as well. You should talk to Susan May, the curator at the Tate Modern Gallery at that time.

MG. How did Juan Muñoz face the existing bridge structure?

JL. The bridge was the architectural element that preoccupied him the most, it cuts the space horizontally. He paid a lot of attention to the existing structure. Thinking about the columns for the space underneath, they look like a reproduction of the existing, someone that hadn't been at the Tate before wouldn't have noticed the new elements.

MG. The openings on the floor seem to have certain geometrical order. How was the orientation of the holes decided? I assume that the spacing between them was also dependant on the platform structure, as the holes are a rotated grid on top of a regular truss grid.

JL. It is hard to remember exactly. He had the desire to work with the illusion of space. From above you didn't know which elements were "real" and which were fictional. He was creating a range of perspectives for the pedestrians, there is no ideal perspective for a person freely walking by foot.

MG. Did Juan Muñoz talk about his sources and influences?

JL. He had a repertoire of different motifs. We should distinguish between sources and influences. He was very interested in baroque art and as well in Mondrian. I asked him about Goya, he didn't want to talk about Goya. Although I think in Double Bind there is a lot of the human condition you can see in the "pinturas negras". 
MG. I have visited the Juan Muñoz Archive. On his notebooks he has some sketches proposing balustrades on the Tate Modern sidewalls. Was this ever an idea that he tried to push forward? It reminded me very much to the Palacio de Velazquez exhibition in 1996 in Madrid.

JL. He had a deep interest in space. The room is the physical container of the body. He explored in many forms the Turbine Hall through his sketches.

MG. I see a parallelism between the transversal sections of diagrams and models he examines during the creative process of Double Bind and the Cabinet Series.

JL. The cabinets display a collection of motifs, they are arrangements of various motifs and interests.

MG. In Double Bind the only areas physically accessible to the viewer relate to the existing architecture: the bridge and the existing ground level.

JL. The sculpture has different levels. There are no figures on the upper level, no figures on the lower level. The viewer is always walking on the existing architectural ground, the figures are in a new interstitial space.

MG. There are many similarities between A Place Called Abroad and Double Bind. Two urban-architectural spaces the viewer explores from the inside, circulating through them, and full of architectural references.

JL. A Place Called Abroad was his most sophisticated project that combined architecture and history, a place through which the visitor walked.

MG. In a Place Called Abroad, the viewer was surrounded by the installation mainly finding the street elements at eye level, something that changes in Double Bind, where the viewer needs to look up and to look forward.

JL. Very early on he presented this preoccupation with the balcony. The implication of the street was there, so was the need to look up or potentially someone looking down from 
the balconies. The hanging figures are as well an earlier body of work that addresses the idea of looking up.

MG. The element of the elevator presented in A Place Called Abroad is recovered and revised in Double Bind. Does it have any particular meaning?

JL. The elevator is a space that could contain a body; it is presented as neutral object, empty, not culturally loaded. It is a box, a container that can be suspended in the air.

MG. How did Muñoz shaped the architecture of the inside faces of the shafts in Double Bind? There are some models of this progress.

JL. He explored a repertoire of different possibilities in the models, playing with the motifs he wanted to bring into the space. He created a unified atmosphere within which he presented certain 'snapshots.'

MG. Muñoz looked at architecture to study the relationship between body and space, what other contemporary artist influenced Muñoz in the approach to this matter?

JL. Bruce Nauman, in particular because of his exploration into the relationship of the built structure to the bodily space. Thomas Schütte was also an artist that he deeply admired.

MG. Muñoz had a very personal approach to space; he also preferred to talk about the 'room' rather the space. Where did he develop his work and what was his relationship with this places?

JL. He had at home a studio where he read and write. Down the road from the family house he had the studio where he drew. Further away, in an industrial zone, there was a big space where he worked with his assistants to make the sculptures. 


\title{
ANEXO 2. Conversación con Vicente Todolí
}

\author{
Vicente Todolí, comisario de la exposición Juan Muñoz Double Bind \& Around (Hangar \\ Bicocca. Milán 2015).
}

04.05.2015 Milán. Hangar Bicocca

Marta González Ruiz. Es la primera vez que se expone Double Bind desde su creación en el año 2001. La instalación fue específicamente proyectada para la sala de turbinas de la Tate Modern Gallery de Londres ¿Se ha adaptado bien la instalación al espacio del Hangar Bicocca? ¿Altera la arquitectura envolvente la percepción de la instalación?

Vicente Todolí. T Sí, Double Bind se ha adaptado perfectamente al espacio del Hangar. Juan Muñoz estaba muy interesado en la arquitectura. En esta obra, el espacio que yo llamo el "limbo" es donde esta la arquitectura. En el "tren descarrilado", y "el coche", la arquitectura también estaba dentro de ellas.

\section{MG. ¿Es Double Bind "site specific"?}

VT. Para Double Bind necesitas un espacio industrial o un megaespacio. Necesita ocupar un espacio arquitectónico imponente. A través de la arquitectura se crea una simbiosis con la obra, y estas trabajan a la una. Como en la Plaza Navona, Bernini logra ocupar el espacio con una figura que levanta el brazo, Juan Muñoz lo hace mediante la arquitectura.

\section{MG. ¿Cual es la relación de las figuras de Double Bind con el espacio?}

VT. En Double Bind no hay relación de las figuras con el espacio de abajo. Solo hay una que mira. Nos mira sabiendo que esos muros son imposibles de fijarse. Nos mira como esas figuras que miran fuera en los grandes cuadros, que en algunos casos responden al retrato del artista. En Double Bind hay un "hidden shaft", donde aparece la única figura con el rostro de Juan Muñoz. Aparece con un tubo fluorescente en las manos, con un rollo como el arquitecto, y con esos claroscuros haciendo referencia a Caravaggio. 
MG. Siendo el gris la tonalidad predominante ¿Qué significado tiene la inclusión del color amarillo en la obra?

VT. Es como en la película de Coppola "Rumble fish" (La ley de la calle) Una película en blanco y negro, ya que es una historia vista a través de los ojos de un daltónico, solo al final aparece el color de la sangre. Juan Muñoz era medio daltónico, aparece el toque de color como algo simbólico, de aquel que lleva su mundo consigo mismo. Las telas de color están hechas con el mismo material que las figuras, el color es como el punto de fuga. La obra sigue un diagrama acéntrico, y el punto de vista es el color.

MG. ¿Cuál es el papel de los elementos arquitectónicos, por qué no son mas abstractos como en A Place Called Abroad? De alguna manera pasa lo mismo con las figuras, han evolucionado, aparecen llenas de detalles realistas.

VT. Una ventana tiene la misma importancia que una figura, y por eso se trata del mismo modo. No es realista, trasciende. Con el realismo hay una integración, esto no es realista, es ilusionismo, es imposible meterse dentro. Utiliza la figura y los efectos ópticos como Borromini, pero es diferente. Es como la figura del ventrílocuo, es una escultura de una escultura. Cada figura esta moldeada con un rostro diferente partiendo siempre de los mismos moldes, como el rostro de la figura de los chinos de Many Times, una escultura que encontró Muñoz y la utilizó como molde.

MG. Juan Muñoz expresó que le hubiera gustado que la sala de turbinas en la Tate Modern no tuviera las entradas de luz natural para potenciar así los clarososcuros. Aquí en el Hangar el espacio es totalmente opaco, resultando en un efecto mucho más teatralizado.

VT. En la Tate la instalación perdía de día, de noche era mas lúgubre. La oscuridad añade dramatismo.

MG. Sin embargo la imponente verticalidad del espacio en la Tate Modern no se da en el Hangar, el juego de los ascensores era mas agonizante en Londres.

VT. Los ascensores son el pasaje de los que se van. Son como los mundos de la infancia, igual que en Looking for Jerry o en In a Shoebox. Es el movimiento que continua.

MG. ¿Cuál es la razón de la escala de las figuras respecto a esta arquitectura de ficción? 
VT. En la obra de Juan Muñoz se va produciendo un cambio de escala, de lo pequeño a lo grande, primero la pequeña escalera en espiral, el ascensor también en pequeña escala. En sus primeras esculturas de enanos, introduce las columnas, elementos arquitectónicos que producen un cambio de escala, lo mismo sucede con los suelos en las esculturas del ventrílocuo.

MG. En la Tate Moder el mundo de la parte inferior es un mundo de pilares, que ahora en el Hangar desaparecen.

VT. La retícula de pilares surgió por necesidades constructivas, no hubiera utilizado las columnas si no hubiera sido necesario, obteniendo un espacio mas diáfano. Así se potencia el limbo, como en Being John Malkovich la película ocurre en una media planta.

MG. Juan Muñoz barajó varias alternativas diferentes ante este encargo. Puentes que se pierden en el infinito, figuras colgando, una alfombra suspendida donde posicionar figuras sobre y bajo ella; incluso planteó un juego de multiples ascensores, muy diferente a la dualidad que se presentó finalmente. Pero todas estas ideas se ven de alguna manera reflejadas en Double Bind.

VT. Son todo elementos coreográficos. El meollo está en el limbo, las ideas que mencionas son arquitectura versus arquitectura, Double Bind escultura arquitectónica o escultura habitada. Si la pieza no tuviera figuras, no seria la pieza, se convertiría en un decorado. No es una escenografía, es una obra de teatro.

MG. Double Bind tiene un ritmo, en el movimiento, en las aperturas de luz...

VT. El ritmo de la pieza es como el de una obra de teatro. Juega también con los elementos arquitectónicos, en algunos casos hay más, en otros menos. Hay también una distribución de las escenas. El ritmo viene dado no solo por las aperturas y la luz, si no también por el número y tipo de elementos arquitectónicos y figuras.

MG. El espectador no puede acceder al limbo, solo asomarse.

VT. Vemos el mundo lúgubre del limbo desde el oscuro mundo del parking. Juan Muñoz había decidido que después de Double Bind no recibiría más encargos "now I am going to take self comission pieces"... 

ANEXO 3. Juan Muñoz: cronología 



\section{3 ,Madrid}

Juan Muñoz nace el 17 de Junio en Madrid. Es el segundo de 7 hijos (Vicente el mayor). 


\section{6-70, Madrid}

Asiste al Colegio Alameda de Osuna en Madrid. Recibe clases en el colegio y particulares de Santiago Amón (redactor de Nueva Forma, historiador y crítico de arte en El País).

Estudios de Arquitectura en Madrid (dos meses). 


\section{0-75, Londres, Estocolmo}

Se traslada a Londres con su hermano Vicente.

Viaja por Europa.

Reside 14 meses en Estocolmo.

Baraja la posibilidad de ser director de cine.

Trabaja de vez en cuando como pintor de viviendas para sacar dinero. También ayuda en la empresa de construcción de su padre cuando regresa ocasionalmente a Madrid.

Estudia historia del arte por su cuenta.

Su hermano Vicente le compra materiales de pintura, y le anima a que empiece a trabajar en ello.

Se apasiona por el acto de mirar y aprender sobre arte.

Juan Muñoz visita frecuentemente la Tate Gallery y la NationalGallery de Londres.

Obra

Realiza en Madrid un corto en 16mm sobre escultura pública. 


\section{6-77, Londres}

Logra una Beca British Council y asiste a la Central School of Art and Design (hoy Saint Martins College of Art and Design). Recibe el título de Estudios Avanzados en Litografía.

Experimenta con esculturas a las que incorpora sonidos, grabadoras, cintas magnetofonías, pesos y objetos en equilibrio.

Juan Muñoz no tiene un especial interés por la litografía, pero este curso le permite tener una financiación para poder quedarse en Londres. 


\section{9-80, Londres}

Segunda Beca British Council. Asiste en Londres al Croydon School of Art. Realiza un curso sobre litografía avanzada. Conoce a Cristina Iglesias.

Para completar su financiación trabaja como pintor de arte y comienza a experimentar con la escultura.

Realiza unas primeras figuras en escayola y piedra, pero rápidamente se inclina por una escultura más experimental que en algunos casos incorpora mecanismos y sonidos.

Croydon Drawing, 1980 Tras dibujar una figura con tiza blanca sobre un muro en el barrio Londinense de Croydon, Muñoz fotografía a los viandantes que pasan bajo sus paraguas sin prestar atención alguna al dibujo. Muñoz volverá a utilizar la tiza blanca sobre fondo negro en sus dibujos sobre tela de gabardina que comienza en 1988.

Untitled,1979-80 Obra con objetos mecanizados montados en pared y suelo donde se incorpora una grabadora de carrete que hacen evidente el sonido.

Minarete provisional. Minarete en la Plaza de toros de La Malagueta. Juan Muñoz construye un minarete de 9 metros de altura. Al igual que los campanarios, desde el minarete se llama a la oración, y es un punto de referencia comarcal. 


\section{1,Nueva York}

Beca Fulbright. Asiste a Pratt Graphic Centre de Nueva York. Trabaja como asistente residente en el P.S.1 Contemporary Art Center de Long IslandCity NY.

\section{Textos}

Entrevista a Richard Serra.

[On Public Sculpture], Froman Introduction to an Unpublished Interview with Richard Serra. Texto Inédito 


\section{2 ,Madrid}

Se traslada a Torrelodones. Trabaja como Comisario.

\section{Experiencia profesional}

Comisario junto a Carmen Giménez. De la exposición Correspondencias: 5 Arquitectos, 5 Escultores.

\section{Obra}

Untitled Primera escalera. Escalera de caracol en pequeño formato colgada en la pared.

\section{Textos}

Dejar una inscripción en el espacio Texto Inédito. 1981-82

Notas afines a trespara el Catalogo exposición Correspondencias: 5 Arquitectos, 5 Escultores.

Philby. Texto Inédito 


\section{3 , Madrid}

Continúa con su trabajo como comisario.

Abandona el comisariado. Primeros trabajos en hierro fundido.

\section{Experiencia profesional}

Comisario de la Exposición: La imagen del animal: arte prehistórico, arte contemporáneo. Palacio de las Alhajas. Madrid.

\section{Obra}

Segunda maleta Berlinesa

Con maleta (aparece la oreja dibujada)

Para Valle (silla y mano con brazo agarrando la silla)

Oreja (oreja esculpida en madera)

Retrato

\section{Textos}

Los primeros / Los últimos. Catálogo de la exposición por Juan Muñoz. La imagen del animal: arte prehistórico, arte contemporáneo. Madrid, Palacio de las Alhajas, Caja de Ahorros y Monte de la Piedad. 


\section{4, Madrid}

Artista: Escultor

Experiencia profesional

Primer balcón.

Continua apoyándose en objetos de mobiliario donde integra planchas de piedra con dibujos. Primeros minaretes. Una base alargada que en algunos casos incorpora una escalera en espiral, en la parte superior encajona un elemento de madera o barios "tótems".

Evoluciona el tratado de partes del cuerpo humano.

Repite la escalera en espiral sobre pared.

Evolución los balcones. Realiza unos pequeños miradores/balcones que cincha alrededor de columnas circulares.

\section{Obra}

Primera exposición individual: Galería Fernando Vijande. Juan Muñoz: últimos trabajos

Guerrero, Escudo, y Muerte en la Gliyptothek de Munich

Balcón a tres (minarete)

Sin título ventana con hojas abiertas. En el hueco de la ventana coloca una piedra con una oreja pintada.

Dentro y fuera (Minarete)

Sin título (balcón con perspectiva forzada)

T.S.E o R.S (zapatos y terracota. También suelo como si fuera nieve. Primera mención a T. S. Elliot.)

Pieza con Alvar Aalto

Junto a mi Dibujo de Walter Walde

Si ella supiera Minarete con muchas figuras en madera en la parte superior encintadas Ejercicio Barroco 
El juego chino de la caja

El General Miaja buscando el río Guadiana

Spiral Staircase (inverted)

Oreja II

Dándole temor al miedo

Baranda de Alcamé 


\section{5 , Madrid}

\section{Obra}

Minarete para Otto Kurz

El juego del Pozo

Minarete for General Miaja IV

El boxeador (busto sobre una estructura delgada y compleja de minarete)

Astrolabio para el norte de la tormenta (maqueta para la obra "North of the storm")

\section{Textos}

Desarrollo de la escultura inglesa actual: La palabra como escultura. Exposición Richard Long. Ian Hamilton Finlay. Figura no 4 (winter) pg 18-20

The best Sculpture is a Troy (Trojan) Horse/ También metáfora. Domus 659 (March ) p.77.

Desarrollo de la escultura inglesa actual II: Hacia delante. De Richard Deacon a Anthony Caro" Figura no5 (spring-summer) pp. 32-33.

De la luminosa opacidad de los signos: Borromini- Kounellis Figura, 6, p. 94-95. 


\section{6, venecia}

\section{Obra}

Bienal de Venecia: Trabaja junto a su cuñado el compositor Alberto Iglesias.

North of the Storm Escultura en la selección Aperto 86 de la Bienal de Venecia, junto con un disco homónimo de $45 \mathrm{rpm}$ creado junto a su cuñado el compositor Alberto Iglesias.

The Wasteland. Muñeco de ventrílocuo sobre balda colgante en pared y suelo ilusión óptica

Waste Land.Muñeco de ventrílocuo sobre prisma rectangular y suelo ilusión óptica (Wasteland-T.S. Elliot)

Jack Palance a la Madeleine

Double Balcony

Balcony Under the ceiling

\section{Textos}

De la precisión en las distancias Madrid, Palacio de Velazquez, Piedras: Richard Long, Catalogo Ministerio de Cultura y The Brithish Council. Catálogo de la exposición.

Un hombre subió a una farola (entre la escultura británica y la escultura a solas) Madrid, Palacio de Velazquez, Entre el objeto y la Imagen: escultura británica contemporánea. Catálogo de la exposición.

El hijo mayor de Laocoonte / Laocoon'sEldest Son In Bern, Kunstmuseum Bern, Chema Cobo, Catálogo de la exposición.

Del oficio de ser visto 1986-1987. Texto Inédito 


\section{7 ,Burdeos}

\section{Obra}

Juan Muñoz: Sculptures de 1985 a 1987. Cap Muséed'ArtContemporain de Burdeos. Primera exposición individual en un Museo.

I saw it in Marsaille

Hotel Declercq II

De l'identite

Wooden Figure on Optical Floor

First Banister

Popular Songs NoIII

\section{Textos}

Ilusionismo, percepción, proyecto, Sur Express, no 1 (15 Abril-15 Mayo) p. 35. 


\section{8 ,Burdeos}

\section{Obra}

Dwarf with Three Columns. Primera escultura con enano

Primer dibujos sobre tela de gabardina

Ventriloquist Looking at a Double Interior

Balcony

Perfect Balcony

Pasamanos favorito

An Entrance

\section{Textos}

Un Objeto Metálico / A metalic object Jan van de Pavert and Juan Muñoz, Ámsterdam Maatschappij Arti et Amicitiae, Ámsterdam. Catálogo de la exposición.

Die Zeitder Pose el tiempo de posar, Durch 5, pp. 25-27. 


\section{9 ,Burdeos}

Nace su hija Lucia.

Obra

Bailarinas. Primeras esculturas en bronce.

A Room for a Doctor of Pain

Ballerina in Optical Floor

Dwarf with Parallel Lines

Greek Ballerina I

Two Japanese Instruments

Japanese Cabinet

Textos

The Prompter, Long Island City NY, P.S.1 Contemporary Art Center de Long Island City NY, Theater garden Bestiarium: The Garden as Theater as Museum Catálogo de la exposición por Chris Dercon y otros. Cambridge, Mass.

Un Texto de Juan Muñoz / A Text by Juan Muñoz. Spazio umano Human Space 1 (March) pp. 20-24.

Yotsu No Imeji / Tres Imágenes o Cuatro en Karuizawa, Takanawa, Japan. The Museum of Modern Art, Supeinaatotoudi / Spainarttoday c Jaime Birhuega y Miguel Fernandez- Cid. 


\section{0 , chicago}

\section{Obra}

Primera exposición monográfica. Museo The Renaissance Society de la Universidad de Chicago.

Figure by a Windows in Chicago

Barco con motor III

Media Esfera XII Bailarina

Double Ballerina

Backson Bronze

Two Figures

Dos centinelas en suelo óptico

\section{Textos}

Segment En lugar de un catalogo de la exposición, el artista publica Segment en The Renaissance Society at the University of Chicago / Center d'art Contemporain, Geneve Aufeinem Platz Weitersehen, Museen Haus Lange and Haus Esters, Krefeld El ventrilocuismo es una forma de polifonía Texto Inédito. Nota sin fecha 1990 


\section{1}

Se traslada a Roma y alquila un estudio en el Trastevere.

\section{Obra}

Realiza su primera escena “en conversación” escultórica.

An Outpost of Progress. Ilustra una edición del texto de Joseph Conrad

Balcony

Window Shutter withHinges

London Balcony with Figure

Krefel Dwarf

I Saw it in Bologna

From one to Five Personajen

Double Shoutter

Double Large Figures

Converation Piece

\section{Textos}

A Drawing-Room Trick, The Carnegie Museum of Art, Carnegie International, vol 1 Catálogo de la exposición por Lynne Cooke en Pittsburgh y NY .

An introduction (To George Steiner From Jorge Steiner)Texto Inédito. 


\section{2, Londres, Roma}

Vive en Roma.

Obra

Una Avanzada del Progreso. Exposición de los bocetos.

Untitled Monument (London). Por encargo de James Lingwood de Artangel

A Man in a Room, Gambling Por encargo de James Lingwood de Artangel. Pieza sonora en colaboración con el compositor Gavin Bryars

A Room Where it Always Rains. Por encargo de Gloria Moure para la Olimpíada Cultural Barcelona '92

Third Ear, realiza junto al crítico Adrian Searle la cinta sonora Third Ear, emitida por la $\mathrm{BBC}$ radio. Roma

Building Sights EuropeLa BBC le invita a participar en Building Sights Europe, una serie de televisión dedicada a la arquitectura moderna europea. Juan Muñoz selecciona el Museo Nacional de Arte Romano de Mérida de Rafael Moneo.

Building for Music Obra sonora realizada con Alberto Iglesias y emitida posteriormente. Grabada en Torrelodones.

Conversation Piece New York

Pasamano de Valencia

Textos

A Imagem Proibida, FundaçãoSerralves, Oporto. Julião Saramento, Catálogo de la exposición por Michael Tarantino

Building Sights: Juan Muñoz, Texto Inédito

Texto sin Titulo, Catálogo de la exposición Juan Muñoz, IVAM, Valencia

A Man in a Room, Gambling PorGavinBryars y Juan Muñoz 1992. La voz sola. Esculturas, dibujos y obras para la radio, La Casa Encendida. Obra Social Caja Madrid, Madrid 2005.

Se emitirá posteriormente (1197-99)

Construyendo imágenes, Texto inédito.

Building Rights: Juan Muñoz, Texto inédito 


\section{3}

\section{Obra}

\section{Two Figures for Middelheim}

Stuttering Piece. Su primera escultura figurativa con sonido.

Building for Music. Primera emisión durante la exposición Sonsbeek 93, celebrada en la localidad holandesa de Arnhem.

Carpet piece III.

Conversation Piece.

Textos

A Building for Music, 1993 Publicado en La voz sola. Esculturas, dibujos y obras para la radio, La Casa Encendida, Obra Social Caja Madrid, Madrid 2005

[Talking in Alburquerque]Texto Inédito 


\section{4}

\section{Obra}

Exposición monográfica Irish Museum of Modern Art de Dublin. Incluye Conversation Piece, la escultura al aire libre más grande del artista con 22 figuras. Y la pieza sonora Doors of My House.

Table with Hold-Out

Conversation Piece, Dublin

Last Conversation Piece

Living in a (shoe box for Diego)

Many Drums

\section{Textos}

El Rostro de Pirandello / The Face of Pirandello Barcelona, Urban Configurations por Gloria.

Monólogo del ventrílocuo, Texto Inédito 


\section{5 ,Boston}

Trabaja como artista residente en el Isabella Stewart Gardner Museum de Boston. Nace su hijo Diego.

Obra

The Arab

Sara in Front of a mirror

Living in a round shoebox 


\section{6}

Obra

Juan Muñoz: Monólogos y Diálogos, Exposición organizada por James Lingwood en el Palacio de Velazquez, Museo Nacional de Arte Reina Sofía, que en 1997 viaja al Museum für Gegenwarts-KunstZürich.

A Place Called Abroad Dia Center for the Arts NewYork (que en 1998 viaja a SITE Santa Fé, Nuevo México, como Streetwise)

Will It Be a Likeness? Escrita y dirigida por Juan Muñoz y John Berger e interpretada entre otros por el propio Berger en el Theateram Turm de Frankfurt. La actuación emitida por la Hessischer Rundfunk y otras emisoras alemanas, así como la BBC, gana el premio Hörspiel de 1996 al mejor programa radiofónico realizado en Alemania.

\section{Conversation Piece}

Five Seated Figures

Elevator

Double Kneeling

Arabs with Masks

\section{Textos}

Anochecer, Santiago de Compostela, Medardo Rosso. Catálogo de la exposición por Gloria Moure.

Rein, I am sitting in this train station, Zurich Museum für Gegenwartskunst Zurich Catálogo de la exposición por Arina Kowner y Rein Wolfs

Silence Please!: Stories After the Works of Juan Muñoz. Con motivo de la exposición en el Irish Museum of Modern Art de Dublin publica Silence Please!: Stories After the Works of Juan Muñoz (1996) con relatos cortos de John Berger, William Forsythe, Dave Hickey, Patrick McCabe, Alexandre Melo, Vik Muniz, Quico Rivas, Luc Sante, Adrian Serle, Lynne Tillman y Marina Warner. 


\section{7}

\section{Obra}

A Man in a Room, Gambling. En septiembre de 1997, durante unos conciertos celebrados en Estudio Uno de la BBC en Londres, el Gavin Bryars Ensemble interpreta ante el público A Man in a Room, Gambling. Ese mismo año se publica en disco compacto.

A Correspondence About Space en colaboración con John Berger.

Stockholm I. Figura con rostro chino

Two Figures, One Phused into theWall

Neal's Last Words

Staring at the SeaI

Hanging Figures

Textos

Two in one / Zwei in einem,1997 en Zurich, Museum für Gegenwartskunst Zurich. Catálogo de la exposición por Arina Kowner y Rein Wolfs 


\section{8}

Obra

Two Chineses with Noses and Mirrors

Towards the Shadow

The Killing of a Chinese Bookie

Standing Arab with Fez Árabe

Loaded Car

\section{Textos}

My dear friend 1998 en Works in Architecture, Paul Robbrechand Hilde Daem, by Steve Jacobs, Architecture Monographs, no 1, Ghent: Ludion. 


\section{9}

Obra

Will it Be a Likeness? Muñoz colabora con Berger en A Correspondence About Space, una conferencia y una actuación en el Geheimnisserder Raumproduktion de Hamburgo en mayo de 1998. Will it Be a Likeness? Se presenta en Thik Theatreim Kornhaus, de Baden, Suiza, en Noviembre de 1999

Many Times

Three Chineses

Seated Figures with Five Ddums

Two Measuring Figures

The Inventor of Mirrors

The Crossroads Cabinets: September

The Crossroads Cabinets: November

The Crossroads Cabinets: May

The Crossroads Cabinets: March

The Crossroads Cabinets: October

The Crossroads Cabinets: June

The Crossroads Cabinets: January

The Crossroads Cabinets: February

The Crossroads Cabinets: December

The Crossroads Cabinets: April

The Crossroads Cabinets: July

Four Laughting at Each Other Cuatro figuras sentadas en una grada riendo

Figura de pie. 
WelcheBedeutunghat Picasso fürSieheute?,Du Magazine 9 "EineUmfrage"(September 1998), p.73.

Hipnotizando el tiempo, Texto inédito 


\section{0}

Premio Nacional de Artes Plásticas.Concedido por el Gobierno de España.

\section{Obra}

Unilever Series, Tate Modern Londres. Unilever, uno de los patrocinadores de la Tate Modern le encarga un trabajo para la Sala de Turbinas del centro.

Three Laughing at One

Two Seated on the Wall

Biting your Nails

Derailment

One Laughting at Each Other

One Laughing at the Red Ball

Two Figures with Scisors

\section{Textos}

A Standard IntroductiontoLectures, Gagarin 1 no 1, pp. 3-4.

Tagliches Leben in einem Mies van der Rohe-Haus / Everyday Life in a Mies van der Rohe House, Ein Ortderdenkt: Haus Lange undHausEstersvonLwdwing Mies van derRohe. Modern Architektur und Gegenwart / A Plac that Thinks: Hauslange and Haus Esters by Ludwing van derRohe, Modern Architecture and Contemporary Art por JulianHeynen, Krefeld, Krefelder Kunstmuseen. 


\section{1}

Juan Muñoz muere el 28 de Agosto en Ibiza (España).

\section{Obra}

Double Bind. En Junio se inaugura en la Tate Modern de Londres DoubleBind.

A Registered Patent.Se presenta en la Documenta 11, de Kassel, Alemania la obra A Registered Patent, con la música de Alberto Iglesias y la voz de John Malkovich.

Thirteen Laughing at Each Other

Conversation Pieces

Four Piggybacks with Knives

Walking with a Glove

Walking with a Pointing Stick

Looking at Himself

Looking at the Old Man

Louisiana I

First Shaft with Two Figures

One Figure

Three Seated on the Wall with Ladder

With Silver Feet

With Painted Hands

\section{Textos}

Una correspondencia sobre el espacio, con John Berger. Arte y Parte no 32 (Abril Mayo) po. 50-61. 
